\title{
FOOTPRINTING NEW ZEALAND URBAN FORMS AND LIFESTYLES
}

\author{
BY \\ ELLA SUSANNE LAWTON
}

\author{
A thesis \\ submitted to the Victoria University of Wellington \\ in fulfilment of the requirements for the degree of \\ Doctor of Philosophy
}

Victoria University of Wellington

2013 





\section{Table of Contents}

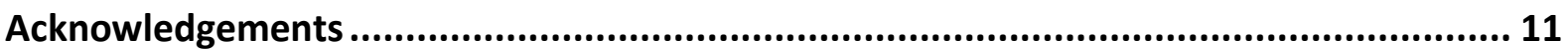

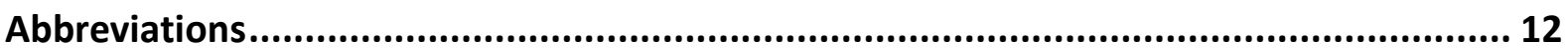

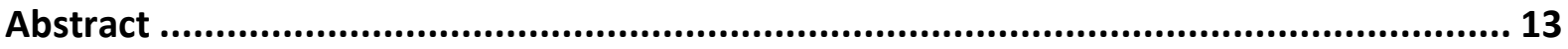

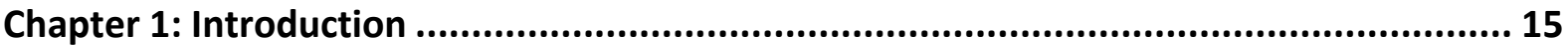

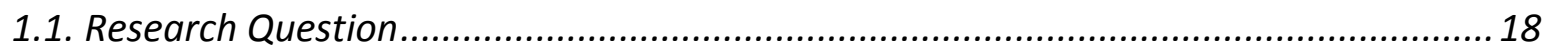

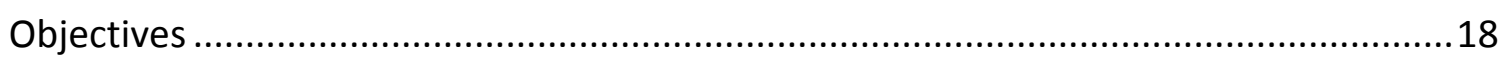

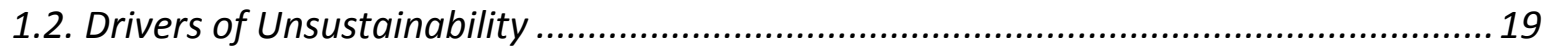

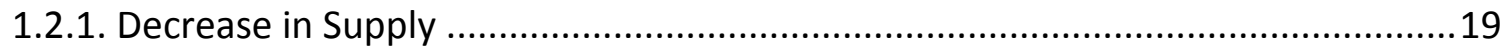

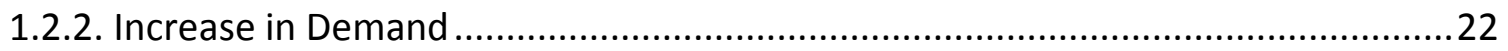

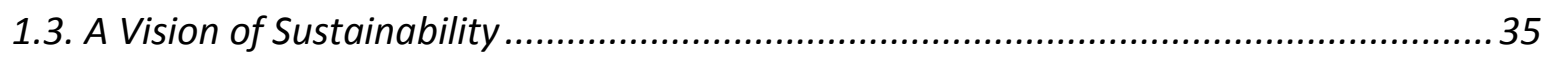

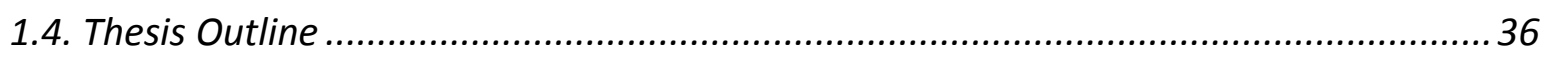

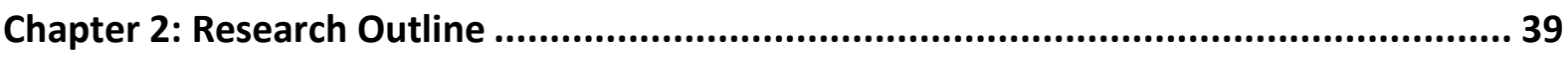

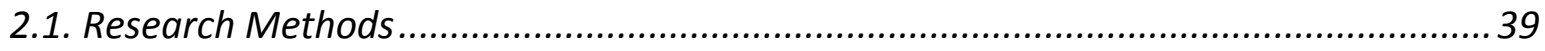

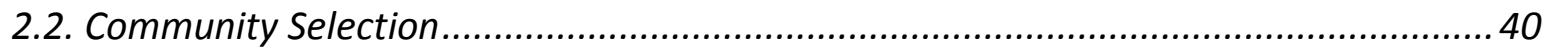

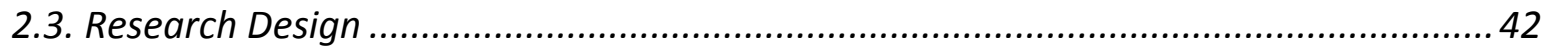

Part 1: Background to the ecological footprint .......................................................... 42

Part 2: Calculating a New Zealand ecological footprint as a basic template ................... 42

Part 3: Generating an EF calculator and survey .....................................................43

Part 4: Gathering community data and calculating community ecological footprints ....44

Part 5: Creating a range of fair earth share ecological footprint scenarios ......................45

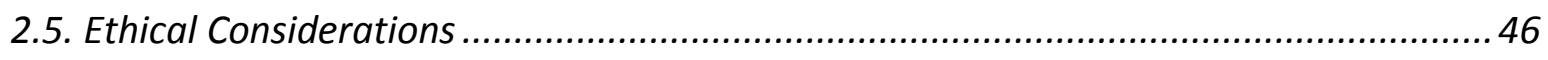

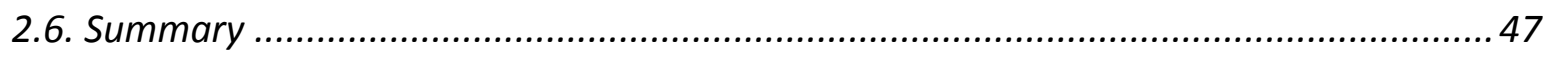

Chapter 3: The Ecological Footprint ................................................................ 49

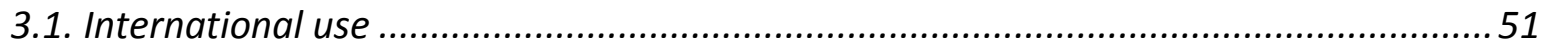

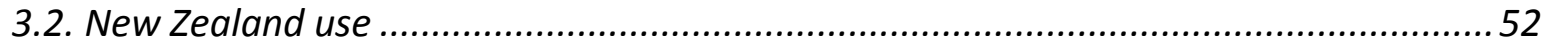

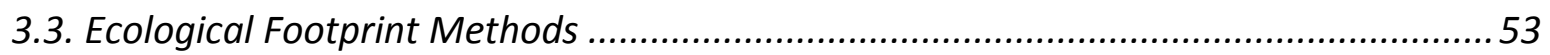

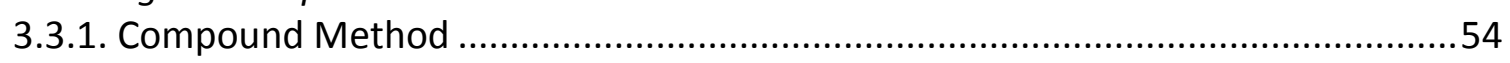

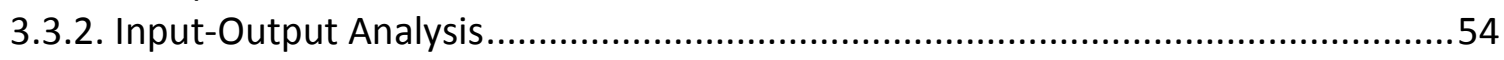

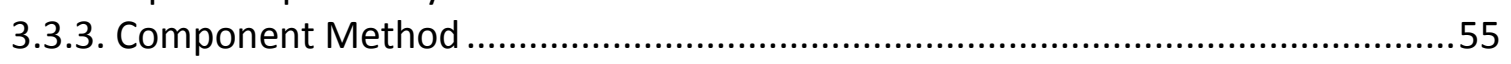




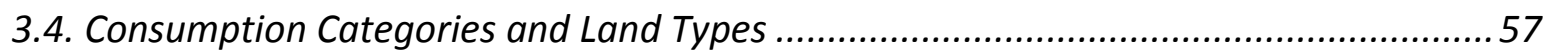

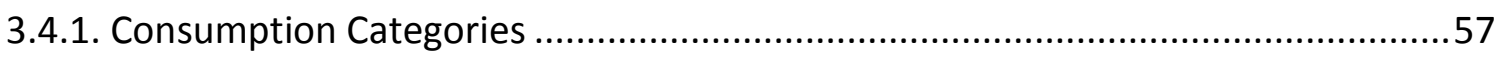

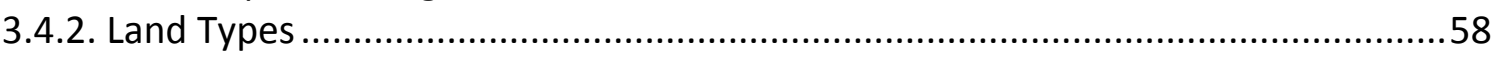

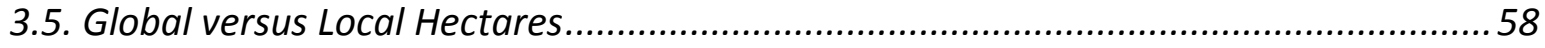

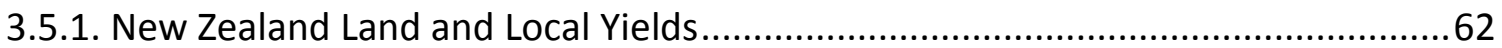

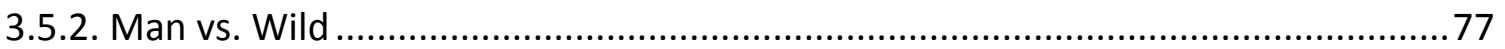

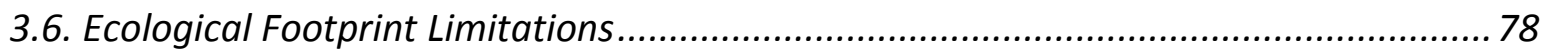

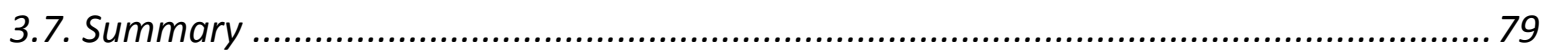

Chapter 4: New Zealand Ecological Footprint ............................................................... 81

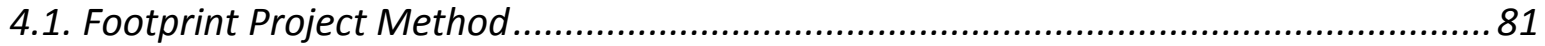

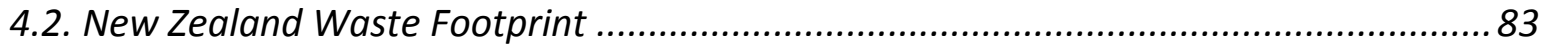

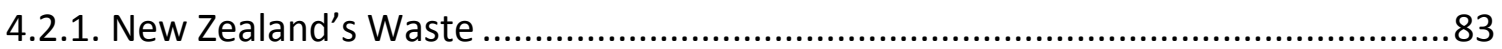

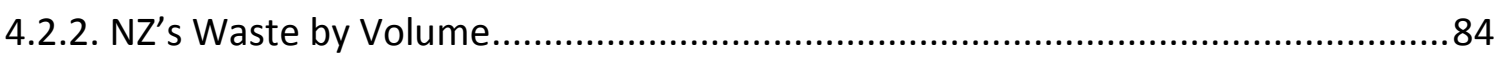

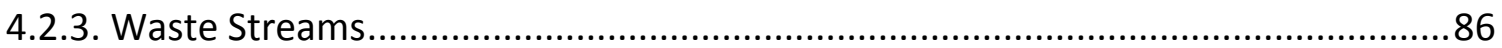

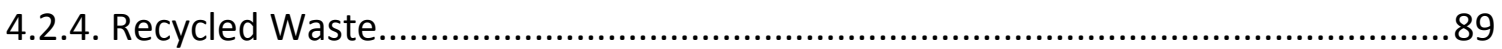

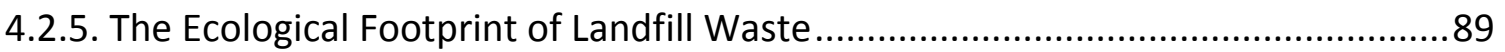

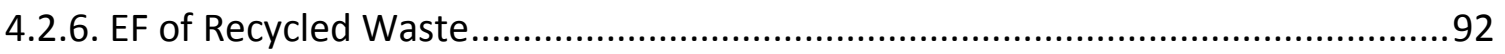

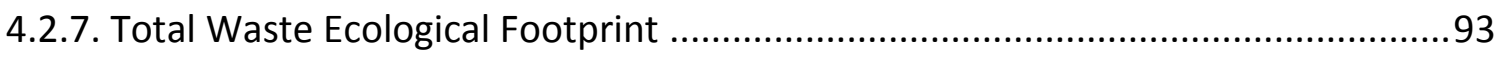

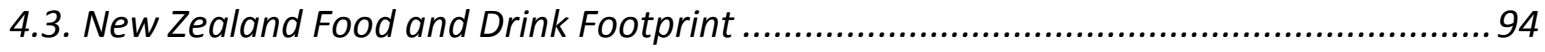

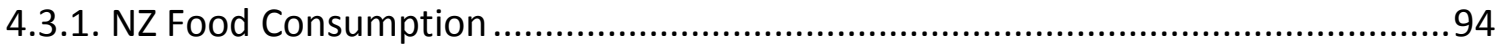

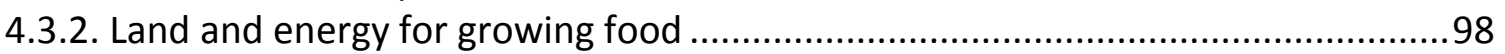

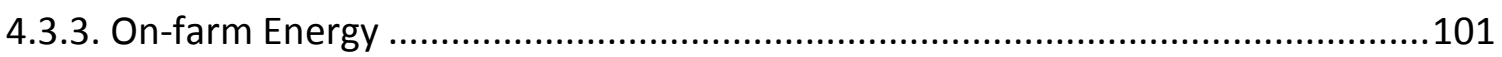

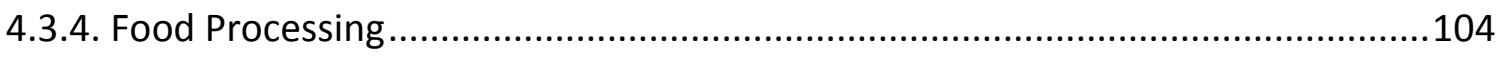

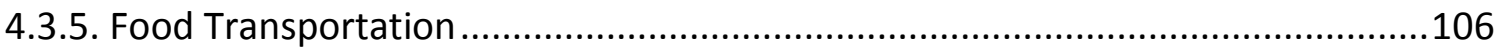

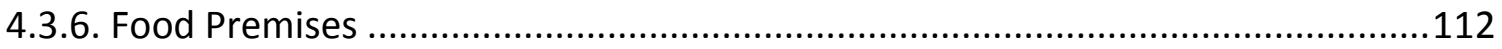

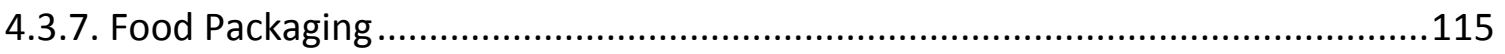

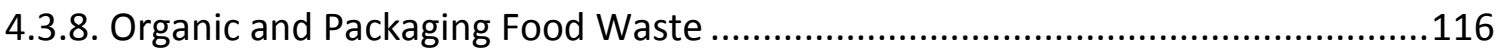

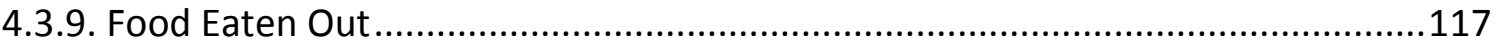

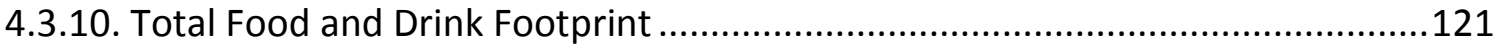

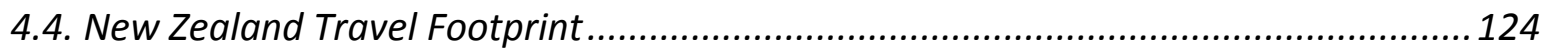

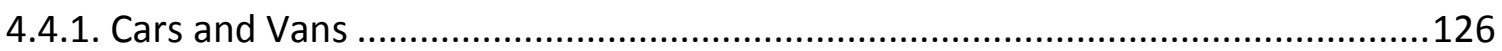

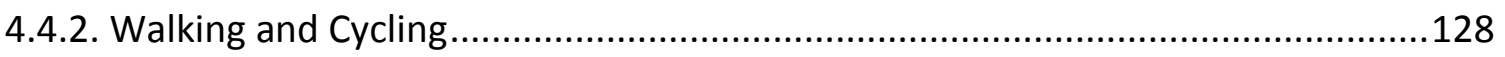

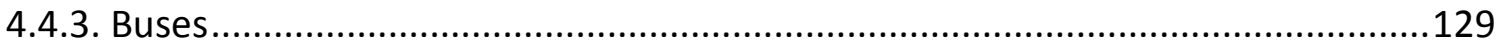

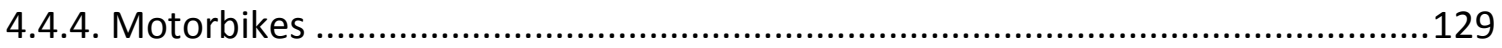

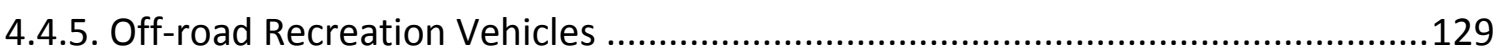

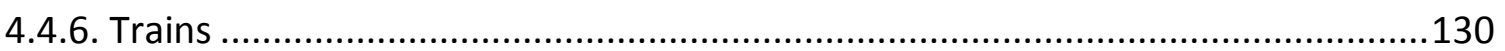

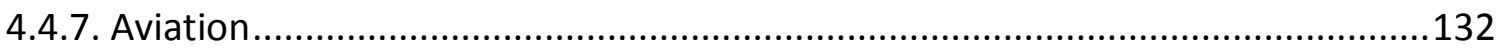

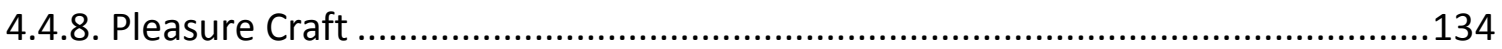

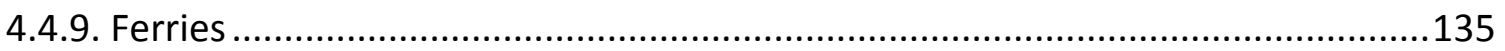

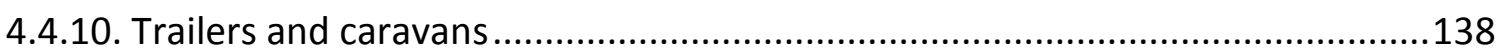

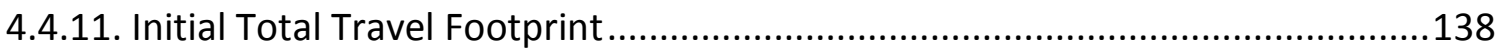

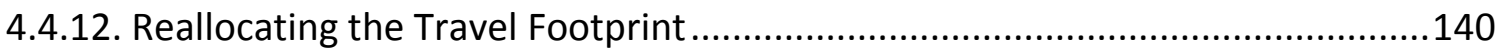

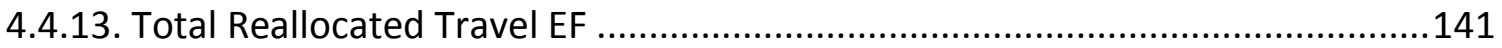




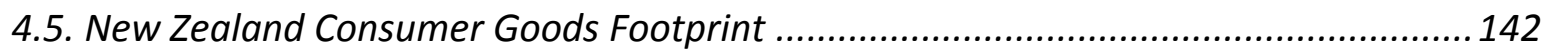

4.5.1. Embodied Manufacturing Energy of Consumer Goods...................................... 145

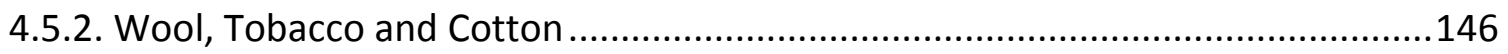

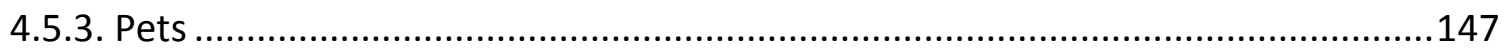

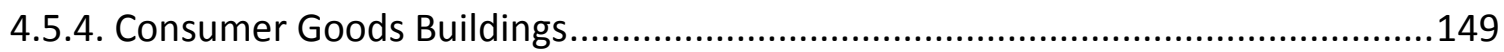

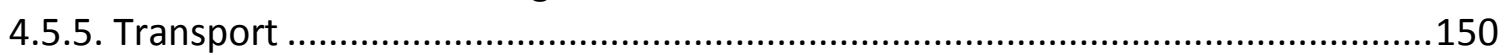

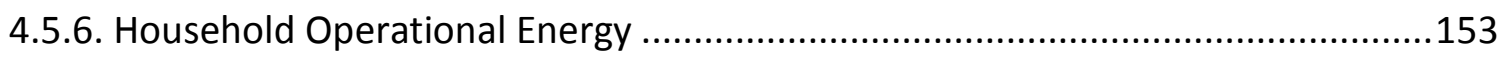

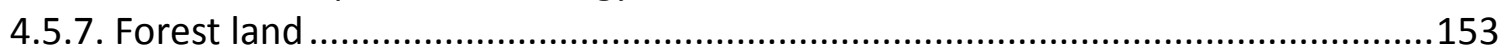

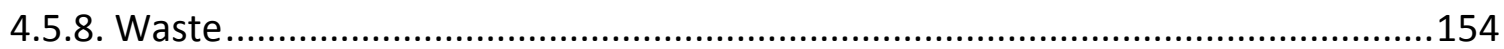

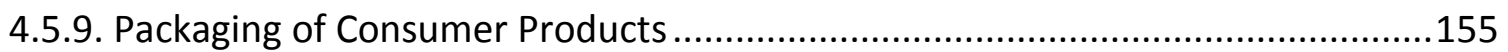

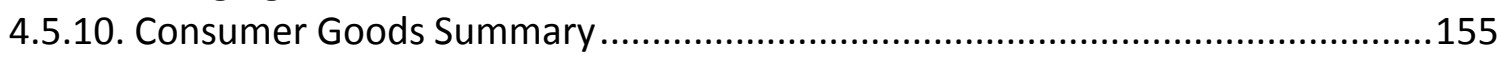

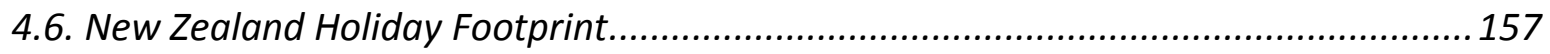

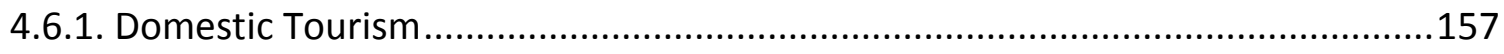

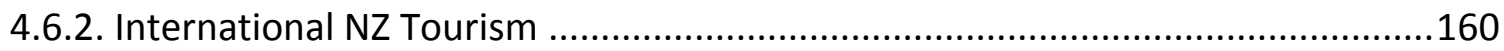

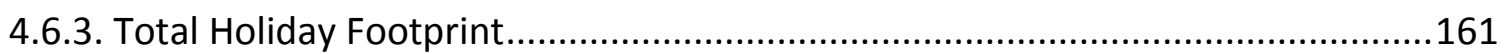

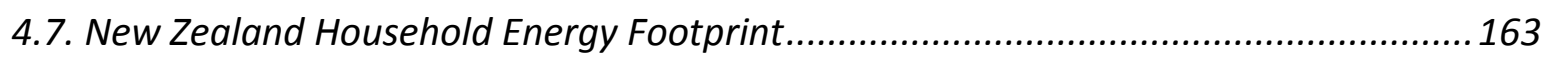

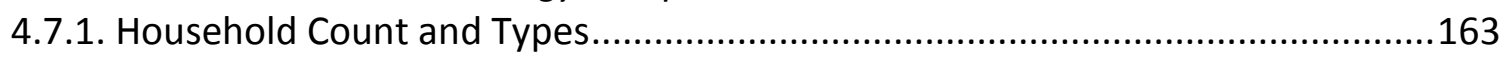

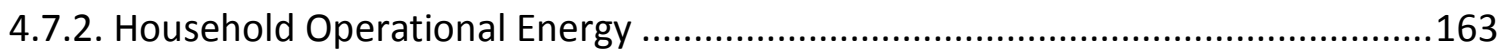

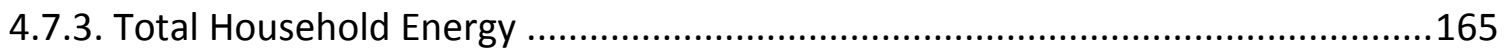

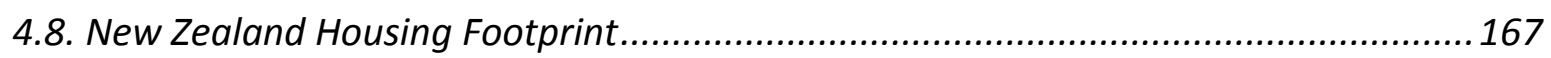

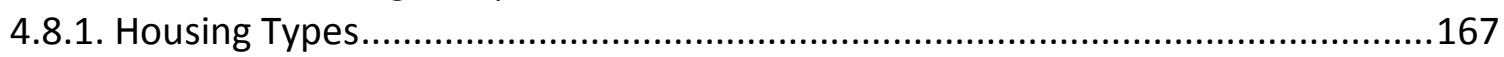

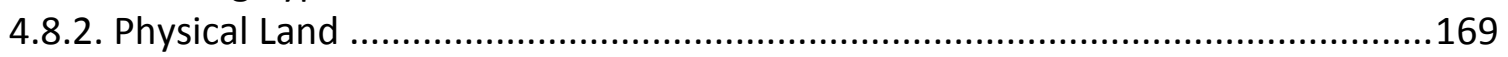

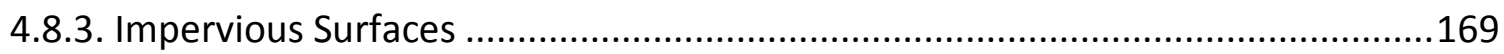

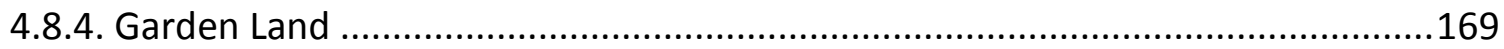

4.8.5. Housing Construction and Demolition Waste ................................................. 170

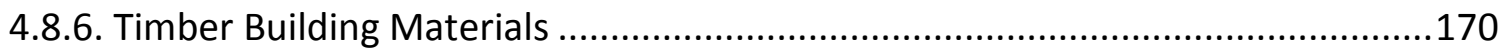

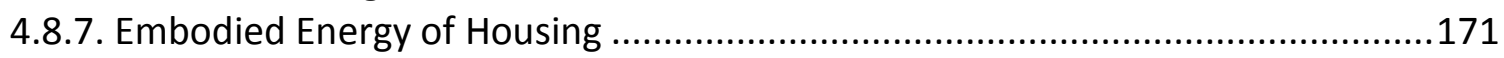

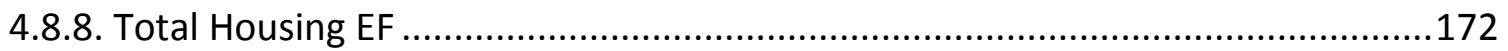

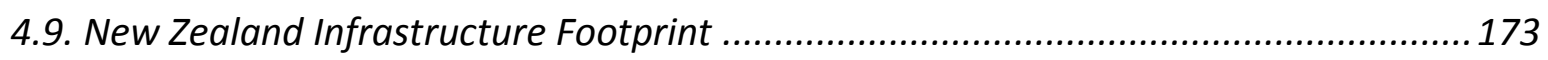

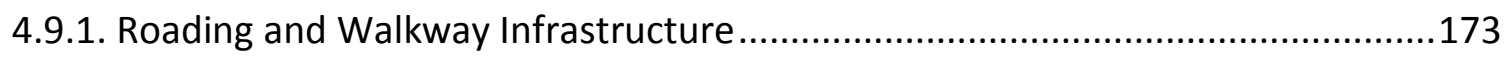

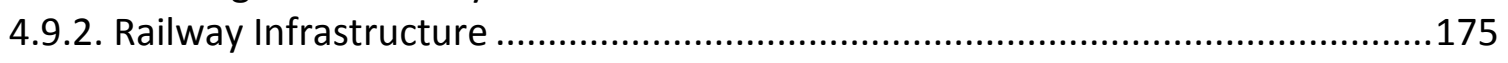

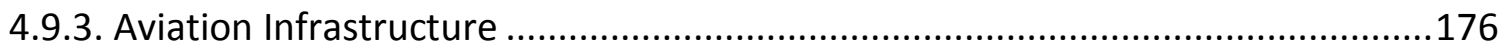

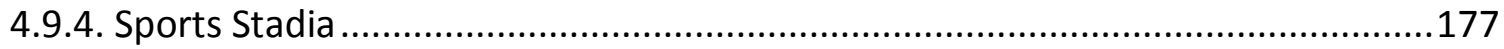

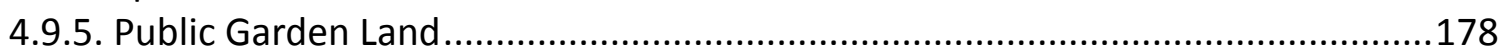

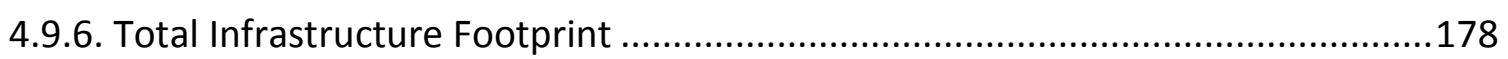

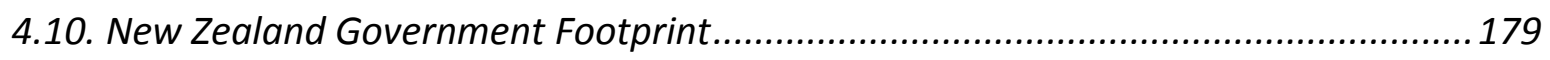

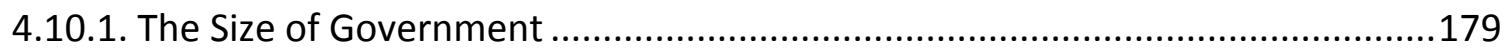

4.10.2. Method 1: Resource Use Case Studies for Government.................................179

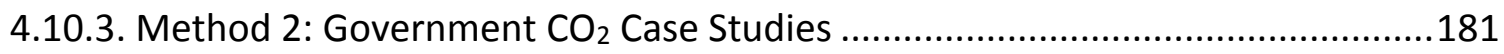

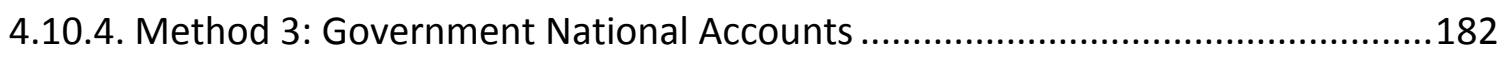

4.10.5. Method 4: EECA Energy Use Database for Government..................................183

4.10.6. Comparison of the four methods for the Government Footprint ....................183

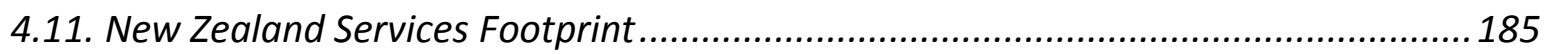

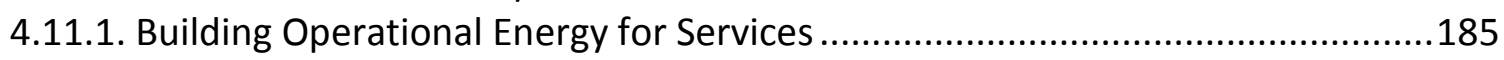




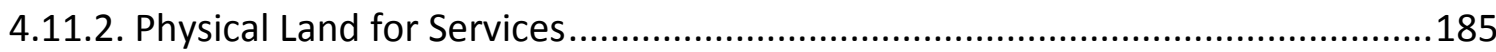

4.11.3. Construction, Maintenance, Demolition and Disposal of Services Buildings ....186

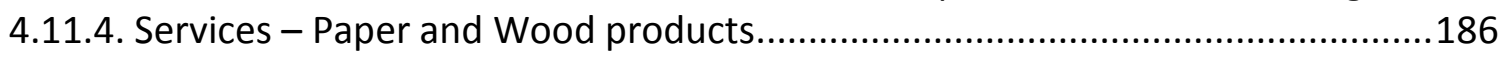

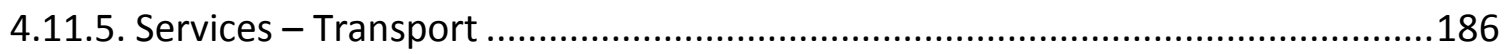

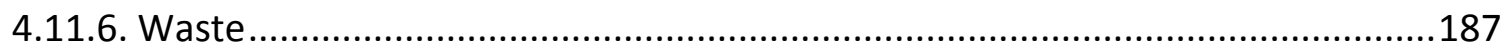

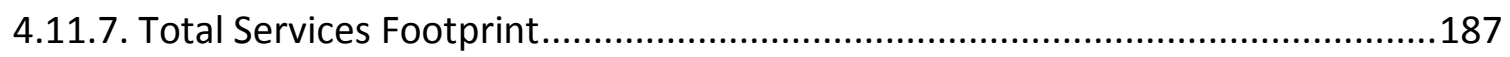

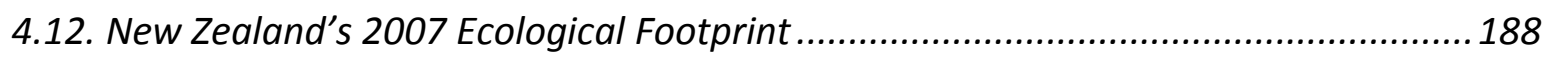

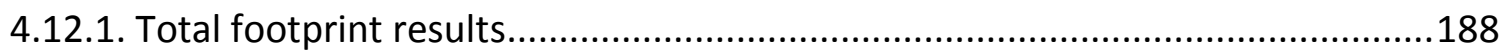

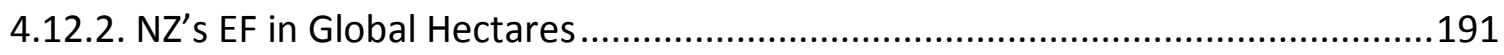

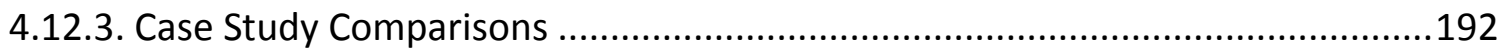

Chapter 5: Community and Individual Footprints .............................................. 197

5.1. Footprint Calculator and Community Survey ..................................................... 197

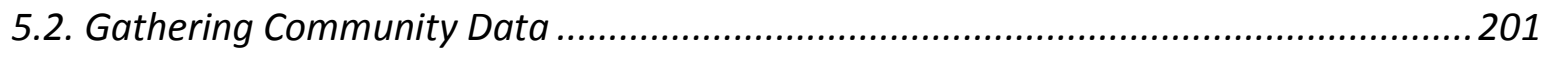

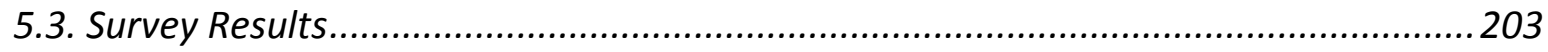

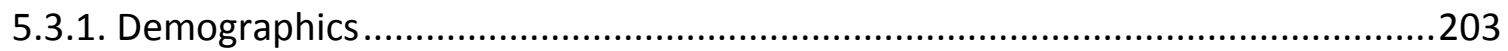

5.3.2. Community Urban Form and Housing Definitions .............................................206

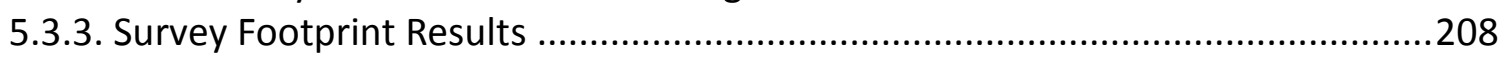

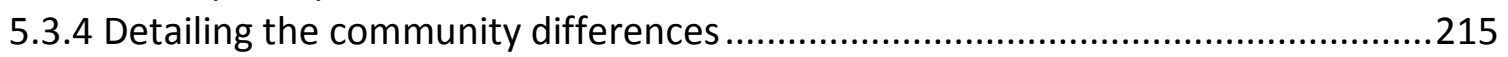

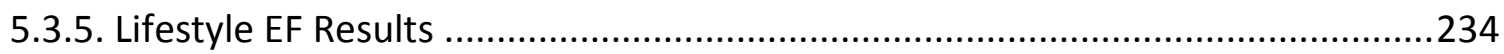

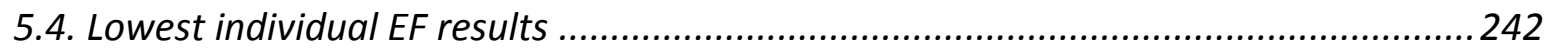

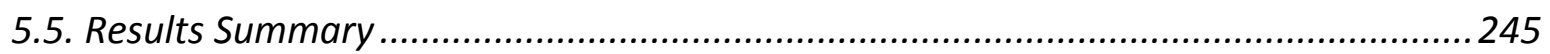

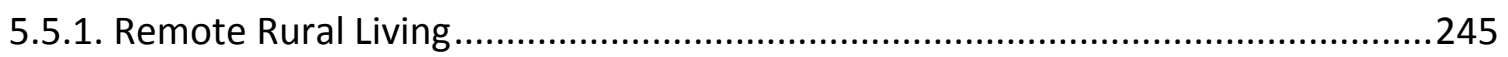

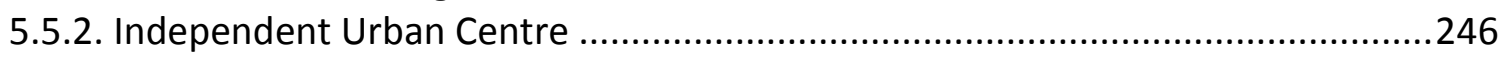

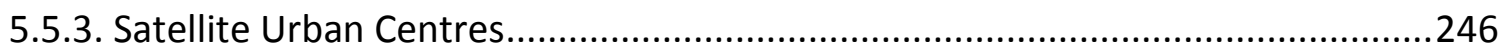

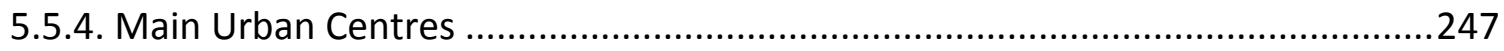

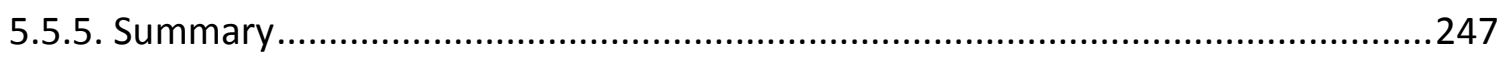

Chapter 6: Fair Earth Share Futures...................................................................... 249

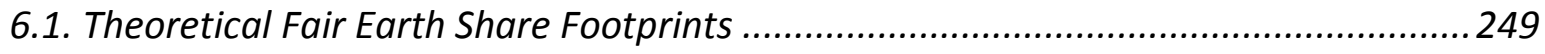

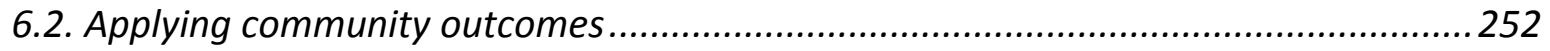

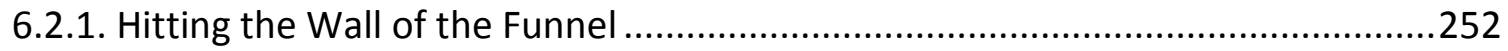

6.2.2. Proposed community actions and EF reductions ...............................................254

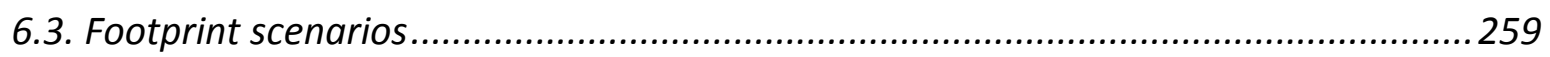

6.3.1. Using scenarios to provoke and inspire creative change ..................................260

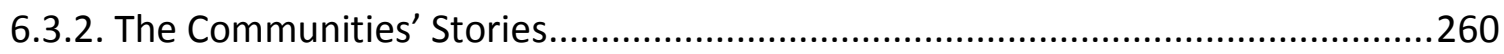

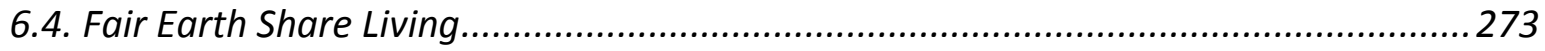

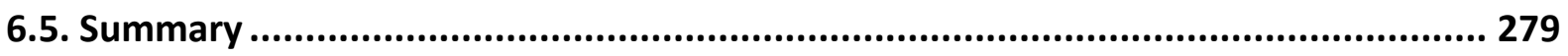

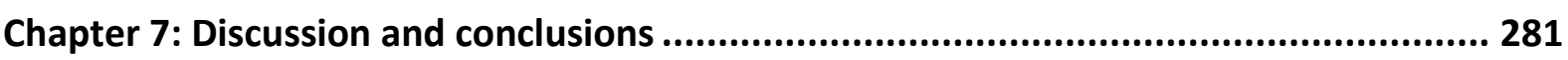

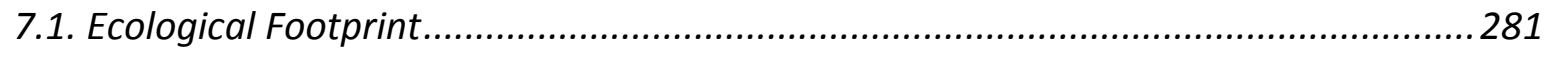




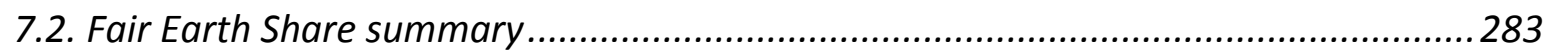

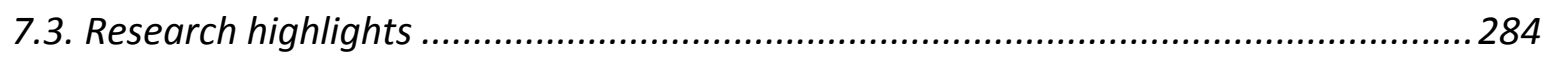

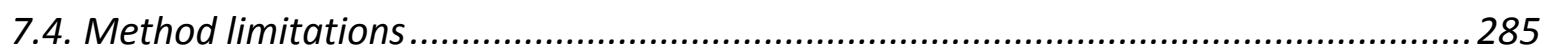

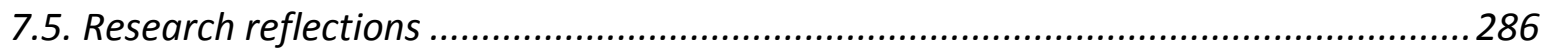

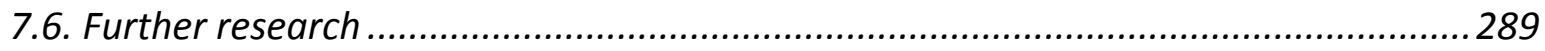

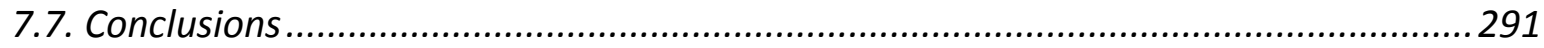

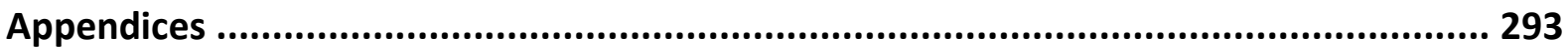

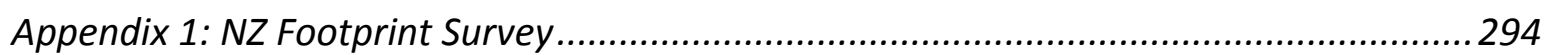

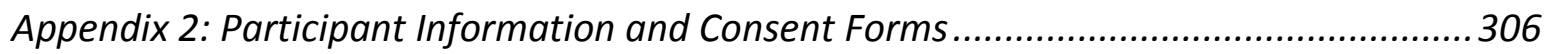

Appendix 3: Breakdown of crop and grazing land tables for food consumed in NZ in

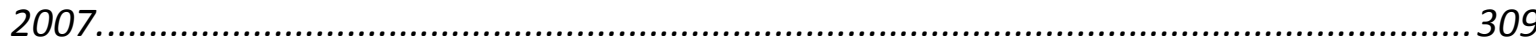

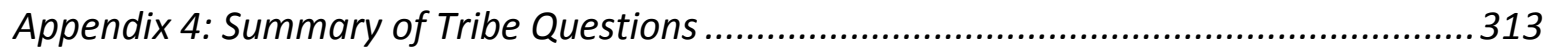

Appendix 5: Low Footprint Lifestyles from each community ......................................... 315

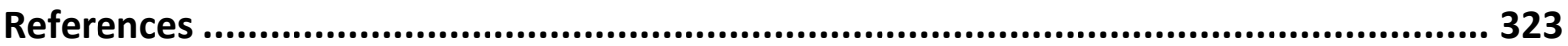

\section{Figures}

Figure 1.1: Change in 'earth share' as population increases over time.

Figure 1.2: The Funnel Metaphor showing trends resulting from unsustainable use of the Earth's biocapacity (Boisvert et al., 2009).

Figure 1.3: Spheres of Influence on Consumption.

Figure 1.4: Aspirations of First-Year College Students in the United States, 19712008 (Assadourian, 2010, p. 10).

Figure 4.1: Composition of NZ Waste to Landfill, 2007-08 (MfE, 2009b).

Figure 4.2: The Food and Drink Footprint Map: the map is a summary of components of the food footprint and the associated land types, also showing excluded components.

Figure 4.3: Comparison of the average food (average yield in $\mathrm{kg} / \mathrm{ha}$ ) that can be grown on one hectare of each land type.

Figure 4.4: Distribution of electricity uses in NZ households (Isaacs et al., 2010, p. 9). 115

Figure 4.5: Distribution of land types (minus fishing land) in NZ's 2007 food EF. 
Figure 4.6: The EF of each non-land food category.

Figure 4.7: The Transport Footprint Map.

Figure 4.8: Distribution of the five largest transport footprints in 2007.

Figure 4.9: The Consumer Goods Footprint Map.

Figure 4.10: The Holiday Footprint Map.

Figure 4.11: The Household Energy Footprint Map.

Figure 4.12: The Housing Footprint Map.

Figure 4.13: The Citizenship Footprint Map.

Figure 4.14: Distribution of the 2007 NZ EF by land type excluding fishing land.

Figure 5.1: Age distribution of survey respondents by community.

Figure 5.2: Household description.

Figure 5.3: EF of the entire community sample.

Figure 5.4: Box and whisker plots of the five community total footprints including outliers.

Figure 5.5: EF of household by income.

Figure 5.6: Distribution of food grown at home and land for growing food.

Figure 5.7: Reasons why people grow their own food, organised by community.

Figure 6.1: fair earth share EF (in green) in relation to current average community sample EF (in green + red), assuming a similar percentage reduction in each category.

\section{Tables}

Table 2.1: NZ EF Template: An individual's EF is made up of three parts, each comprising a number of categories. A description of these categories specifies some of the data required

Table 3.1: Equivalence and yield factors as calculated in the National Accounts New Zealand 2007 (GFN, 2011)

Table 3.2: Comparison of NZ land as categorised by the NZ MfE and GFN National Footprint Accounts in NZha and gha 
Table 3.3: The 'world average' energy-to-land ratio compared ratios for two types of NZ forest using the 2007 energy-to-land conversions for different fuels

Table 4.1: Waste streams and associated sources

Table 4.2: Summary of waste streams by weight from residential and nonresidential activities in 2007

Table 4.3: Summary of waste EF and corresponding land required by different sectors in 2007

Table 4.4: EF of recycling in NZ (2007)

Table 4.5: Comparison of daily food consumption between FAOSTAT and LINZ

Table 4.6: Estimated total EF of crop land for food consumed in NZ in 2007

Table 4.7: Estimated EF of animal products and resulting grazing land used by NZ in 2007

Table 4.8: Total grazing, crop and fishing land required for food derived from animals consumed in 2007

Table 4.9: The EF of on-farm activities for 2007 for all NZ food

Table 4.10: Food industry energy for export and internal consumption by food sectors in 2007

Table 4.11: Energy and land required for all travel modes for food purchases in 1998107

Table 4.12: The EF of transport of food products within NZ in 2007

Table 4.13: EF and energy land of imported food transport to NZ

Table 4.14: Summary of EF of food transport in 2007

Table 4.15: Consumed land required by NZ supermarkets

Table 4.16: Embodied energy of food retail premises (construction, maintenance, demolition and disposal)

Table 4.18: EF of food for average Cardiff resident 
Table 4.21: Total EF associated with food

Table 4.22: Total distance, energy and EF for NZ cars in 2007

Table 4.23: Distance travelled, and resulting energy required, for walking and cycling in NZ in 2007

Table 4.24: Operational and embodied energy of trains in NZ in 2007

Table 4.25: Total energy and land required for national and international flying by New Zealanders in 2007

Table 4.26: Energy and land for NZ commercial passenger ferry transport in 2007

Table 4.27: Distances travelled and corresponding operational and embodied energy and per person EF for various transport modes in 2007

Table 4.28: Transport reallocated to other components of the NZ EF

Table 4.29: EF of land and water transport in 2007

Table 4.30: Consumer goods embodied manufacturing energy

Table 4.31: Grazing and crop land required for the EF of three products

Table 4.32: Consumer goods transport EF 2007

Table 4.33: Waste EF of NZ consumer goods in 2007

Table 4.34: EF of NZ consumer goods 2007

Table 4.35: Domestic holiday transport EF for 2007

Table 4.36: The EF of NZ domestic tourist accommodation

Table 4.37: EF of NZ holidays in 2007

Table 4.38: Annual household energy use

Table 4.39: Land occupied by residential buildings in 2007

Table 4.40: EF and corresponding land for NZ housing and household energy in 2007

Table 4.42: Data from sample airports used for the aviation infrastructure EF 
Table 4.44: Comparison of the results of four methods for calculating the EF of national and local government

Table 4.45: The EF of the NZ government

Table 4.46: Total EF of the services industry in 2007

Table 4.47: Summary EF for NZ (2007)

Table 4.48: EF CLUM of NZ in 2007

Table 4.49: Comparison of different land category scenarios for the 2007 NZ EF

Table 4.50: A comparison of NZ EF in NZha from various case studies

Table 4.51: Comparison of the NZ EF to international EF case studies

Table 5.1: Demographic characteristics of the whole sample

Table 5.2: Official urban form categories for each community and survey results to 'where they live'

Table 5.3: Statistical analysis of EF results

Table 5.4: EF by category (NZ average, sample average, and averages of the five communities)

Table 5.5: The percentage of respondents who caught each mode of public transport and the distance they travelled

Table 5.6: Reasons why communities go on holiday and the activities they undertake

Table 5.7: Wood use by community respondents

Table 5.8: Comparison of urban categorisation, number of people per household, average house size, average impervious surface, most popular housing type, and average housing $\mathrm{EF}$

Table 5.9: Perceived barriers to having a less resource-intensive lifestyle (four communities) including barriers for individuals with footprints over 4NZha

Table 5.10: Comparison of ' 8 Tribes' in the survey with average EF, standard deviation of survey EF, and average household income

Table 5.11: Tribe and community association

Table 5.12: Five highest-scoring questions, by community 
Table 5.13: Selection of possible 'high EF' statements, and associated EF

Table 5.14: Comparison of the lowest EF individual from each community with the NZ average

Table 5.15: Summary of a respondent's NZ fair earth share EF

Table 6.1: NZ average EF and community sample average EFs, and reductions required to achieve a theoretical fair earth share EF

Table 6.2: Examples of actions for reducing the average NZ EF

Table 6.3: Actions suggested by Waiheke residents (EF 2.51NZha) and potential EF reductions

Table 6.4: Actions suggested by Waitakere residents (EF 2.62NZha) and potential EF reductions

Table 6.5: Actions suggested by Cromwell residents (EF 2.59NZha) and potential EF reductions

Table 6.6: Actions suggested by Tarras residents (EF 3.44NZha) and potential EF reductions

Table 6.7: Suggested EF actions that could be carried out by Kapiti residents (EF 2.77NZha)

Table 6.8: Proposed food and drink EF reductions

Table 6.9: Proposed travel EF reductions

Table 6.10: Proposed consumer goods EF reductions

Table 6.11: Proposed holiday EF reductions

Table 6.12: Proposed housing and household energy EF reductions

Table 6.13: Proposed citizenship EF reductions

Table 6.14: New individual and total NZ 'fair earth footprints' for 14 million citizens

\section{Boxes}

Box 1.1: '8 Tribes' summary including indicative average income per year (Lawton, in press) 


\section{Acknowledgements}

This thesis is dedicated to the two most inspirational women in my life: my mother and my grandmother. Thank you for your support, encouragement and shared wisdom.

Thank you to:

- My family for their support; you are always close to my heart.

- Riki and family for your support in the earlier stages of this research, and for reminding me that happiness is a little girl under a feijoa tree.

- Friends who provided me with meals and accommodation whilst visiting Wellington, particularly Jane, Greer, Pip, Andy, Rob and Kate, Kim and Mike, Jamie, Susan and Nigel, and Jade and Rauru.

- My friends in New Zealand and around the World who remind me that true happiness comes when I am feeling most connected to them.

I would like to acknowledge the wealth of knowledge and experience of Professors Robert and Brenda Vale. Thank you for guiding me through this journey; it is greatly appreciated.

Thank you to Robbie Andrews, Dr. Andrea Collins, Carmeny Field, Michael Green, Joanne Gumpatzes, Nigel Isaacs, Dr. Maggie Lawton, Robbie Lawton, Dr. Winsome Parnell, Dalice Sim, Amelia Smith, James Richardson and Simon Williams for the research support; and to Cheryl Lawton, Maggie Lawton, Deborah Laurs, and Heather North, my editing team.

I would like to acknowledge Otago Polytechnic for the professional support, opportunities and travel funding during the past four years. Thank you specifically to Steve Henry, Jean Tillyshort, and the past and present staff, associates and students of the Centre for Sustainable Practice. I look forward to continuing the journey with you.

Lastly, I would like to acknowledge the Foundation for Science Research Technology (FRST) for the Footprint Project Funding and the scholarship, which provided the financial means to carry out this research. 


\section{Abbreviations}

\begin{tabular}{|l|l|}
\hline C & Carbon \\
\hline CO2 & Carbon Dioxide \\
\hline C\&D & Construction and demolition \\
\hline CLUM & Cumulative Land-Use Matrix \\
\hline EECA & Energy Efficiency and Conservation Authority \\
\hline EF & Ecological Footprint \\
\hline FAOSTAT & FAO Statistics Division \\
\hline FAO & Food and Agriculture Organisation of the United Nations \\
\hline GJ & Gigajoules \\
\hline GFN & Global Footprint Network \\
\hline gha & Global hectares \\
\hline Ha & Hectares \\
\hline IOA & Input-Output Analysis \\
\hline NZha & Local New Zealand hectares \\
\hline NZ & New Zealand \\
\hline pkm & Passenger kilometre \\
\hline tkm & Tonne kilometre \\
\hline UK & United Kingdom \\
\hline vkm & Vehicle kilometres \\
\hline WWF & World Wildlife Fund \\
\hline
\end{tabular}




\begin{abstract}
More than $90 \%$ of New Zealand's ecological footprint results from the lifestyle choices of individuals, although the size and impact of their lifestyle footprint depends on the type of urban form in which they live.

The aim of this research is to highlight the degree to which New Zealanders are living beyond their fair earth share and how this appears through lifestyles. As the population continues to increase and resources become scarce, it is vital that both governments and communities have effective resource accounting tools to inform further urban development, given its influence on resource use. The thesis highlights how urban form could reduce barriers to people's future wellbeing and it identifies the types of lifestyles that support a shift towards lower footprint living.
\end{abstract}

To understand how the ecological footprint of New Zealand's communities is generated by a combination of the community members' lifestyle choices and interaction with their urban form, the research comprised five steps.

1. Designing a footprint method and calculating local footprint yields for the New Zealand context.

2. Calculating the New Zealand footprint in nine categories: food and beverages, travel, consumer goods, holidays, household energy, housing, infrastructure, government and services.

3. Creating a calculator and survey, and collecting household footprint data from five New Zealand communities.

4. Processing data and analysing community results highlighting differences and similarities between them.

5. Using the community output creating fair earth share scenarios which highlight those footprint categories within each urban form that provide the best opportunity for reducing a community's footprint.

Throughout this project the ecological footprint has been an effective indicator which has provided the means to communicate complex environmental data in a simplified form to diverse groups. The project used the ecological footprint to measure and communicate the trends that are putting pressure on the planet's finite availability of land; a growing demand and the decreasing supply. It was found to be an effective communication tool for both 
communities and local government organisations that formed a way of discussing how to reduce their footprint in the future.

Although many New Zealand lifestyles exist in a variety of types of urban form, some lifestyle types are more typical in certain urban forms. Food was found to be the predominant driver of a household's footprint. Use of commercial land for growing, on-farm inputs and food processing made up the largest portion of the food footprint. Holidays and pets were also large contributors to an individual's footprint. Due to the high amount of renewable energy that goes into producing New Zealand's electricity, household energy was proportionally much less than found in similar international footprint case studies.

The final scenarios show that fair earth share living in New Zealand is possible; some individuals are already doing it. However bringing about large-scale change will require collective community strategic planning, planning tools to develop resource efficient urban design, and immediate action. 


\section{Chapter 1: Introduction}

The aim of sustainable development is to achieve a decent quality of life for everyone within the carrying capacity of ecosystems (Wackernagel, 2001). An 'earth share' is the portion of the world's resources available to each person on the planet, under the limitations that total consumption of resources is within the planet's natural ability to renew itself and that the resources are equally shared amongst all.

The world's available biocapacity has been quantified by Global Footprint Network (GFN) in terms of a measure of the biologically productive land and water available for human use (Lenzen, Borgström Hansson, \& Bond, 2007). It is an aggregate of the productivity of various ecosystems within the area, for example, arable or crop land, pasture, forest and bioproductive sea, and built or degraded land. Biocapacity is dependent not only on natural conditions but also on prevailing farming and forestry practices (Chambers et al., 2005, p. 26). The equation for biocapacity is (GoodPlanet.info, 2012):

$$
\text { Biocapacity }=\text { Land area } \times \text { bioproductivity }
$$

Bioproductivity is the amount of biological production required to renew the biotic resources humans use (food, timber) and to absorb their waste (mainly carbon dioxide emissions from energy use). Bioproductivity is essentially the ability of a piece of land to produce biomass, and different ecosystems have different levels of bioproductivity (Chambers et al., 2005, p. 26). Biocapacity is therefore the measure for the bioproductive utility of land for humans. This unit of resource measurement is known as a 'global hectare' (gha) and GFN has calculated a total of 11.9 billion gha available on the planet (Ewing et al., 2010; GFN, 2011; WWF, 2010).

As the global population continues to increase, the 'earth share' of ecological goods and services available to all continues to decline (Wackernagel \& Yount, 2000). Figure 1.1 shows this relationship. The global population increased from 3 billion in 1959 to 7 billion in 2011, resulting in the 'earth share' decreasing by more than half, from 3.96gha/person to 1.70 gha/person. The global population is projected to reach 10 billion by 2083 , causing a further decrease in the 'earth share' to 1.2gha/person (Ewing et al., 2010; United Nations Department of Economic and Social Affairs Population Division, 2010). 


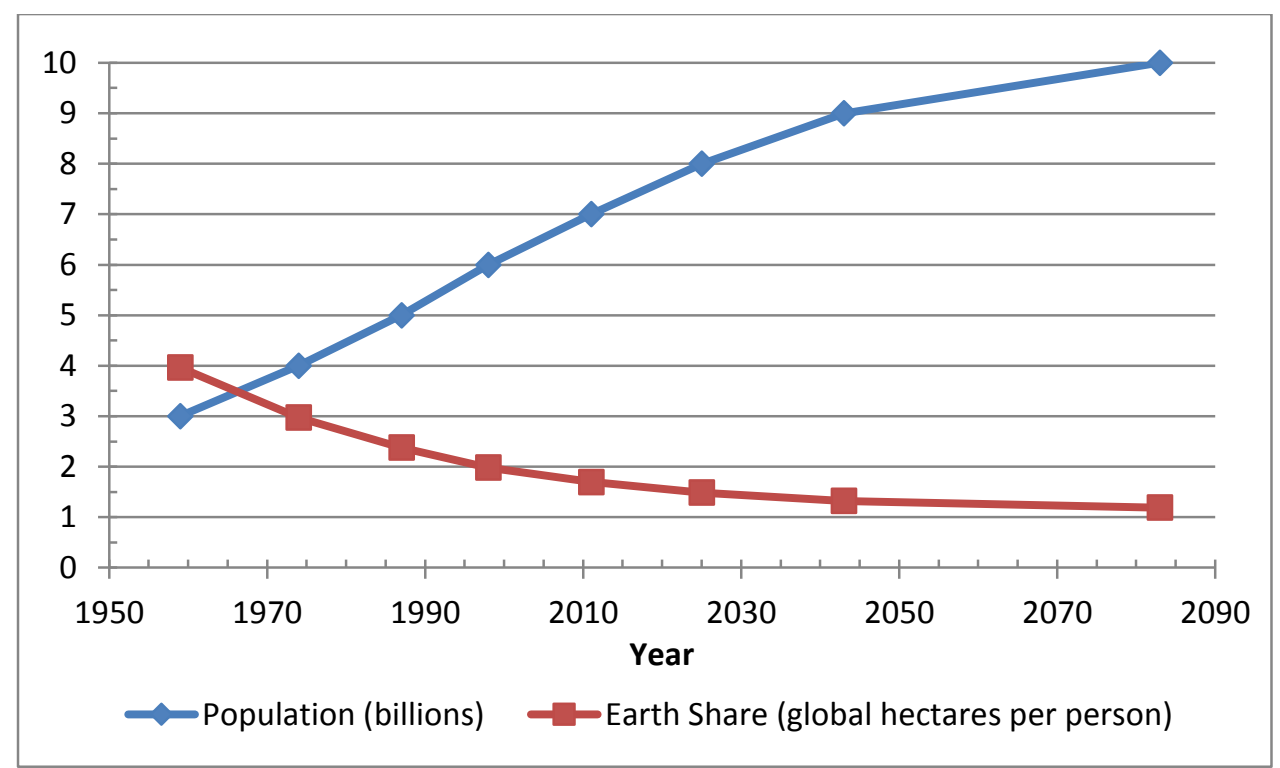

Figure 1.1: Change in 'earth share' as population increases over time (prepared by author).

Currently the world's communities are in 'overshoot'; a condition in which ecological goods and services are consumed at a rate beyond the biosphere's regeneration rate (Catton, 1980; Wackernagel et al., 2002). Humanity is exhausting the planet's ecological capital, and is operating beyond the planet's carrying capacity by 156\% (Freeling, 2012). To function in overshoot, humanity continues to meet its ecological demand by liquidating resource stocks and accumulating carbon dioxide in the atmosphere (Freeling, 2012; Wackernagel et al., 2002).

Overshoot is caused by two predominant trends (Robèrt, 2009) which interact in society's unsustainable use of the planet's finite resources. These are depicted in the Funnel Metaphor (Figure 1.2) (Holmberg et al., 1999; Robèrt et al., 2002). The first of the trends is a decreasing supply of resources and decline in the health of natural systems. The second is the rising demand for resources from an increasing population with growing expectations. These trends are putting considerable pressure on society's ability to create and sustain wellbeing for all. This raises the question of what a sustainable future might look like.

For humanity to live sustainably the supply of, and demand for, resources must be equal. The drivers of unsustainability need to be reversed and ecosystems returned to a healthy steady state for a sustainable future. The ability to renew resources and sustain the health of natural systems must be able to happen perpetually, for both current and future generations (United 
Nations Environment Programme, 1992). To achieve this goal it is necessary to understand the quantity of resources available, how quickly they are used, and for what purposes. It is important to compare how much of Earth's resources society demands from nature's supply. Measurement tools, such as the Ecological Footprint (EF) (Wackernagel \& Rees, 1996), are therefore required to help guide humanity in a sustainable direction (Barrett, 2001; White, 2007; WWF, 2010).

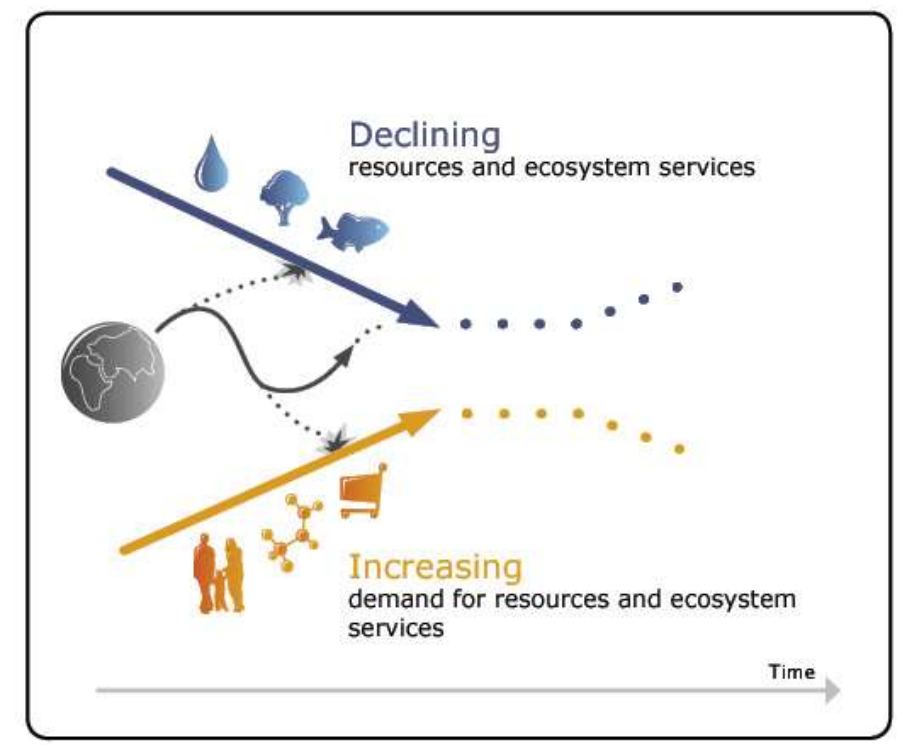

Figure 1.2: The Funnel Metaphor showing trends resulting from unsustainable use of the Earth's biocapacity (Boisvert et al., 2009).

Adopting the concept of the 'earth share' provides a quantitative measure against which to measure whether sustainability is achieved (WWF, 2010). For a number of years the United Kingdom (UK) based not-for-profits organisation Bioregional and the World Wildlife Fund (WWF) have promoted One Planet Living as a way to explain living within the Earth's biocapacity (BioRegional \& WWF, 2008). A state of sustainability, both in terms of the bioproductivity of the physical natural environment and equity within society, requires that humanity lives with the total available bioproductive land and that this is shared. The result would be that on average every person lives within their fair earth share of the Earth's resources (Vale \& Vale, 2013; WWF, 2010).

Sustainability is a complex concept. The individuals, communities and organisations that create plans and strategies for moving toward it have a vision that is difficult to communicate 
to the general public. Organisations such as the WWF (Barrett et al., 2005), Bioregional (BioRegional \& WWF, 2008; Desai, 2009; Ravetz, 2007b) and progressive government bodies such as Cardiff Council (Collins \& Flynn, 2005) have used the EF to provide a picture of what life within a fair earth share would look like. International case studies show that changes need to occur both in urban form and the lifestyle choices people make in relation to that urban form. However, this detailed level of analysis and discussion has not been carried out for New Zealand (NZ).

In late 2009, the NZ Footprint Project was launched as a 3-year collaborative research effort between Victoria University of Wellington, Otago Polytechnic and Auckland Council. One of its aims was to develop a better understanding of resource use in NZ communities, and what resources underpin the products and services NZ communities use. According to the GFN, if everyone on Earth used as many resources as the average New Zealander, 2.7 planets would be required to support this (GFN, 2011).

The current research was developed to support the NZ Footprint Project by providing the baseline NZ EF calculations in sufficient detail that they could be used to create scenarios of how to live within a fair earth share. The final chapter of this thesis is a theoretical look at four variations in urban form and lifestyle that allow individuals and communities to live in this way.

\subsection{Research Question}

What types of urban form and lifestyle scenarios provide a basis for New Zealanders to live within their fair earth share of the Earth's biological capacity?

\section{Objectives}

1. To provide a baseline understanding of how particular NZ communities use resources in relation to both urban form and the lifestyles of individuals.

2. To construct a theoretical scale and type of built environment and lifestyle for a community whose EF is equal to or below its fair earth share $\mathrm{EF}$.

The steps to achieve these objectives are: 
1. Gather data and calculate the average NZ EF. Gather and analyse data from five NZ communities regarding personal and household resource use.

2. Highlight aspects of urban form and lifestyle that make up the largest proportions of individual and community EF.

3. Use community discussions to guide the creation of a variety of scenarios describing how people with different NZ lifestyles residing in various urban forms could live within their fair earth share EF.

4. Create a theoretical ideal type and scale of both the built environment and behaviour for a community that has an EF that is equal to or below their fair earth share EF.

5. Develop a rigorous EF methodology that is flexible enough to use with a range of populations, realistic for the proposed research concerning resources and time, and replicable for use in further research.

\subsection{Drivers of Unsustainability}

The trends shown in figure 1.2 have created a state of unsustainability where society can no longer provide resources for current and future generations within the biocapacity of the Earth. The drivers of unsustainability-decrease in supply and increase in demand-are influenced by environmental, social and economic actions.

\subsubsection{Decrease in Supply}

The planet is finite; there is a limited amount of land for distribution amongst the growing global population (United Nations Environment Programme, 1992; Wackernagel et al., 2002). Land is the source of all renewable resources and provides a platform from which all ecological systems have to assimilate and recycle resources (Wackernagel \& Rees, 1996). In 2010, arable land, both grazing and crop land, totalled $13.31 \%$ of the land surface. Crop land has the highest biocapacity of all land types but is only $4.71 \%$ of total land on the planet (United States Central Intelligence Agency, 2008). Overall global bioproductivity has increased. Widespread use of irrigation and nitrogen fertilisers, increased crop efficiency and clearing of natural forest has enhanced biocapacity, although "this often comes at the cost" (Laurance, Cook, \& Verweij, 2012, p. 41) of requiring more resources and creating more waste 
elsewhere. In order to increase biocapacity humans remove natural systems and disrupt ecological systems, creating a feedback loop which in turn further decreases available biocapacity.

The decrease in supply of biocapacity is prompted by two pressures: the declining biocapacity of land and the declining health of the Earth's ecosystems.

\section{Declining Biocapacity of Land}

Biocapacity is a measure of the biologically productive land and water available for human use (Lenzen et al., 2007). There are six types of biologically productive land, comprising five land types for production (crop, grazing, forest, fishing and consumed land), and one for assimilating waste (energy land). Bioproductive land excludes areas that are not defined as productive for human use such as deserts, glaciers, and the open ocean (Lenzen et al., 2007). Bioproductivity is the ability of a piece of land to produce biomass, which is the weight (or estimated equivalent) of organic matter, including animals, plants and micro-organisms (living or dead) above or below the soil surface. The amount of resource produced by a piece of land is measured in yields.

Maximising the immediate production of goods and services from land has long caused problems for cultures around the globe (Diamond, 2005). A piece of land is intricately connected to its surrounding ecological dimensions, including both environmental and societal systems.

The economic Theory of Production asks the question "what combination of inputs, known as factors of production, will generate the quantity of output that yields maximum profit" (Cobb \& Douglas, 1928). Since the human race shifted to an agrarian lifestyle, people have altered the bioproductivity of land, largely in an attempt to increase potential biocapacity (Larsen, 1995). They have done this by manipulating the natural quantity of the key inputs. Altering water availability is perhaps the most obvious change, with the introduction of irrigation. The addition of chemicals such as phosphorus, nitrogen, and calcium carbonate to alter the $\mathrm{pH}$, has also been common practice for centuries. More recently, however, synthetic inputs such as inorganic fertilisers and pesticides have also been used to increase land productivity. Many 
of the negative effects of these manipulating activities are not accounted for in the current economic system. They are described as 'externalities' and, as they are excluded from economic accounting, are not included in the price of the final product (Caplan, 2012).

For a while the biocapacity of land can be manipulated by using resources that have been moved from one place to another, and these may temporarily substitute for the decreasing health of land. For example, as the natural availability of nutrients in soil is depleted by industrialised food systems, chemical-based substitutes are added (Brown, 2012). This allows for similar yields to be produced from a given area of land; however, the hidden total land required has increased because additional 'energy land' has been used to sequester the carbon dioxide emissions related to transport, production processes, fertiliser production and on-farm processes. The amount of currently available resources, particularly food, is reliant on this model of substituting cheap energy such as oil for natural systems services. It is estimated that half of the world's food is provided using systems reliant on this substitution, which is clearly only a temporary measure (Brown, 2012; Erisman et al., 2008).

\section{Health of the Earth's Ecosystems}

Ecosystems are the planet's life-support systems for the human species and all other forms of life (Corvalan, Hales, \& McMichael, 2005), yet every year the natural systems at a planetary scale are in decline (Laurance et al., 2012, p. 12). The Millennium Ecosystem Assessment Working Group (Millennium Ecosystem Assessment, 2005) reported that approximately 60\% (15 out of 24) of the ecosystem services it examined are being degraded or used unsustainably, including fresh water, capture fisheries, air and water purification, and the regulation of regional and local climate, natural hazards, and pests. The Living Planet Report, shows a 30\% global decline in biodiversity health since 1970 (Laurance et al., 2012, p. 8). This decline not only affects people but also the billions of other life forms that depend on these systems and each other. A decline in the health of ecosystems reduces the bioproductivity of the land and often has irreversible negative effects.

Brown (2012) highlights the importance of healthy soils and the impact that industrial farming has on natural systems. For example, overgrazing and bad agricultural management have caused extensive tracts of the world's grain-producing areas to suffer desertification. 
As the health of Earth's natural systems declines, so does the potential biocapacity available to humans, and as the planet heads further into resource-use overshoot, the health of systems declines further. In order to overcome this trend, the current economic system encourages adding more inputs, which substitute for bioproductivity, by transporting it from one geographical location or ecosystem to another. This substitution generally reduces the health of all natural systems and, as with desertification, will lead to the eventual collapse of the system.

\subsubsection{Increase in Demand}

The second trend shown in figure 1.2 is the increasing demand for the earth's resources. This has two drivers: the first is the increase in the world's population, and the second is the increasing resource-linked expectations of people. Population increase is acknowledged as a serious global issue (Laurance et al., 2012), however for NZ, the major impact on consumption is increasing demand.

\section{Population}

The global population continues to increase, with a forecast of 9 billion by 2050 (DESAPD, 2009). Whilst some populations have plateaued, others continue to grow with the support of better health care and food availability. On the other hand, there are more people living in poverty than ever before (Brown, 2012; UNFPA, 2007). Increasing access to education and equity for women has been shown to slow population growth; however, the most successful campaigns have been the widespread accessibility of birth control to women. In 2012 World Population Day promoted universal access to reproductive health care for "a world where every pregnancy is wanted, every childbirth is safe, and every young person's potential is fulfilled" (United Nations Population Fund, 2012). The population explosion has been the unspoken 'elephant in the room' for some time, but it is finally being accepted as the issue that cannot be ignored (Crossette, 2011; TIME, 2011). Slowing the rate of population increase will lighten the pressure the human race puts on the natural environment (Biello, 2009), but only if consumption of resources first stabilises, then declines. 


\section{Consumption}

Consumption is increasing as individuals require more resources to support their lifestyle demands (Assadourian, 2010). Consumption, the purchase of goods and services (Oxford University Press, 2010), has grown dramatically over the past five decades. In 2010 consumption was up $28 \%$ from $\$ 23.9$ trillion spent worldwide in 1996 and up $600 \%$ from the \$4.9 trillion spent in 1960 (in 2008 dollars). Some of the increase came from growth in population, but human numbers only grew by a factor of 2.2 between 1960 and 2006, meaning consumption expenditure per person almost tripled (Assadourian, 2010).

Consumer 'lock-in', a situation in which the buyer is more or less trapped in their purchases (Sodeman, 2008), demonstrates how factors such as convenience, habits and norms influence people's behaviour (Brown, 2009; Sanne, 2002). Evidence also shows citizens are often 'locked-in' to unsustainable consumer practices due to social and institutional norms and even physical structures (Power \& Mont, 2010; Sanne, 2002). It is vital, therefore, that governments shift the institutional architecture of consumer 'lock-in' (Power \& Mont, 2010).

On the demand side are three main spheres of influence. In terms of their individual control, these range from political and cultural systems (least control) through to community urban form and dwelling type, to personal lifestyle decisions (most control). Within the spheres of influence three different factors influence resource consumption behaviour in relation to lifestyle: values (Taylor \& Allen, 2010), time (Fitt \& McLaren, 2010), and income (Assadourian, 2010; Canadian Centre for Policy Alternatives, 2008; Clark, Frijters, \& Shields, 2008). These spheres and factors are shown in diagrammatic form in figure 1.3. 


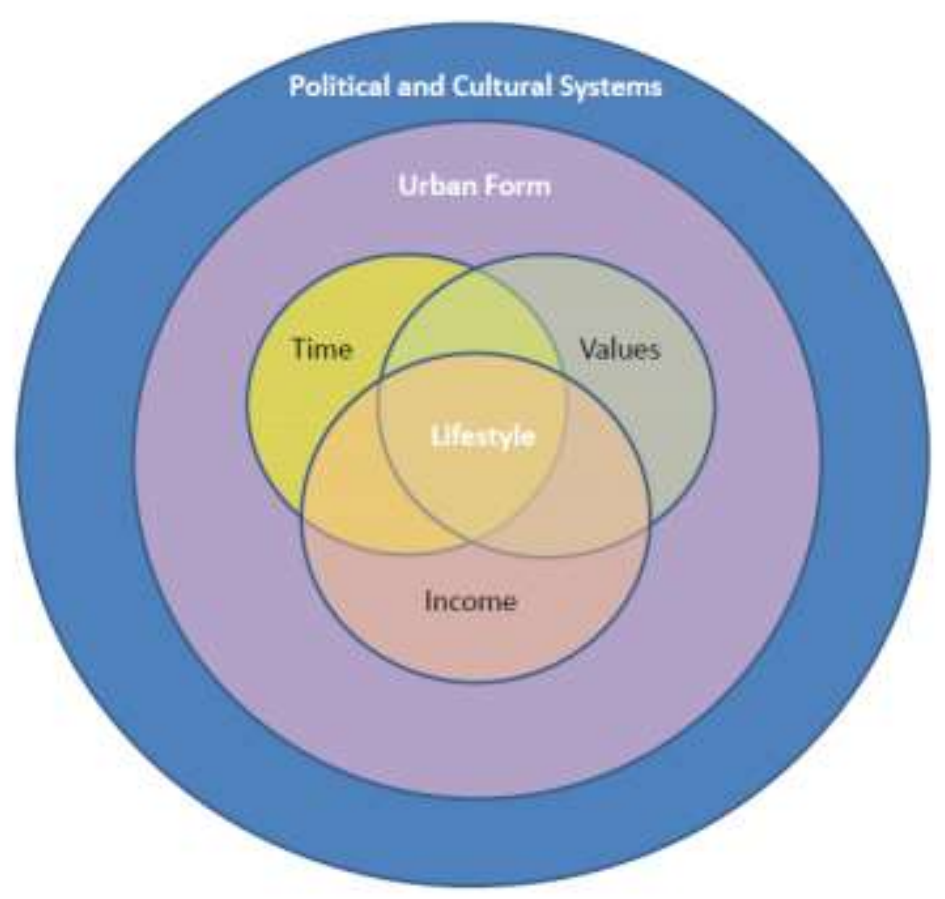

Figure 1.3: Spheres of Influence on Consumption (prepared by author).

\section{Governing political and cultural systems}

The type of political, cultural and belief system governing a community of people can have considerable influence over their ability to access and use natural resources. Governance is about how governments and other social organisations interact, how they relate to citizens, and how decisions are made (Plumptre \& Graham, 1999, p. 2). There is a growing awareness that institutional structures and relationships, not only within government but between governments and other sectors of society, have a determining impact on outcomes (Plumptre \& Graham, 1999, p. 8). Governance occurs not only through those with official power but also through the conscious transfer of power from individuals to an entity such as a religious or cultural group. The ability to change these overarching systems is virtually unavailable at an individual level and requires large-scale shifts involving many members of a population.

Spaargaren and Vliet (2000, p. 53) note that within 'structuration theory', rules and resources together constitute the structures that are involved in the reproduction of social practices. Governance, in relation to the availability of resources to individuals, could be viewed on an axis from capitalist freedoms, through to a restricted communist regime. For example, the rise in China's middle class in an increasingly capitalist society, has shown consumption 
increase exponentially (Brown, 2012; Chen \& Chen, 2006). Prioritisation of material consumption, the perceived source of stability in Western societies, means that the economy, political institutions, and even the popular media all serve the task of continuous economic growth (Brown, 2009). This economic requirement has taken governments and communities' hostage, making it seem impossible to decouple economic growth from the increasing consumption of resources.

The drive to 'maximise production' within an economic paradigm that does not accept 'limits to growth' has created an increasing demand on common resources, creating a situation known as the 'tragedy of the commons' (Hardin, 1968). This tragedy develops when unregulated common land becomes overgrazed as each individual attempts to maximise their use of the land and associated economic output. The result is tragedy for all as the natural systems that support the land collapse. In some cases governance systems have created means for avoiding this, such as the NZ Fisheries Quota Management System of the Ministry of Primary Industries (2012). Instances of other governing bodies creating a shift toward lower resource use are discussed below.

\section{Ration/Quota Systems}

Rationing was used by Britain in World Wars I and II as a way of fairly distributing the limited amount of resources available to the British public (Trueman, 2012). This government intervention was justified on the basis that it was for the 'greater good'. More recently Lucy Brown (2009) investigated an Individual Carbon Quota System (ICQS) on the basis that limiting the amount of carbon dioxide $\left(\mathrm{CO}_{2}\right)$ each individual can emit limits the amount of environmentally harmful consumption that can take place. Brown's $(2009$, p. 6) exploration of this concept from both a collective and individual perspective concluded such $\mathrm{CO}_{2}$ limitation could be carried out as "government intervention may be justified on the grounds of being necessary for the citizen's well-being".

\section{Sufficiency Economy}

The Sufficiency Economy as defined by Krongkaew (2003) is a philosophy that guides the livelihood and behaviour of people at all levels, from the family to the community to the 
country, on matters concerning national development and administration. Krongkaew explains that the Sufficiency Economy theory was developed by His Majesty the King of Thailand after the 1997 economic crisis. Sufficiency means moderation and reasonableness, including the need to build a resilient system against internal and external shocks. In this way the King hoped to maintain balance and be ready to cope with rapid physical, social, environmental, and cultural changes from the outside world. The sufficiency economy premises that each person strives for 'true happiness', to be attained when a person is fully satisfied with what he or she has and is at peace with the self. A sufficiency economy would be an economy fundamentally conditioned by basic need, not greed, and restrained by a conscious effort to cut consumption.

\section{Māori World View}

Indigenous cultures worldwide have evolved from being largely self-sufficient communities with some use of trade, to groups of individuals many of whom are now immersed in a Western capitalist way of life. Morrison (1999) gives some insight into how the Māori people's relationship with the land has changed. "Capitalism and colonialism are responsible for viewing land in Aotearoa (NZ) as a commodity and ... breaking communal possession of land... The emphasis on individualism rather than communalism has caused the change from a selfsufficient lifestyle to one largely alienated from the means of production" (Morrison, 1999, p. 49).

Traditional Māori perspective is one in which the land they live on forms the most important aspect of life. The people who inhabit land, the kaitiaki (people with a connection to a place), are its guardians. Preserving their way of life is dependent on the treatment of the land and all things living on it, emphasising that the health of the land is paramount to survival. There are examples where local custom provided resource management to ensure populations stayed within the biocapacity of the land (Morgan, 2004; Outlook From Someday, 2008). Customary limits, for example, were imposed for gathering kaimoana (sea food), where certain areas were under rāhui (protection) at various times of the year in order to protect fishing grounds under pressure and give species of fish, shellfish and seaweed a chance to multiply (Department of Conservation, 2012). 
Governing political and cultural systems can affect an entire population's resource consumption. Capitalist systems allow for minimal management of the natural commons, whereby resource use is encouraged and there is a decline in the health and reproductive ability of the natural systems. Alternative governing systems can be implemented through laws and policies, or using management processes based on customary knowledge or a philosophy. However, the ways in which individuals act within these governing constraints also depend on the urban form in which they live and its associated lifestyles.

\section{Urban Form}

The world is undergoing the largest wave of urban growth in history. In 2008, for the first time, more than half of the world's population lived in towns and cities (UNFPA, 2007). By 2030 this number will be almost 5 billion, with urban growth concentrated in Africa and Asia. The trend in NZ is similar. Most New Zealanders live in urban areas, within 50 kilometres of the coast, and three out of four live in the North Island. While the national population density is low, it is high in major urban areas (Ministry for the Environment, 2007b, p. 35). Even though many New Zealanders identify with rural landscape or wilderness areas, $86 \%$ of the population lives in urban areas. This makes NZ one of the most urbanised nations in the world (Ministry for the Environment, 2007, p. 41). As the urban environment continues to increase, it is important to understand the effects that urban form has on NZ consumption patterns.

Infrastructure can be perceived as both a constraint and a driver of consumption (Mont \& Power, 2010). Numerous authors have assumed that urban living reduces an individual's EF because of an increase in shared infrastructure, smaller dwellings, and shorter distances to travel to work and the shops. However, recent research has shown that this may not be the case (Rees \& Wackernagel, 1996; Wiedmann et al., 2007a; Wood \& Garnetta, 2009). Ghosh et al. (2007) show that low-density urban forms could have more potential to be resourceuse efficient than more compact urban forms, due to an increased ability to be self-sufficient. On the other hand, with at least $50 \%$ of an individual's EF dependent on lifestyle choices (Barrett et al., 2006) lifestyle is as influential as urban form.

Urban infrastructure is long-lasting and influences resource needs for decades to come (Wackernagel et al., 2006). It can 'lock-in' residents to high footprint activities. Sanne (2002) 
gives the example of the preferred low-density, one-family housing creating urban sprawl. This spurred a move away from public transport and made it easier to increase car ownership. Therefore designing or redesigning urban centres for a lower EF while retaining high "liveability" could also influence people's behaviour.

\section{Lifestyle}

Lifestyle drives how individuals decide to fulfil their fundamental human needs and therefore the consumption of goods and services.

A lifestyle is a more or less integrated set of practices embraced by an individual, not only because they fulfil utilitarian needs, but also because they give material form to a particular narrative of self-identity (Cockerham, 2005; Giddens, 1991). Lifestyle is a characteristic set of behaviours specific to a given time and place (Assadourian, 2010; Spaargaren \& Vliet, 2000). An individual's lifestyle therefore determines the choice of satisfiers to fulfil the perception of needs.

Fundamental human needs are finite, few and classifiable. They are the same for all cultures and historical periods (Maslow, 1943; Max-Neef, 1991; Tay \& Diener, 2011). Manfred MaxNeef (1991), a Chilean economist, proposes nine needs: subsistence, protection, affection, understanding, participation, idleness, creation, identity and freedom. Max-Neef and others (Spaargaren \& Vliet, 2000; Walter, 2012; Zorondo-Rodríguez et al., 2011) suggest needs are expressed through satisfiers and it is the satisfiers that vary according to historical period and culture. Hence, satisfiers are what render needs historical and cultural, and economic goods are their material manifestation (Max-Neef, 1991). Max-Neef further proposes that needs must be treated as being equal rather than hierarchical, as suggested by Maslow. The importance of giving needs equal importance is emphasised by the media's use of human needs to sell products and services, increasing society's consumption. It seems that for many individuals the need for true subsistence (healthy food and drink) is much less important than other needs such as participation, identity and affection. An important step towards reversing consumption trends would be to increase people's ability to disregard the media's manipulation of these fundamental needs. 
Certain satisfiers have a larger or smaller EF than others. Where and how they are produced, consumed and disposed of has a greater or smaller impact on local and distant environments and communities. Some people are choosing their satisfiers more carefully, either using 'green' credentials (Doerr, 2007; United States Environmental Protection Agency, 2004), or by questioning the ability of physical satisfiers to fulfil their fundamental needs (Becker, 2012; Mont \& Power, 2010; Mortimer \& Abrahamse, 2010).

There has been research into segmentation of society with respect to resource requirements. In 2008 DEFRA, the Department for Environment, Food and Rural Affairs in the United Kingdom, created a framework for pro-environmental behaviours. The framework pulls together evidence on public understanding, attitudes and behaviours; identifies behaviour goals; and draws conclusions on the potential for change across a range of behaviour groups (DEFRA, 2008, p. 3). The NZ Ministry for the Environment (MfE) commissioned research using DEFRA's framework. The results were somewhat similar to the UK though NZ had considerably more 'waste watchers' and fewer 'stalled starters', 'side-line supporters' and 'cautious participants' (Johnson, Fryer, \& Raggett, 2008, p. 67; Taylor \& Allen, 2010). DEFRA's framework for pro-environmental behaviours specifically looks at an individual's perceptions and actions that are 'green' or 'environmental'. Therefore there is a danger of missing other actions that may not be seen as 'green' but have a considerable effect on lowering an individual or household's EF.

Other research into NZ lifestyles also shows the distribution of resource consumption across a range of different lifestyles based on broader socio-economic values. Market research by Caldwell and Brown (2007) attempts to overturn the idea of the 'typical New Zealander' by providing a snapshot of the varying cultural and socio-economic backgrounds that, in turn, cause distinct ways of thinking and living. The 8 Tribes outlined in their research cover a range of NZ lifestyles which are particularly focused on the resonant values of people, although, as with the pro-environmental behaviours framework above, individuals' incomes and place of residence vary within each tribe. A summary of each tribe is provided in box 1.1. An indication of the average income is shown but this should be used with caution as some tribes, such as the Raglan tribe, have a large deviation around the mean income. 
Box 1.1: ' 8 Tribes' summary including indicative average income per year in 2010 (Lawton, in press)

- \$130,000 - The North Shore tribe are typified by their love of winning, of being richer, higher up the ladder at work, smarter, more fashionable, more influential and more beautiful than the people around them.

- \$105,000 - The Remuera tribe are also wealthy; old wealth. They rest on old values including their obligation to contribute to the world.

- $\$ 125,000$ - The Grey Lynn tribe are likely to earn almost as much as the North Shore tribe but spend their money in different ways. Their affluence allows them to live in comfort and have access to things they love - art, travel, a vibrant social life, well made things.

- \$90,000 - The Balclutha tribe is the heartland tribe, down to earth, practical, conservative people from the provinces. The Balclutha tribe is efficient with their resources, making do with what they have, and they have a strong sense of community. They are reasonably 'well-to-do' particularly as their income is subsidised by the goods they receive straight from the land.

- \$70,000 - Cuba Street tribe members are opportunists and masters of the new. They are the young culture makers, and are business innovators especially in the tech industries, but may be seen as a little 'weird' by the mainstream. The Cuba Street tribe could be earning a considerable amount of money.

- $\$ 60,000$ - The Papatoetoe tribe is the home of the 'kiwi' working man and woman whose approach to life is characterised by down-to-earth common sense, a focus on life's essentials and a mistrust of intellectualism. This tribe is thrifty; they are in the lower income bracket but have practical skills to ensure a little money can go a long way.

- $\$ 75,000$ - The most important thing in life to the Raglan tribe is freedom; freedom from authority, financial constraints and possessions. The Raglan tribe will not waste money on things that do not matter, but those things that do matter will be of the best quality and be well looked after. They may have high earning power and this provides the luxury to work less.

- $\$ 50,000$ - The Otara tribe is made up of ethnic minorities, often immigrants, whose lives centre on family and a community of people from the old countries. The average income of an Otara tribe household is likely to be relatively low, they tend to work long hours fulfilling roles in low 
How individuals choose satisfiers to fulfil their fundamental human needs is a manifestation of lifestyle characteristics, but dependent on values, incomes and time.

\section{Values}

Values are the principles that guide and motivate attitudes and actions (Navran, 2010). They are informed by an individual's cultural and socio-economic background, and influence behaviour as well as attitudes (Crompton \& Kasser, 2009, p. 51). As a result, values are an important driver of lifestyle decisions, affecting the types of satisfiers chosen which, in turn affect the level of individual resource use (Brown \& Kasser, 2005; Gatersleben et al., 2008; Kasser, 2005; Richins \& Dawson, 1992). Brown \& Kasser (2005) examined how the footprints of 400 North American adults were associated with their life goals. A relatively high focus on materialistic goals related to a higher EF arising from lifestyle choices regarding transportation, housing and diet.

\section{Income}

Income affects a person's wealth and reflects their chosen lifestyle. Increasing or decreasing a person's income can have both positive and negative effects on their lifestyle. For example, earning an income is not only a means of making money but also forms an important part of their social wellbeing for many. The amount of money an individual has affects their access to resources and what they choose to consume.

Employment is a source of income, social relationships, identity and individual self-esteem (Winkelmann \& Winkelmann, 1998). The workplace provides a space to share ideas, feel empowered and create community (Winkelmann \& Winkelmann, 1998). Losing one's job, and hence income, could have negative effects on a person's social relationships (Lawlor, Kersley, \& Steed, 2009).

Wilkinson and Pickett (2009, p. 13) found that rich people tend to be, on average, healthier and happier than poor people in the same society. However they also found that when comparing multiple 'rich' countries with each other it made no difference whether, on average, people in one society were twice as rich as people in another. What mattered was 
not the actual income level and living standard, but how one person compared to others in the same society.

In many countries the gap between the richest and the poorest people continues to increase (Wilkinson \& Pickett, 2009). In the UK this is influenced by many factors, but wage inequality is critical. It is a corrosive, destabilising issue that is linked to a range of social problems (Lawlor et al., 2009). The research above suggests that individuals compare themselves with those around them. It is unlikely that individuals are comparing income directly but, rather, those goods and services that different incomes can afford. As the income gap increases individuals scramble to 'keep up with the Joneses' by increasing their income and/or by going into debt to buy things that they cannot really afford.

Being financially well-off is becoming the end goal. Assadourian (2010) (figure 1.4) found that, by the 1980 s, $80 \%$ of first-year college students in the United States stated it was 'essential' or 'very important' to be financially well-off, whilst only $40 \%$ thought it was 'essential' or 'very important' to 'develop a meaningful philosophy of life'.

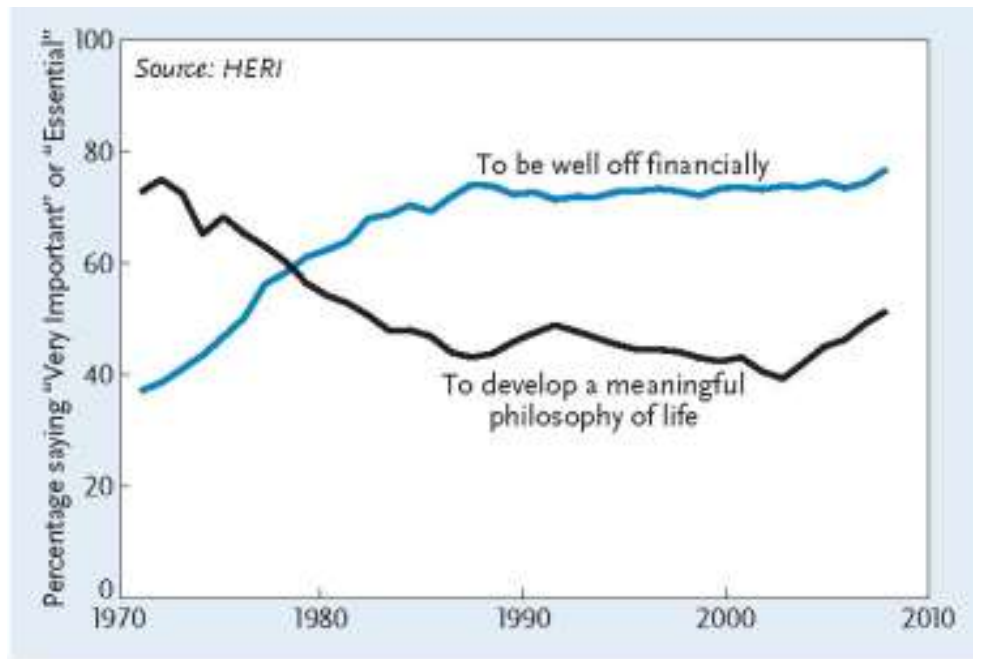

Figure 1.4: Aspirations of first-year college students in the United States, 1971-2008 (Assadourian, 2010, p. 10).

The drive to ' $w i n$ ', rise up the pecking order, and out-do each other has created a situation where societies are destroying the environmental, social and economic systems they rely on in an attempt to achieve their desired lifestyles (Barrett et al., 2006). Individuals with sufficient income have gone beyond satisfying their fundamental needs. There seems to be a belief that the amount of money they possess gives them the right to satisfy their needs and 
wants however they can, with little or no concern for environmental or social consequences. Numerous case studies show that generally the more money a country or individual has, the more natural resources they consume, and the higher their EF. In Canada "the ecological footprint of the richest $10 \%$ is nearly two-and-a-half times that of the poorest $10 \%$ " (Canadian Centre for Policy Alternatives, 2008, p. 1). One fifth of the global population, living in the highest-income countries, account for $86 \%$ of private consumption expenditure while the poorest fifth account for a little over $1 \%$ (Tilford, 2000).

If healthy land and water are not available to provide for people's needs, such as food, then income is required in the place of land, which in turn helps to shape lifestyle. For the World's increasing urban population (United Nations Population Fund, 2007), inequality of income correlates not only with growing social issues but also with inequality of access to natural resources (Tilford, 2000). The research by Wilkinson and Pickett (2009) shows that people not only feel they need to earn more money to fulfil their fundamental human needs, but they also compete with others through a type of 'show and tell' in an effort to keep up with the social norms set by their peers. It could be argued that with a smaller income gap, people would not have such strong desires to buy so much 'stuff' and would not feel the need to earn a large income. As a result people would have more time to do other things and possibly have a lower EF.

Time

Time is a finite resource and for many people it is a luxury that is sought after, in a similar way to other drivers such as gaining income (Robin \& Dominguez, 1992). There is regular commentary about lack of time and increasingly 'busy' lifestyles (Kreider, 2012). However people are starting to resist such pressures: "I made a conscious decision, a long time ago, to choose time over money, since I've always understood that the best investment of my limited time on earth was to spend it with people I love" (Kreider, 2012, p. 1).

NZ men aged $25-44$ spend $31 \%$ of their waking lives at work. Another $34 \%$ is spent engrossed in mass media and 'free-time' activities which include reading, writing, watching television (TV) and playing video games (Statistics New Zealand, 2011e). Data on time spent watching TV for this demographic are not available. However, statistics averaged over the whole 
population show that, of the time spent engaged in mass media and free-time activities, $70 \%$ is watching TV (Statistics New Zealand, 2011b). If the majority of their mass media and freetime activity is watching TV then, on average, young men spend two-thirds of their waking lives either earning an income or watching television (an effective tool for promulgating the types and amounts of satisfiers required to fulfil their needs in order to 'keep up with the Joneses'). In turn this encourages people to work more, increase their income, buy more belongings and watch more TV.

Proponents of the 'living lightly' concept (Librova, 2008) argue that the consumer's life is difficult because he or she must constantly make decisions. The consumer is a slave to neverending pseudo-needs. The consumer strives for greater work productivity and higher financial rewards, obsessively studies product catalogues, drives between supermarkets, and makes Herculean efforts to get through the maze of advantageous offers and loans. All this clutters the mind, takes time, and complicates life, suggesting it is necessary to simplify life to make it easier (Librova, 2008, p. 1122).

The amount of money earned allows for the exercise of different types of lifestyles with varying levels of resource consumption. A case study using the ' 8 Tribes' categories shows that, on average, income correlates with EF (Lawton, in press). Some reduction in footprint can be made by moving to 'greener' products and services but the general rule-of-thumb is that the more products and services people buy, the bigger their EF (Vale \& Vale, 2009b). Reducing components of the NZ footprint, such as food and transport, is likely to require time. A decision to change how people spend their time is dependent on what they value, the urban form in which they live, and finally the broader governing political and cultural systems.

These drivers of consumption - political and cultural systems, urban form and lifestyle-can therefore be used to identify why individuals and communities are consuming resources at such a fast rate, and also to identify some of the key changes necessary to help people to consume fewer resources and live within their fair earth share EF. But the question remains open: what does a fair earth share EF look like in the context of a NZ community? 


\subsection{A Vision of Sustainability}

"A vision without a task is but a dream, a task without a vision is drudgery, a vision and a task is the hope of the world"- cited in Outhwaite (2009) from a church in Sussex, UK, 1730 A.D.

The first international report on sustainable development is more than 25 years old (Brundtland Commission, 1987) and there is still a lack of consensus about what sustainability looks like, how it might be governed, and how the economy would operate. Providing scientific and artistic visions for a sustainable future will help to provide direction for plans and policies to achieve this. In addition to a vision, measurement tools are required to track the progress of an individual or community in achieving the vision (Holmberg, 1998; Holmberg \& Robèrt, 2000; Outhwaite, 2009).

The concept of fair earth share can be used to provide a vision of sustainability, where a person's lifestyle can be supported by a certain quantity of land in perpetuity. A number of communities and organisations have used the concept of a fair earth share, or one planet living, as a guide for creating scenario options for moving toward this vision. WWF Wales provides scenarios illustrating how a range of different Welsh sectors, including food, transport, governance and lifestyles, could achieve a '75\% reduction in their EF by 2050' (Ravetz, 2007a, p. 1). The One Planet Wales challenge is, "...for the people of Wales to lead healthy, prosperous lives within their fair share of the Earth's resources" (Ravetz, 2007a, p. 1). Others have also adopted this concept for 'one planet economy' (One Planet Economy Network, 2010) and 'one planet business' (Beloe et al., 2007).

What has not yet been demonstrated is a picture of what life and communities could look like when operating within the constraints of a fair earth share EF? Visions and strategies are generally at the national level rather than allowing for individuals to tailor their lifestyles within their own personal fair earth share. What people do with their share is up to them and is dependent on their own preferences. The fair earth share is relatively small in comparison to most current Western lifestyles. Thus some activities, such as international flights, would require a considerable amount of 'savings' (a trade-off with other resource consumption) for the person to stay within their 'fair share' allocation. To create a plan for achieving a fair earth share, the vision must be created by back-casting to current time, and then a strategic plan 
created for reaching the vision. Back-casting is a process of starting from a vision of success then looking back to the present to identify the most strategic steps to success (Outhwaite, 2009). The method of back-casting increases the likelihood of handling the ecologically complex issues in a systematic and coordinated way, and foreseeing certain changes (Holmberg \& Robèrt, 2000).

Unsustainability is being driven by decreasing availability and an increasing demand on the World's resources. In order to achieve a sustainable future, society needs to realign all aspects of consumption to achieve a vision of fair earth share communities. Governing organisations must provide political and cultural systems that support the creation of an urban form that reduces barriers to communities achieving sustainable consumption habits. Communication of the fair earth share vision can be achieved through campaigns appealing to each of the ' 8 Tribes', their values, and how they decide to spend their income and use their time.

This research proposes that a range of scenarios is required, showing how individuals with a range of lifestyles living in different urban forms might live within their fair earth share. The ultimate question is 'in what urban form could an individual live, and what kind of lifestyle could they have, to maximise their wellbeing whilst living within a fair earth share footprint?' For large-scale change that supports individual capacity to live more sustainably, communities must work collectively in all spheres of consumption influence. Defining the constraints by which people need to live will inspire individuals and communities to think and act creatively.

\subsection{Thesis Outline}

This thesis sets out a number of steps towards understanding what a sustainable fair earth share state for NZ might look like. The EF has been proven (Collins et al., 2009; Laurance et al., 2012) to be an effective accounting tool that allows for measurement of current and future resource use in relation to urban form and lifestyles, increasing society's understanding of whether or not specific actions are moving towards a state of sustainability. The thesis is made up of six further chapters:

Chapter 2: Research Outline is a description of the five-part research project undertaken and an introduction to the methods used. 
Chapter 3: The Ecological Footprint provides detail about the EF tool, including examples of national and international case studies. The chapter explores multiple footprint methods and provides justifications for the choice of methods used in this project. NZ-specific yield calculations are explored and defined for use in the footprint calculations.

Chapter 4: New Zealand's Footprint looks specifically at resource use and waste creation in the NZ context. This is the main chapter of the thesis because of the detailed research required to calculate a component-style EF. NZ's EF is divided into 11 types of resource use: food and drink, travel, consumer goods, holidays, housing, household energy, infrastructure, government, services, tourism and waste.

Chapter 5: Community Footprint Results explains how the results from chapter 4 are used to inform a footprint survey and calculator development. The survey was used to collect data from five NZ communities and the calculator provided individual and community EF results. The results are then analysed to understand the similarities and differences between the five communities. The aim of the data analysis is to use the community-derived data to determine the impact of different urban forms and lifestyle choices on a community's EF.

Chapter 6: Fair Earth Share Scenarios reports on outcomes from the footprint workshops where communities had the opportunity to discuss the findings from chapter 5 . These are used to create fair earth share scenarios for each of the four communities who took part in workshops. An additional scenario is created by back-casting from a theoretical fair earth share NZ community EF. Chapter 6 ends with four scenarios created to inspire people with ideas on what NZ might look like in 2040, and each story explains how different urban forms might react to resource scarcity.

Chapter 7: Discussion summarises the results and discusses what they mean for NZ's future EF. There is also reflection on the methods and processes used during the research and suggestions of what could have been done differently. The chapter closes with recommendations for future research and the benefits to communities from using resourceaccounting tools such as the EF in their planning and decision-making. 


\section{Chapter 2: Research Outline}

The NZ EF Project was launched in late 2009. It proposed that the EF could be an effective means of measuring resource demands, and that these EF measures could be communicated to a range of different audiences. Further, it showed that plans and strategies could be devised for reducing EF, to shift New Zealanders towards living equitably within the Earth's natural regenerative capacity.

The following chapter provides a brief outline of the proposed research design and methods relating to this thesis as part of the project. The methods introduced below are explained in greater detail at the beginning of each of the following chapters.

\subsection{Research Methods}

This research has contributed to basic science by providing fundamental data on the flow and use of resources within communities. The research is predominantly descriptive in nature, providing data sets that have previously not been available in a concise form. Use of the EF as an index provides an effective tool for consolidating large amounts of data into comparable and easily communicable figures.

Though the main aim of collecting quantitative resource data is to understand resource flow, there is also an opportunity to draw on qualitative analysis methods to better appreciate why these resources flows are occurring. The project undertook a 'mixed methods' approach: "...the class of research where the researcher mixes or combines quantitative and qualitative research techniques, methods, approaches, concepts or language into a single study" (Johnson \& Onwuegbuzie, 2004). A quantitative methodology guided the collection of resource flow data and community statistics regarding urban and social form. Qualitative methods were used to further inform the creation of the fair earth share scenarios.

The research worked with project partners to collect and generate local EF data. Good quality local EF data are often too costly for communities to gather themselves (Walsh et al., 2010; Wilson \& Grant, 2009), but national data lacks specificity for local use. Therefore local secondary data were used where available, and these were compared to and, in some cases, substituted for primary data gathered from individuals within the community. Hunter et al. 
(2006) promote the collection and analysis of suitable primary data rather than heavy reliance on secondary data sources. Individuals within five geographically diverse communities were asked to participate in the research by providing data for analysis. Data collection was carried out using household surveys. Household data were used to calculate community-specific footprints using the component method.

The process of undertaking research and data collection alongside individuals also provides the opportunity to support and educate those who take part (Hunter et al., 2006). As part of the larger research project, individual members of the communities were able to discuss the resource requirements of their lifestyles. Community members were invited to take part in a visioning exercise to discuss what their community might look like in a resource-constrained future.

\subsection{Community Selection}

One of the aims of the NZ Footprint Project was to engage with potential end-users. Previous research shows a lack of effective tools that allow individuals and communities to get coherent feedback about their resource requirements and how they might reduce these in the face of rising resource costs (Barrett \& Simmons, 2003). The NZ Footprint Project therefore worked with communities and their local government organisations. The communities were chosen by the Footprint Project Managers because of their previous relationships and willingness to take part in the research. However this created weaknesses in the methodology of choosing the most fitting communities with the ideal community criteria. The goal was to measure and compare the EF of a range of urban forms within NZ and how different lifestyles interact with these urban forms. To address this goal, the communities that took part in this research needed to differ in both size and scale, and vary in the demographic and socio-economic make-up of the people living there in an effort to characterise different NZ lifestyles. Two of the partner communities were in Auckland, two were in Central Otago and the fifth community was from the Kapiti Coast. The latter represented culturally diverse lower socio-economic lifestyles and further research is recommended to include such communities in the footprint analysis. The Central Otago District Council had been involved in the preliminary conversations regarding funding for the 
project and was invited to take part. Kapiti Coast District Council became involved in the project through a mutual interest in using the EF tool for engaging the community in behaviour change and communicating the impacts caused by the over-use of resources. The Kapiti residents were already involved in the Kapiti Coast Greenest Streets competition (Kapiti Coast District Council, 2011) and provided their household data for use in this research.

Statistics New Zealand (2004) identifies urban and rural as the two main profile classification categories with seven sub-categories. Urban areas are divided into 'main urban centres', 'satellite urban areas', and 'independent urban areas'. Rural areas are divided into those with 'high', 'moderate' and 'low' urban influence, and 'highly rural remote areas'. The aim of the project was to have five communities from different profile classification categories representing both the urban and rural identities.

In the Auckland area four possible communities were suggested, all of which were 'satellite urban areas'. Of these, Waiheke and Waitakere became involved. In Central Otago only two communities were proposed: Cromwell (an 'independent urban area') and Tarras (a 'highly rural remote area'). Kapiti was the final community, representing a 'main urban centre'.

Managers of the NZ Footprint Project suggested the project was likely to have greater success if the communities themselves were open and willing to take part. Interested communities were invited to volunteer. The engagement process for each of the five communities was different depending on the specific networks that were available for the Footprint Project Managers to work with. Further detail regarding the process of inviting questionnaire and workshop participants is provided in section 2.5.3.

Because the sample communities took part in the research voluntarily rather than being selected at random, the selection method included non-sampling errors. It is possible that the communities that volunteered already had lower EF lifestyles and were therefore more interested in taking part. The project team, although satisfied with the representation of urban forms, were less satisfied with the representation of lifestyle types. 


\subsection{Research Design}

The research was designed with the aim of calculating the average NZ EF, then gathering reliable household data describing the products and services specifically used by different communities and individuals. Data collection also provided a process for engaging communities of individuals in reflection on, and discussion of, their current and future EF. The description of the research design is in five parts. Part one provides background information about the EF and the EF methods and calculations that will be used. Part two is the calculation of the 'average' NZ EF, which is then used to create an EF template. Part three outlines the creation of a footprint calculator and survey. Part four describes the collection of urban form and lifestyle data from the five community partners. Part five describes the creation of fair earth share scenarios that reflect specific types of urban forms and lifestyles.

\section{Part 1: Background to the ecological footprint}

Part 1 (chapter 3 ) of the research provides background information, including different methods for calculating the EF. A decision was made to use local New Zealand hectares (NZha) rather than gha. A NZha is the amount of NZ land required to produce a certain amount of resource according to NZ specific yields. However, there is almost no published material on NZ yields or explaining how to carry out detailed footprint calculations in local hectares. Therefore the local yields for non-renewable and renewable energy, fishing and forest land are calculated in part 1 of the research. These are required to provide a unit of measurement for these land types in part 2.

\section{Part 2: Calculating a New Zealand ecological footprint as a basic template}

Part 2 (chapter 4) makes up the bulk of the thesis due to the level of detail needed to calculate the NZ EF. A two-fold method was used to create a template based on a NZ 'average' EF calculation. The NZ EF template then became the baseline data used to create the more detailed footprint calculator for individuals.

Table 2.1 suggests how the NZ EF can be broken down into three parts (Collins, Flynn, \& Netherwood, 2005; Vale \& Vale, 2009a) - the individual footprint, household footprint and the collective footprint-providing a clear and logical basis for gathering data for the 'average' 
EF calculations. These footprint levels are also reflected in the spheres of influence on consumption mentioned in chapter 1 (Figure 1.3). The method chosen for gathering the required EF data can be described as two-fold, using both the component method for aggregating EF totals for products and services, and a 'top-down bottom-up' approach for resource use within a given population.

Table 2.1: NZ EF Template: An individual's EF is made up of three parts, each comprising a number of categories. A description of these categories specifies some of the data required.

\begin{tabular}{|c|c|c|}
\hline Parts & Category & Sub-categories \\
\hline \multirow[t]{4}{*}{$\begin{array}{l}\text { 1. The EF related to individual } \\
\text { lifestyles }\end{array}$} & Food and drink & $\begin{array}{l}\text { Food and drink at home and eating } \\
\text { out }\end{array}$ \\
\hline & Travel & Car, bus, train and air travel \\
\hline & $\begin{array}{l}\text { Consumer } \\
\text { goods }\end{array}$ & $\begin{array}{l}\text { Pets, clothes, computers, } \\
\text { televisions, books, furniture, } \\
\text { appliances }\end{array}$ \\
\hline & Holidays & Holidays at home and abroad \\
\hline \multirow[t]{2}{*}{$\begin{array}{l}\text { 2. Household EF related to the } \\
\text { urban form and built environment }\end{array}$} & Energy & Energy used in the home \\
\hline & Housing & $\begin{array}{l}\text { House building, maintenance and } \\
\text { repairs }\end{array}$ \\
\hline \multirow[t]{3}{*}{$\begin{array}{l}\text { 3. Collective EF, related to central } \\
\text { and local government and services }\end{array}$} & Infrastructure & $\begin{array}{l}\text { Motorways, railways, bridges and } \\
\text { stadia }\end{array}$ \\
\hline & Government & $\begin{array}{l}\text { Consumables and durables for } \\
\text { local and central government }\end{array}$ \\
\hline & Services & $\begin{array}{l}\text { Water, phone, post, hospitals, } \\
\text { education, finance, police etc. }\end{array}$ \\
\hline
\end{tabular}

The total of each of these categories is divided by the total NZ population to get an average per capita EF. Further detail regarding the specific EF methodology used in this project can be found at the beginning of 'Chapter 3: Ecological Footprint' and 'Chapter 4: New Zealand's Footprint'. The results of the average NZ EF are discussed at the end of chapter 4.

\section{Part 3: Generating an EF calculator and survey}

The calculation of NZ's average EF provided a template from which data could be manipulated to reflect the variation in EF depending on an individual's consumption of goods and services, depending on their lifestyle and urban form. Four calculators were used in a comparative case study to highlight the issues that other research has perceived to be the most important in footprint calculations. These findings were compared with the NZ template to verify whether 
these issues were also important for NZ and whether they could assist in highlighting how behaviour and urban form affect the NZ EF. The survey went through a rigorous 6-month testing phase before it was finalised for use with the sample communities (see appendix 1 for a copy of the New Zealand Footprint Survey).

The calculator included questions covering each of the EF categories and sub-categories shown in the NZ EF template (table 2.1). The footprint calculator was created based on a sliding scale in relation to the NZ average. The questionnaire was multi-choice, and if the interviewee's answer was higher or lower than the NZ average, this was reflected in the EF result for that question. For example, on average, New Zealanders drive 7,453 km per year and $143 \mathrm{~km}$ per week (MfE, 2010b). There were five options the interviewees could choose as the distance driven in an average week, at $80-\mathrm{km}$ intervals. The average distance was included in option B.

The calculator was specifically designed to calculate the individual and collective EF of the sample communities involved in this research. The Footprint Project Calculator can be viewed on the 'supplementary information'. Further detail regarding the design process of the questionnaire and calculator can be found at the beginning of Chapter 5.

\section{Part 4: Gathering community data and calculating community ecological footprints}

The aim of part 4 was to gather EF data from five NZ communities and carry out data analysis that would provide information about the size and make-up of each community's EF. The five sample communities were then used as examples of the influence of particular urban forms and lifestyle in the creation of the EF scenarios.

Primary household and lifestyle data were obtained using surveys and workshops. Having people participate in both of these options is preferable, with completion of the individual survey as a minimum requirement. A number of barriers were anticipated when collecting the data, either due to people's unresponsiveness to taking part and/or time-constraints. The individual questionnaire was carried out before the household survey, and was designed to help gain the participant's trust, spur on enthusiasm for the project, and provide momentum for the participant's own data gathering. 
The community selection process was voluntary. The community engagement process was specific to each community, depending on existing contacts and relationships. For many cases individuals stepped forward voluntarily and others were specifically invited to be involved.

The aim of the data analysis phase was to provide a detailed understanding of how and why NZ communities use resources in relation to both urban form and lifestyles. Data were amalgamated in the statistics software SPSS (Statistics Package for the Social Sciences). The amalgamated data was then used to test the significance of differences of means between communities to highlight those that have significantly different EF and compare the similarities and differences between the community footprints and selected survey questions. The results provide insight into how and why the community footprints change depending on the type of urban form and the lifestyle choices of the people who live there.

\section{Part 5: Creating a range of fair earth share ecological footprint scenarios}

Community perspectives, conversations, comments and visions were collected from the community workshops. Workshops were carried out in four of the five communities who took part in the project. Kapiti Coast community was not involved in the workshops and scenarios sections of the research. During the workshops the footprint results from part 4 were presented to the community members. They were then asked to share their thoughts about the causes of increased pressure on available land and to suggest action that the community could undertake to reduce their EF.

The results of the community discussions were used to drive the development of four fair earth share scenarios. Chapter 6 of this research presents the community data and resulting fair earth share scenarios in two ways:

1. Focusing on the largest component of each community's EF, actions for decreasing a community's footprint are suggested. Some but not all of these actions were suggested by the community during the workshop. The actions were used in a process of reduction in order to reach an average fair earth share footprint for the members of that community. 
2. The workshop outcomes were also used in the development of a scenario proposing a potential future for NZ. A story was then developed for each of the four communities detailing how they might respond to this future and how their actions could affect their EF.

The five parts of the research each build upon the previous part, in an effort to create footprint data that can be used to better understand resource use in NZ and whether this differs depending on the urban form of a community and the chosen lifestyles of the individuals within it.

\subsection{Ethical Considerations}

Ethical approval for the research was received from Victoria University of Wellington Human Ethics Committee in January 2011. There were ethical considerations in relation to the engagement with individuals regarding personal details about their lifestyles. Individual engagement was on a voluntary basis where the survey was completed face-to-face, in a place that could be mutually agreed upon between the participant and the interviewer. A number of steps were carried out to ensure that the identities of individuals were confidential and there were options for people to omit information if they were not comfortable for it to be used.

The means for inviting individuals to take part in the project varied for each of the five communities, although the most common way was through the email databases of the Footprint Project partners and newspaper stories. Individuals were asked to respond to the invitation by email or phone, which allowed for an interview time to be set up. If possible, at this time they were sent a 'participant information form'. The form clearly explained that individuals were able to skip a particular question if they were not comfortable with divulging the information. If questions were deemed sensitive in nature (e.g., what is your annual household income?), a 'no comment' option was provided.

Upon arrival at the scheduled interview individuals were given a participant information form and the project was briefly explained to them. They were then were asked to sign participant consent form acknowledging that the NZ EF Project would use their information as a dataset 
and would not identify any one community member. This was particularly important for the smaller communities where individuals could be identified more easily. The participant information form and participant consent form are shown in appendix 2 . Individuals were allocated an identification number that was used to label their questionnaires and household surveys. This information was kept separately under electronic password access.

Participants were treated with respect, and many reported they 'enjoyed' their interview experience as it provided an opportunity for reflecting on their resource use.

\subsection{Summary}

The planning of this research worked within the aims of the broader NZ EF project in order to fulfil the objectives of both. This also provided considerable opportunities for the research to engage with participants in two NZ local councils and across five communities. The research outcomes are dependent on the qualitative and quantitative data retrieved from the household surveys and community workshops. These communities are indicative sample communities and, because of the voluntary nature of the data collection, it is likely that the information is slightly skewed towards those individuals with lower footprints. Data will be presented by way of both statistical analysis and observational reflection.

The footprint calculation will be presented in nine consumption categories (table 2.1) that can also be described in terms of possible influence for reducing an individual and community's footprint. 


\section{Chapter 3: The Ecological Footprint}

Chapter 2 described the process used to collect resource use data for NZ and NZ communities. This chapter provides background about the EF, the tool for analysing the data, the method, and specific NZ yields that will be used.

Modern society is made up of a complex web of economic, social, environmental and political systems integrating at global and local scales. Chapter 1 introduced the drivers of unsustainability and the key influences on consumption. As society becomes increasingly urbanised the ability for communities to receive feedback in response to resource use becomes increasingly difficult. There is an increased mental separation between the resources people use and where these come from. Measurement tools are required to keep track of both the supply of available biocapacity and the demands that society is making on biological systems at a global, national and local levels. The EF provides these measures by using 'land' as a common unit of measurement and provides a clear understanding of what it means to be 'sustainable' or live within the planet's biocapacity (Robèrt et al., 2002). The specific EF method required depends on the project.

The EF was first introduced by Wackernagel and Rees (1996) in Our Ecological Footprint: Reducing Human Impact on the Earth. EF accounting enables an estimate of the resource consumption and waste assimilation requirements of a defined human population or economy (Wackernagel \& Rees, 1996). The EF also provides a baseline and comprehensive method for evaluating whether human populations meet a minimum condition for sustainability, namely that humanity's demands on the biosphere remain within the biosphere's regenerative capacity (Monfreda, Wackernagel, \& Deumling, 2004; Wackernagel et al., 2005; Walsh et al., 2010). Initially developed for measuring national consumption, the $E F$ is increasingly being used to support policy formation through scenario creation and communication (Collins et al., 2009; Cornforth, 2009; Monette, Colman, \& Wilson, 2001; Monfreda et al., 2004; Moran et al., 2007; Wiedmann et al., 2007a; Wilson \& Grant, 2009). Community planners, policy-makers and leaders see the EF as a tool for measuring the state of unsustainability in their communities, indicating society's biggest impacts on the environment, raising awareness about sustainability issues, and assisting with defining 
sustainability goals (Best Foot Forward Ltd., 2002; Calcott \& Bull, 2007; Collins \& Flynn, 2005; Wilson \& Grant, 2009). Increasingly, research shows that at least a 50\% reduction in resource consumption can come from an individual's change in lifestyle. Further reductions could then come from changes in government procurement, urban form and infrastructure, and improvements in the eco-efficiency of products and services (Barrett et al., 2006).

The original EF indices created by Wackernagel and Rees in 1996 were based on six assumptions (Wackernagel et al., 2002, p. 9266):

1. The majority of the resources people consume and the wastes they generate can be tracked.

2. Most of these resource and waste flows can be measured in terms of the biologically productive area necessary to maintain flows. Resource and waste flows that cannot be measured are excluded from the assessment, leading to a systematic underestimate of humanity's true EF.

3. By weighting each area in proportion to its bioproductivity, different types of area can be converted into the common unit of gha, (defined as equivalent hectares of land area with world average bioproductivity).

4. Because a single gha represents a single use, and all gha in any single year represent the same amount of bioproductivity, they can be added up to obtain an aggregate indicator of EF or biocapacity.

5. Human demand, expressed as the EF, can be directly compared to nature's supply, biocapacity, when both are expressed in gha.

6. Area demanded can exceed area supplied if demand on an ecosystem exceeds that ecosystem's regenerative capacity. Humans can temporarily demand more biocapacity from forests or fisheries than those ecosystems have available. Alternatively natural systems can be saturated with waste beyond their ability to sequester it, e.g. the carbon cycle causing an increased concentration of carbon dioxide in the atmosphere. This situation, where EF exceeds available biocapacity, is known as 'overshoot'.

All assumptions relate to each of the EF methods discussed below except, as in this research, where local yields are used in place of global yields. In the case where local yields are used, 
assumptions 3 and 4 do not apply. The implications of these assumptions and the various EF methods will be discussed below.

Chapter 3 provides an introduction to the EF tool that is used internationally and within NZ by governments, non-governmental organisations, businesses, schools and individuals as a way to measure, communicate and compare how individuals and communities use resources. An introduction to various EF methods is also provided, highlighting the method used by this research. EF calculations are carried out for NZ yields in order to calculate the NZ EF in local yields. The final section of this chapter discusses some of the limitations of the EF and how caution should be exercised regarding the role of the EF in measuring sustainability.

\subsection{International use}

International case studies, particularly from the UK and Canada, have shown that EF can successfully measure and communicate the complexities of resource flows through society (Barrett et al., 2002; Collins \& Flynn, 2005; Hunter et al., 2006). The data have been used to inform individual purchasing decisions at the household level (BioRegional \& WWF, 2008; Simmons \& Chambers, 1998; Vale \& Vale, 2009b) and at national level (Lenzen \& Murray, 2001; McDonald \& Patterson, 2003; Wackernagel et al., 2005; WWF, 2010), as well as to inform product producers and designers about the resource impacts of their products (Wiedmann \& Barrett, 2010; Wiedmann, Barrett, \& Lenzen, 2007). EF data is increasingly being used to support policy formation through scenario creation and communication (Collins et al., 2009; Cornforth, 2009; Monette et al., 2001; Monfreda et al., 2004; Moran et al., 2007; Wiedmann \& Barrett, 2010; Wiedmann et al., 2007b; Wilson \& Grant, 2009).

An influential international case study was funded by Cardiff City Council in partnership with BRASS Research Centre at Cardiff University and the Stockholm Environment Institute. Initiated in January 2003, the aim of the project was to "show where Cardiff's EF is heaviest, and highlight areas of concern for the future" (Collins et al., 2005, p. 1). The project report also showed that the fundamental challenge was to slow down the growth of Cardiff's EF, even before plans were put in place for reducing it. The report stated that "in order to slow down the growth of the City's EF, significant changes in forward planning and activities will be needed from the Council, and its partners in the public and private sectors" (Collins et al., 
2005, p. 1). It also identified that Cardiff's citizens and visitors have a key role in minimising their own EF and the City's overall ecological impact.

\subsection{New Zealand use}

Use of the EF in NZ has been varied and ranges from official publications and journals through to demonstration on television for education and behaviour change purposes. At the national level, the EF has been used by the MfE as a way of communicating environmental limits and personal consumption (MfE, 2008a; Taylor \& Smith, 1997). In 2003 the MfE also commissioned a technical paper entitled The Ecological Footprint of New Zealand and its Regions (McDonald \& Patterson, 2003). The report compared NZ's regions with their biocapacity in an effort to show resource overshoot at the local level as well as resource exchange between regions. However with regard to policy and plan development, the EF has not been used at the national level.

The EF has been used with success at the local and individual level as a communication and education tool. The EF has been tested with primary school children as a way of learning about resource limits and encouraging behaviour change (Baldwin, Becken, \& Allen, 2008), as a baseline measurement tool to encourage households to reduce their overall resource consumption (Far North Environment Centre, 2011; Kapiti Coast District Council, 2011), and as a communication tool and calculator for the television series 'Wa\$ted' (Andrew \& Patterson, 2008). There are multiple research projects where the EF has been used to measure the resource consumption of specific places, activities, products or buildings, including: the EF of the NZ economy (Bicknell et al., 1998); the EF of Auckland's transport system (Huang, 2010); a comparison of Wellington's 1956 and 2006 footprints (Field, 2011); the EF of the Waikato Region (Market Economics, 2006; McDonald \& Patterson, 2001); the EF of the University of Otago School of Business (Aporo et al., 2007); the total environmental impacts of NZ's food and fibre industries (Andrew et al., 2005); the EF of NZ's aging population (McDonald, Forgie, \& MacGregor, 2006); and, to be completed in 2013, the creation of a template to calculate the EF of major NZ sporting and cultural events (Spearing, 2012).

The EF has been used in NZ to fulfil a range of aims from whole country analysis to calculators for individual footprints. The uses have been restricted to a top-down approach to ecological 
footprinting which does not include the detail required to understand the key drivers of people's EF. The following section explains the differences between the EF methods used in the projects above and introduce the component based, top-down bottom-up method used in the current research.

\subsection{Ecological Footprint Methods}

Since its conception in the late 1990s the EF has undergone a number of methodological revisions, altering not only where the data comes from, but also the level of detail at which the EF can track changes in an individual or community's resource consumption. Wiedmann and Barrett (2010), surveying over a decade's worth of case studies, highlighted that there is no one-size-fits-all approach to projects using the EF. The footprint methodology should be adapted depending on:

1. whether the aim of the project is to compare footprints locally, nationally or internationally

2. who are the expected target audience for the project results, i.e. individuals, local community groups, policy makers, international agencies;

3. the level of resource accounting detail required, i.e. at an organisational level, community wide level, national or international level;

4. availability of data which must also be considered in association with required detail; and

5. the skills of the project team and available resources including money and time.

Though it is generally acknowledged as a valuable education tool that enriches the sustainability debate, the original EF is limited as a regional policy and planning tool for ecological sustainable development, because it does not reveal where impacts really occur, what the nature and severity of these impacts are, and how these impacts compare with the self-repair capability of the ecosystem. In response to the problems highlighted, the concept has undergone significant modification. These modifications include the use of input-output analysis, renewable energy scenarios, land disturbance as a better proxy for sustainability, and the use of production layer decomposition, structural path analysis and multivariate regression in order to reveal rich EF details (Lenzen \& Murray, 2003). 
There are primarily three different overarching methods. These are the original compound method created by Wackernagel and Rees (1996), the input-output analysis (IOA) method developed by Bicknell et al. (1998) and her team in NZ, and the component method, which is becoming increasingly successful with local EF projects. There are also variations within these methods which will be discussed below. Use of local NZha is less likely using the compound method than in input-output or component based methods; however it could be used, as there are method options available. How the data is intended to be used is paramount to how the EF calculations should be carried out.

\subsubsection{Compound Method}

The most established method of conducting EF Accounting is the compound method (Rees, 1992; Wackernagel \& Rees, 1996). It has become increasingly standardised over the years and is typically used at the national level. Consumption of more than 200 resources is included in the calculation and the footprints of these resources are aggregated into one of six land categories required to support that consumption (Wackernagel et al., 2005). To understand this method in more detail the GFN have created standardised guidelines for reporting on footprints using both the compound and input-output method mentioned below (GFN, 2009).

Aggregated forms of the EF make it difficult to understand the specific reasons for the unsustainability of a given population's consumption, and to formulate appropriate policy responses (Lenzen \& Murray, 2003, p. 4). However, the method provides a means for international comparison that can be replicated and therefore also provides a basis for comparing footprints over time.

There are two distinct parts to calculating EF using the compound method. The first is to find the embodied EF of the product or service and the second is to calculate the total consumption of the product or service in question.

\subsubsection{Input-Output Analysis}

IOA is a macroeconomic technique that relies on data on inter-industrial monetary transactions (Lenzen \& Murray, 2003, p. 8). The calculations for the footprints of populations by Wackernagel and Rees (1996) were mainly those items and services directly required by 
households, and by the producers of consumer items. These producers draw on numerous input items themselves, and the producers of these inputs also require land. Generally speaking, in modern economies all industry sectors are dependent on all other sectors, and this process of industrial interdependence proceeds infinitely in an upstream direction, through the whole life cycle of all products, like the branches of an infinite tree (Lenzen \& Murray, 2003). IOA is an accounting procedure that relies on national input-output tables. A country's input-output tables document the flow of money to and from the various industry sectors, showing just how interdependent they are. In broad terms IOA tables show an industry's output, i.e. what is sold by the industry to other industries (and to itself), and an industry's inputs, i.e. what is bought by an industry in order for it to produce its goods or services (sometimes called its production recipe) (Murray \& Lenzen, 2010, p. 7). In order to use IOA to calculate an EF of a given population, physical and economic data are integrated into a combined flow account which helps connect environmental and economic fields. The resulting tables reveal the flows from the environment to industry in the form of ecosystem inputs and natural resources (Murray \& Lenzen, 2010). Since its introduction by Nobel Prize laureate Wassily Leontief (1936), IOA has been applied to numerous economic, social and environmental issues. It was first applied to EF by Bicknell et al. in 1998 to calculate an EF for NZ (Lenzen \& Murray, 2003).

Wiedmann and Barrett (2010) found that the main advantage of IOA lies in its unambiguous and consistent accounting of all upstream life-cycle impacts and the good availability of expenditure data that allow a fine spatial, temporal and socio-economic breakdown of consumption footprints. Limitations with the IOA method relate to the availability of data on embodied energy and land, in relation to monetary flows through the population under assessment. There continue to be advances in this area of research (Wiedmann \& Barrett, 2010).

\subsubsection{Component Method}

There are numerous case studies detailing multiple methods to calculate the EF at a local community level. These case studies aim to provide local EF calculations that are complete, capturing all resources used by a community or individual (Aall \& Norland, 2005; Hunter et al., 2006; Klinsky, Sieber, \& Mered, 2009; Monette et al., 2001; Paul, 2006; Wilson, 2001). 
Recent case studies focused on the EF of sub-national populations have increasingly supported the component method for its suitability in the local context. The method was developed to connect with people through their daily activities (for example waste production and electricity consumption) (Barrett, 2001; Ryan, 2004; Simmons, Lewis, \& Barrett, 2000).

In the component-based model the EF values for certain activities are pre-calculated using data appropriate to the region under consideration (Simmons et al., 2000). For example, to calculate the impact of a ferry ride, local average data on fuel consumption, manufacturing and maintenance energy are calculated. These figures may then be converted to total EF per kilometre. The total kilometres travelled by a population are then multiplied by EF per kilometre to give a result of the final EF of an individual or community. Many of the original EF compound calculations aimed to capture indirect effects in a life-cycle context (Barrett, 2001; Simmons \& Chambers, 1998; Simmons et al., 2000). Problems involved a general lack of data, and methodological issues such as boundary selection and double-counting. In addition, many consider embodied energy but not embodied land (Lenzen \& Murray, 2003, p. 9; Simmons et al., 2000).

The component method is time consuming in finding the data, and the data are not readily substituted, i.e. data do not originate from a regularly updated database. The component method was selected for this research due to the level of detail that could be gained and the insight this might provide into the relationship of the EF to lifestyle trends. The method could also be carried out through a bottom-up approach using a range of different data sources.

To calculate the EF using the component method, life-cycle data (for most forms of consumption), the output of non-productive waste, and the loss of productive land through building activities are combined into an overall EF (Chambers et al., 2004; Hunter et al., 2006; Simmons \& Chambers, 1998). For example, to calculate the impact of car travel, data on fuel consumption, manufacturing and maintenance energy, land apportioned to road space, and average occupancy are sourced for the country in question. The total can be used as an average EF estimate derived for a single passenger kilometre (pkm), which can then be used to calculate the impact of an individual's vehicle use (Simmons et al., 2000). 
The second part of the component method deals with the collection of data to produce figures for 'per person' consumption for a given population. This requires information from a range of national datasets at the international, national, regional, community, household and individual level involving both a 'top-down' and a 'bottom-up' approach. A top-down approach uses secondary data, providing a population total for any given resource or service. The total is then shared equally amongst all members of that population, providing a population average. The bottom-up approach provides primary and secondary place-specific data-if available-which can be used to replace the 'top-down' modelled data above (Collins et al., 2006). This includes census data, primary interviews, questionnaire data and other local information.

There are limitations to both the top-down and bottom-up approaches. Often data required for calculating EF is difficult to acquire, either because it is too general, not available in the correct measurement, or is weak in its own methodology (Aall \& Norland, 2005; Collins \& Flynn, 2008; Hunter et al., 2006).

\subsection{Consumption Categories and Land Types}

As well as the scale and detail required to fulfil the aims of an EF project, consideration must be given to what will work in the NZ context. This is discussed in Section 3.4, along with the consumption categories that will be used to show the breakdown of the population's EF, types of land included in the research, and the selection of gha or NZha as the unit for communicating the results of the research. If local land is chosen as the unit of choice, then calculations must also be carried out to provide local yields for each land type.

\subsubsection{Consumption Categories}

The EF is calculated by compiling a matrix in which a land area is allocated to each consumption category (Lenzen \& Murray, 2003). Consumption, as shown in table 2.1 , is divided into nine categories: food, transport, consumer goods, holidays, household energy, housing, infrastructure, government, and services. The final EF calculations are shown in a Consumption Land-Use Matrix (CLUM), a matrix combining the consumption categories with the land types. The CLUM is the most effective way of communicating the amount and types 
of land required to provide a population with the resources they consume. EF calculation results for each footprint category in chapter 4 will be shown using a CLUM.

\subsubsection{Land Types}

In EF calculations land is divided into seven types: energy land, degraded or built land, gardens, crop land, grazing land and managed forests, 'land of limited availability' (considered to be untouched forests), and 'non-productive areas', defined as deserts and ice-caps (Wackernagel \& Rees, 1996). The 'non-productive' areas are not included in the following analysis, but fishing land is included. Thus seven land types are used in the EF calculations with data collected from disparate sources such as production and trade accounts, state of the environment reports, and agricultural, fuel use and emissions statistics.

\subsection{Global versus Local Hectares}

One of the important initial aims of the EF tool as developed by Wackernagel and Rees (1996) was to have the ability to compare different countries or populations. International comparison of footprints requires consideration of the differences in biological productivity. Wackernagel and Rees (1996) introduced the concept of gha as a method for international land comparison. Gha are used for converting both the EF calculation and available biocapacity to an average land unit that can be compared internationally. The following section discusses whether the use of gha is justified for the current research.

\section{Global Hectare Method}

Differences in local yields are primarily due to environmental factors, including solar flux, soil type, climatic conditions and type of vegetation cover. This issue is addressed in EF calculations by relating consumption to global average yields, rather than to local yields (McDonald \& Patterson, 2004). GFN (2012) states the gha is a productivity weighted area used to report both the biocapacity of the earth, and the demand on biocapacity (the EF). Using gha rests on the assumption that different types of biologically productive areas can be expressed in the same unit once they are scaled proportionally to their productivity (Sustainability Report, 2002). When using the gha the areas of forest, pasture and crop land do not represent real land, but are hypothetical areas that would be needed to support the 
consumption of the population if local farming and forestry was conducted at 'world average productivity' (Lenzen and Murray, 2003). In comparison, NZha are those hectares of land actually used to produce resources in New Zealand.

The use of gha, initially created by Wackernagel and Rees, requires two scaling factors, the equivalence factor and the yield factor, in relation to the six different land types. NZ's yield and equivalence factors are shown in table 3.1 below. The definition of each is explained by Klinsky et al. (2009):

1. Equivalence factors relate to land categories. The bioproductivity of each land type is unique, so all categories must be made comparable before they can be aggregated into the total EF. Consequently each land category is given an equivalence factor that is multiplied by the subtotal EF of that land category. The equivalence factor reflects the comparative bioproductivity of all land categories and converts hectares consumed per category into hectares of average bioproductive land, the final unit of the EF.

2. Yield factors relate specifically to a country. They estimate the productivity per hectare of a particular type of land for a particular country; a yield factor converts the use of a NZha of cropland into a gha of cropland.

Table 3.1: Equivalence and yield factors as calculated in the National Accounts - New Zealand 2007 (GFN, 2011)

\begin{tabular}{|c|c|c|}
\hline & Equivalence Factors & Yield Factors \\
\hline Cropland & 2.5133 & 0.7941 \\
\hline Garden land $^{1}$ & 2.5133 & 0.7941 \\
\hline Grazing land & 0.4593 & 2.5008 \\
\hline Forest land & 1.2604 & 2.0177 \\
\hline Fishing grounds & 0.3674 & 0.9623 \\
\hline Consumed land ${ }^{2}$ & 2.5133 & 0.7941 \\
\hline
\end{tabular}

1. Garden land is considered to be the same as consumed land though it has more potential for subsequent uses in the future.

2. In the current methodology, hydroelectricity generation land is accounted for as consumed land.

After each land category subtotal has been converted into average bioproductive hectares, all categories are summed to a final EF figure (Klinsky et al., 2009). The equivalence and yield factors are both averages that generalise how much more or less productive one country or 
land type is compared to another. Thus, they help to provide a result that can be compared between countries because all calculations have been based on the same average.

However, using equivalence and yield factors means there is little benefit in NZ having some of the most productive land in the world. New Zealanders do not then benefit from growing food in their own country even if they can produce more food per hectare than anyone else. In other words, if the transport energy is low enough, there is no incentive to consume local produce because the yield is assumed to be the same. Conversely, if the calculations are done in local hectares then the yields of different foods and crops can be compared for the adequacy of NZ conditions. If the yield of NZ-produced food is higher than elsewhere then there is an additional incentive for it to be grown in NZ because the EF of the food will be lower. Using local hectares also helps when deciding on the types of food that should be grown locally, rather than using an international average yield which may not reflect local NZ growing conditions. Where NZ does benefit by using the equivalence and yield factors is when the biocapacity is calculated.

\section{New Zealand Biocapacity}

The yield and equivalence factors are also used to calculate the available biocapacity for NZ. The way in which NZ land is categorised into 'productive' and 'non-productive' is important in allocating the amount of available bioproductivity. The biocapacity calculations carried out for this research and those by GFN are very dissimilar due to differences in how land has been categorised, both in NZha and gha. The recalculated biocapacity in NZha will be used for the remainder of this research.

As discussed by Andrew and Forgie (2009) the GFN Land use Data for NZ seem very different from the NZ MfE (2009b) Land Cover Database. The MfE data were 'categorised' into crop, grazing, forest, consumed and garden land. Fishing land was not included.

As shown in table 3.2, in 2007 GFN found NZ had a total of 20.7 million NZha of productive land, whilst this research based on MfE data (2009) only found 13.7 million NZha. Once the equivalence factors and yield factors are applied these figures become 36.4 million gha and 20 million gha respectively, a difference of 16 million gha. Estimates using the MfE data would 
suggest that only $52 \%$ of $\mathrm{NZ}$ is 'productive' land and the remainder is 'unproductive' meaning it is covered in indigenous forests, shrub lands, wild grasslands, ice, snow, gravel and sand. This is supported by an MfE statement that “in 200249.6 per cent of NZ's total land area was covered by native land cover" (MfE, 2009b, p. 1).

Table 3.2: Comparison of NZ land as categorised by the NZ MfE and GFN National Footprint Accounts in NZha and gha

\begin{tabular}{|c|c|c|c|c|}
\hline \multirow{2}{*}{ NZ land } & MfE & GFN & MfE & GFN \\
\hline & NZha & NZha & gha & gha \\
\hline Crop land & 417,444 & 932,000 & 833,181 & $1,860,189$ \\
\hline Grazing land & $10,538,079$ & $11,354,000$ & $12,104,313$ & $13,041,501$ \\
\hline Forestry land & $2,598,309$ & $8,342,000$ & $6,607,542$ & $21,213,841$ \\
\hline Consumed land & 210,996 & 134,727 & 421,129 & 268,597 \\
\hline Total & $13,764,828$ & $20,762,727$ & $19,966,165$ & $36,384,128$ \\
\hline \multicolumn{3}{|c|}{ New sub-total including indigenous forests } & $27,217,682$ & \\
\hline
\end{tabular}

The GFN 'productive land' figures are very high. In order to have such high figures a lot of NZ's currently unproductive or less productive land would need to have been included. Three land types seem to have been overestimated by the GFN categorisation in comparison to the MfE data.

1. GFN data suggest that NZ has 11.3 million NZha of grazing land. NZ grazing land is calculated to be two-and-a-half times more productive than world average land, i.e. an equivalence factor of 2.5. The MfE dataset shows that NZ only has 8.9 million NZha of 'high producing exotic grassland'. Other land categories that GFN may have included as grazing land are 'tall tussock grasslands' and 'low producing grasslands' totalling 2.4 and 1.7 million NZha respectively. However, these are both much less productive than 'high producing exotic grassland' and therefore the equivalence factor should not be the same.

2. GFN have included 8.3 million NZha as forest land. The total for planted exotic 'forested land' in the MfE data is only 2.6 million hectares with an additional 6.5 million hectares of indigenous forest. With the inclusion of NZ's indigenous forest, NZ's total biocapacity is suggested by GFN to be 36.4 million gha. However, as discussed in the energy land section below indigenous forests are much less productive than exotic forests and are not used as a source for wood and paper 
products. As a result indigenous forests should not have the same yield and equivalence factors or be included in the forest land calculations. Indigenous forests sequester $\mathrm{CO}_{2}$ at $44 \%$ the rate of plantation forests. If this rate were applied, the biocapacity of NZ's indigenous forests would be 7.3 million hectares. The new figure for NZ's total biocapacity including indigenous forest at a reduced yield would total 27.2 million gha. It could also be argued that indigenous forests should not be included as available 'biocapacity' as they play an important role as biodiversity land to support NZ's non-human species, as discussed below.

3. GFN's crop land figure is twice that estimated by MfE. 'Short-rotation cropland', 'orchard and other perennial crops' and 'vineyards' are included in the MfE crop land category which totals 0.4 million NZha, whilst GFN's crop land estimate is 0.9 million hectares. As a result the GFN figure is 1 million gha more than the MfE estimate.

According to the GFN (2011) figures NZ has an available biocapacity of 45.2 million gha and an EF of 20.5 million gha, of which about half is produced in NZ (10.1 million gha). NZ exports another 37 million gha. GFN therefore estimate 47.2 million gha of NZ's available biocapacity is consumed locally and in exports, making the total resource consumption by the nation overshoot by $5 \%$.

The available biocapacity calculated by GFN seems a considerable over-estimate because it is based on unrealistically high estimates of productive land. If the more realistic figures of MfE are used instead, the lower biocapacity calculated shows that NZ could be in overshoot by as much as $170 \%$.

\subsubsection{New Zealand Land and Local Yields}

Use of either gha or local hectares is hotly contested by those using the EF index (Klinsky et al., 2009; Wiedmann \& Lenzen, 2007; Wiedmann, Wood, et al., 2007a). It seems that when and how the global or local hectare is used depends predominantly on the aims of the research and how the EF information is to be used. For this research it was decided that the majority of the EF results would be shown in local hectares. The use of local hectares has been supported by previous NZ case studies (Bicknell et al., 1998; Field, 2011; Huang, 2010; McDonald et al., 2006; McDonald \& Patterson, 2001, 2003). Local NZha are used to create the 
EF template for NZ in chapter 4, compare community footprints in chapter 5 and create fair earth share scenarios in chapter 6 . Gha are briefly used at the end of chapter 4 to compare the NZ 2007 'average' EF with other national and international EF case studies.

NZha are a more appropriate unit of measurement primarily because the EF results are intended only for NZ audiences. The level of detail required for the project to make good scenario decisions requires the ability to compare NZ-grown resources with each other. NZ is in a unique situation compared with many other developed nations in that a very large portion of primary goods are produced internally. NZ's land is extremely productive making the footprint of NZ goods much smaller. As discussed extensively by Weidmann and Lenzen (2007, p. 676), "footprint analyses measured and expressed in global hectares cannot answer research (or policy) questions related to the regional characteristics of (primary) production activities, at least not as a sole metric." As a result Weidmann and Lenzen recommend the use of local hectares when EF data is being used at a local level. In addition, using NZha is more meaningful to people when communicating the impact of resource use with communities and individuals. People can imagine an area of land approximately the size of a rugby pitch as one hectare, but when gha are used the actual land area is warped and the unit of measurement becomes less meaningful.

The challenge of using NZha is that additional research to find local yields is required to carry out the EF calculations. If gha units were used, the 'world average yield' for various resources could be bought from the GFN. As there is very little guidance on the methodology for calculating local yields for use in footprint accounting, the remainder of this section will provide a discussion on the different land types, a brief description of how the footprint calculations are carried out for each, and the 'local hectare' workings for some of the more contentious local yields such as energy land.

Productive lands such as forest, grazing and crop lands produce raw resources that are often changed or transformed to produce a whole range of secondary products. The efficiency of this transformation is called the extraction rate. For example wood from trees, the parent product, could be used for making paper and card or for house framing. These secondary products could be a more or less efficient use of the raw material compared with directly using the parent product. This depends on the amount of waste created during the 
transformation. For example the extraction rate for 'newsprint paper' is only $0.25 \mathrm{~m}^{3}$ of derived product per $\mathrm{m}^{3}$ of parent product, and therefore the yield is only $0.45 \mathrm{~m}^{3} /$ gha, whilst the extraction rate for the parent product, 'roundwood logs' is 1.0 and the yield is $1.81 \mathrm{~m}^{3} /$ gha (GFN, 2011, forest_yield). Extraction rates have been used where possible for the current research although data was often very difficult to find. Where extraction rates have not been used, basic yields have been substituted, which would be higher. As a result the EF for some products may be slightly lower. A lack of data regarding extraction rates for processed food from crop and grazing land could also be a limitation of the EF calculations carried out here.

\section{Consumed Land and Garden Land}

Infrastructure for housing, transportation and industrial production occupies consumed land. Best estimates indicate a global total of 0.2 billion hectares of built-up land (Wackernagel et al., 2002). Built-up land is assumed to have replaced cropland, as human settlements are predominantly located in the most fertile areas. Areas occupied by hydroelectric dams and reservoirs, used for the production of hydropower, are also counted within consumed land.

Garden lands are areas covered in private gardens, urban parks and recreation spaces. These are often open areas or used to grow ornamental trees and flowers. Garden land is separate from crop, grazing or forest land as it is not used specifically for producing products, and it is also not consumed land as it still has potential biocapacity for future uses. The biocapacity of garden land is assumed to be the same as crop land.

\section{Crop and Grazing Land}

Crop and grazing land is a calculation of the physical area required to supply a primary resource such as wheat or apples from cropland, and beef and chicken from grazing land. Grazing animals often require crop land for the supply of supplementary food, such as cornfed battery chickens. The yield, which is the amount of product from a hectare of land, differs considerably between products. As explained for forest land above, parent products from grazing and crop land, such as milk or wheat, are used to make secondary products. For many of the highly processed goods New Zealanders consume these extraction rates were not 
available and as a result the yield used on its own is likely to be higher than reality, causing the footprint to be slightly lower.

Growing crops for food, animal feed, fibre, and oils requires cropland, the land type with the greatest average bioproductivity per hectare (Kitzes et al., 2007). In 2003 the Food and Agriculture Organisation of the United Nations (FAO) estimated there were roughly 1.5 billion hectares of cropland worldwide. This area is $13.4 \%$ of the total land but $30 \%$ of the biocapacity. In 2009 the NZ MfE (2009b) reported that there were 392,044ha of land being used for 'short-rotation crops', 'orchard and other perennial crops' and 'vineyards', making up $1.5 \%$ of NZ's total landmass.

The National Footprint Accounts (Ewing et al.,2010) use FAO harvest and area data for more than 70 major crops to calculate the area of cropland needed to produce a given quantity of crop product. The accounts do not track activities that decrease the long-term productivity of cropland such as soil degradation, erosion or salination, even though these processes will be reflected in future decreases in biocapacity.

Raising animals for meat, hides, fibre and milk can entail the use of feed products grown on cropland, fishmeal from wild or farmed fish, and/or range land area for grazing (Kitzes et al., 2007 , p. 5). Worldwide there are approximately 3.5 billion hectares of natural and seminatural grassland and pasture. To calculate the grazing land EF of a livestock product, diet profiles are created to determine the mix of concentrate feed, cropped grasses, and grazed grasses consumed by that type of livestock. Due to NZ's highly productive land the majority of its stock is fed on grasslands; however there is an increasing trend to supplement grass with bought-in feed and an increase in intensive farming of pigs, chickens and grain-fed fish, causing an increased use of crop land for additional grain supply.

\section{Fishing Land}

The fishing land EF of a population is based on its fish and seafood consumption. According to Ewing et al. (2008, p. 12) the EF of fishing land is based on the amount of annual primary production produced in the area above a hectare of ocean floor required to sustain a harvested aquatic species. Initially the fishing grounds calculations were straightforward. 
Rees and Wackernagel (1996, p. 233) suggest the maximum sustainable yield from the oceans is about 100 million tonnes $(t)$ of fish per year. To calculate the world-average yield per hectare the global fish catch is divided by the total productive ocean area. About $96 \%$ of the world's fish catch is produced in shallow coastal and continental shelf areas that constitute only $8.2 \%$ of the world's oceans (about 2,970 million hectares). Average annual production is therefore about $32.3 \mathrm{~kg}$ of fish per productive hectare $(0.03 \mathrm{ha} / \mathrm{kg}$ of fish).

In recent years the fishing land calculations have become more specific at the regional or country level. Andrews and Forgie $(2009$, p. 3 ) describe the fishing land calculations as first calculating the 'primary production' necessary to support the fish caught, and dividing that by the "harvestable primary production per hectare of marine area". Primary production is an indication of the photosynthetically generated biomass required in the food chain of each fish species, and is determined by the trophic level of the species, which in turn is estimated from diet composition (Ewing et al., 2008, p. 12). Using a discarded by-catch rate of 1.27, a transfer efficiency of 0.10 t of live fish per tonne of feed, and a carbon content of $11.1 \%$ of fish gives the primary production. When calculating in gha, this is then converted to a yield using the world average available primary productivity of 4.25 and finally the equivalence factor is applied (Ewing et al., 2008). To calculate from gha of fishing land, back to NZha, the equivalence factor and world average yield were reversed and NZ-specific yields used for every fish species.

Yields for fishing land were also gathered from a range of international case studies in the hope they would support a common yield and could be used in the current research. Unfortunately the three estimates found varied considerably from $29.00 \mathrm{~kg} / \mathrm{ha}$ (Barrett et al., 2002), $74.46 \mathrm{~kg} / \mathrm{ha}$ (Vale \& Vale, 2009b, p. 40 from Collins et al. (2005)) to $99.01 \mathrm{~kg} / \mathrm{gha}$ in Collins and Fairchild (2007). The case studies were not always clear regarding the method used. One of the yields above is in gha, but the unit for the other two is uncertain. As a result it was difficult to know whether the calculation could be used as a guide for fish yields in this research.

It was decided for the fishing land footprint calculations in chapter 4 that the GFN calculations would be used as an estimate. The fishing land total figure was divided by the equivalence 
factor and the yield factor. This would provide the project with NZ's EF for fish and seafood in NZha.

\section{Forest Land}

The EF of firewood, wood products and paper and card is calculated using the amount of forest land required to grow them. The $\mathrm{CO}_{2}$ absorption methods for energy land (forested land required to sequester $\mathrm{CO}_{2}$ ) and forest land are based on similar calculations regarding the number of trees per hectare of land. However, the land is mutually exclusive. Energy land and forest land cannot be the same land. The world average production of wood is $1.81 \mathrm{~m}^{3} /$ gha/year (GFN, 2011; forest_efp, sawlogs + veneer Logs (C)) with $3.32 \mathrm{~m}^{3} /$ gha/year for firewood (GFN, 2011; forest_efp, Wood Fuel (C)).

Forest land in NZ is much more productive than in many other countries. As trees grow they sequester $\mathrm{CO}_{2}$ from the atmosphere and trap it in the wood. Once the wood is burnt it releases the sequestered carbon back into the atmosphere as $\mathrm{CO}_{2}$. Wood is therefore carbon neutral (NZ Wood, 2012) and does not require any energy land (discussed below) for absorbing carbon emissions, unlike non-renewable fuels. Pinus radiata (also known as 'pine') is a medium density softwood and a common firewood source in NZ. One tonne of air-dried wood contains 11GJ of energy (Engineering Toolbox, 2011), with typical average tree basic density values of $400-420 \mathrm{~kg} / \mathrm{m}^{3}$ (RPBC, 2003). Pine has a mean annual harvest increment of between $18 \mathrm{~m}^{3}$ and $25 \mathrm{~m}^{3} /$ ha/year (New Zealand Forest Industries Council, 2010). The higher density of $420 \mathrm{~kg} / \mathrm{m}^{3}$ is used here as a more generous value, with a yield of $25 \mathrm{~m}^{3} / \mathrm{ha} /$ year because the whole tree can be used for firewood, rather than only the superior parts required for infrastructure and buildings. Firewood is assumed here to be all from plantation timber grown for the purpose. This may in practice be an over-estimate, with much firewood probably coming from waste wood in various forms.

The EF of paper is calculated using the amount of forest land required for growing trees used to produce paper. Additional energy land is also needed for the manufacture of the paper and the felling and milling of the wood, however these calculations have not been included. To calculate the number of hectares requires the following information. Four tonnes of wood are needed to produce 1.4t of paper (Paper Round, 2010). Therefore, 2.88t of wood are required 
to make $1 \mathrm{t}$ of paper. The average density value for medium density Pinus radiata in NZ is $420 \mathrm{~kg} / \mathrm{m}^{3}$ (RPBC, 2003). A more conservative estimate for the mean annual harvest increment for NZ forests of $18 \mathrm{~m}^{3} /$ ha/year (New Zealand Forest Industries Council, 2010) was used for the production of wood products, paper and card. Using the world average recycled paper content of 38\% (Abramovitz \& Mattoon, 1999), the paper forest land conversion is $0.2092 \mathrm{ha} / \mathrm{t}$ of paper. NZ's forest land produces almost ten times more wood for paper production than world average land, and seven-and-a-half times more wood fuel than the world average for firewood.

NZ's forest land is considerably more productive than world average forest land. NZ wood uses range from building infrastructure to paper and card for packaging. Different yields are used for these two different uses in the calculations here because of the different product extraction rates.

\section{Energy land}

Research by Wackernagel and Rees (1996) suggested that for most developed countries the energy land component can be up to $50 \%$ of the overall EF. Consequently the energy to land conversion method and ratio have a considerable impact on EF calculations (McDonald \& Patterson, 2004, p. 52). NZ's total primary energy supply comes from a mix of renewable and non-renewable sources. In 2007, 68\% of NZ's total primary energy came from non-renewable fuels such as liquid fuels, gas and coal. The remaining $32 \%$ came from renewable sources such as hydropower, geothermal, wind and waste heat (Ministry of Economic Development, 2010b, pp. 10-11). The footprints of these two energy sources require different types of land and use different energy to land values, so they need to be calculated separately. Nonrenewable energy primarily emits $\mathrm{CO}_{2}$ as a waste which needs to be assimilated (or the fuel needs to be replaced with a sustainable alternative) through the use of 'energy land'. In comparison, renewable hydroelectricity energy emits much less $\mathrm{CO}_{2}$ but requires physical or 'consumed land'.

There are three methods for calculating the energy land EF, none of which gain full support from EF practitioners. The methods discussed below are the ethanol approach, the biomass replacement approach and the $\mathrm{CO}_{2}$ sequestration approach (Wackernagel \& Rees, 1996, pp. 
72-74) as discussed above. Based on the discussion below this research will use the $\mathrm{CO}_{2}$ approach. In order to calculate energy land in NZha additional research into the rate of carbon sequestration by NZ trees is necessary. The energy to land calculations and a summary of values are provided below.

\section{Non-Renewable Energy}

Three approaches for converting non-renewable energy to land equivalents were proposed by Wackernagel and Rees. For all approaches, the rate at which biomass grows and sequesters $\mathrm{CO}_{2}$ varies depending on the type of trees and where they are growing (Wackernagel \& Rees, 1996, p. 73), making it necessary to have a local NZ energy to land ratio. All three methods have their benefits and limitations.

The 'ethanol approach' calculates the land required to produce a biologically-produced fuel substitute, such as corn and wood biomass for ethanol or methanol. This approach reasons that a sustainable economy requires a sustainable energy supply, and should not be dependent on the world's reducing fossil capital. Wackernagel and Rees (1996, p. 72) further note that for a carbon-based fuel it is preferable to use carbon already cycling in the ecosphere rather than carbon that has been stored for millennia in an inactive pool. This approach avoids further $\mathrm{CO}_{2}$ accumulation in the atmosphere. The rate of growth depends on the type of vegetation and the geography where it is grown. Wackernagel and Rees' life-cycle calculations showed that the most optimistic net productivity from herbaceous plants for this approach was $80 \mathrm{GJ} /$ ha of land and $150 \mathrm{GJ} /$ ha from wood. However methods for using more land-efficient substitutes for liquid fossil fuels, such as biodiesel, continue to develop. New technologies are emerging using waste products (Biofuel.org.uk, 2010) and algae (known as Oilgae) (Scientific American, 2009) to produce liquid fossil fuel substitutes. The lifecycle of these future fuels needs to be researched in detail to gain better insight into their energy-toland ratios.

The 'biomass replacement method' estimates the land area required to rebuild natural capital at the same rate as fossil fuel is being consumed. This method is similar to the ethanol approach whereby as society consumes non-renewable resources, a portion of the profit made from the use of these is reinvested into the equivalent value of manufactured capital 
or renewable resource assets such as forest or plant materials. Therefore once the fossil fuel reserves dry up, society can start cropping the energy land. Calculations show that one hectare of average forest could accumulate about 80GJ of recoverable biomass per year in standing timber (Wackernagel \& Rees, 1996, p. 73). The concept of creating 'sustainable forests' or 'green energy' also sits behind the idea of 'carbon offsetting' and 'green investment' (CarboNZero, 2011).

The 'biomass approach' continues to be debated; Kunstler (2005) highlights one of the potential dangers is that the method supports the argument for countries to convert land previously in food production or indigenous forests into liquid fuel production. He also suggests this approach supports society's addiction to 'easy energy' by suggesting, through technological developments, that there is direct substitution of one cheap energy source for another, allowing society to continue to use as much or more energy as before. However as yet, these technologies have neither been developed nor are at the scale needed for a complete renewal of infrastructure to support current energy use. The benefits of using the biomass approach are that using only current technologies there are definite sustainable limits. NZ only has so much land and the calculation of how much ethanol and methanol can be produced is simple. NZ has $26,900,000$ ha of land, of which 430,400 ha (1.6\%) is currently used for horticulture (MfE, 2009b). Vale and Vale (2009b, p. 90) calculated that if NZ attempted to replace its 2009 vehicle fuel requirements with an ethanol/vegetable oil mix this would require 1,050,000ha. This calculation shows that NZ would need almost 2.5 times the current area used for horticulture to produce liquid fuel using current technologies. Another benefit of the biomass approach is its potential to generate sustainable energy and therefore the method could be said to be a truer reflection of the amount of land needed in a sustainable scenario. As a result the biomass approach is likely to be an effective approach when calculating future post peak-oil scenarios.

The third method is the ' $\mathrm{CO}_{2}$ approach' which estimates the additional biologically productive area needed to sequester atmospheric $\mathrm{CO}_{2}$ through afforestation (Wackernagel et al., 2005, p. 16). The argument is that to avoid possible climate change, fossil carbon (in the form of $\mathrm{CO}_{2}$ ) cannot be allowed to accumulate in the atmosphere. The energy footprint is calculated by estimating the biologically productive area of land and its biomass needed to sequester 
enough carbon emissions to avoid an increase in atmospheric $\mathrm{CO}_{2}$ (Loh et al., 2004). Land and biomass, such as forests, act as a 'carbon sink', which is a process, activity or mechanism that removes a greenhouse gas or a precursor to a greenhouse gas from the atmosphere (UNFCCC, 1990). Some $\mathrm{CO}_{2}$ approach methods also include the oceans' capacity for emissions absorption by deducting as much as one-third of the anthropogenic emissions (Wackernagel et al., 2005, p. 16). The calculations required for this concept are the basis for 'carbon offsetting' where individuals and organisations 'offset' their carbon emissions by planting a certain area, or number of trees (carbon footprint, 2011). Data on typical forest productivities of temperate, boreal and tropical forests used by Wackernagel and Rees (1996) explain that average forests can accumulate approximately $1.8 \mathrm{tC} /$ ha/year. This means that annually one hectare of average forest can sequester the $\mathrm{CO}_{2}$ emission generated by consuming $100 \mathrm{GJ}$ of fossil fuels. As a result the world average energy to land ratio is $100 \mathrm{GJ} / \mathrm{ha}$.

The ' $\mathrm{CO}_{2}$ approach' is flawed because it assumes society can 'fix' the problem of greenhouse gases by growing more trees or creating additional carbon sinks. According to GFN's latest figures, society's energy/carbon EF is 9,633 million gha (Ewing, Moore, et al., 2010, p. 44). This is the equivalent of world-average productive land covering an area the size of Asia (4,457.9 million hectares), North and South America (4,207.5 million hectares) and Europe (993.8 million hectares) combined. In addition, the carbon cycle is very complicated. In support of the ' $\mathrm{CO}_{2}$ approach' this method is the most broadly used and supported. Wackernagel and Rees promote the use of the ' $\mathrm{CO}_{2}$ approach' as the one that 'would enjoy the highest public acceptance' (Wackernagel \& Rees, 1996, p. 73), and acceptance by the biggest organisations using EF (Barrett \& Simmons, 2003; GFN, 2009; Simmons \& Chambers, 1998; Venetoulis \& Talberth, 2006). Locally all NZ EF case studies have also used the $\mathrm{CO}_{2}$ approach (Andrew et al., 2005; Bicknell et al., 1998; Field, 2011; Fricker, 1998; Huang, 2010; Market Economics, 2006; McDonald \& Patterson, 2004), allowing for easier comparison with other EF case studies.

In deciding what energy method to use for this research, each was assessed for use in NZ. The biomass replacement method is a cross between the 'ethanol approach' and the ' $\mathrm{CO}_{2}$ approach'. This method suggests that as long as society replaces what it uses with something else there is no need to consider whether what society is doing is sustainable. On the other 
hand putting land aside as a way of replacing biomass means, much like the ' $\mathrm{CO}_{2}$ approach', that the amount of land required would be significantly more than currently used. The most evident short-coming of the ' $\mathrm{CO}_{2}$ approach' is that it relies on the false premise that fossil fuels are somehow infinite when in fact they are a finite non-renewable resource. In comparison the ethanol and biomass replacement approaches are alternative methods based on a paradigm of sustainable energy. An argument for the use of the ' $\mathrm{CO}_{2}$ approach' is that society is almost fixated with this approach. As a result the ' $\mathrm{CO}_{2}$ approach' will be adopted for this research. The main reason for this is the ease of comparison with other footprint case studies.

\section{The $\mathrm{CO}_{2}$ Approach for New Zealand}

The amount of carbon flowing through the carbon cycle changes slightly with the ability of the carbon sinks, particularly biomass and oceans, to sequester carbon dioxide from the atmosphere. As a result the 'world average energy-to-land ratio' is not the best value to use for NZ. However a method for calculating energy-to-land conversions in NZha for the ' $\mathrm{CO}_{2}$ approach' is not available. When calculating a specific energy-to-land ratio a number of aspects are considered, including the type and amount of biomass and energy used by the specific region. Biomass includes both commercial forests and indigenous forests (broadleafed southern podocarp) and carbon sequestration by the world's oceans.

The energy per hectare conversion for world average forest requires calculating the $\mathrm{CO}_{2}$ needed to create the carbon in wood, then the energy produced by that carbon. The world average forest assimilation rate is approximately $1.8 \mathrm{tC} /$ ha per year (Wackernagel \& Rees, 1996, p. 73 ; Wada, 1994) which is converted to $\mathrm{CO}_{2}$ using a molecular weight conversion ratio of 3.67. Therefore $1.8 \mathrm{tC}$ equates to $6.6 \mathrm{tCO}_{2} / \mathrm{ha}$. The energy-to-land ratio for non-renewable energy is therefore $73 \mathrm{GJ} / \mathrm{ha}$ under the ' $\mathrm{CO}_{2}$ approach' (see column 2, table 3.3).

Oceans also sequester $\mathrm{CO}_{2}$. In relation to preindustrial carbon reservoirs, as much as $80 \%$ is thought to be held in the intermediate and deep ocean. However the ability for the deep ocean to sequester and cycle $\mathrm{CO}_{2}$ is thought to be extremely slow, as much as 1,000 years for a cycle, because of the sluggishness of the vertical exchange between the surface and interior of the ocean (Sarmiento \& Gruber, 2002, p. 31). Recent calculations used by the Stockholm 
Environment Institute in the Cardiff Footprint Project use 31\% absorption (Collins et al., 2005, p. 161). A number of other EF studies (Barrett et al., 2002; Loh et al., 2004; Wackernagel \& Rees, 1996) have included provision for the world's oceans to absorb $35 \%$ of anthropogenic $\mathrm{CO}_{2}$-equivalent emissions from fossil fuel combustion (IPCC, 2000). Using the absorption rate of $35 \%$ as proposed by the IPCC, the energy-to-land and ocean ratio becomes $99 \mathrm{GJ} / \mathrm{ha}$, rounded up to $100 \mathrm{GJ} / \mathrm{ha}$. This figure is commonly applied in EF research internationally and in some NZ case studies (Bicknell et al., 1998; WWF, 2010).

However, McDonald and Patterson (2003) suggest this world average energy-to-land ratio is not fitting for NZ. This is primarily because NZ's forests are much more productive than world average forests and therefore sequester a greater amount of $\mathrm{C} /$ ha of land. NZ 'forest specific' calculations are explored below in an effort to produce a more appropriate NZ energy-to-land ratio. Wackernagel and Rees $(1996$, p. 72$)$ note that NZ forests are among the most productive in the world. If the 'ethanol approach' were used as a substitute for liquid fossil fuel, the yield could be as much as 120 to $150 \mathrm{GJ} /$ ha per year. As a result, previous NZ case studies have used a much higher energy-to-land ratio. McDonald and Patterson $(2003,2004)$ and Huang $(2010)$ both used an energy to land ratio of $13.2 \mathrm{tCO}_{2} / \mathrm{ha}$, resulting in an average of $185 \mathrm{GJ} / \mathrm{ha}$, whilst Field (2011) used an energy-to-land ratio of $150 \mathrm{GJ} / \mathrm{ha}$ or an average of $10.4 \mathrm{tCO}_{2} / \mathrm{ha}$. The former two studies use a NZ-specific carbon-to-land conversion factor of $0.0758 \mathrm{ha} / \mathrm{tCO}_{2}$ or $13.2 \mathrm{tCO}_{2} / \mathrm{ha}$. The calculation behind this figure relies on NZ plantations mainly consisting of Pinus radiata (Hollinger, Maclaren, Beets, \& Turland, 1993, p. 196) which can maintain a carbon sequestration rate of 3.6tC/ha/year (Hollinger et al., 1993). This is the equivalent of $13.2 \mathrm{tCO}_{2} /$ ha/year, which is double the world average. Other NZ research supports higher figures. Berg (2009) suggests $15-26 \mathrm{tCO}_{2} /$ ha/year and Kirschbaum et al (2009, p. 4) $25 \mathrm{tCO}_{2} /$ ha/year. In comparison Hall and Hollinger (1997) found that indigenous NZ forests have a much lower sequestration rate of $5.87 \mathrm{tCO}_{2} /$ ha/year. A more recent publication from the Ministry of Agriculture and Forestry (2011) found that in simulated even-aged stands of indigenous forest, mean carbon sequestration rates varied across species from 1.26 $\mathrm{tCO}_{2} /$ ha/year for Podocarpus hallii to $6.47 \mathrm{tCO}_{2} / \mathrm{ha} /$ year for Dacrydium cupressinum (Kirschbaum et al., 2011, p. 21). Other vegetation such as pasture is also a carbon sink, however the carbon sequestration rate is low, averaging around $3-5 \mathrm{tCO}_{2} /$ ha/year $(\mathrm{MfE}$, 2007a). Pasture figures are not included in the calculations below. Both the plantation estate 
and indigenous forest results vary greatly depending on the geographical distribution across $\mathrm{NZ}$ in terms of temperature and rainfall.

Some steps were taken to verify the above energy-to-land calculations. Three calculations were carried out. The first was to find the $\mathrm{CO}_{2}$ emissions values for NZ's most common nonrenewable fuels. The second was to recalculate the emissions values in relation to the total energy produced by NZ's common forms of non-renewable energy, and the third was to apportion the sequestration contribution by plantation estates and indigenous forest.

The first step in table 3.3 provides a summary of three energy-to-land ratios: the world average, NZ plantation estate (assumed to be Pinus radiata), and indigenous forest. The emission factors of non-renewable energy sources were from the NZ Ministry for Economic Development's Greenhouse Gas Emissions Report (2010b). Calculations provided by Wada (1994), IPCC (2000) and Wackernagel et al. (1999) were used for the world average. Figures from Hall and Hollinger (1997) were used for indigenous forests and those of Hollinger et al. (1993) for exotic Pinus radiata forests.

Table 3.3: The 'world average' energy-to-land ratio compared ratios for two types of NZ forest using the 2007 energy-to-land conversions for different fuels

\begin{tabular}{|c|c|c|c|c|}
\hline \multirow{2}{*}{\multicolumn{2}{|c|}{$\begin{array}{l}\text { Energy-to-land } \\
\text { comparisons }\end{array}$}} & $\begin{array}{l}\text { 'World average' } \\
\text { energy-to-land }\end{array}$ & $\begin{array}{l}\text { Pinus radiata }{ }^{2} \\
\text { energy-to-land }\end{array}$ & $\begin{array}{l}\text { Native NZ forest } \\
\\
\text { energy-to-land }\end{array}$ \\
\hline & & GJ/ha & GJ/ha & GJ/ha \\
\hline \multirow{3}{*}{$\begin{array}{l}\text { Liquid } \\
\text { Fuels }\end{array}$} & Petrol & \multirow{3}{*}{71} & 201 & 89 \\
\hline & Diesel & & 192 & 85 \\
\hline & Aviation & & 195 & 87 \\
\hline \multicolumn{2}{|l|}{ Coal } & 55 & 148 & 66 \\
\hline \multicolumn{2}{|l|}{ Gas } & 93 & 248 & 110 \\
\hline \multicolumn{2}{|l|}{ Average } & 73 & 197 & 87 \\
\hline
\end{tabular}

Table 3.3 shows the average energy-to-land ratio for non-renewable energy sources. The average for the three fuel types in relation to Pinus radiata forest is 197GJ/ha whilst the average for indigenous forest is only $87 \mathrm{GJ} / \mathrm{ha}$.

The second step was to consider the fuel sources of $\mathrm{NZ}^{\prime} \mathrm{CO}_{2}$ emissions. The Ministry for Economic Development's Greenhouse Gas Emissions Report (2010b) reports that 51\% of NZ's non-renewable energy is derived from liquid energy, $20 \%$ is from coal and $23 \%$ from gas. Using 
the values in table 3.3, the energy-to-land ratio for Pinus radiata becomes $188 \mathrm{GJ} / \mathrm{ha}$ and for indigenous forest it becomes $83 \mathrm{GJ} / \mathrm{ha}$. The average is $136 \mathrm{GJ} / \mathrm{ha}$.

Pinus radiata: $(196 \times 51 \%)+(148 \times 20 \%)+(248 \times 23 \%)=188 \mathrm{GJ} / \mathrm{ha}$

Podacarp: $(87 \times 51 \%)+(66 \times 20 \%)+(110 \times 23 \%)=83 \mathrm{GJ} / \mathrm{ha}$

The third step considered the type of forest cover in NZ. In 2006 there were an estimated 1.96 million hectares of planted exotic forests and 5.25 million of indigenous forest vegetation (MfE, 2008c, p. 227), totalling 7.21 million hectares of forest. These forests represent $27 \%$ and $73 \%$ respectively of NZ's total forest area. If these proportions are used to show sequestration potential, the result becomes $112 \mathrm{GJ} / \mathrm{ha}$.

$(188 \times 27 \%)+(83 \times 73 \%)=112 \mathrm{GJ} / \mathrm{ha}$

The world's oceans also play a role in $\mathrm{CO}_{2}$ absorption and the IPCC estimate this is at a rate of $35 \%$ of the anthropocentric $\mathrm{CO}_{2}$ released. Although recent NZ EF case studies, including McDonald \& Patterson (2003, 2004) and Huang (2010), have not included the ocean sequestration rate, it is internationally recognised as best practice by the GFN (Ewing, Reed, et al., 2010) and will be included here. Using the figure of $112 \mathrm{GJ} / \mathrm{ha}$ and a $35 \%$ sequestration rate by the oceans, the new energy-to-land conversion would be $151 \mathrm{GJ} / \mathrm{ha}$, very similar to Field's (2011) 150GJ/ha per year. The energy-to-land ratio for non-renewable energy for the following NZ EF calculations is $150 \mathrm{GJ} /$ ha of energy land, or $10.4 \mathrm{tCO}_{2} / \mathrm{ha}$. This is between the world average of 100GJ/ha and McDonald and Huang's calculations of 185GJ/ha. According to Huang (2010), in 2006 the Auckland transport $\mathrm{CO}_{2}$ footprint was 16.9 million tonnes. Comparing NZ's EF using these two rates of sequestration, $13.3 \mathrm{tCO}_{2} /$ ha would give a total 1.28 million hectares, and $10.4 \mathrm{tCO}_{2} /$ ha a total of 1.63 million hectares. The difference is 345,433ha, suggesting that Huang's (2010) and McDonald and Patterson's (2003, 2004) energy-to-land conversion is too high, therefore lowering NZ's total EF. As mentioned above, the energy-to-land conversion is a very important calculation because of the difference it can make to total EF. Without clear guidance on a best method for calculating NZha different conclusions could be drawn depending on which modes of sequestration are included. More research is required to propose a comprehensive energy-to-land conversion for NZ for common use. 


\section{New Zealand's Renewable Energy}

In $200732 \%$ of NZ's primary energy came from harnessing renewable energy sources such as water, wind, geothermal and the combustion of renewable natural fibres such as wood. The largest contribution from renewable energy to NZ's primary energy makeup was $38 \%$ from geothermal producing 90.64PJ per year. Hydroelectricity contributed 35\%, or $85.10 \mathrm{PJ}$, of renewable energy and the remaining renewables, such as wind and bioenergy, supplied $27 \%$ (Ministry of Economic Development, 2010a).

Some research has been carried out into energy-to-land conversions for renewable energy sources, although this needs further investigation. The land use of hydro-electricity is estimated by dividing total energy production by the typical area required by hydro-dams and corresponding corridor spaces for transmission rows (Wackernagel \& Rees, 1996, p. 69). The result is an estimated $1,000 \mathrm{GJ} / \mathrm{ha}$ of land. This land is energy land for the embodied energy of the infrastructure and the physical space required by hydropower storage lakes. However due to lack of data regarding the proportions of land needed for storage and infrastructure, all non-renewable energy areas are assumed to be consumed land. Calculations have also been carried out for a range of other renewable energy sources including wind and tides. The average conversion factor for these sources calculated by Chambers, Simmons and Wackernagel (2000) was 9,090GJ/ha per year. There were no available estimates for the energy-to-land conversion of geothermal. NZ's most common renewable energy sources are geothermal, hydroelectricity and bioenergy. Therefore the energy to land ratio for wind and tides may not be suitable for use here. As a result the hydroelectricity conversion of $1,000 \mathrm{GJ} / \mathrm{ha}$ of consumed land is used for the following calculations. However caution is required since wind and tidal systems are nine times more effective at generating energy than hydropower, so assuming all non-renewable energy is hydropower may cause the calculations to be an overestimate.

The change in the energy-to-land ratios largely reflects the science available at the time of the study. Between Hollinger et al.'s (1993) work and the current research there have been advances in the science related to sequestration by different types of forest species. For example the inclusion of sequestration by underground root systems had not been determined in 2003, but by 2008 had been included in the sequestration rates (McDonald, 
2011). In addition, the split between renewable and non-renewable energy sources in electricity and primary energy differs annually in NZ. Hydroelectricity generation is heavily dependent on the South Island lake levels which vary with seasonal climatic conditions.

The energy EF of countries and communities makes up a large portion of the overall EF and therefore using an appropriate energy-to-land ratio for both renewable and non-renewable energies is important, hence the discussion of the assumptions made in this section.

\subsubsection{Man vs. Wild}

As previously discussed, bioproductive lands are those areas that are classified as being of productive use to people and the economy. However there is also the question of the land required to support the other 7-14 million species with which humans share the planet (Wackernagel et al., 2002). There is an estimated 13 billion hectares of land available on planet earth. Of this, GFN estimates that 10.8 billion hectares is biologically productive land (Ewing et al., 2010). The World Watch Institute suggests that the remaining $21 \%$ is unsuitable for crops, pasture, and/or forests because the soil is too infertile or shallow to support plant growth, or the climate and terrain is too cold, dry, steep, stony, or wet (Pimentel \& Wilson, 2004). It is not possible to determine how much bioproductive area needs to be reserved (Wackernagel et al., 2002) although some ecologists and biogeographers have recommended at least $10 \%$ of the earth's land surface (and a critical although undetermined amount of the marine realm) (McNeely, 1999). Other scientists propose at least 25\% (Soulé \& Sanjayan, 1998). The Brundtland Report, Our Common Future (Brundtland Commission, 1987) proposed protecting $12 \%$ of the biosphere (Wackernagel et al., 2002).

If $12 \%$ were needed in addition to the $21 \%$ that is currently not 'useful' to society, it would equate to 1.2 billion hectares, making the total area left for human use 9.56 billion hectares. The GFN supports the idea that the 'biodiversity buffer' should be enough to maintain representative ecosystem types and viable populations of species. How much needs to be set aside depends on biodiversity management practices and the desired outcome (GFN, 2012). The fair earth share discussion in chapter 1 was based on the calculation that, in 2007, humans had 11.9 billion hectares of land to produce goods and services, providing $1.7 \mathrm{gha} /$ person. If the 2007 fair earth share included land for other species it would decrease to 1.37gha/ 
person. In order to move towards a sustainable future, society needs to balance out the supply and demand of biocapacity. As discussed earlier the planet is already in overshoot. If further land is to be set aside for 'nature' then society is in an even more unsustainable position.

The discussions above provide some insight into where improvements could be made to the footprint method, particularly when calculating footprints in NZha. Section 3.6 points out some of the limitations of the EF and criticisms of this tool.

\subsection{Ecological Footprint Limitations}

The EF is a proven tool for communicating resource use and constraints to a diverse range of audiences (Hunter et al., 2006; Kooten \& Bulte, 2000; Simmons \& Chambers, 1998; Wiedmann \& Barrett, 2010), however the EF methodology has been under scrutiny since its conception. A number of authors have focused on highlighting its perceived weaknesses (Beynon \& Munday, 2008; Ferguson, 2001; Fiala, 2008; Lenzen \& Murray, 2001; McDonald \& Patterson, 2004; Paul, 2006).

Criticisms are numerous, including the generality of the equivalence and yield factors (McDonald \& Patterson, 2004), the lack of specificity for local use (Paul, 2006), the inability to consider degraded land (Fiala, 2008; Lenzen \& Murray, 2001), difficulties in finding reliable data (Ryan, 2004), and the energy land methodology (Fiala, 2008). As already discussed, the GFN's 'one-size-fits-all' methodological design shows significant inaccuracies. A recent paper from the New Zealand Centre for Ecological Economics (NZCEE) shows that GFN's attempt at using a generic methodology for over 120 countries and international datasets (Ewing et al., 2008) resulted in the NZ calculations being over-exaggerated. NZCEE's recalculations dropped $\mathrm{NZ}$ ten places in the world ranking from 6th to 16th place (Andrew \& Forgie, 2009). The GFN has since amended parts of their method in order more accurately to reflect NZ's EF (Ewing et al., 2010).

Many of these weaknesses are accepted because it is argued that even with these the footprint tool is the most effective way of providing high-level resource accounting for communities. There are a number of other tools and methods available that attempt to 
quantify the level of sustainability that is (or is not) being attained by any given community, including Green Globe (Green Globe, 2012), Visible Solutions (Community Matters, 2012), and Green Star Communities (Green Building Council of Australia, 2012). The majority of these are a tick-box assessment rather than a quantitative measurement. Many also struggle to communicate the impacts that highly consumer-oriented lifestyles are having on the natural environment. Kooten and Bulte (2000) assessed the ability of the EF to communicate complex messages to a range of audiences and found it to be successful, as have a number of other projects (Andrew \& Patterson, 2008; Baldwin et al., 2008; Barrett \& Simmons, 2003; Collins, Cowell, \& Flynn, 2007; Collins et al., 2005; GFN, 2010; NZCEE, 2007; Redefining Progress, 2006; Simmons \& Chambers, 1998).

The EF is one of many tools in the areas of resource accounting and environmental reporting. However, to get a complete view of current sustainability issues more than one tool is required in order to obtain multiple measurements. Research needs to continue in this field to find effective ways of both measuring societies' demands on the natural environment as well as ensuring that the results can be used to influence individual, community, business and government decision-making and actions.

\subsection{Summary}

The EF has been found to be an effective tool for making high-level assessments of the amount of land available to a population and the land that population is currently consuming. There are numerous methodologies used in EF projects, many of which have been designed to fulfil the aims and outcomes of specific projects. This variability causes confusion and makes it difficult to compare case studies. The current project has found a number of inconsistencies with the most commonly used data, the GFN National Accounts, particularly when converting NZha into gha. NZha are more suitable for projects wanting to look at local conditions and have a detailed breakdown of EF data. The current research has undertaken EF calculations in NZha, though gha have been used briefly at the end of chapter 4 to compare findings with other case studies. 


\section{Chapter 4: New Zealand Ecological Footprint}

This chapter calculates the EF of NZ and the average New Zealander. The results are then used to develop the NZ EF Template and calculator. The project uses a two-fold footprint method which gives a detailed breakdown of the EF. The specific EF methodology used is discussed below.

Table 2.1 showed a breakdown of the NZ EF into nine categories: food and drink, travel, consumer goods, holidays, household energy, housing, infrastructure, government, and services. In addition to these there is a satellite category; the EF of residential and nonresidential waste (section 4.2). It is classed as a 'satellite category' because its EF is distributed across a number of the main EF categories. For example, 'waste' can be portioned out amongst food, consumer goods, government and services. This chapter will work through the breakdown of each consumption category, divided into its sub-categories. For example, the travel category is divided into 13 sub-categories discussing each type of travel mode.

The reference year 2007 was the most recent available dataset for a crucial large dataset required for the study, the food and drink database from the FAO. Datasets not available for 2007 were manipulated using earlier or later data to provide estimates. Where limited or no NZ information could be found, international data were used and checked using either topdown or bottom-up data from NZ. The average NZ EF was calculated using the 2007 population of 4,228,300 (Statistics New Zealand, 2011f).

\subsection{Footprint Project Method}

The two-fold component EF method was used for the following calculations as it provides the best opportunity to create a detailed and useful NZ EF template. This template is used to produce the footprint calculator discussed in chapter 6 .

Table 2.1 shows how an individual's EF can be broken down into three parts (Collins et al., 2005; Vale \& Vale, 2009a)-the collective EF, household built environment EF, and the lifestyle EF. These categories provide a logical basis for creating a template for further individual and community EF calculations. 
Data for the collective footprint are extracted from national datasets for infrastructure, government and services. The total of each of these categories is then divided by the NZ population for an average per capita 'citizenship EF'. Data for these categories are drawn from publicly-available databases, which often need to be manipulated to become usable. For example, Statistics New Zealand's Household Economic Survey (2007c) provides average household energy expenditure per month. The average is then converted into energy units per household per month and divided by the average number of people per household. Where no data were available, assumptions were based on both NZ and international data.

The EF only measures resources consumed and waste produced by New Zealanders. The equation is:

$$
\text { Consumption }=(\text { production }- \text { export })+\text { import }
$$

As a result the calculations will discuss NZ consumption rather than NZ's total production of a particular resource or product. The resources consumed by international tourists whilst visiting NZ are also subtracted.

Where possible, the EF has been broken down so that each category represents a major part of the footprint. For example, although the waste EF is calculated in section 4.2 it is then accounted for in the categories of food, consumer goods, government and services. A footprint map is provided at the beginning of each section. The result of each EF analysis is presented in a CLUM showing the supply of the different resources used. The final summary is a CLUM for the overall NZ EF showing the consumption category in relation to the amount and type of land required. 


\subsection{New Zealand Waste Footprint}

Cardiff described waste as a satellite category (Collins \& Flynn, 2005, p. 17) because it is intimately intertwined with all other categories, yet it can be seen as category on its own. Due to the mixed nature of waste, considerable sorting is required to categorise and account for it. To address this, the waste calculations have first been carried out collectively and then allocated to the specific EF categories of food, consumer goods, government, housing, and services.

\subsubsection{New Zealand's Waste}

The initial challenge is to calculate the amount of waste produced each year and where the waste ends up; whether in landfill, cleanfill, recycling or individuals' private landfills. As shown in table 4.1, it was decided by the author that waste would be initially divided into two main streams-landfill waste and recyclable waste.

Table 4.1: Waste streams and associated sources

\begin{tabular}{|c|c|c|c|c|}
\hline Type of Waste & Was & itreams & Source & Iste \\
\hline \multirow{9}{*}{ Waste to Landfill } & \multirow{2}{*}{\multicolumn{2}{|c|}{$\begin{array}{l}\text { Construction and Demolition } \\
\qquad \text { (C\&D) }\end{array}$}} & \multicolumn{2}{|c|}{ Residential } \\
\hline & & & \multicolumn{2}{|c|}{ Non-residential } \\
\hline & \multirow{2}{*}{\multicolumn{2}{|c|}{ Food Packaging }} & \multicolumn{2}{|c|}{ Residential } \\
\hline & & & $\begin{array}{l}\text { Non- } \\
\text { residential }\end{array}$ & $\begin{array}{c}\text { Eating } \\
\text { Out }\end{array}$ \\
\hline & \multirow{2}{*}{ rood vvaste } & \multirow[b]{2}{*}{ Kitchen Food } & \multicolumn{2}{|c|}{ Residential } \\
\hline & & & $\begin{array}{l}\text { Non- } \\
\text { residential }\end{array}$ & $\begin{array}{c}\text { Eating } \\
\text { Out }\end{array}$ \\
\hline & \multicolumn{2}{|c|}{ Garden Waste } & \multicolumn{2}{|c|}{ Residential } \\
\hline & \multirow{2}{*}{\multicolumn{2}{|c|}{ Consumer Goods }} & Resic & \\
\hline & & & Non-re & tial \\
\hline \multirow{5}{*}{$\begin{array}{l}\text { Recycled } \\
\text { Materials }\end{array}$} & & nium & \multirow{3}{*}{\multicolumn{2}{|c|}{ Residential }} \\
\hline & & & & \\
\hline & & & & \\
\hline & & ttic & \multirow{2}{*}{\multicolumn{2}{|c|}{ Non-residential }} \\
\hline & & & & \\
\hline
\end{tabular}

The sections from 4.2.5 onward provide the EF calculations for the different types of waste and sources as set out in table 4.1. 


\subsubsection{NZ's Waste by Volume}

Between 1995 and 2006 NZ's wealth, expressed as real gross domestic product (GDP), increased $40 \%$, largely as a result of expansion in the economic sectors that are major sources of waste (agriculture, manufacturing, transport, tourism, energy, and construction) (MfE, 2008 b, p. 127). Converted to tonnes of waste disposed to landfill per thousand dollars of GDP, waste was 29\% lower in 2006 than 1995 (MfE, 2008b, p. 127, cited from New Zealand Institute of Economic Research, pers comm). This decrease indicates a decoupling of economic growth and waste disposal to landfills. However, it is not known whether this decrease was accompanied by an increase in the waste to cleanfills or other disposal sites (MfE, 2008b, p. 127).

The following calculations only include waste that ends up in NZ, and do not go into detail regarding the waste produced during the production of imported goods and services. The total industrial waste may be slightly higher than reality because the calculations include waste produced for export products. The Canberra report (CSIRO, 1998, p. 32) cites MarsdenBallard's OECD figures for building and construction waste. "For every tonne of waste at the consumer level, there are $5 \mathrm{t}$ created during the manufacturing processes and a further $20 \mathrm{t}$ of resource extraction waste, from activities such as farming, logging or mining." As a result the following waste calculations are only half the waste story and further research is required to reflect the waste footprint of products consumed. On the other hand, as shown below, the footprint of waste is minimal and therefore the missing data is unlikely to affect the total NZ footprint significantly.

Waste Not Consulting (2006) estimated that around 8.7 million tonnes of solid waste (from domestic, tourism, commercial, industrial, and institutional sources) was generated in NZ in 2006, of which 2.4 million tonnes went to landfill. The remaining 6.3 million tonnes were sent to cleanfill sites. "A cleanfill site is any disposal facility that accepts only cleanfill material, which is defined as material that, when buried, will have no adverse effect on people or the environment" (Auckland Council, 2010; MfE, 2007c). Cleanfill waste is not considered here due to lack of data for the amount of waste going to cleanfill, the total number of cleanfills or the footprint of waste that ends up there. This lack is a result of cleanfills being a 'permitted activity' under the Resource Management Act 2001 with no monitoring requirements (MfE, 
2008b, p. 128). Waste to cleanfills is supposedly inert or biodegradable (Auckland Council, 2010; MfE, 2007c) and thus would have a very small EF.

In comparison to the Waste Not Consulting landfill estimate of 2.4 million tonnes (in 2006), the NZ MfE estimates 3.2 million tonnes of waste to landfill in 2008 (MfE, 2009c). They also estimate that landfill waste makes up $50 \%$ of the total, the remainder being either recovered through reuse and recycling or sent to cleanfill. There are a number of estimates for the total waste to landfill; however, they are all only indicative as substantially less waste data was collected before 2009 (MfE, 2011). New reporting standards implemented in 2009 and first reported in 2010 have provided more comprehensive quantitative and compositional data for NZ waste. The 2010 total was 2,450,181t (MfE, 2011), a 20\% reduction on MfE's 2007 estimate. National estimates were also calculated using local and regional waste reports. These ranged from 2,000,000t (Mander, 2011) to 3,500,000t (Morrison Low, 2010). It was decided that MfE's 2010 figure of 2,450,181t would be used for the 2007 landfill waste data in the following analysis.

There are no national estimates for the amount of waste from the commercial and manufacturing sectors. There are regional estimates which vary in relation to the level of nonresidential activity within the region. A range of regional non-residential waste estimates were used to estimate the portion of non-residential waste in NZ's total waste stream. Auckland Council calculated that $85 \%$ of the waste to landfill comes from commercial activity and industry (Auckland Council, 2010), whereas Central Otago estimated a 23\% contribution by industry (Mander, 2011). Some 66\% of the country lives in NZ's four commercial hubs (MfE, 2008a, p. 40) which, using the MfE estimate of 2,450,181t of landfill waste, would be responsible for $1,617,119 t$. In the commercial hubs, non-residential waste is assumed to make-up $85 \%$ of the waste, totalling $1,374,551$ t. The remainder of New Zealanders live in less populated areas where non-residential waste is assumed to contribute $23 \%$ of the waste, totalling 833,061 t. Total non-residential waste makes up $1,566,155 t$, which is $64 \%$ of NZ's total waste. Residential activity generated the remaining 884,000t. Although some of this waste comes from the production of exports, this is assumed to be balanced by the waste from imports not included here. 


\subsubsection{Waste Streams}

Different waste streams have different footprints so to calculate the total $E F$, waste needs to be divided into its various streams. The MfE provides a composition breakdown (figure 4.1) but also adds "the percentages associated with waste composition data are indicative only... the margin of error associated with analysing the composition of waste disposed of to landfill is typically 20\%" (Statistics New Zealand, 2008c, p. 1). There are also inconsistencies in the available data.

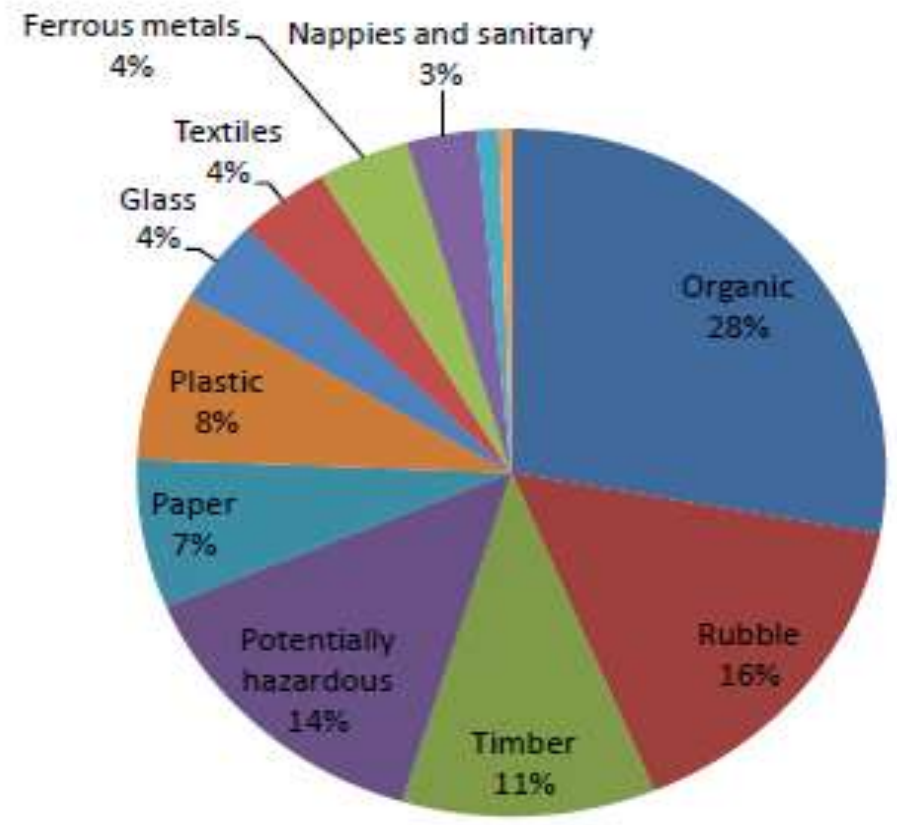

Figure 4.1: Composition of NZ Waste to Landfill, 2007-08 (MfE, 2009b).

\section{Construction and Demolition (C\&D) Waste}

There is limited data regarding C\&D waste to landfill and "only 70\% could be specified" (MfE, 2007c; Waste Not Consulting, 2006). The same report stated that of this $70 \%$, more than half (53\%) of all C\&D waste was timber and rubble and the remainder was as assortment of paper, plastics, metals, glass, textiles and hazardous substances. According to figure 4.1 , if all rubble and timber were C\&D waste (making up 53\% of total C\&D waste) then it would be $1,298,596 \mathrm{t}$ or approximately half of all waste to landfill (using the MfE figure for total waste). In comparison, an estimate for 2005 suggested that "C\&D waste made up approximately $17 \%$ of total waste to landfill" (MfE, 1997, figure 3.1.4). Of the MfE 2010 total waste of 2,450,181t, $17 \%$ is 416,531 t. Therefore, it is likely that not all timber and rubble in figure 4.1 is C\&D waste. 
Building consent data were used to calculate the proportions of C\&D waste from residential and non-residential activity. In 2007, \$1,151 million was spent on building consents, of which $65 \%$ (\$753 million) were for residential consents (Statistics New Zealand, 2007a). Using the 416,531t total, residential C\&D contributed 270,745t. In 2007 there were 7,900,000 $\mathrm{m}^{2}$ of new buildings consented, of which residential consents totalled $5,162,000 \mathrm{~m}^{2}$ (Statistics New Zealand, 2007a), amounting to $52.45 \mathrm{~kg} / \mathrm{m}^{2}$ of residential C\&D waste, presumably including refurbishment waste.

MfE's top-down estimate for C\&D waste of 416,531 t will be used for the remainder of the waste calculations. The remaining waste in landfill less C\&D waste is $2,033,650 t$.

\section{Waste Associated with Food}

There are two waste streams in food waste; organic waste and packaging waste, which come from residential and non-residential activities. Non-residential activity includes food wholesalers and retailers and eating out.

Australian figures show that a significant amount of waste is produced in the food supply chain. The Australian Food and Grocery Council's 2005 Environmental Report (Queensland Government, 2005) suggests that for every tonne of meat and meat product that reaches retail stores, 38kg of waste goes to landfill. A 2008 British case study by the Waste and Resource Action Programme (WRAP) found that, of the waste produced in the food and drink supply chain, $69 \%$ was organic and $31 \%$ was packaging. The residential sector accounted for $74 \%$ of organic waste and $70 \%$ of packaging waste (Lee, Willis, Hollins, \& WRAP, 2010).

\section{Organic Waste}

Organic waste includes garden waste, food scraps and food processing waste from both nonresidential and residential activities (MfE, 2009c). According to figure 4.1, organic waste was the largest waste stream, making up $28 \%(686,051 \mathrm{t})$. A subsequent NZ study (MfE, 2007c, p. 34; Waste Not Consulting, 2006) showed that kitchen waste formed 53\% (363,607t) of total organic waste, and 'garden waste' and 'multi-material/other' waste made up 39\% and 8\% respectively $(322,444 t)$. 'Multi-material/other' organic waste comprises "non-residential organic waste such as paunch grass and food-processing waste" (MfE, 2007, p. 34). According 
to WRAP the non-residential sectors (manufacturing, distribution and retail) contributed the remaining $26 \%(129,540 t)$ of organic food waste. WRAP also suggests $17 \%(22,022 t)$ of nonresidential organic waste is produced from food eaten-out (Lee et al., 2010; table 1).

\section{Food Packaging Waste}

The 1997 New Zealand State of the Environment noted, "much of the paper, plastic, metal and glass comes from discarded packaging, particularly food and drink containers" (MfE, 1997, cited Taylor \& Smith, 1997, p. 3:36). Statistics New Zealand (2008c) reported that between 1994 and 2007 packaging grew from $126 \mathrm{~kg}$ to $162 \mathrm{~kg}$ per person per year, the latter totalling 684,985 tonnes. The WRAP figures suggest that $33 \%(225,042 t)$ was from food. These figures suggest that for every tonne of food waste there is almost half a tonne $(0.46 \mathrm{t})$ of food packaging to landfill. As noted above the eating-out industry produced $22,022 \mathrm{t}$ of organic waste in 2007 which produced 10,130t of packaging waste. The quantities of recycled food packaging, glass and plastic bottles and containers are calculated in the recycled section below.

\section{Consumer Goods Waste}

No specific data on consumer goods waste were available so the figures will be calculated through a process of reduction. Total NZ waste in $2007(2,450,181 t)$ minus C\&D waste $(416,531 t)$ and food-related waste $(888,040 t)$ leaves $993,017 t$ of non-residential waste, which is $41 \%$ of the total.

\section{Total breakdown of waste data}

There is very little reliable NZ data on the make-up of residential and non-residential waste. Table 4.2 is a summary of the waste attributed to each waste stream. These figures will be used to calculate the EF of waste in section 4.2.5.

Of the total $2,450,181$ t of waste disposed of in $2007,36 \%$ was from residential activity of which $59 \%$ was associated with food waste (organic and packaging). Thus $63 \%$ of all waste comes from non-residential activities. 
Table 4.2: Summary of waste streams by weight from residential and non-residential activities in 2007

\begin{tabular}{|lcccccc|}
\hline \multirow{2}{*}{$\begin{array}{c}\text { Waste } \\
\text { summary }\end{array}$} & $\begin{array}{c}\text { Total } \\
\text { waste }\end{array}$ & $\begin{array}{c}\text { C\&D } \\
\text { waste }\end{array}$ & $\begin{array}{c}\text { Organic } \\
\text { waste }\end{array}$ & $\begin{array}{c}\text { Food } \\
\text { packaging } \\
\text { waste }\end{array}$ & $\begin{array}{c}\text { Garden } \\
\text { waste }\end{array}$ & $\begin{array}{c}\text { Consumer } \\
\text { goods waste }\end{array}$ \\
\cline { 2 - 7 } & tonnes & tonnes & tonnes & tonnes & tonnes & tonnes \\
\hline Residential & $\mathbf{8 8 4 , 0 2 5}$ & & 363,607 & 157,709 & 235,384 & 127,325 \\
\hline $\begin{array}{l}\text { Non- } \\
\text { residential }\end{array}$ & $\mathbf{1 , 5 6 6 , 1 5 6}$ & $\mathbf{4 1 6 , 5 3 1}$ & $\mathbf{1 0 7 , 5 1 9}$ & $\mathbf{5 7 , 2 0 3}$ & $\mathbf{8 7 , 0 6 0}$ & $\mathbf{8 6 5 , 6 9 1}$ \\
\hline Eating out & & & $\mathbf{2 2 , 0 2 2}$ & 10,130 & & \\
\hline Total & $\mathbf{2 , 4 5 0 , 1 8 1}$ & $\mathbf{4 1 6 , 5 3 1}$ & $\mathbf{4 9 3 , 1 4 7}$ & $\mathbf{2 2 5 , 0 4 2}$ & $\mathbf{3 2 2 , 4 4 4}$ & $\mathbf{9 9 3 , 0 1 7}$ \\
\hline
\end{tabular}

\subsubsection{Recycled Waste}

There is a range of estimates for recycling of waste in NZ for 2007. These vary between 410,145t (Statistics New Zealand, 2008c), 1,098,636t (COVEC, 2007, p. 43) and 2.4 million tonnes a year (MfE, 2008b, p. 129); a 2 million tonne difference. COVEC's figure of 1,098,636t will be used in the following calculations as it lies in the middle of the range and seems to include (though not clearly stated) all recycled waste streams.

Packaging Council New Zealand (PCNZ) data were used to break the recycling waste stream into different types (PCNZ, 2009). PCNZ found paper represented 53\% $(582,277 \mathrm{t}$ ) of total recyclables, glass $34 \%(373,536 t)$, plastic $9 \%(98,877 t)$, steel $3 \%(32,959 t)$ and aluminium $1 \%$ $(10,986 t)$. Total recyclables were split further using COVEC's data $(2007$, p. 43$)$, showing that $29 \%$ of recyclables were sourced from households and $71 \%$ from non-residential activity.

Of the total recycling waste, figures above suggest approximately $43 \%$ of all packaging waste is associated with food. Figures from the WRAP case study (Lee et al., 2010) suggest that recycled food-related waste is closer to $50 \%$ of the total waste. As a result, $549,318 \mathrm{t}$ of recycling is assumed to be from food and the remainder from consumer goods.

\subsubsection{The Ecological Footprint of Landfill Waste}

The footprint of waste has two land types; consumed land for the physical space needed to store waste, and energy land required to sequester $\mathrm{CO}_{2}$ from the transport and processing of waste and the methane produced as the waste breaks down. 


\section{Consumed Land}

The consumed land is calculated by approximating the area of land needed to store a tonne of waste produced in 2007. There is considerable variation in the area of land needed for different waste types.

The MfE states that the total land required for 'dumps' or landfills in NZ is 568NZha (MfE, 2009c). Divided by the total waste to landfill in 2007 and assuming that landfills have an average lifetime of 20 years, the required land would be $12 \mathrm{~m}^{2} / \mathrm{t}$ or $8.63 \mathrm{t} / \mathrm{m}^{2}$. An MfE report (2009a) provides figures for tonnes of waste per cubic metre (density) as collected at the waste depot. High-density waste such as C\&D waste is $1.5 \mathrm{t} / \mathrm{m}^{3}$, compacted waste is $0.32 \mathrm{t} / \mathrm{m}^{3}$, and uncompacted general waste is $0.2 \mathrm{t} / \mathrm{m}^{3}$ (MfE, 2009a, p. 38). Assuming a landfill that is $100 \mathrm{~m} \times 100 \mathrm{~m}$ (i.e. 1 ha) and approximately $50 \mathrm{~m}$ deep (Cointreau, 2008), the waste-to-land conversion for high density waste is $0.7 \mathrm{~m}^{2} / \mathrm{t}$, for compacted waste is $5 \mathrm{~m}^{2} / \mathrm{t}$, and for uncompacted general waste is $8 \mathrm{~m}^{2} / \mathrm{t}$. In comparison to the top-down calculation, these figures seem more plausible as waste compacts over time. They will be used for the following footprint calculations.

A case study by Barrett and Simmons (2003, p. 44) shows a breakdown of the average landfill waste footprint for a United Kingdom resident per year (0.5154gha) from $520 \mathrm{~kg}$ of waste. The breakdown includes landfill operational energy (50\%), physical land (40\%), methane emissions (9.2\%), landfill processing energy (0.6\%), and transport energy (0.2\%). Physical land therefore makes up $40 \%$ of the total landfill waste footprint, and energy land the remaining $60 \%$. NZ proportions are likely to be quite different because of the higher portion of renewable energy in electricity for landfill operations. However with no simple alternative means for calculating the NZ waste footprint, the UK proportions will be used.

Table 4.2 provides the weight for each waste stream based on the MfE compaction values. The total consumed land footprint of 1,805 ha represents NZ's residential and non-residential waste footprint. This consumed land will be attributed to the appropriate footprint template category. For example, food waste and food packaging waste will be attributed to the food footprint and further split between household and eating-out waste. Non-residential food 
waste also needs to be accounted for by the end-users of the products, mainly households, although government services may also be a factor.

\section{Landfill - Energy Land}

There is some concern that the following 'energy' required for landfill operation and recycling of waste is included in the 'community services' energy in section 4.9, although there is insufficient information to clarify this (EECA, 2007; Ministry of Economic Development, 2010a). Calculations from the Barrett \& Simmons (2003) case study provide the figures for the energy EF of waste. These found $60 \%$ of the total EF is energy land, probably a mix of electricity (a mix of renewables and non-renewables) and non-renewable energies. However, without further information the energy is assumed to be $100 \%$ non-renewable here. Consumed land is $40 \%$ of total waste EF, therefore the energy land portion of C\&D waste is $8 \mathrm{~m}^{2} / \mathrm{t}$ and for general waste is $12 \mathrm{~m}^{2} / \mathrm{t}$. The energy land footprint for landfill waste was 3,368 ha. A summary of the results is shown in table 4.3.

Table 4.3: Summary of waste EF and corresponding land required by different sectors in 2007

\begin{tabular}{|c|c|c|c|c|c|c|}
\hline $\begin{array}{l}\text { Landfill } \\
\text { categories }\end{array}$ & $\begin{array}{c}\text { C\&D } \\
\text { waste }\end{array}$ & $\begin{array}{l}\text { Food } \\
\text { waste }\end{array}$ & $\begin{array}{c}\text { Food } \\
\text { packaging } \\
\text { waste }\end{array}$ & $\begin{array}{l}\text { Green } \\
\text { waste }\end{array}$ & $\begin{array}{c}\text { Consumables } \\
\text { waste }\end{array}$ & $\begin{array}{l}\text { NZ } \\
\text { EF }\end{array}$ \\
\hline & NZha & NZha & NZha & NZha & NZha & NZha \\
\hline Residential & & 280 & 121 & 181 & 98 & 680 \\
\hline Non-residential & 208 & 100 & 83 & 44 & 535 & 1,101 \\
\hline Eating out & & 17 & 8 & & & 25 \\
\hline $\begin{array}{l}\text { Consumed land } \\
\text { subtotal }\end{array}$ & 208 & 379 & 204 & 248 & 633 & 1,805 \\
\hline Residential & & 402 & 174 & 260 & 141 & 977 \\
\hline Non-residential & 1,097 & 119 & 63 & 119 & 957 & 2,355 \\
\hline Eating out & & 24 & 11 & & & 36 \\
\hline $\begin{array}{l}\text { Energy land } \\
\text { subtotal }\end{array}$ & 1,097 & 545 & 249 & 379 & 1,097 & 3,368 \\
\hline Total EF & 1,305 & 924 & 453 & 627 & 1,730 & 5,173 \\
\hline
\end{tabular}

\section{Total Landfill Waste Footprint}

The landfill waste footprint combines consumed and energy land. The total waste to landfill footprint is 5,173 ha and the two largest waste streams are consumer products at $33 \%$ of the 
total $E F$, and C\&D waste at $25 \%$. The residential sector contributes $33 \%$ and non-residential $67 \%$. Eating out contributes less than $1 \%$.

\subsubsection{EF of Recycled Waste}

Publicly-available figures for the energy requirements of recycling facilities in NZ could not be located so Barrett and Simmons' (2003) UK case study from landfill waste will be used again. Their study found that the consumed land EF for recycled waste was $75 \%$ lower per tonne than for landfill waste, and the energy land EF $18 \%$ lower for recycled waste compared to landfill waste. Therefore the 'land-to-waste' conversion for NZ recycled waste is $1.8 \mathrm{~m}^{2} / \mathrm{t}$ for consumed land and $9.7 \mathrm{~m}^{2} / \mathrm{t}$ for energy land. The energy required to operate recycling equipment is probably mostly electricity. As discussed above, electricity-to-land figures are different for NZ and the UK. However, because of the lack of data, all energy for this is assumed to be non-renewable.

Table 4.4 shows the footprint of each recycled waste stream in relation to the type of land required and where the waste originated.

Table 4.4: EF of recycling in NZ (2007)

\begin{tabular}{|lcc|cccc|}
\hline \multirow{2}{*}{$\begin{array}{c}\text { Recycled } \\
\text { waste }\end{array}$} & $\begin{array}{c}\text { Energy } \\
\text { land }\end{array}$ & $\begin{array}{c}\text { Consumed } \\
\text { land }\end{array}$ & $\begin{array}{c}\text { NZ } \\
\text { households }\end{array}$ & $\begin{array}{c}\text { NZ } \\
\text { commerce }\end{array}$ & $\begin{array}{c}\text { Total } \\
\text { NZ EF }\end{array}$ & $\begin{array}{c}\text { Individual } \\
\text { EF }\end{array}$ \\
\cline { 2 - 7 } & NZha & NZha & NZha & NZha & NZha & NZha \\
\hline Aluminium & 12 & 2 & 4 & 10 & 14 & 0.0000 \\
\hline Glass & 421 & 69 & 142 & 348 & 490 & 0.0001 \\
\hline Paper & 656 & 107 & 221 & 542 & 764 & 0.0002 \\
\hline Plastic & 111 & 18 & 38 & 92 & 130 & 0.0000 \\
\hline Steel & 37 & 6 & 13 & 31 & 43 & 0.0000 \\
\hline Total & $\mathbf{1 , 2 3 8}$ & $\mathbf{2 0 2}$ & $\mathbf{4 1 8}$ & $\mathbf{1 , 0 2 3}$ & $\mathbf{1 , 4 4 1}$ & $\mathbf{0 . 0 0 0 3}$ \\
\hline
\end{tabular}

The total land required for waste recycling is minimal, at only $1,441 \mathrm{ha}$ or $3 \mathrm{~m}^{2} /$ person. The Barrett and Simmons (2003) case study also credits the recycled material which re-enters the waste stream. The recycling credit system has not been used here but would be worthwhile investigating in the future. As mentioned above, an estimated $50 \%$ of all recycled materials are associated with food, totalling 720 ha. As noted in the section on landfill waste, $17 \%$ of food waste is from eating out, totalling $122 \mathrm{ha}$. 


\subsubsection{Total Waste Ecological Footprint}

Landfill waste has a footprint of 5,173ha and recycling waste a footprint of $1,441 \mathrm{ha}$. The total waste EF in 2007 was 5,961ha, comprising 3,894ha of energy land and 2,067ha of consumed land. Non-residential waste makes up $69 \%$ of the total waste footprint, although this includes C\&D waste that should be attributed to households. 


\subsection{New Zealand Food and Drink Footprint}

The food and drink category required the most information and research due to the complexities of its interconnected systems. The EF calculation of food and drink contains numerous steps using a range of different resources and land types. A breakdown of the food and drink section is shown in the Food Footprint Map, figure 4.2. Energy land includes nonrenewable and renewable energy types. These have been separated in figure 4.2 into energy land (non-renewable) and electricity land (67\% renewable and 33\% non-renewable).

\subsubsection{NZ Food Consumption}

The amount and types of food consumed by New Zealanders on an annual basis form a complex topic. The following food EF calculations use a top-down method with figures provided by the FAO Statistics Division (FAOSTAT) for the reference year of 2007. These statistics only include the food consumed by New Zealanders, excluding food exports and food consumed by tourists. However, it is important to understand how much of the food grown in NZ is consumed by New Zealanders as this affects other components of the food footprint, such as transport, processing, distribution and eating out.

Of the NZ adult population $94 \%$ consume a regular (omnivorous) diet, in which $75 \%$ of the food consumed is plant-based and just over $20 \%$ animal-based. The remainder is highly processed and therefore difficult to summarise (Russell, Parnell, \& Wilson, 1999, p. 2).

Two sources of data were used to calculate the food consumed by an average New Zealander. One was top-down using national data from the FAOSTAT (FAO, 2007) and the other was bottom-up using individual food intake data from The Nutrition and Activity Research Unit at Otago University (formerly known as the Life in New Zealand (LINZ) Activity and Health Research Unit) (Parnell, Blakey, Gray, Fleming, \& Walker, 2010).

The FAOSTAT and LINZ data are compared in table 4.5, showing similar values for the overall amount of food New Zealanders consume per day (a difference of $0.16 \mathrm{~kg}$ ) but considerable differences between the levels of plant- and animal-based foods. Nationally, the larger LINZ consumption amounts to an additional $685 \mathrm{t}$ of food per day or $250,483 \mathrm{t}$ per year. The LINZ figure for consumption of plant-based food is $0.36 \mathrm{~kg} /$ day higher than the FAO estimate. The 


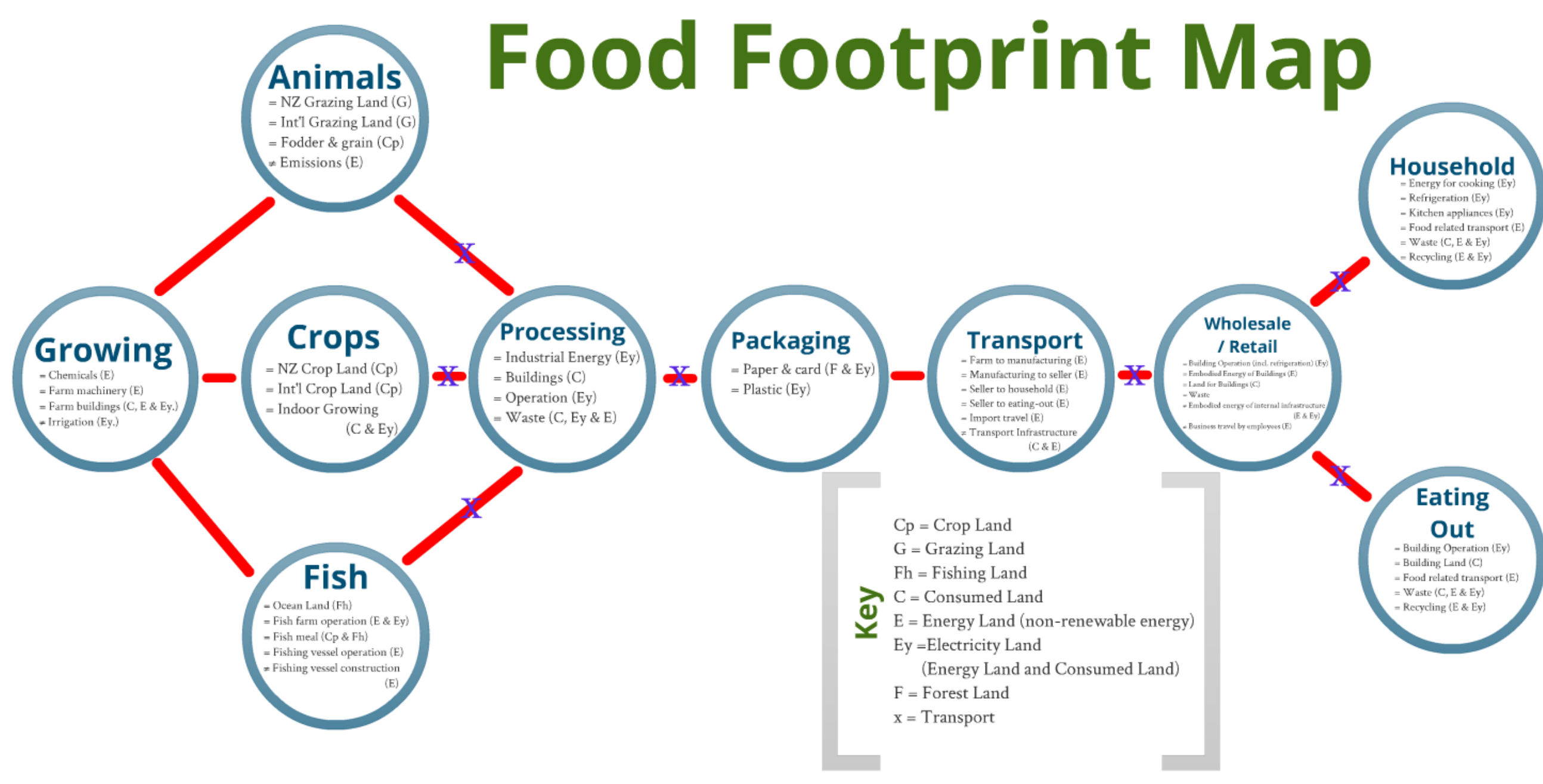


FAO figure for animal-based foods is $0.2 \mathrm{~kg} /$ day higher than the LINZ estimate. Because plant-based foods have a lower EF than meat-based foods these differences affect the total NZ food footprint.

Table 4.5: Comparison of daily food consumption between FAOSTAT and LINZ

\begin{tabular}{|lcccc|}
\hline \multirow{2}{*}{$\begin{array}{c}\text { Average daily } \\
\text { consumption }\end{array}$} & $\begin{array}{c}\text { Plant- } \\
\text { based }^{1}\end{array}$ & $\begin{array}{c}\text { Animal-based } \\
\text { (minus fish) }\end{array}$ & $\begin{array}{c}\text { Individual } \\
\text { consumption }\end{array}$ & $\begin{array}{c}\text { NZ } \\
\text { consumption }\end{array}$ \\
\cline { 2 - 5 } & $\mathrm{kg}$ & $\mathrm{kg}$ & $\mathrm{kg}$ & Tonnes \\
\hline FAO & 1.5687 & 0.7154 & 2.2841 & 9,658 \\
\hline LINZ & 1.9318 & 0.5144 & 2.4463 & 10,344 \\
\hline
\end{tabular}

1. Includes LINZ food categories that could not be identified by main foods such as 'salad' or 'pastries'.

Reasons for the differences between the two datasets include: different food categories in the datasets; FAOSTAT considers foods 'consumed' by New Zealanders in their primary form whilst LINZ also includes processed foods; there may be inaccuracies in the national data submitted to FAOSTAT because food that is not purchased is excluded; and FAOSTAT reports the total food consumed within the country for a given year, including by tourists.

This research also compared NZ consumption with other populations. A comparison with the Cardiff EF Project would suggest Cardiff residents eat $0.43 \mathrm{~kg}$ of food per day less than New Zealanders (Collins et al., 2005, p. 23). FAOSTAT data for the UK in the year 2000 were slightly higher but similar to NZ in the same year, though there were considerable differences in what was eaten.

It is not clear whether the FAOSTAT data only include food that is commercially grown or all food including home-grown. There is some suggestion that household food production is on the increase (Barry, 2008), however, the most recent quantitative data for food grown by NZ households are from the 1957 census (Statistics New Zealand, 1957) so they are not helpful for current production. As a result these food figures could be an underestimate depending on the amount of non-commercial food consumed by New Zealanders.

There are a number of gaps in the FAO data which create uncertainties in the EF calculation. However, the food and drink data are presented as raw rather than processed food, which is the clearest way to calculate footprints. As a result the FAOSTAT data will be used here for the total food consumed by New Zealanders. 


\subsubsection{Land and energy for growing food}

The majority of the total EF of food and drink is the land to grow it. As discussed earlier, different land types are more or less productive and so are used to produce certain types of food. The fertility of land can be altered, for example, using fertilisers and irrigation. In conventional food systems this requires borrowing land from elsewhere, particularly energy land for running machinery, making and applying fertilisers and pesticides, and pumping water.

Growing land includes the crop, grazing and fishing land required to produce the food New Zealanders eat. The average per capita figures use the national 2007 population figure of 4,228,300 (Statistics New Zealand, 2011f). All yield figures are NZ yields as reported by the FAO except where specified. The footprints of all food types have been calculated using conventional farming and food production methods unless otherwise explained. Section 4.3.3 discusses organic farming.

\section{Crop Land}

The 'business-as-usual' path for food consumption shows the absolute demand for cropland worldwide increasing by $60 \%$ by 2050 (Kitzes et al., 2008). Arable crop land is, ecologically speaking, the most productive land as it can grow the most plant biomass (Wackernagel et al., 1999, p. 383). Crop land calculations are divided into vegetables, fruit, grains, beverages and 'other food crops' including legumes, nuts and vegetable oils.

Table 4.6 is a summary of crop land tables 1 to 5 in appendix 3.

Table 4.6: Estimated total EF of crop land for food consumed in NZ in 2007

\begin{tabular}{|lcc|}
\hline \multirow{2}{*}{ Total crop land } & NZ EF & Individual EF \\
\cline { 2 - 3 } & NZha & NZha \\
\hline Vegetables & 26,551 & 0.0063 \\
\hline Fruit & 41,605 & 0.0098 \\
\hline Grains & 259,933 & 0.0615 \\
\hline Beverages & 63,545 & 0.0150 \\
\hline Other food crops & 20,630 & 0.0049 \\
\hline Total & $\mathbf{4 1 2 , 2 6 4}$ & $\mathbf{0 . 0 9 7 5}$ \\
\hline
\end{tabular}


These calculations found that, in 2007, New Zealanders consumed an estimated 2.4 million tonnes of plant-based food, with a footprint of $975 \mathrm{~m}^{2} /$ person.

\section{Grazing Land}

Grazing land produces meat, dairy products, eggs and fibre. If meat consumption continues to increase due to changing lifestyles and population growth, the demand for grazing land is expected to increase worldwide by $85 \%$ by 2050 (Kitzes et al., 2008). As calculated in section 4.3.4, NZ exports considerably more meat and dairy than New Zealanders consume, resulting in an estimated total grazing land of 12 million hectares. Yield calculations in the next section were carried out by James Richardson (2012) and further detail is provided in tables 6 to 8 in appendix 3.

New Zealanders consumed a total of 1.1 million tonnes of animal-based food in 2007. The EF for animal-based food is three times that of plant-based foods per tonne of food.

Table 4.7: Estimated EF of animal products and resulting grazing land used by NZ in 2007

\begin{tabular}{|c|c|c|}
\hline \multirow{2}{*}{ Total Grazing Land } & NZ EF & Individual EF \\
\hline & NZha & NZha \\
\hline Meat and meat products & $1,023,443$ & 0.2420 \\
\hline Poultry and eggs & 127,957 & 0.0303 \\
\hline Dairy products & 142,942 & 0.0338 \\
\hline Total & $1,294,161$ & 0.3061 \\
\hline
\end{tabular}

\section{Fishing Land}

As discussed in section 3.5.1 fishing land calculations are beyond the scope of this research. Consequently data from the GFN's (2011) National Accounts-New Zealand 2007 were used instead. The GFN method is different as an average global yield is used rather than a local yield. To use the GFN data, the land units need to be converted from gha to NZha. GFN data shows that New Zealanders require 1,314,299gha for fish and shellfish. Total gha are divided by the equivalence factor ( 0.37 fishing land hectares to world average hectares) to give $3,552,160$ ha of NZ fishing land. The equivalence factor is the same as saying that fishing grounds are only $37 \%$ as productive as 'average' world land. 
The final step is to convert the land back into NZha. This considers how productive NZ fishing land is in comparison to global average productivity for fishing land. The yield factor for NZ fishing land is 0.96 local hectares to global average hectares, meaning NZ fishing land is $96 \%$ as productive as the world average fishing land. The yield factor used by GFN is usually only used to consider the biocapacity of land. Here it will be used for the comparative yield of land between countries. Therefore, 3,552,160ha of global fishing land divided by 0.96 gives $3,700,167$ NZha of fishing land.

New Zealanders consume $110,678 \mathrm{t}$ of fish per year (FAO, 2007) so the NZ seafood yield is 33.4kg per hectare of NZ fishing land. This estimate is slightly higher than the estimate given in Barrett et al (2002) of $29 \mathrm{~kg} / \mathrm{gha}$. These figures should be used with caution as the yield and equivalence factors are world averages only.

\section{Total Growing Land}

Table 4.3.4 shows a breakdown of the NZ total and per capita food consumed, and hectares of each land type required.

Table 4.8: Total grazing, crop and fishing land required for food derived from animals consumed in 2007

\begin{tabular}{|lcccc|}
\hline \multirow{2}{*}{ Land Type } & Total food & Food/person & NZ EF & Individual EF \\
\cline { 2 - 5 } & Tonnes & $\mathrm{kg} /$ year & NZha & NZha \\
\hline Crop land & $1,104,939$ & 261.32 & 412,259 & 0.0975 \\
\hline Grazing land & $2,422,611$ & 572.95 & $1,294,342$ & 0.3061 \\
\hline Fishing land & 110,678 & 26.18 & $3,700,167$ & 0.8751 \\
\hline Total & $\mathbf{3 , 6 3 8 , 2 2 8}$ & $\mathbf{8 6 0 . 4 5}$ & $\mathbf{5 , 4 0 6 , 7 6 8}$ & $\mathbf{1 . 2 7 8 7}$ \\
\hline
\end{tabular}

Fishing land made up $68 \%$ of the total required for meat-based foods, and grazing land made up $24 \%$.

Figure 4.3 shows that one hectare of fishing land produces $30 \mathrm{~kg}$ of food, whilst one hectare of grazing land produces $1,872 \mathrm{~kg}$ of animal products. Crop land has the highest average yield of $2,680 \mathrm{~kg}$ of plant-based products per hectare.

The FAOSTAT data shows that, in 2007, New Zealanders consumed 3.6 million tonnes of food with a footprint of 5.4 million hectares, the majority of which was fishing land. 


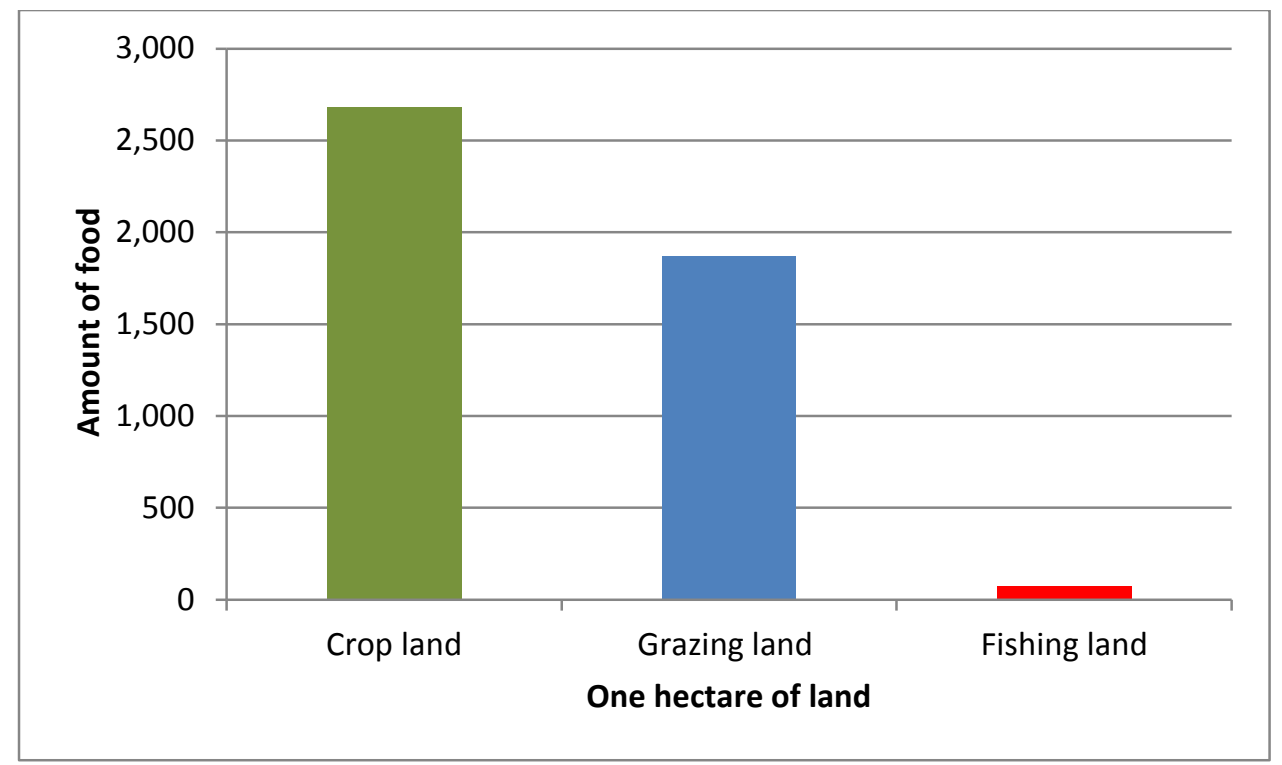

Figure 4.3: Comparison of the average food (average yield in $\mathrm{kg} / \mathrm{ha}$ ) that can be grown on one hectare of each land type.

\subsubsection{On-farm Energy}

Conventional farming methods require a range of energy and chemical inputs to produce food. Energy is direct energy, indirect energy and the embodied energy of farm infrastructure and machinery. In 2006 Saunders, Barber and Taylor undertook energy research on four food types (milk, apples, onions and lamb) on a number of farms across NZ. Total food figures from table 4.8 and on-farm energy estimates by Saunders et al. (2006) have been used to estimate the amount of on-farm energy for all food consumed by New Zealanders. The 'apples, onions and lamb' calculations from Saunders et al. were extrapolated to include all 'fruit, vegetables and meat'. Milk includes all dairy products. The embodied on-farm energy of meat is likely to change depending on whether it is pasture-fed or barn-raised. Saunders et al. calculations are all for pasture-fed animals and consequently, the use of their figures may not give an accurate reflection, and further research is required. However, data on energy per tonne of food from Saunders et al. were used to calculate the embodied EF per tonne of food consumed by New Zealanders. Data from Saunders et al. also give the split between electricity and nonrenewable fuels, and this has been used in table 4.9 .

Milk and milk products have the highest energy inputs of all food groups with an ecological footprint of $0.1302 \mathrm{ha} / \mathrm{t}$ of milk. Meat is a close second with an EF of $0.1064 \mathrm{ha} / \mathrm{t}$, and fruit and vegetables are much lower at $0.0050 \mathrm{ha} / \mathrm{t}$. 
Table 4.9: The EF of on-farm activities for 2007 for all NZ food

\begin{tabular}{|lccccc|}
\hline $\begin{array}{c}\text { On-farm food } \\
\text { category }\end{array}$ & $\begin{array}{c}\text { Total } \\
\text { food }\end{array}$ & $\begin{array}{c}\text { Energy per } \\
\text { tonne }\end{array}$ & $\begin{array}{c}\text { Total } \\
\text { energy }\end{array}$ & NZ EF & $\begin{array}{c}\text { EF/tonne of } \\
\text { food }\end{array}$ \\
\cline { 2 - 6 } & Tonnes & MJ/tonne & GJ & NZha & NZha/t \\
\hline Dairy products & 495,642 & $\mathbf{2 2 , 9 1 2}$ & $11,356,150$ & 64,533 & 0.1302 \\
\hline Fruit & 462,029 & 950 & 438,927 & 2,552 & 0.0055 \\
\hline Vegetables & 843,129 & 820 & 691,366 & 4,526 & 0.0054 \\
\hline Meat & 424,629 & 16,444 & $6,982,599$ & 45,174 & 0.1064 \\
\hline Total & $\mathbf{2 , 2 2 5 , 4 2 9}$ & $\mathbf{n / a}$ & $\mathbf{1 9 , 4 6 9 , 0 4 2}$ & $\mathbf{1 1 6 , 7 8 5}$ & $\mathbf{n} / \mathbf{a}$ \\
\hline
\end{tabular}

\section{Organic Food}

There is an increasing trend towards 'organically grown' food both in NZ and internationally (Dimitri \& Oberholtzer, 2009; NPD Group, 2009; Statistics New Zealand, 2002). People are becoming more aware of the environmental, social, economic and human health effects of adding chemicals to land to grow food. On the other hand there is also a strong desire to increase food yields, leading to increased use of chemicals (Parliamentary Commissioner for the Environment, 2004, p. 43). The following section summarises the findings of the embodied energy of the chemicals used in conventional farming methods in NZ. These figures will be used to show the decrease in the footprint for four food types as a result of producing them organically.

Two methods were used to estimate the embodied ecological footprint of the chemicals used in conventional farming in NZ. One was a further breakdown of the embodied energy of chemicals per tonne provided by Saunders et al. (2006), and the other a range of miscellaneous references used to test the data of Saunders et al.

Saunders et al. found that dairying requires almost three times more indirect energy $(9,180 \mathrm{MJ} / \mathrm{t})$ than lamb $(3,361 \mathrm{MJ} / \mathrm{t})$, due to the higher use of fertilisers, 21 times more than onions $(428 \mathrm{MJ} / \mathrm{t})$, and 30 times more than apples $(300 \mathrm{MJ} / \mathrm{t})$. Using the total food consumed by New Zealanders in table 4.10, the EF of the embodied energy and emissions of the chemicals used in dairying was 30,333ha; with 9,515ha for meat, 2,406ha for vegetables and 924ha for fruit. The total chemical EF for all food consumed by New Zealanders in 2007 was 43,178 ha, forming $37 \%$ of the total on-farm energy EF. 
In the second method the total fertiliser use for NZ was calculated and divided by the total food consumed. Various relevant data for total fertiliser use were inconsistent ranging from 1.5 million tonnes (Parliamentary Commissioner for the Environment, 2004) to 4.3 million tonnes (Ravensdown, 2011; Statistics New Zealand, 2003; 2006a, p. 4). The NZ GHG inventory uses a constant emissions factor of 6.82 $\mathrm{tCO}_{2}$-e per tonne of fertiliser (Brown \& Plume, 2004). The $\mathrm{NZ} \mathrm{CO}_{2}$-to-land conversion of $10.4 \mathrm{tCO}_{2} /$ ha along with the percentage of total fertiliser were used to calculate the fertiliser EF of each food group in table 4.9. The proportion of each food category consumed by New Zealanders (table 4.10) was also calculated and showed that New Zealanders consume approximately $16 \%$ of the total national fertiliser use, with the remainder going for export. The EF results for the highest and lowest fertiliser use estimates above show a range of $152,722-437,803$ NZha for consumption by New Zealanders.

The calculations from Saunders et al. show different foods and farming methods use different amounts of fertilisers, herbicides and pesticides. Therefore caution must be used when generalising the fertiliser per tonne of food above. The Saunders et al. bottom-up calculation gave a total footprint of 43,178 ha whilst the more conservative top-down approach gives $152,722 \mathrm{ha}$. The Saunders et al. calculation included only the fruit, vegetables, meat and dairy products consumed by New Zealanders, so is therefore not inclusive. The top-down method of total fertiliser use included official estimates of total fertiliser and chemical use less food exports.

The calculations based on Saunders et al. show that producing food without the use of fertiliser, but keeping all other primary energy components the same, would reduce the EF by $35 \%$. This figure is supported by research from Wood et al. $(2006$, p. 334) that shows that the energy intensity of conventional farms is $36 \%$ higher than for similar organic farms.

Fertilisers have a high EF due to the energy required for their production and the $\mathrm{CO}_{2}$ emitted during this. There is limited data detailing whether organic growing operations require additional energy for on-farm work such as tilling soils and weed eradication and further research is needed. This suggests food produced by conventional farming methods is likely to have a higher EF than food produced organically but it is not clear by how much. 


\subsubsection{Food Processing}

The embodied processing energy required by the food industry was calculated using two different methods, which were then compared.

The first method uses the Energy and Economy report 1997-2006 (Statistics New Zealand, 2008a). This provides the energy intensity data of the various food industries in relation to 'value added'. Energy intensity is measured as the amount of energy (GJ) to produce $\$ 1,000$ of product or 'value added'. The energy consumed by New Zealanders is calculated using the money spent on various types of food per household, as provided by the Household Economic Survey (Statistics New Zealand, 2007c).

In 2007 NZ households spent an average of \$7,138.22 on groceries (excluding eating-out). The average household in 2006 consisted of 2.6 people (Statistics New Zealand, 2009b) giving a figure of $\$ 2,745.47$ per person spent on food and drinks. As much as $30 \%$ of this money went on buying processed foods, $14 \%$ on meat and poultry, $14 \%$ on alcohol, and $13 \%$ on fruit and vegetables (Statistics New Zealand, 2007c). Aligning the energy per $\$ 1,000$ spent on various food categories and the individual expenditure, the total energy intensity for the primary processing of food was an estimated 7.2GJ per person, whilst secondary processing totalled 11.4GJ per person. This gives a total of $18.6 \mathrm{GJ}$ per person in 2007 , which can be compared with the international average calorific intake of food for humans of $4.2 \mathrm{GJ}$ per person per year (Fisher \& Bender, 1975; Vale \& Vale, 2009b, p. 30). This shows that the food New Zealanders consume requires more than four times the energy to transport and process it than it provides when consumed.

In 2007, $21.5 \%$ of the energy for primary and secondary processing came from electricity, of which $33.3 \%$ was from a non-renewable source and $66.7 \%$ from renewables (Ministry of Economic Development, 2010a). The total land required for all the food processing needs of New Zealanders is therefore $435,624 \mathrm{ha}$, of which $44 \%$ is for the production of animal-based products and $56 \%$ for non-animal products.

The second method used to calculate the total energy for the primary and secondary production of food used a cumulative figure of the various food sectors provided in the Energy 
Efficiency and Conservation Authority (EECA) End-Use Database (EECA, 2007). The sectors selected for this research were 'retail trade - food', wholesale trade - food', 'other food processing', 'dairy products', slaughter and meat processing', and 'indoor cropping'. However, these figures provide summaries of the total energy for all food processed in NZ, rather than the food consumed by New Zealanders. The total food exported is considerable (New Zealand Trade \& Enterprise, 2012; Statistics New Zealand, 2011b), therefore additional calculations were required to clarify this. Using data from a range of sources (Dairy NZ, 2011; Ministry of Agriculture and Forestry, 2012; Plant and Food Research, 2008; Richard Paling Consulting, 2008; Statistics New Zealand, 2007b, 2008b), table 4.10 was created using the EECA sectors to provide a summary of the food grown in NZ that is exported and that consumed by New Zealanders.

Table 4.10: Food industry energy for export and internal consumption by food sectors in 2007

\begin{tabular}{|lcc|}
\hline \multicolumn{1}{|c}{ Sector } & Export total & NZ consumption \\
\hline Indoor cropping & $21 \%$ & $79 \%$ \\
\hline Other food processing sectors & $8 \%$ & $92 \%$ \\
\hline Slaughtering and meat processing & $85 \%$ & $15 \%$ \\
\hline Dairy products sector & $89 \%$ & $11 \%$ \\
\hline Retail trade - Food sector & $0 \%$ & $100 \%$ \\
\hline Wholesale trade - Food sector & $0 \%$ & $100 \%$ \\
\hline
\end{tabular}

Of the total food industry energy accounted for by EECA, only a small portion is consumed by New Zealanders. The NZ food industry requires 20.7 million GJ with an ecological footprint of 233,751 ha. Food transport including freight and business travel, less exports, requires $15,671 \mathrm{ha}$, which is subtracted and included in the food transport section (4.3.5). The remaining EF for the food industry energy is $63,982 \mathrm{ha}$, of which $82 \%$ is energy land. These figures should however be used with caution due to the lack of reliable data for production, imports and exports of food produced in NZ.

The EECA End-Use Database does not include fishing industry energy and this is calculated separately below. GFN data show that NZ produced 490,729 t of fish, imported $28,162 t$ and exported 315,738t (Global Footprint Network, 2011). According to the Energy and Economy 
Report (Statistics New Zealand, 2008a) the fishing industry required 7.1PJ of energy, of which only $2 \%$ was electricity (Statistics New Zealand, 2008a), making 14.47GJ/t of fish. New Zealand consumed 110,678 t of fish in 2007 , the equivalent of 73,785 ha of energy land. Therefore, adding this to the EECA figure above, New Zealanders required 137,767 ha of energy land.

There is a considerable difference between the total processing energy figures from method 1 and method 2. The total for method 1 was 435,624 ha, compared with 137,767 ha for method 2. Tracking money is not always a reliable way to track energy use because there is no clear way to ascertain the true spending on food by households, as this expenditure also includes GST and additional taxes. Method 1 is also based on averages rather than being based on totals as in method 2. As a result the EECA End-Use Database method was used for the total food EF calculations.

\subsubsection{Food Transportation}

As shown in table 4.11, in 2007 New Zealanders consumed $2.28 \mathrm{~kg}$ of food per day per person, totalling 3.64 million tonnes of food for the year. It is assumed that all this food is commercially grown and would have required transport. The following details the four stages of food transportation:

1. Transport used by the consumer to procure the food from the place of retail, described as household food travel;

2. National transport to move food either from a port to a distribution point, from the farm to a location for processing, and/or from processing to a distribution point. The food is then transported to a food wholesaler or retailer;

3. International transport for imported products from the exporting nation to a NZ port;

4. Transport from place of production to the international port via distribution agencies. Exported products travelling from NZ to another country are not included in the NZ EF.

\section{Household Food Travel}

The background data to produce the New Zealand Travel Survey (The New Zealand Road Safety Trust, 2006) were acquired to calculate the total trips made to purchase food. Of 
approximately 742 million shopping trips in 1998 (the most recent data), 28\% were in some part to do with food. Of these food-related trips, $83 \%$ were to dairies, supermarkets and convenience stores (herein called 'supermarket trips'), whilst the remaining $17 \%$ were to purchase convenience or 'eat-out' food.

It is assumed that one person shops for the household and the average NZ household is 2.6 people (Statistics New Zealand, 2009b). As calculated in section 4.3.9 New Zealanders consume $774.41 \mathrm{~kg}$ of food per year at home and $86.04 \mathrm{~kg}$ is eaten out. Therefore $(774.41 \mathrm{~kg} \times$ 2.6) $2,013.5 \mathrm{~kg}$ of food per household per year is bought from supermarkets.

Table 4.11: Energy and land required for all travel modes for food purchases in 1998

\begin{tabular}{|c|c|c|c|c|c|}
\hline Food shopping & $\begin{array}{l}\text { Energy } \\
\text { intensity }\end{array}$ & Supermarket & $\begin{array}{c}\text { Eating } \\
\text { out }\end{array}$ & Supermarket & $\begin{array}{c}\text { Eating } \\
\text { out }\end{array}$ \\
\hline & $\mathrm{MJ} / \mathrm{km}$ & GJ & GJ & NZha & NZha \\
\hline Vehicle driver & $3.95^{1}$ & $3,170,703$ & 649,421 & 21,138 & 4,329 \\
\hline $\begin{array}{l}\text { Vehicle } \\
\text { passenger }\end{array}$ & $1.98^{2}$ & 800,570 & 163,972 & 5,337 & 1,093 \\
\hline Walking & 0.9 & 34,114 & 6,987 & 227 & 47 \\
\hline Bus & 1.81 & 42,657 & 8,737 & 284 & 58 \\
\hline Bicycle & 0.38 & 2,173 & 445 & 14 & 3 \\
\hline Other & $4.51^{3}$ & 10,749 & 2,202 & 72 & 15 \\
\hline Total & N/A & $4,060,966$ & 831,764 & 27,073 & 5,545 \\
\hline
\end{tabular}

1. Average energy consumed for a NZ medium sized car.

2. The car is assumed to be carrying 2 people and therefore the $\mathrm{MJ} / \mathrm{km}$ figure is divided between the two occupants.

3. Average energy intensity for a motorbike, ferry and train.

The New Zealand Travel Survey (The New Zealand Road Safety Trust, 2006) provides information on the mode of travel and the average distance travelled for each mode. It is assumed these somewhat dated data are still relevant, though potentially the footprints are even larger in the present day, as the amount of personal travel is increasing (The New Zealand Road Safety Trust, 2006).

Supermarket trips totalled $172,464,040$ and eating-out trips totalled $35,323,960$. Car transport as a driver made up 53\% of all trips, travelling an average $9 \mathrm{~km}$ per trip. Car transport as a passenger was $23 \%$ of total trips at an average $10 \mathrm{~km}$ per trip. Walking an average of $1 \mathrm{~km}$ to the shop made up $22 \%$ of trips, whilst shopping by bus (travelling an average of $14 \mathrm{~km}$ ) only made up $1 \%$. Fewer trips were made by bike $(0.8 \%$ at $3 \mathrm{~km})$ and other (motorbike, ferry, train) 
$(0.3 \%$ at $5 \mathrm{~km})$. A total 1,537 million $\mathrm{km}$ were travelled in 1998 by all vehicle modes to purchase food, split between 1,276 million $\mathrm{km}$ to buy groceries and 261 million $\mathrm{km}$ to eat out (see table 4.11).

The energy intensity figures for the different transport types are shown in the transport section (section 4.4) and include both embodied and operational energy per km travelled. Table 4.11 shows NZ households required 27,073ha of energy land for trips to the supermarket and an additional 5,545ha to reach their eating-out destinations. The average household has 2.6 inhabitants and therefore each household had a food travel EF of 0.0201ha. Each tonne of food consumed in the home had a travel footprint of 0.010 ha.

\section{National Food Transport}

Food can travel a considerable distance before it reaches the retail centres. The following national food calculations include all the transport required to get food from farms, ports, processing plants and wholesale stores to retail outlets. For the energy of the international transport connected with food imports, two methods are compared: the EECA End-Use Database results, and a bottom-up transport calculation by Richard Paling Consulting.

From the EECA End-Use Database calculations, the total food transport portion of 'processing energy' was 15,091ha of energy land. However, the specific data used to carry out the EECA calculations is not available for closer examination of distances travelled and tonnage carried. Therefore a bottom-up approach to calculating the total ecological footprint of national food transportation was carried out.

In 2008 freight research was commissioned by the Ministry of Transport, the New Zealand Transport Agency and Ministry of Economic Development from Richard Paling Consulting (2008). Their report provides an analysis of food freight patterns that was used to create table 4.12 The table provides a breakdown of the distances travelled by different food categories by mode, the amount of each food category consumed within NZ (see table 4.10), and the resulting EF of national food travel. 
Table 4.12: The EF of transport of food products within NZ in 2007

\begin{tabular}{|c|c|c|c|c|}
\hline \multicolumn{2}{|c|}{ National food transport } & $\begin{array}{l}\text { Total freight in tonne- } \\
\text { kilometers }^{1}\end{array}$ & $\begin{array}{l}\text { National } \\
\text { consumption }\end{array}$ & NZ EF \\
\hline & & tkm (million) & $\%$ & NZha \\
\hline \multirow[b]{2}{*}{ Horticulture } & Rail $^{3}$ & 77 & $86 \%$ & 313 \\
\hline & Road $^{3}$ & 1,023 & $86 \%$ & 17,126 \\
\hline \multirow{2}{*}{$\begin{array}{l}\text { Milk and dairy } \\
\text { products }\end{array}$} & Rail $^{3}$ & 428 & $11 \%$ & 223 \\
\hline & Road $^{3}$ & 1,473 & $11 \%$ & 3,153 \\
\hline \multirow[b]{2}{*}{ Livestock and meat } & Rail $^{3}$ & 129 & $15 \%$ & 92 \\
\hline & Road $^{3}$ & 471 & $15 \%$ & 1,375 \\
\hline $\begin{array}{l}\text { Supermarket and } \\
\text { other food }\end{array}$ & Road $^{3}$ & 1,380 & $100.00 \%$ & 26,864 \\
\hline \multicolumn{2}{|l|}{ Total } & 5,273 & $n / a$ & 49,146 \\
\hline
\end{tabular}

1. Freight data from Richard Paling Consulting (2008)

2. Various sources for export and import detail (see table 4.10)

3. Road transport in NZ calculated using $2.92 \mathrm{MJ} / \mathrm{tkm}$ and rail using $0.72 \mathrm{MJ} / \mathrm{tkm}$ (Vale \& Vale, 2009b, p. 43)

In 2007 NZ required 49,146ha of energy land to assimilate the $\mathrm{CO}_{2}$ created by national food transport. In comparison, the EECA Database results showed a national food freight transport footprint of 15,670ha, possibly because of EECA's use of different energy conversions for types of transport. The calculations in table 4.12 are used for the total food transport EF. They are preferred due to the additional level of detail and the inclusion of freight by train which is not expressly included in the EECA calculations.

\section{International Transport}

NZ imports foreign food for use in manufacturing of NZ products and for sale directly to wholesale and retail. The total food imported into NZ was calculated and the different modes of transport for this considered. Three sources of data were compared.

The first calculation used an estimate of the annual expenditure in supermarkets and other food outlets (Richard Paling Consulting, 2008, pp. 92-93) compared to annual expenditure on imports (Statistics New Zealand, 2011b). It showed that $21 \%$ of all food bought in NZ was imported. FAO data in section 4.3.1 showed New Zealanders consumed 3.64 million tonnes of food in $2007.21 \%$ of this is $764,028 \mathrm{t}$ of imported food. The second dataset was FAOTrade figures which showed that, in 2007, NZ imported 2.27 million tonnes of 'crops and livestock products' (FAOSTAT, 2007). The third calculation used the Richard Paling (2008) freight case 
study with its estimate of 2.5 million tonnes of primary products. These figures are significantly higher than the supermarket expenditure case study above.

Neither the FAOSTAT nor the Richard Paling Freight figures provide the information needed to ascertain the amount of food which is both imported and consumed by New Zealanders, as some imports used for manufacturing are then exported or used in non-food products and services. Consequently this research will use the supermarket expenditure estimate of 764,028 t of imported food consumed in NZ, although more research is required to verify this result.

The International trade, investment and travel profile, published each year by the Ministry of Foreign Affairs and Trade and Statistics New Zealand (2011b), was used to estimate the amount of consumer goods which travelled from the exporting country to NZ and these were multiplied by the distance $(\mathrm{km})$ travelled to give total tonne-kilometres $(\mathrm{tkm})$ for food imported to NZ in 2007 . The majority (98.86\%) of commodities are transported by container ship (Richard Paling Consulting, 2008). Shipping freight only accounts for $0.12 \mathrm{MJ} / \mathrm{tkm}$ (IMO Library Services, 2006). However, $1.14 \%$ of horticultural commodities are imported by air (Richard Paling Consulting, 2008) using 9.7MJ/tkm (Vale \& Vale, 2009b, p. 43), almost doubling the imports transport EF/person (table 4.13).

Table 4.13: EF and energy land of imported food transport to NZ

\begin{tabular}{|lcccr|}
\hline \multirow{2}{*}{ International transport } & \multirow{2}{*}{ Food imports } & Distance and weight & Transport energy & NZ EF \\
\cline { 2 - 5 } & tonnes & tkm & GJ & NZha \\
\hline Container ship & $\mathbf{7 5 5 , 3 1 8}$ & $5,788,032,580$ & 694,564 & 4,630 \\
\hline Air freight & 8,710 & $66,744,458$ & 647,421 & 4,316 \\
\hline Total & $\mathbf{7 6 4 , 0 2 8}$ & $\mathbf{5 , 8 5 4 , 7 7 7 , 0 3 8}$ & $\mathbf{1 , 3 4 1 , 9 8 5}$ & $\mathbf{8 , 9 4 7}$ \\
\hline
\end{tabular}

NZ's EF for imported food transport is an estimated 8,947ha of energy land or an average 0.0117ha/t.

\section{Production to Port}

Imported food products also travel from the farm or factory where they were produced to a port for dispatch. NZ imports 764,028 t of food from a variety of countries. Of all imported primary and processed food products, $46.5 \%$ and $43.4 \%$ respectively are from Australia. A 
large portion of Australian primary products are produced in the Murray Darling Basin (Strudwick, 2012). The majority of all domestic transport of foods in Australia (excluding Tasmania) involves road travel in rigid and articulated trucks (Gaballa \& Abraham, 2007). A case study detailing the food miles for a basket of food purchased in Melbourne was used for the following calculation. Data from Gaballa and Abraham (2007) show the average distance that Australian-grown produce travels is $878.28 \mathrm{~km}$. The emissions for an average truck transporting one tonne of food are $0.00022 \mathrm{t}$ of $\mathrm{CO}_{2}$-equivalent. Assuming these figures represent production-to-port travel for all imported food to NZ, this totals $147,960+\mathrm{CO}_{2}-\mathrm{e}$, giving an EF of 14,227ha. This again, is an area of further investigation.

\section{Total food transport EF}

The total NZ food transport EF for 2007 was 95,825ha of energy land, of which $28 \%$ was for households travelling to retail stores to buy food, $49 \%$ was for food transport within NZ, $9 \%$ was for transport from an international port to NZ, and $14 \%$ was to get goods from the point of production to an international port (table 4.14).

Table 4.14: Summary of EF of food transport in 2007

\begin{tabular}{|lcc|}
\hline \multirow{2}{*}{ Food transport } & NZ EF & Portion \\
\cline { 2 - 3 } & NZha & $\%$ \\
\hline Household transport & 27,073 & 28 \\
\hline National transport & 49,146 & 49 \\
\hline International transport & 8,947 & 9 \\
\hline Production to port & 14,227 & 14 \\
\hline Total & $\mathbf{9 9 , 3 9 3}$ & n/a \\
\hline
\end{tabular}

The results in table 4.14 are of interest given international food miles debates. Moving food between other nations and NZ creates the smallest portion of the food transport EF. In comparison, moving food around NZ by truck is half the food transport EF and shopping for food is a quarter of it. This suggests the emphasis should be on national rather than international food miles. The findings also highlight that Saunders et al. (2006) 'food miles' research should have included the transport required within NZ by NZ's export products. 


\subsubsection{Food Premises}

Food premises include all buildings used for the distribution and retail of food. Buildings for the cooking and serving of food will be included in 'eating out' (section 4.3.9). The following calculations include the physical space as well as the embodied energy of the construction, maintenance, demolition and disposal of these buildings. The operational energy of buildings required for the processing of food was included in section 4.3.4, although their embodied energy has not been included in these calculations.

Data detailing the floor area of buildings for the sale of food and drink could not be located. The following is therefore an estimate only. Omissions from these figures are the local 'kiwi' dairy and numerous liquor stores, due to lack of data. However, although these outlets are numerous, they are small and their overall impact is probably not high. These calculations also exclude distribution warehouses and wholesalers, dairies, organic food stores, and mixed use department stores such as The Warehouse, which stocks some food items. Land consumed by household kitchens is also not included, as this is part of the house footprint and is accounted for in the household section (4.8).

\section{Consumed Land}

The consumed land ecological footprint is an estimate of the physical land for buildings used to sell food. Data for this specific type of building were limited and the following calculations are based on store numbers and sizes from data on the internet.

The total land required by NZ's supermarkets (the majority) is only 143 hectares. Although further research would be needed, these low numbers suggest that it would not significantly increase the total consumed land. 
Table 4.15: Consumed land required by NZ supermarkets

\begin{tabular}{|c|c|c|c|}
\hline \multirow{2}{*}{ Supermarkets and food stores } & Number of stores & Average store size & Total area \\
\hline & buildings & $m^{2}$ & NZha \\
\hline Countdown ${ }^{1}$ & 133 & 4,200 & 55.86 \\
\hline Foodtown ${ }^{1}$ & 7 & 3,000 & 2.10 \\
\hline New World ${ }^{1}$ & 132 & 2,800 & 36.96 \\
\hline Pak'n'Save $^{1}$ & 45 & 4,000 & 18.00 \\
\hline Woolworths ${ }^{1}$ & 25 & 2,800 & 7.00 \\
\hline Woolworths Quickstop ${ }^{1}$ & 22 & 250 & 0.55 \\
\hline Bin $\ln n^{2}$ & 32 & 250 & 0.80 \\
\hline Four Square 3 & 300 & 250 & 7.50 \\
\hline Supervalue 4 & 52 & 2,800 & 14.56 \\
\hline Total & 748 & N/A & 143.33 \\
\hline
\end{tabular}

1. Supermarket data gathered from Wikipedia pages.

2. Binn Inn Website (Bin Inn, 2010).

3. Four Square Website (FoodStuffs, 2005).

4. SuperValue website (Wholesale Distributors Ltd, 2011).

\section{Energy Land}

Food technology has created a range of methods for storing, preparing and cooking food. Food retail and wholesale premises require energy for their everyday operation and for the embodied energy of the building's construction, maintenance, demolition and disposal (embodied energy). Household kitchens also expend energy on the storage, preparation and cooking of food. The following is a discussion of the energy requirements of both food retail and household kitchens. A summary of the calculations for NZ retail premises is in table 4.16.

\section{Food Retail Energy}

The initial embodied energy of buildings relates to the embodied energy of the materials used, the construction process, and the transportation of materials to the site. From the calculations above, food-related buildings have a floor area of $1,433,300 \mathrm{~m}^{2}$. The embodied energy intensity of the construction of a warehouse or industrial building is $3.4 \mathrm{GJ} / \mathrm{m}^{2}$ (CSIRO, 1998, p. 125; Lawson, 1995; Lukaszyk, n.d.). Assuming the life of a retail building is 50 years, the construction energy for food-related buildings is 4.9 million GJ over 50 years, with an EF of $1,083 \mathrm{ha} /$ year.

Australian calculations suggest construction makes up $60 \%$ of total embodied energy over the life-cycle of a house, maintenance is $34 \%$ of the total, and transport, demolition and disposal 
make up the remaining $6 \%$ (CSIRO, 1998, p. 126). This split is similar to that used in the household section (section 4.8) (although the latter is from different sources).

Given that total area of food retail buildings is $1,433,300 \mathrm{~m}^{2}$, a summary of the energy required for the construction, maintenance, demolition and disposal of food retail buildings is shown in table 4.16. This sums to an energy EF per year of 1,083ha of energy land.

Table 4.16: Embodied energy of food retail premises (construction, maintenance, demolition and disposal)

\begin{tabular}{|lccc|}
\hline \multirow{2}{*}{ Embodied Energy } & Embodied energy (50 years) & Total energy (1 year) & NZ EF \\
\cline { 2 - 4 } & GJ & GJ & NZha \\
\hline Construction & $\mathbf{4 , 8 7 3 , 2 2 0}$ & 97,464 & 650 \\
\hline Maintenance & $2,761,491$ & 55,230 & 368 \\
\hline Demolition and disposal & 487,322 & 9,746 & 65 \\
\hline Total & $\mathbf{8 , 1 2 2 , 0 3 3}$ & $\mathbf{1 6 2 , 4 4 1}$ & $\mathbf{1 , 0 8 3}$ \\
\hline
\end{tabular}

After construction the building requires energy to run equipment such as refrigerators, office equipment, heating, cooling and lighting. The EECA 'Energy End-Use Database' (EECA, 2007) also provides guidance for the energy used in the operation of food-related buildings, separating the data into food wholesale and food retail. The total energy was $6,821,366 \mathrm{GJ}$ for retail buildings and 557,894GJ for wholesale, making the total land required for operating these premises 26,398 ha, $23 \%$ of which is consumed land. It is not clear from the EECA information if the 'retail - food sector' includes buildings for 'eating out', so additional calculations for eating-out buildings were carried out (section 4.3.9).

\section{Kitchen Energy}

The Household End-Use Energy Project (HEEP) (Isaacs et al., 2010) examined how NZ households used energy in the home and provides detail about energy used in relation to food. As shown in figure 4.4, HEEP found $20 \%$ of average electricity use was for 'other appliances' and $15 \%$ for refrigeration. These 'other appliances' include entertainment such as computer games and spa pools, laundry appliances, phone chargers and alarm clocks.

It is assumed here that food storage and cooking accounted for $20 \%$ of all energy used in an average NZ household (5.21GJ/year). Using 2.6 people per household (Statistics New Zealand, $2009 \mathrm{~b}$ ) gives $1,626,269$ households. The total EF for kitchen energy is $18,002 \mathrm{ha}, 23 \%$ of which 
is consumed land. The remaining $80 \%$ of household energy not used for cooking, preparing and storing food (22.47GJ per household) is included in the section on household energy (section 4.7).

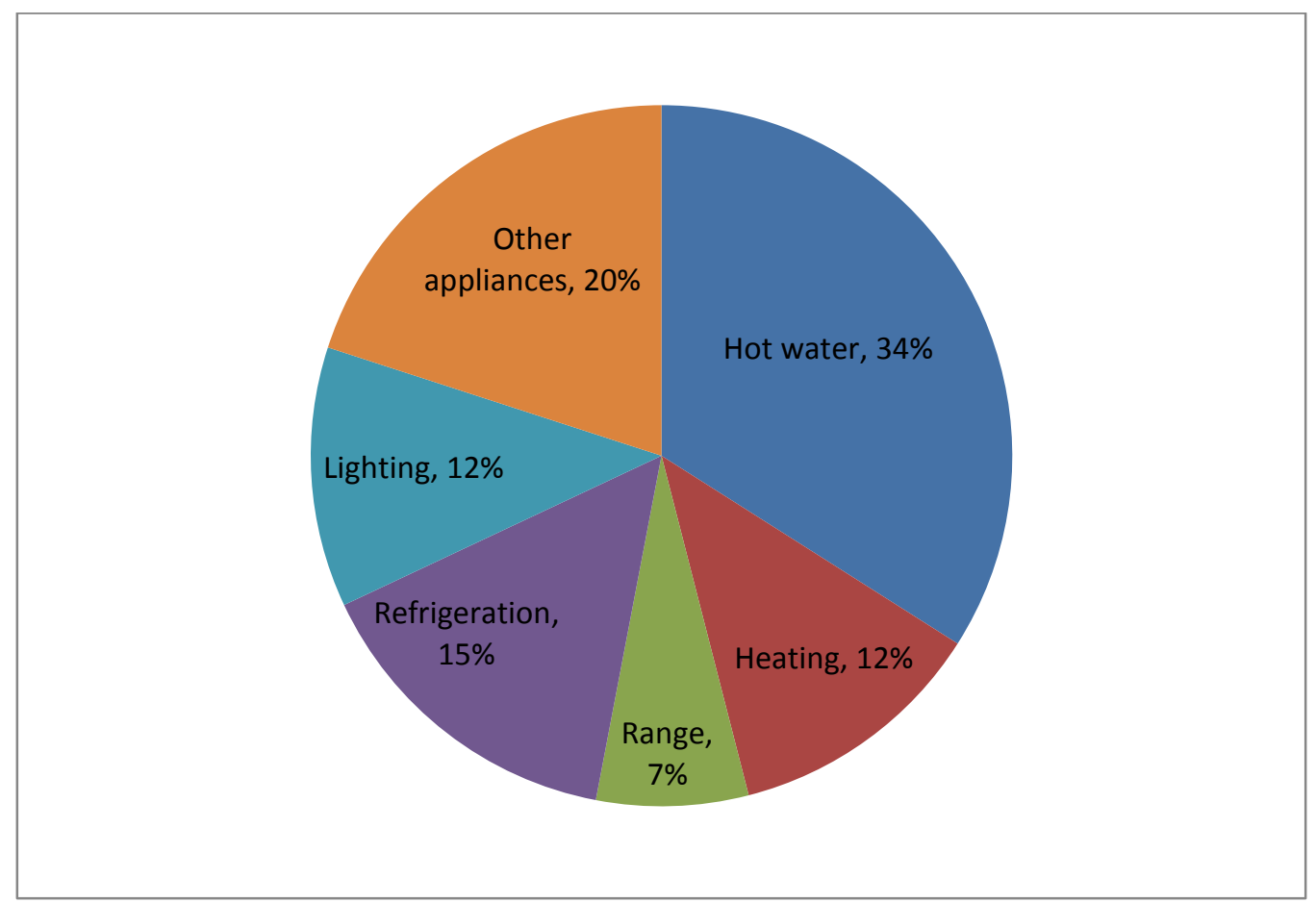

Figure 4.4: Distribution of electricity uses in NZ households (Isaacs et al., 2010, p. 9).

\subsubsection{Food Packaging}

Packaging is required 'to preserve and protect products' (PCNZ, 2009). One international study found the loss of foodstuffs between grower and consumer is $2 \%$ in the developed world and up to $33 \%$ in the developing world, the difference largely due to packaging. Packaging requires resources for its production and energy, and land for its disposal to landfill or recycling. The following sections explore the three types of land required for food packaging: forest land required for trees for paper and cardboard; energy land for making plastics and the embodied energy in packaging such as aluminium cans and paper; and consumed land associated with the use of electricity in making packaging.

\section{Forest land}

Calculating the forest land EF for food packaging requires the following data: the amount of paper and card consumed; the land to grow the trees for paper-making; and the yield per tree. 
There are a number of estimates regarding the annual NZ paper consumption (COVEC, 2007; FAOSTAT, 2007; PCNZ, 2009). These range from 99,625t to 793,537t. Another calculation from FAOSTAT (2007) states the total paper consumed (produced + imported - exported) in NZ was $758,200 t$. This is probably the most reliable top-down measure for paper consumed in NZ across all industries. The Canberra case study (CSIRO, 1998), although dated, states that $54 \%$ of all paper products are in some way associated with food. Using this figure, NZ uses $409,428 \mathrm{t}$ of food-related paper each year, with the remaining $348,772 t$ for other consumer products.

Calculations show that 0.2092 ha of forest land is required per tonne of paper (New Zealand Forest Industries Council, 2010; Paper Round, 2010; RPBC, 2003). Some 409,428t of paper are used in the food packaging industry, or $0.1125 t$ for every tonne of food consumed. The EF of food packaging is 85,652 ha of forest land. Lee et al. (2010) estimate that $17 \%$ of all food packaging is for food eaten out, totalling 14,561 ha.

\section{Energy and Consumed Land}

Due to a lack of data for non-paper food packaging, figures for packaging waste are used to represent non paper based packaging. These are only an estimate as some packaging may be lost from the system before it is counted as waste. Four references were used to create an EF for packaging materials (Alcorn, 2003; G. Hammond \& Jones, 2011; Oswald, 2011; Reddy \& Jagadish, 2002). Unfortunately only the Oswald (2011) case study had estimates for plastics, finding these were $12 \%$ of the total energy from four packaging types (aluminium, glass, plastic and steel). Hammond and Jones (2011) give an EF of 43,807ha across all four packaging types. COVEC (2007) break down packaging waste into $29 \%$ household and $71 \%$ nonresidential. Using this gives 12,704 ha of residential food packaging and 31,103ha of nonresidential. Of the non-residential packaging, $17 \%(5,288 \mathrm{ha})$ came from eating out (Lee et al., 2010).

\subsubsection{Organic and Packaging Food Waste}

In $2007 \mathrm{NZ}$ produced 493,147t of organic food waste (section 4.2.3) and 225,042t of food packaging waste which went to landfill, totalling 718,189 t. Food eaten-out is subtracted, leaving 596,097t. Section 4.2.4 calculated an additional 549,318t of recycled waste. Again subtracting the $17 \%$ for eating out (Lee et al. 2010) leaves 455,934 t of recycled food related 
waste. Summing the landfill and recycled food-related waste gives a total of $1,052,031 \mathrm{t}$. Note that recycled organic waste has not been included due to its extremely low EF (Vale \& Vale, 2009b, pp. 68-69). Waste produced whilst eating out is included in section 4.2.9.

Table 4.17: Summary of food-related waste from 2007

\begin{tabular}{|lccccccc|}
\hline \multirow{2}{*}{ Food waste } & $\begin{array}{c}\text { Recycled } \\
\text { waste }\end{array}$ & $\begin{array}{c}\text { Landfill } \\
\text { waste }\end{array}$ & $\begin{array}{c}\text { Total } \\
\text { waste }\end{array}$ & $\begin{array}{c}\text { Consumed } \\
\text { land }\end{array}$ & $\begin{array}{c}\text { Energy } \\
\text { land }\end{array}$ & $\begin{array}{c}\text { NZ } \\
\text { tonnes }\end{array}$ \\
\cline { 2 - 8 } & tonnes & tonnes & NZha & \multicolumn{2}{|c|}{ NZha } & NZha \\
\hline $\begin{array}{l}\text { Organic } \\
\text { waste }\end{array}$ & & 493,147 & 493,147 & 379 & 569 & 948 \\
\hline $\begin{array}{l}\text { Packaging } \\
\text { waste }\end{array}$ & 549,318 & 225,042 & 774,360 & 274 & 791 & 1,065 \\
\hline Sub-total & $\mathbf{5 4 9 , 3 1 8}$ & $\mathbf{7 1 8 , 1 8 9}$ & $\mathbf{1 , 2 6 7 , 5 0 7}$ & $\mathbf{6 5 4}$ & $\mathbf{1 , 3 6 0}$ & $\mathbf{2 , 0 1 4}$ \\
\hline Eating out & $\mathbf{9 3 , 3 8 4}$ & 122,092 & $\mathbf{2 1 5 , 4 7 6}$ & 183 & 231 & 414 \\
\hline Total & $\mathbf{4 5 5 , 9 3 4}$ & $\mathbf{5 9 6 , 0 9 7}$ & $\mathbf{1 , 0 5 2 , 0 3 1}$ & $\mathbf{4 7 1}$ & $\mathbf{1 , 1 2 9}$ & $\mathbf{1 , 6 0 0}$ \\
\hline
\end{tabular}

The consumed land EF of landfill waste in NZ is $8 \mathrm{~m}^{2} / \mathrm{t}$ (MfE, 2009a) and is $11 \mathrm{~m}^{2} / \mathrm{t}$ for energy land (Barrett \& Simmons, 2003). The NZ recycling conversion factor for consumed land is approximately $1 \mathrm{~m}^{2} / \mathrm{t}$ and is $10 \mathrm{~m}^{2} / \mathrm{t}$ for energy land (Barrett \& Simmons, 2003). Using these conversions, the EF of non-recycled organic waste was 379ha of consumed land and 569ha of energy land. The EF of packaging waste for both landfill and recycling was 274 ha of consumed land and 791ha of energy land. The approximate EF of total household and non-residential food-related waste to landfill was $1,600 \mathrm{ha}, 71 \%$ of which is energy land.

\subsubsection{Food Eaten Out}

The NZ food service industry generates \$14 million in sales on a typical day (RANZ, 2008). Between 2002 and 2007, restaurant industry sales increased 46\% from \$3,466 million to $\$ 5,062$ million (RANZ, 2008). Restaurants, cafes and take-away food services occupy $44 \%$ of the ready-to-eat foods industry (RANZ, 2008), with the rest in food preparation, which have been accounted for in section 4.3.3. There is growing literature on the effects of fast-food advertising (Hammond, Wyllie, \& Casswell, 1999) and fast-food (Utter et al., 2007) on the health of New Zealanders, although the environmental impact of this growth industry do not seem to have been monitored. 
The EF of 'eating out' includes the land for the physical buildings for food preparation and dining out, the waste associated with building them, and their operating and embodied energies.

\section{Cardiff Case Study}

As discussed earlier (section 4.3.1) the figures for total food consumed by the Welsh are very different from the NZ estimates. Conversely, the Cardiff Footprint Project (Collins \& Flynn, 2005 ) is one of the few case studies that investigates the EF of eating out in detail. Table 4.18 (Collins \& Flynn, 2005, p. 25) shows that annually, each Cardiff resident consumed $675.46 \mathrm{~kg}$ of food, with $67.04 \mathrm{~kg}(10 \%)$ eaten outside the home.

Table 4.18: EF of food for average Cardiff resident

\begin{tabular}{|lccc|}
\hline \multirow{2}{*}{$\begin{array}{c}\text { Cardiff food } \\
\text { comparison }\end{array}$} & Food weight & Food EF & EF by weight \\
\cline { 2 - 4 } & $\mathrm{kg}$ & gha/cap & gha/kg \\
\hline Eaten in & 608.42 & 0.429 & 0.0007 \\
\hline Eaten out & 67.04 & 0.886 & 0.0132 \\
\hline Total & $\mathbf{6 7 5 . 4 6}$ & $\mathbf{1 . 3 1 5}$ & N/A \\
\hline
\end{tabular}

Table 4.18 shows that EF of food eaten out is almost $95 \%$ higher than the food eaten in. These conversions are not directly transferable to NZ because they are calculated in global rather than local hectares. In the Cardiff study food eaten out was $32.4 \%$ of the total food EF although only $10 \%$ of the food (Collins et al., 2005, p. 32). Two reasons were given for the higher EF of food eaten out:

1. The EF of catering is high because it takes account of all energy and material flows associated with the service, for example the whole infrastructure of a restaurant (Barrett et al., 2005).

2. When people eat out they consume different types of food from what they eat at home, often with a substantially higher EF (seafood or animal products).

In the Cardiff Footprint Project, the production of food eaten out caused $98.3 \%$ of the increased impact compared with food eaten in (Collins et al., 2005, p. 32). 


\section{NZ's Eating Out Food EF}

This section investigates the reason for the much higher EF of eating out and whether this applies to NZ.

NZ households spend $\$ 9,636.08$ per year on food, of which $80 \%$ is spent on groceries and $20 \%$ on eating out at restaurants and cafes (Statistics New Zealand, 2007c). Assuming restaurant and take-out food is approximately double the price of groceries, only $10 \%$ of all food is eaten out. (The cost of $300 \mathrm{~g}$ of hot chips in a NZ 'fish and chips' shop is $\$ 3.00$ ( $\$ 1 / 100 \mathrm{~g}$ ) whilst a $1 \mathrm{~kg}$ bag of fries at the supermarket is $\$ 5.00(\$ 0.5 / 100 \mathrm{~g})$. The hot chips from a take-away are twice the price for the added convenience. This is the same as found in the Cardiff case study.

New Zealanders consumed 3.6 million tonnes of food in 2007. Assuming the Cardiff split applies to NZ, $10 \%$ of the total food is $363,823 \mathrm{t}$ or $86.05 \mathrm{~kg} /$ person. It is rational to assume that this food would require $10 \%$ of the total land previously calculated as growing land $(552,338 \mathrm{ha})$, industry energy $(13,777 \mathrm{ha})$ and national, international and production to port transport $(7,232 \mathrm{ha})$. The household transport for eating out was 5,545ha (table 4.11). As discussed in section 4.2, food waste associated with eating out is $17 \%$ of all food-related packaging and waste, totalling $20,262 \mathrm{ha}$. The EF of food that is eaten out is therefore $599,155 \mathrm{ha}$. This leaves the eating-out EF from the construction and operation of the related buildings. A summary of figures relating to food eaten out in NZ is in table 4.19.

Buildings for eating out require physical land (consumed land). In 2007 NZ had 11,640 food service industry outlets (RANZ, 2008). Of these 64\% were restaurants and cafes, coffees houses and caterers, $20 \%$ were fish and chips, ethnic food, hamburger and chicken takeaways, $14 \%$ were lunch bars, ice-cream parlours, and vendors and other takeaways, and $2.5 \%$ were pizza takeaways. Average building sizes were ascribed to each type of outlet to give a total 289ha of consumed land.

Section 4.2.3 gives $28 \mathrm{~kg}$ of C\&D waste for every square metre of new housing, and this is assumed to apply to small scale commercial buildings. As previously noted, in 2007, 2.89 million $\mathrm{m}^{2}$ of floor space was used for eating out, creating C\&D waste from construction and demolition of $817,413 t$ to landfill. Assuming a 50 year lifespan makes a waste total of 
$16,348 \mathrm{t} /$ year. The C\&D waste conversion factor is of $5 \mathrm{~m}^{2} / \mathrm{t}$ (MfE, 2009a). Therefore C\&D waste from buildings for eating out account for 8ha of consumed land and 12ha of energy land, totalling $20 \mathrm{ha}$.

The calculations for the construction, maintenance, demolition and disposal of eating-out premises are the same as those used for the retail premises in section 4.3.6. The total embodied energy of all buildings for eating out in NZ is 28.9 million GJ over 50 years, giving an ecological footprint of 3,853ha/year.

Footprint results from top-down and bottom-up approaches were compared to find a footprint for the operation of buildings used for eating out. The first three studies (Statistics New Zealand, 2007c, 2008a, 2009a) offered top-down approaches to calculating the ecological footprint of such buildings, but the results were inconsistent. A bottom-up approach using energy per $\mathrm{m}^{2}$ was used as a compromise. Becken et al. (2001, p. 377) report that backpacker accommodation uses $617 \mathrm{MJ} / \mathrm{m}^{2}$ per year whereas warehouse space uses $1,048 \mathrm{MJ} / \mathrm{m}^{2}$ per year (Bannister et al.,1998). Backpacker accommodation is assumed to be an underestimate as a restaurant will probably have more electrical products such as large fridges; however without additional information the backpacker figure is used here. The estimated 2.89 million square metres of eating out premises require $1,785,771 \mathrm{GJ}$ of electricity per year or 5,143ha ( $23 \%$ consumed land) and in addition to the physical land and embodied energy totals 9,299ha (table 4.19).

Table 4.19: Eating out food footprint

\begin{tabular}{|c|c|c|c|c|c|c|c|}
\hline \multirow{2}{*}{ Component } & Crop & Grazing & Fishing & Forest & Consumed & Energy & NZ EF \\
\hline & NZha & NZha & NZha & NZha & NZha & NZha & NZha \\
\hline Growing & 41,226 & 129,416 & 370,017 & & 230 & 11,449 & 552,338 \\
\hline Industry energy & & & & & 1,161 & 12,615 & 13,776 \\
\hline Transport & & & & & & 12,777 & 12,777 \\
\hline Waste & & & & & 183 & 231 & 414 \\
\hline Packaging & & & & 14,561 & & 5,288 & 19,848 \\
\hline Dining premises & & & & & 1,473 & 7,826 & 9,299 \\
\hline Total & 41,226 & 129,416 & 370,017 & 14,561 & 3,049 & 50,190 & 608,460 \\
\hline & otal food & per year & & & & & $363,823 t$ \\
\hline
\end{tabular}

The total EF for food eaten out in NZ in 2007 is 608,460 ha, $90 \%$ of which is land growing the food. Transport and packaging were the next largest components. The EF of food eaten out 
in NZ is approximately $1.67 \mathrm{ha} / \mathrm{t}$ of food consumed. The footprint for food eaten at home was recalculated subtracting the components in the eating-out calculations. The total EF for food eaten in was $5,338,815 \mathrm{ha}$, equivalent to $1.63 \mathrm{ha} / \mathrm{t}$ of food. A further breakdown of the differences between the eating out and eating in is shown in table 4.20.

Table 4.20: Comparison of the EF of food eaten in and food eaten out

\begin{tabular}{|c|c|c|c|}
\hline \multirow{2}{*}{ Component } & Eating in & Eating out & Difference \\
\hline & NZha/t & NZha/t & \\
\hline Growing & 1.5182 & 1.5182 & 0.0000 \\
\hline Packaging & 0.0335 & 0.0546 & 0.0211 \\
\hline Industry energy & 0.0379 & 0.0379 & 0.0000 \\
\hline Transport & 0.0281 & 0.0351 & 0.0070 \\
\hline Buildings & 0.0159 & 0.0256 & 0.0097 \\
\hline Waste & 0.0006 & 0.0011 & 0.0005 \\
\hline Total & 1.6341 & 1.6724 & 0.0383 \\
\hline
\end{tabular}

Further analysis of table 4.20 shows that the EF values are very similar for eating in and eating out. This gives little support to the Cardiff study's claim that food eaten out has a considerably higher ecological footprint, because of the premises required to cook the food (Collins \& Fairchild, 2007, p. 16). The much larger ecological footprint for buildings in Cardiff could be affected by the lower energy-to-land ratio used for calculating footprints in the United Kingdom and by the climate. Additional research is needed to determine the difference in ecological footprint of the food itself when eaten out.

\subsubsection{Total Food and Drink Footprint}

The NZ food EF is $5,946,746$ ha. There are numerous steps in the food footprint map, many of which are very complicated due to the movement of food both within NZ and internationally. Of the total EF, $91 \%$ is required for the physical land to grow the food, and an additional $2 \%$ for the on-farm embodied energy needed to produce the food. A summary of the food EF for 2007 is presented in table 4.21.

As mentioned above, fishing land substantially skews the NZ food and drink EF. Arguably fishing land could be subtracted as, unlike farmland, fishing land is not used exclusively for producing fish for the table. Fishing land has been subtracted from the results in figure 4.5, where $57 \%$ of the food footprint is now in grazing land, $18 \%$ in crop land and $20 \%$ in energy 
land. The remainder is distributed between forest and consumed land. Crop and grazing land form a combined $75 \%$ of the food EF.

Table 4.21: Total EF associated with food

\begin{tabular}{|c|c|c|c|c|c|c|c|}
\hline \multirow{2}{*}{ Component } & Crop & Grazing & Fishing & Forest & Consumed & Energy & NZ EF \\
\hline & NZha & NZha & NZha & NZha & NZha & NZha & NZha \\
\hline Growing & 412,264 & $1,294,161$ & $\begin{array}{c}3,700 \\
167\end{array}$ & & 2,296 & 114,490 & $5,523,378$ \\
\hline Packaging & & & & 85,652 & & 43,807 & 129,460 \\
\hline $\begin{array}{l}\text { Industry } \\
\text { energy }\end{array}$ & & & & & 11,613 & 126,154 & 137,767 \\
\hline Transport & & & & & & 104,938 & 104,938 \\
\hline Buildings & & & & & 11,807 & 43,123 & 54,930 \\
\hline Waste & & & & & 654 & 1,501 & 2,155 \\
\hline Total & 412,264 & $1,294,161$ & $\begin{array}{c}3,700, \\
167\end{array}$ & 85,652 & 26,369 & 434,013 & $5,952,627$ \\
\hline & food per & & & & & & $3,638,228$ \\
\hline
\end{tabular}

Figure 4.6 shows the distribution of the food EF if the physical grazing, crop and fishing land are subtracted. Industry energy has the largest footprint of 137,767 ha, comprising $25 \%$ of the non-growing land categories. Next is packaging at 129,460 ha (23\%), then on-farm energy with a footprint of 116,785 ha (21\%). Transport, food premises and waste are 104,938ha (19\%), 61,388ha (11\%) and 2,155ha (<1\%), respectively.

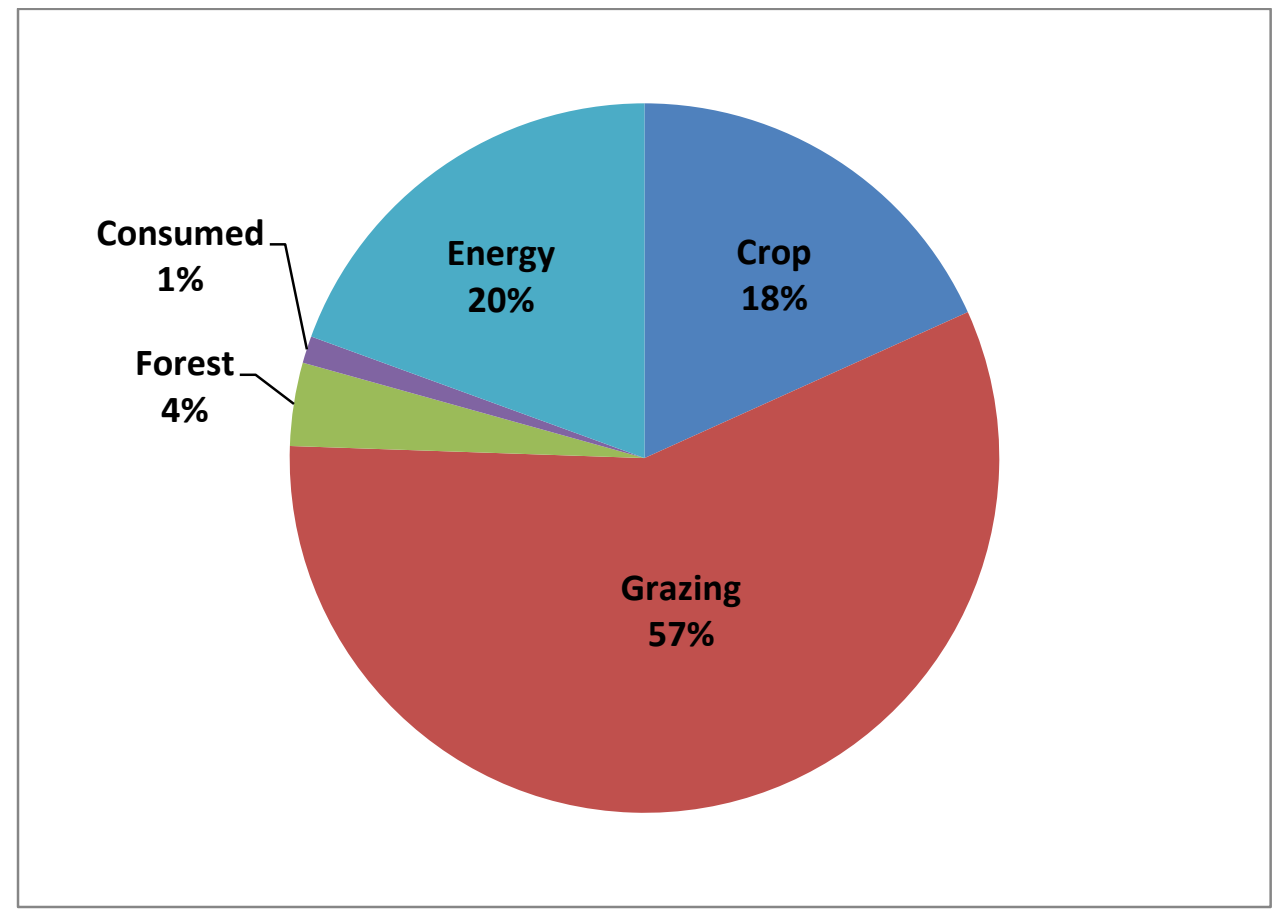

Figure 4.5: Distribution of land types (minus fishing land) in NZ's 2007 food EF. 


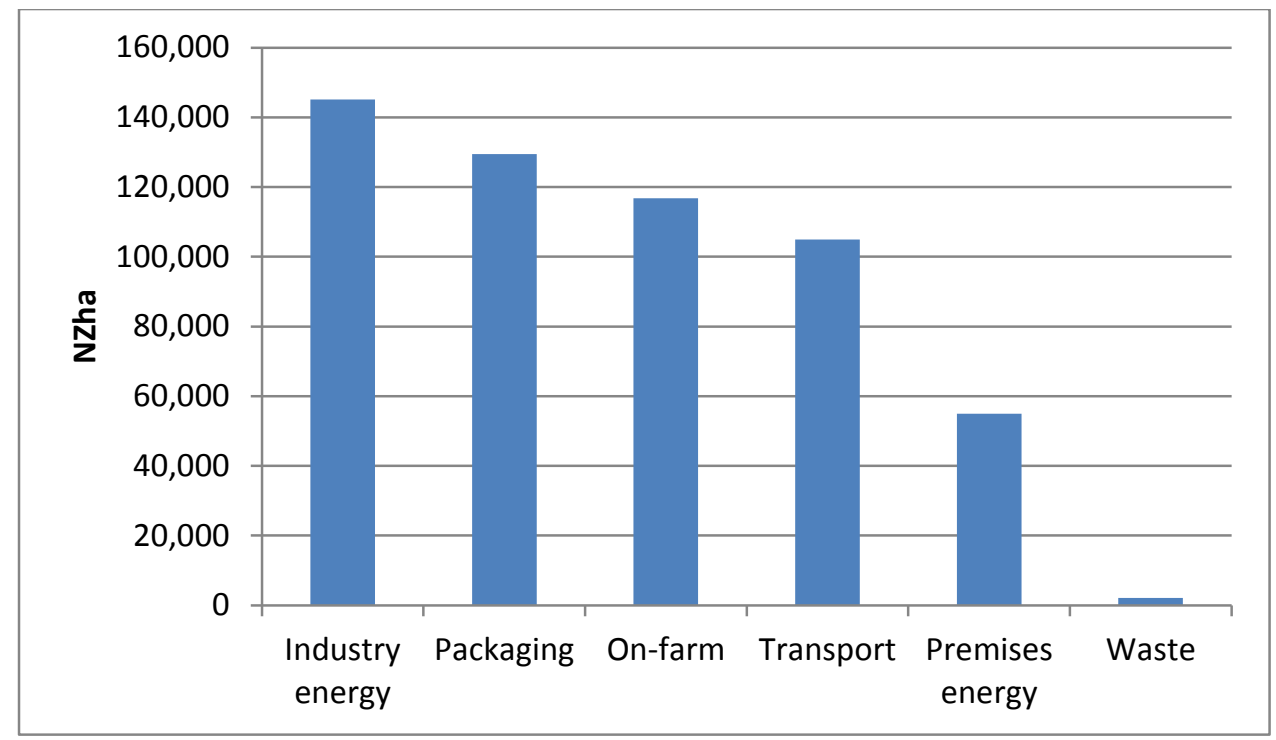

Figure 4.6: The EF of each non-land food category. 


\subsection{New Zealand Travel Footprint}

As with the choices that people make about their food, how and where they travel can change both the size and make-up of a community's EF. “In 2007, the total distance travelled on NZ roads by all types of vehicle was 40.2 billion kilometres. This equals travelling from the Earth to the Sun and back 135 times" (MfE, 2010b, p. 1). There is a high degree of car ownership in NZ; the latest OECD comparison (2006) shows NZ ranks third highest amongst OECD countries, with 74 road vehicles per 100 people. NZ also has one of the highest figures for roads per capita of any country in the world (New Zealand Transport Authority, 2011).

This section investigates the total energy associated with NZ household travel. As shown in figure 4.7, the research covers eight modes of motorised vehicles (cars and vans, buses, motorbikes, off-road vehicles, trains, ferries, pleasure craft, and planes) and five nonmotorised modes (walking, cycling, caravans, trailers, and non-motorised boats). Transport infrastructure is included section 4.9.

Transport calculations have been carried out collectively although where possible 'travel' has been related back to its main purpose. For example, if households are travelling to buy food then the footprint is allocated to the food EF, if travelling to go on holiday it is included in the holiday EF. Freight transport is not calculated in this section, but is included in relation to the food or consumer goods being freighted. There is an attempt to connect business travel with the category to which it most closely relates, such as consumer goods (section 4.5), government (section 4.10), or services (section 4.11).

In 2007 the official NZ population was 4,228,300 (Statistics New Zealand, 2011b) including all ages, whether or not of legal driving age, and irrespective of the modes of vehicle they use, This total population figure is used to calculate the transport EF. For example, all kilometres travelled by individuals on motorbikes are divided amongst the total population even though many people do not ride motorbikes. As with food, travel here is assumed to be undertaken by New Zealanders, although some NZ road users are visitors or tourists. 


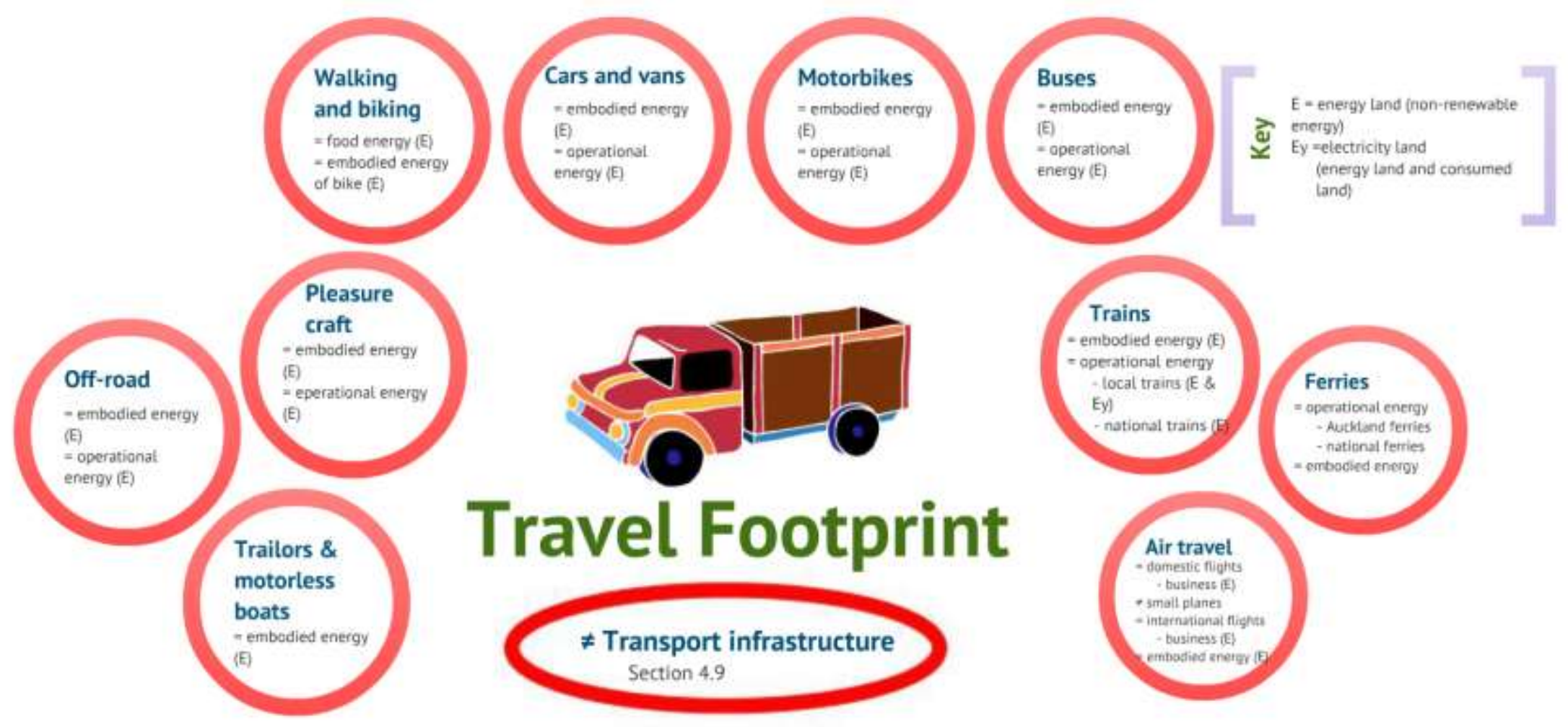

Figure 4.7: The Travel Footprint Map. 
Consequently, most calculations here probably include international tourist travel, such as tourist use of national and international flights. In 2007, 2.5 million tourists visited NZ, travelling an estimated 3.81 million pkm on national and international flights. Tourist travel will be discussed at the end of the section, and tourist figures for cars and vans, buses, trains, and ferries will be subtracted in section 4.4.12.

The three pieces of data required to calculate transport footprints are the distances travelled, and the operational and embodied energies of vehicles. Most operational energy comes from a liquid fuel; however some modes, such as trains, can run on electricity, and biking and walking are propelled through energy derived from food. The embodied energy is "an assessment that includes the energy required to extract raw materials from nature, plus the energy used in primary and secondary manufacturing activities to provide a finished product" (Mumma, 1995).

\subsubsection{Cars and Vans}

NZ has one of the highest percentages of per capita private vehicle ownership in the world (MfE, 2005 , p. 40). The predominant users of roads, accounting for about $80 \%$ of road traffic, are people in cars. About $90 \%$ of people travelling to work in cars do so alone (New Zealand Government, 2008 , p. 23). For the $1997-2006$ period households accounted for $83 \%$ of NZ's petrol consumption (Statistics New Zealand, 2008a, p. 5). This means that household car/van transport is the largest component of the transport EF. Data required are the energy expended per kilometre travelled and the total pkm travelled by New Zealanders in 2007.

EECA reports that amongst similar-sized cars, fuel consumption can vary, noting that "a New Zealand car uses on average 10 litres of fuel per $100 \mathrm{~km}$ travelled. This figure is an average of all the cars on the road-including a lot of big, old, inefficient vehicles" (EECA, 2011). Ten litres per $100 \mathrm{~km}$ is $3.42 \mathrm{MJ} / \mathrm{km}$ and is the value used in the following calculations.

To find the total distances travelled by New Zealanders in 2007, two methods were compared. The first was the total kilometres travelled by cars and vans. The Ministry for Transport (2009d) 
stated the total vehicle kilometres $(\mathrm{vkm})$ by all cars and vans was 31,514 million which, at $3.42 \mathrm{MJ} / \mathrm{vkm}$, used 107.8 million GJ.

On a per person basis, the (Ministry of Transport, 2009b) showed that 30,090 million pkm were travelled as a driver and 15,050 million pkm as a passenger, totalling 45,150 million pkm. The most commonly-used average occupancy rate is 1.69 persons per car (New Zealand Government, 2008, p. 23; Sullivan \& O'Fallon, 2003; 2010, p. 10), making the operational energy for private vehicles per passenger $2.02 \mathrm{MJ} / \mathrm{pkm}$, giving an energy use of 91.4 million GJ. The difference between the two estimation methods is 16.41 million GJ (equivalent to the potential chemical energy of 2.7 million barrels of oil). For an individual it is $3.88 \mathrm{GJ}$ or the equivalent of an additional $1,918 \mathrm{~km}$. Although method two provides the lower result, method one, with a total operational energy of 107.8 million GJ is considered more reliable due to not having to infer the average vehicle occupancy rate, and is used here.

The energy embodied in the materials and manufacturing processes for conventional vehicles is small compared to the fuel energy consumed by the vehicle over its lifetime (Stodolsky, Vyas, Cuenca, \& Gaines, 1995). To calculate the embodied energy of a car or van, four sources of data were tested (CSIRO, 1998; I Bike Toronto, 2010; Maclean \& Lave, 1998; Stodolsky et al., 1995). An average life-span of 250,000 km for a private car (Ashby et al., 2012, p. 12) was used for the embodied energy estimates. As none of the case studies related well to NZ, a conservative estimate of $0.53 \mathrm{MJ} / \mathrm{km}$ or $15.5 \%$ of the total energy (operation and embodied energy) is used, based on data that New Zealanders own their cars much longer than in other countries (Biddle, 2011). The total embodied energy required by NZ cars is therefore 16.7 million GJ per year. The total energy required (operational energy plus the embodied energy) is 3.95MJ/vkm (table 4.22).

Table 4.22: Total distance, energy and EF for NZ cars in 2007

\begin{tabular}{|lcccc|}
\hline \multirow{2}{*}{ Private vehicle } & \multirow{2}{*}{ Total distance travelled } & Total energy & Total energy per vkm & NZ EF \\
\cline { 2 - 5 } & vkm (million) & GJ (million) & MJ/vkm & NZha \\
\hline Cars and vans & 31,514 & 124.5 & 3.95 & 829,869 \\
\hline
\end{tabular}

The $2007 \mathrm{EF}$ of cars and vans is $829,869 \mathrm{ha}$ of energy land, or $0.1963 \mathrm{ha} /$ person. 


\subsubsection{Walking and Cycling}

Walking and cycling are the means of travel for a large portion of the world's population. However in the developed world they are also seen as sport or pastimes for exercise. The following section only includes the walking and cycling New Zealanders carry out as a means of transport rather than for exercise.

There are a number of estimates regarding the distance travelled by cyclists in 2007. The Ministry of Transport (2009a, 2010) state that annually, New Zealanders travel 289 million kilometres by bike and 934 million kilometres on foot. The energy for travel by foot and bike based on eating bread (Vale and Vale, 2009, p. $104 \& 109$ ) show the operational energy for cycling is $0.5 \mathrm{MJ} / \mathrm{km}$ and for walking is $0.9 \mathrm{MJ} / \mathrm{km}$. Using these values, New Zealanders consumed 144,849GJ whilst walking and $840,000 \mathrm{GJ}$ whilst cycling, totalling $985,449 \mathrm{GJ}$ of food energy.

Due to the very low numbers involved in the calculation of the embodied energy of resources associated with walking, the figures have been omitted from this research. The embodied energy of a bicycle was calculated by the Australian Public Transport Users Association (PTUA) (PTUA, 2009 ) at $0.08 \mathrm{MJ} / \mathrm{km}$ (21\% of operational energy). New Zealanders rode a total of 289.7 million $\mathrm{km}$, requiring $23,176 \mathrm{GJ}$.

Table 4.23: Distance travelled, and resulting energy required, for walking and cycling in NZ in 2007

\begin{tabular}{|lcccc|}
\hline \multirow{2}{*}{ Walking and cycling } & Total travel & Operational energy & Total NZ energy & NZ EF \\
\cline { 2 - 5 } & $\mathrm{Km}(\mathbf{0 0 0})$ & $\mathrm{MJ} / \mathrm{km}$ & $\mathrm{GJ}$ & NZha \\
\hline Cycling operation & 289,698 & 0.50 & 144,849 & 966 \\
\hline Cycling embodied & $\mathrm{n} / \mathrm{a}$ & 0.08 & 23,176 & 155 \\
\hline Walking & 934,000 & 0.90 & 840,600 & 5,604 \\
\hline Total & $\mathbf{1 , 2 2 3 , 6 9 8}$ & $\mathbf{N} / \mathbf{A}$ & $\mathbf{1 , 0 0 8 , 6 2 5}$ & $\mathbf{6 , 7 2 4}$ \\
\hline
\end{tabular}

The total energy required for cycling in 2007 was $0.58 \mathrm{MJ} / \mathrm{km}(168,025 \mathrm{GJ})$ with an EF of 1,121 ha. The total energy land for biking and walking combined was $6,724 \mathrm{ha}$. 


\subsubsection{Buses}

There are four bus systems in NZ: those that operate within cities and regions, those that run between cities and regions, privately-owned tourist buses, and chartered buses rented for specific events. The following statistics include all bus transport throughout NZ in 2007. New Zealanders travelled 1,520 million km by bus in 2007 (Ministry of Transport, 2009b, p. 4, table 1.), the equivalent of $359.5 \mathrm{~km} /$ person. Huang (2010) found the majority of NZ buses are diesel and, on average, Auckland buses travel at $17.3 \%$ passenger capacity, giving an energy use of 1.72MJ/pkm (Huang, 2010, p. 89 and 92). New Zealanders therefore used 2.6 million GJ of energy for the operation of buses in 2007.

CarbonNeutral (2008, p. 16) showed the embodied energy of a diesel bus is $5 \%$ of the total energy intensity. If the operating energy is $1.72 \mathrm{MJ} / \mathrm{pkm}$ then the total energy is $1.81 \mathrm{MJ} / \mathrm{pkm}$ and the embodied energy is $0.091 \mathrm{MJ} / \mathrm{pkm}$. This gives a total of 2.7 million GJ for bus travel in 2007 , or 18,341ha.

\subsubsection{Motorbikes}

Official Ministry of Transport figures show New Zealanders travelled 240 million kilometres by motorbike in 2007, or $57 \mathrm{~km} /$ person (Ministry of Transport, 2009b). The PTUA states the average operational energy of a motorbike is $1.95 \mathrm{MJ} / \mathrm{pkm}$, which is used in the following calculations. The total energy use by motorbikes in 2007 was $468,000 \mathrm{GJ}$ with an EF of 3,120ha. PTUA (2009) estimate the embodied energy of a motorbike is between 0.2 and $0.5 \mathrm{MJ} / \mathrm{pkm}$, giving a mean of $0.35 \mathrm{MJ} / \mathrm{pkm}$ ( $18 \%$ of operational energy), and a total energy per pkm of $2.3 \mathrm{MJ}$. Therefore, in 2007 , the total energy required by NZ motorbikes was 552,000GJ with an EF of 3,680ha.

\subsubsection{Off-road Recreation Vehicles}

Off-road recreation vehicles include 4-wheel-drive trucks, and 2-, 3- and 4-wheel off-road motorbikes. Only vehicles used for recreation have been included in the following calculations. Off-road vehicles for commercial farm activities are included in 'on-farm' energy (section 4.3.4). 
There is little official information regarding the number of off-road vehicles in NZ, particularly since these do not need to be registered and riders do not need to report their off-road activities.

In 2008 the Auckland Regional Physical Activity \& Sports Strategy (ARPASS) carried out research into the off-road vehicle activity of Aucklanders. Assuming off-road use is similar across NZ, this research has been extrapolated. Total distances travelled have been calculated using a range of data sources (ARPASS, 2008, table 2.4.2; R. Ryan, 2011). Motorbikes travelled 87 million kms, 4wheel-drive trucks travelled 14 million kilometres and 4-wheel motorbikes 6 million kms. Operational and embodied energy figures were gathered from the same sources as previously (sections 4.4.1 and 4.4.4). The total energy per pkm for off-road 2-wheel motorbikes is 2.3MJ, for 4-wheel-drive trucks is $3.84 \mathrm{MJ}$, and for 4-wheel motorbikes is $2.3 \mathrm{MJ}$. This gives a total energy use of $267,569 \mathrm{GJ}$ with an EF of 1,784ha of energy land.

\subsubsection{Trains}

Calculations for urban and national railways are undertaken separately. The trains on these two systems use different energy sources and different levels of energy per pkm depending on the average number of passengers carried.

\section{Urban Trains}

Two NZ cities have significant urban railway systems: Auckland and Wellington. There are 6.8 million (Ministry of Transport, 2009c) and 11.5 million (On Track, 2009) passenger train boardings respectively in Auckland and Wellington each year. The average trip length is $9 \mathrm{~km}$ for Auckland (Huang, 2010, p. 121) and $23.7 \mathrm{~km}$ for Wellington (Watson, 2003). Auckland urban railway passengers travel approximately 61.2 million $\mathrm{km}$ each year and Wellington passengers 272.6 million km, making 333.75 million $\mathrm{km}$ on urban railways each year in NZ.

Estimates for the energy required per pkm travelled by train vary depending on the assumed average occupancy rate, and whether the train runs on electricity or diesel (Vale and Vale 2009, pp. 109-112). Estimates range from 0.04 to $6.33 \mathrm{MJ} / \mathrm{pkm}$, including both operation and embodied energy (Becken \& Patterson, 2006; Carbon Neutral, 2008; PTUA, 2009; Vale \& Vale, 2009b, p. 
114). The average operational energy estimates by Vale and Vale $(2009$, p. 111) of 0.59MJ/pkm for electric trains and $0.74 \mathrm{MJ} / \mathrm{pkm}$ for diesel trains are conservative estimates and are used for the following calculations. The use of trains in urban areas is slowly increasing (On Track, 2009) though the numbers are still relatively low. In 2007 operational energy for urban trains was 206,093GJ (table 4.24).

\section{Regional and National Trains}

The distances travelled by NZ regional and national trains are summarised by Huang (2010, p. 154) and the number of passenger boardings for each of type are from Auckland Transport (Auckland Transport, 2010). Regional trains are assumed to run on diesel (although this is incorrect as the Main Trunk Line in the North Island is electrified between Hamilton and Palmerston North) and are estimated to use $0.74 \mathrm{MJ} / \mathrm{pkm}$. There were 518,000 passenger boardings in 2009/2010. These passengers travelled 142 million pkm, requiring 113,081GJ of energy.

Trains are mostly long-lived, decreasing the embodied energy per kilometre (Huang, 2010). The average of two embodied energy estimates, 6.8\% of total energy (Carbon Neutral 2008, p. 24; PTUA, 2009), is used here.

\section{Total Energy for Trains}

As shown in table 4.24, the total operational and embodied EF of NZ trains is 1,621ha. Due to the use of electric trains, $161 \mathrm{ha}$ is consumed land and 1,461 ha is energy land.

Table 4.24: Operational and embodied energy of trains in NZ in 2007

\begin{tabular}{|c|c|c|c|c|}
\hline Trains & Passenger kilometres & Total energy & Total energy & NZ EF \\
\hline & pkm & $\mathrm{GJ} / \mathrm{pkm}$ & GJ & NZha \\
\hline Urban diesel & $61,200,000$ & 0.79 & 48,592 & 324 \\
\hline electric & $272,550,000$ & 0.63 & 172,537 & 544 \\
\hline National & $142,420,400$ & 0.79 & 113,081 & 754 \\
\hline Total & $476,170,400$ & $\mathrm{n} / \mathrm{a}$ & 334,210 & 1,621 \\
\hline
\end{tabular}




\subsubsection{Aviation}

Transport New Zealand reported that, in 2007, 96\% of all air travel undertaken in NZ was associated with large commercial aeroplanes (Ministry of Transport, 2007); consequently only commercial flights are considered here. Additional research is required to calculate the energy for small sport and tourist planes and helicopters. Only flights by New Zealanders are included, rather than all flights to and from NZ. The impact of 'positive radiative forcing', associated with the release of emissions into the upper troposphere (Becken \& Patterson, 2006; Carbon Neutral, 2008 , p. 17 and 18) is not included.

\section{International Flights}

International flights use less energy per pkm than national flights due to having more passengers and travelling further at their optimum cruising altitude (Lawyer, 2010; SKF, 2010). However, the overall energy required for the flight is higher because of the longer distances travelled. Three sources of data were investigated for the pkm travelled annually by New Zealanders (Huang, 2010, p. 128; Ministry for Tourism, 2008, p. 15; Statistics New Zealand, 2010a, 2010b). Ministry of Tourism figures show there were 4,126,000 boardings of NZ residents and permanent and long-term migrants. Huang (2010) estimated an average international trip is $5,885 \mathrm{~km}$. New Zealanders therefore flew 24,282 million pkm internationally or 5,743pkm per New Zealander.

Estimates for overall energy per pkm for international flights range from 1.28 to $3.53 \mathrm{MJ} / \mathrm{pkm}$ (Carbon Neutral, 2008, p. 19; Vale and Vale 2009, p. 121; Becken \& Simmons, 2002, p. 119). The Carbon Neutral and British Airways/Lufthansa operational energy of $2.03 \mathrm{MJ} / \mathrm{pkm}$ in Becken \& Simmons (2002) seems a reliable yet conservative estimate. For embodied energy the Carbon Neutral (2008) figures are consistent with estimates for other transport modes at $2.3 \%$ of operating energy. Total operational and embodied energy for international flights is therefore $2.08 \mathrm{MJ} / \mathrm{pkm}$. 


\section{Domestic Flights}

Information detailing total flights or distances flown by NZ travellers is not available so again estimates have been made. There are 67 airports in NZ (Ministry for Tourism, 2008, p. 7), 30 of which provide scheduled domestic air services. Auckland, Hamilton, Wellington, Christchurch, Queenstown, Palmerston North, Rotorua and Dunedin are the busiest airports. Only flights from these eight airports are considered in the following section and therefore the following estimates are probably an underestimate.

Using data from the NZ Ministry of Tourism (Ministry for Tourism, 2008, p. 20, table 6) and a range of 2007 annual reports (ARP Consultants, 2011, p. 3; DIAL, 2008; HIA, 2007, p. 6; PNIA, 2007, p. 6; QACL, 2007, p. 9) the number of domestic travellers passing through NZ's eight largest airports was 15.76 million in 2007. It could be assumed that the majority of passengers fly from one major airport to another, meaning these passengers have been counted twice and the number of passengers needs to be halved to 7.88 million passengers. Huang (2010) estimates the average distance travelled by a domestic flight in NZ is $470 \mathrm{~km}$, giving a total of 3,539 million pkm. The Palmerston North Airport annual report noted 39\% of throughput was 'short-term overseas visitors' (PNIA, 2007). Using this split New Zealanders flew 2,159 million pkm and tourists flew 1,380 million pkm, which is roughly supported by Statistics New Zealand (2007d) and Becken and Gnoth's (2004) international tourist domestic air travel estimates of 1,212 million pkm.

There is a range of published calculations for the energy for national flights (Becken \& Patterson, 2006, table 1; Carbon Neutral, 2008, p. 17; Bradley \& Associates, 2007; Victoria Transport Policy Institute, 2011, citing Lenzen 1999). The figure used here is 2.69MJ/pkm (Bradley \& Associates 2008) because these authors clarified that the figure was just the operational energy. This figure is also the middle ground between the other case studies. Adding the embodied energy, the total energy used by domestic flights is $2.73 \mathrm{MJ} / \mathrm{pkm}$ and New Zealanders consumed 5.9 million GJ for national flights in 2007. 


\section{Total Flights}

Based on these assumptions and 2007 estimates, New Zealanders required 56.4 million GJ for the operating and embodied energy of commercial air travel, making an EF of 375,650ha (table 4.25).

Table 4.25: Total energy and land required for national and international flying by New Zealanders in 2007

\begin{tabular}{|lcccc|}
\hline \multirow{2}{*}{ Aviation } & Distance & Total energy & NZ energy & NZ EF \\
\cline { 2 - 5 } & pkm (million) & MJ/pkm & GJ & Ha \\
\hline International & 24,282 & 2.08 & $50,451,858$ & 336,346 \\
\hline Domestic & 2,159 & 2.73 & $5,895,571$ & 39,304 \\
\hline Total & $\mathbf{2 6 , 4 4 0}$ & n/a & $\mathbf{5 6 , 3 4 7 , 4 2 9}$ & $\mathbf{3 7 5 , 6 5 0}$ \\
\hline
\end{tabular}

$75 \%$ of flights $(281,737$ ha) taken by New Zealanders were transport for holidays (Ministry for Tourism, 2008). The remainder $(93,912 \mathrm{ha})$ was for business. The EF of transport for holidays will be reallocated (section 4.6) and the business flights apportioned between consumer goods (section 4.5), government (section 4.10), and services (section 4.11). Some flights were included in EECA's food industry and consumer goods figures (sections 4.3 .3 and 4.5 .5 ) and will be discussed further in section 4.5.

\subsubsection{Pleasure Craft}

Boating is important to New Zealanders. The Pleasure Boat Safety Advisory Group (PBSAG) reported that $14.6 \%$ of $N Z$ households own at least one pleasure craft (PBSAG, 1999). The Maritime Transport Act 1994 defines "pleasure craft" as a vessel that is "used exclusively for the owner's pleasure or as the owner's residence, and is not offered or used for hire or reward" (Maritime New Zealand, 2008). The following figures only include vehicles defined as boats, excluding water sports vehicles such as jet skis and paddle craft. Tourist-operated boats are not included and larger commercial ferries are included in section 4.4.9.

There were 356,960 pleasure boats in NZ in 2007 (Huang, 2010, p. 190; Maritime New Zealand, 2007, p. 17; PBSAG, 1999, p. 15). Maritime New Zealand estimated $63 \%$ of all pleasure boats are 
fitted with a motor, totalling 224,885 powered boats, $89 \%$ of which are powered by petrol (as opposed to diesel) (Maritime New Zealand, 2007, p. 63). Many non-motor powered boats, such as sailing boats, have back-up motors but because of lack of data these have not been included here.

Fuel use varies between boats due to engine size, on-board weight and water conditions. Powered pleasure boats have an estimated cruising speed of 24 knots or $45 \mathrm{~km}$ per hour and an energy consumption of 38.39MJ/km (Huang, 2010, p. 192; Ministry of Economic Development, 2010a). The amount of time a boat is operated significantly affects the energy consumed. A conservative estimate of 40 hours per boat per year is used here (PBSAG, 1999, Huang, 2010, p. 190; Maritime New Zealand, 2007, p. 63). From the range of estimates for the average number of people carried on pleasure craft (Jon C, 2011; Nautical Know How, 2009), four people per boat is used as the average carrying capacity. Four passengers and 40 hours of travel per year $(224,885$ boats) totals 1,619 million $\mathrm{pkm}$ or $9.60 \mathrm{MJ} / \mathrm{pkm}$.

Huang (2010, p. 200) found the embodied energy of an average NZ motorised pleasure craft is $78.89 \mathrm{GJ}$ or $6.57 \mathrm{GJ} /$ year (over 12 years), and for non-motorised craft is $3.95 \mathrm{GJ} /$ year (over 20 years). This gives an annual EF of 3,469ha for non-motorised craft. Each motorised boat travels $7,200 \mathrm{pkm}$ per year $(9.60 \mathrm{MJ} / \mathrm{pkm})$ and this represents $69.12 \mathrm{GJ}$ which, with embodied energy added, gives $75.69 \mathrm{GJ}$ per year. Thus the 224,885 motorised boats in NZ have an EF of $113,434 \mathrm{ha}$ of energy land. The footprint of all pleasure craft is 116,903ha of energy land, almost one third of the total energy required for aviation. Compared to a car (46GJ/year) the average pleasure boat is $69 \mathrm{GJ} /$ year. A boat uses two-and-a-half times more energy per year than each New Zealander's share of total cars and vans. If the rate of boat ownership was as high as car ownership ( 0.75 vehicles per person) the operation of NZ pleasure craft would use 219.2 million GJ per year and have a footprint of 1.4 million hectares, or $0.3456 \mathrm{ha} /$ person.

\subsubsection{Ferries}

Kenworthy (2008, p. 225 and 226) carried out research in 84 international cities and found "ferries clearly have the highest use of energy per kilometre due to the frictional forces involved 
in operating through water. However there is a huge variation based on vessel size and speed of operation... in fact in 6 out of 9 regions where ferries are featured, their energy use per passenger kilometre exceeds that of private transport." The following section considers commuter passenger ferries rather than water transport. It is also not complete as there are number of additional commercial ferries in use around NZ such as the Paihia-Russell car ferry and smaller ferries that service the Wellington Harbour. Further research is needed to gain a more comprehensive list of ferry services and their total energy requirements.

Due to the range of boat sizes and services the following section has been divided into two parts: Auckland ferries with sub-groups of large and small ferries; and larger ferries such as those crossing the Cook Strait and travelling between the South Island and Stewart Island.

\section{Auckland Ferries}

The majority of the commuter ferries operating in NZ are in Auckland, however passenger transport by ferry only represents a very small percentage of Auckland's total passenger trips. Land Transport New Zealand figures support this with 44.9 million bus boardings and only 3.8 million ferry boardings in the Auckland region (Huang, 2010, p.174, citing Land Transport New Zealand, 2007).

Large Auckland ferries include passenger transport to and from Waiheke and Great Barrier Island. Huang (2010, table 4.69) found these require an average of 500MJ/km and travelled 695,020km in 2007. They carry an average of 113 passengers, so use $4.43 \mathrm{MJ} / \mathrm{pkm}$. Large Auckland ferries travelled 78,537,283 pkm in 2007 and required 347,693GJ of energy (table 4.26).

Small Auckland ferries use 328MJ/km (Huang, 2010, p. 79) and operate for 26,104hours/year travelling 1,062,433km/year. They require 348,280GJ with an average carrying capacity of 28.52 passengers per trip. Small Auckland ferries thus use $11.4 \mathrm{MJ} / \mathrm{pkm}$, the highest energy per pkm of any vehicle in this research. The 1.1 million kilometres travelled resulted in 30.3 million pkm, requiring $374,092 \mathrm{GJ}$. 


\section{Large NZ Ferries}

Large NZ ferries operate all year between NZ's North Island, South Island and Stewart Island, carrying passengers and additional cargo freight. A recent study found large luxury ferries from Bergen, Norway used between 1.80 and 11.94MJ/pkm (Walnum, 2011, p. 15). Walnum's research (p. 16) shows the immense amount of energy required to go on a holiday cruise, at 3.6 times that of travel by plane. The calculations here investigate commercial water transport between the North and South Island, focusing on the Interislander and Bluebridge ships. These boats travelled 82 million pkm and 17.5 million pkm respectively in 2007, requiring an average of 2,365MJ/km and totalling a combined 924,272GJ (Bluebridge, 2009a, 2009b, 2011; Bluebridge representative, 2011; Interislander, 2011; Kiwirail, 2009).

The two boats used for the Stewart Island crossing make 1,928 trips per year (Real Journeys, 2011a, 2011b), travelling 75,192km/year and carrying an average 24 people per trip. The boats require 13.66MJ/pkm and travel a total of 1,804,608pkm, using 24,649GJ in 2007.

Table 4.26: Energy and land for NZ commercial passenger ferry transport in $\mathbf{2 0 0 7}$

\begin{tabular}{|lccc|}
\hline \multirow{2}{*}{ Total ferries } & Total energy & Total energy & NZEF \\
\cline { 2 - 4 } & MJ/pkm & GJ & NZha \\
\hline Large Auckland & 4.76 & 373,461 & 2,490 \\
\hline Small Auckland & 12.34 & 374,092 & 2,494 \\
\hline Interislander & 9.74 & 801,102 & 5,341 \\
\hline Bluebridge & 10.91 & 191,671 & 1,278 \\
\hline Stewart Island & 14.67 & $\mathbf{2 6 , 4 7 6}$ & 177 \\
\hline Total & $\mathbf{n} / \mathbf{a}$ & $\mathbf{1 , 7 6 6 , 7 9 8}$ & $\mathbf{1 1 , 7 7 9}$ \\
\hline
\end{tabular}

Huang (2010, p. 201) calculated the embodied emissions of ferries are $6.9 \%$ of the operating emissions, requiring an additional 107,481GJ of energy per year in embodied energy.

As shown in table 4.26, NZ commercial ferries require 1.77 million GJ of energy annually, with an EF of 11,779ha of energy land. 


\subsubsection{Trailers and caravans}

In $2008 \mathrm{NZ}$ had 30,900 registered trailers (including boat trailers) and 2,928 caravans, a total of 33,828 (New Zealand Transport Authority, 2009). The embodied energy of a non-motorised trailer is approximately 25GJ (CSIRO, 1998, p. 106) and caravans are estimated to be twice that at 50GJ. The total embodied energy of trailers and caravans is $61,260 \mathrm{GJ}$ with an EF of $408 \mathrm{ha}$.

\subsubsection{Initial Total Travel Footprint}

Table 4.27 provides details of the distance, energy and EF for travel in NZ in 2007. The totals presented in table 4.27 are not final as subtractions are required to reallocate some footprints to other categories (see section 4.4.13 for the final transport EF).

New Zealanders travelled 63,350 million kilometres in 2007 by land, water and air, which is the equivalent of $14,983 \mathrm{~km} /$ person. This travel required 205.8 million GJ with a resulting EF of 1.4 million hectares of energy land. Transport by land-based vehicles is $63 \%$ of the total NZ transport $\mathrm{EF}$, of which $96 \%$ is cars and vans ( $61 \%$ of the total transport EF). Flights are an additional $28 \%$ of the total transport EF, of which $90 \%$ is international flights ( $25 \%$ of the total transport EF). Water transport accounts for the remaining 9\% with pleasure craft 91\% of the water transport EF (figure 4.8).

Huang (2010) developed an EF method for transport systems using Auckland as a case study. The distance travelled per person (by mode) was compared between Huang's work and this research, finding that, on average, Aucklanders travel $19,457 \mathrm{~km} /$ person per year, rather than the average $14,550 \mathrm{~km} /$ person per year for the whole country (minus travel on water). The differences were mainly in the distance travelled by public transport, as driving distances were similar. Huang also found Aucklanders had more international flights than the NZ average. If all New Zealanders travelled the same as Aucklanders (distances estimated by Huang (2010) using energy conversions from table 4.27) NZ's transport EF would increase by $227,562 \mathrm{ha}$. 
Table 4.27: Distances travelled and corresponding operational and embodied energy and per person EF for various transport modes in 2007

\begin{tabular}{|c|c|c|c|c|}
\hline \multirow{3}{*}{ Mode } & NZ travel & Total energy & NZ energy & NZ EF \\
\hline & VKT \& pkm & $\mathrm{MJ} / \mathrm{vkm} \& \mathrm{MJ} / \mathrm{pkm}$ & GJ & NZha \\
\hline & $\mathrm{vkm}$ & $\mathrm{MJ} / \mathrm{vkm}$ & & \\
\hline \multirow[t]{2}{*}{ Light vehicles } & $31,514,000,000$ & 3.95 & $124,480,300$ & 829,869 \\
\hline & $\mathrm{pkm}$ & $\mathrm{MJ} / \mathrm{pkm}$ & & \\
\hline Pedestrian & $934,000,000$ & 0.9 & 840,600 & 5,604 \\
\hline Cyclist & $289,698,000$ & 0.58 & 168,025 & 1,120 \\
\hline Buses & $1,520,000,000$ & 1.81 & $2,751,200$ & 18,341 \\
\hline Motorcycle & $240,000,000$ & 2.3 & 552,000 & 3,680 \\
\hline Non-motorised trailers & $\mathrm{n} / \mathrm{a}$ & $\mathrm{n} / \mathrm{a}$ & 61,260 & 408 \\
\hline Off-road truck & $27,899,726$ & 1.93 & 53,707 & 358 \\
\hline Off-road motorbikes & $92,983,557$ & 2.3 & 213,862 & 1,426 \\
\hline Train travel & $476,170,400$ & 0.741 & 352,530 & 1,576 \\
\hline Pleasure craft & $1,619,170,560$ & 7.68 & $17,015,386$ & 116,903 \\
\hline Ferries & $210,486,314$ & $10.48^{1}$ & $1,644,889$ & 10,966 \\
\hline Non-motorised boats & $\mathrm{n} / \mathrm{a}$ & $\mathrm{n} / \mathrm{a}$ & 520,376 & 3,469 \\
\hline Domestic flights & $2,158,787,066$ & 2.73 & $5,895,571$ & 39,304 \\
\hline International flights & $24,281,510,000$ & 2.08 & $50,451,858$ & 336,346 \\
\hline Total travel & $63,350,755,761$ & $n / a$ & $205,786,003$ & $1,369,370$ \\
\hline
\end{tabular}

1. Ferry energy - total energy has been averaged. See transport sections for more detail.

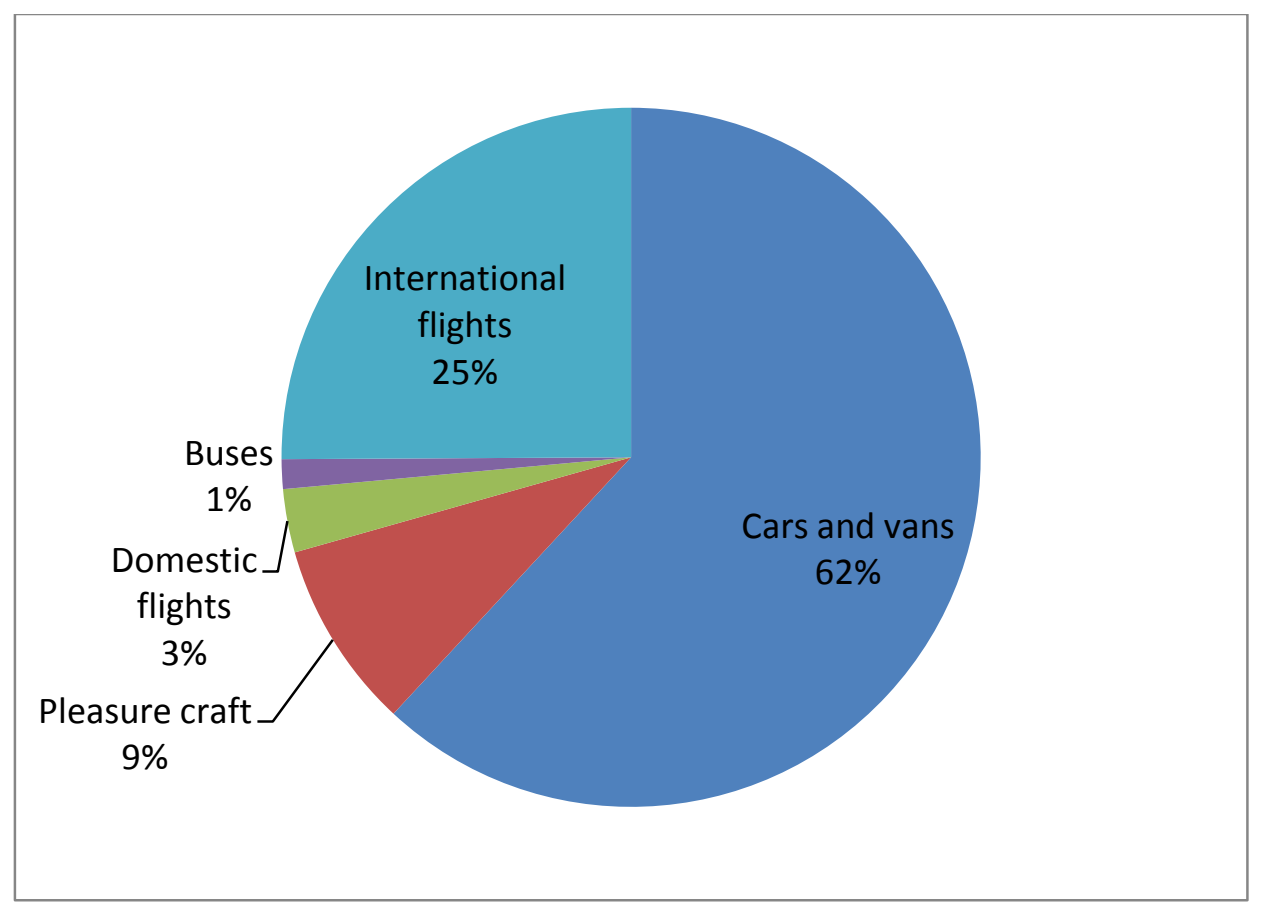

Figure 4.8: Distribution of the five largest transport footprints in 2007. 


\subsubsection{Reallocating the Travel Footprint}

The current research attempts to align the use of transport with its purpose, such as travel for holidays. The following section reallocates part of the travel footprint to give a new personal travel EF.

International tourists visiting NZ use all modes of travel. Using data from Becken (2009), Becken \& Gnoth (2004) and the $\mathrm{EF} / \mathrm{pkm}$ values above, the energy associated with tourist air travel was 4.31 million GJ, with an EF of 28,724 ha.

Purchasing goods and services is an important reason for travel. The total transport EF related to food eaten at home and eaten out was $32,618 \mathrm{ha}$, and for buying consumer goods was $83,875 \mathrm{ha}$. The total transport shopping footprint was $116,493 \mathrm{ha}$.

New Zealanders travel extensively for holidays, both within and outside NZ. The Ministry for Tourism (2008) reported that $75 \%$ of all domestic flights were related to holidays or visiting friends and relatives, and it is assumed that this is the same for international flights. Summing $75 \%$ of the international flights $(252,259 \mathrm{ha})$ and $75 \%$ of the domestic flights $(29,478 \mathrm{ha})$ gives $281,737 \mathrm{ha}$. The car occupancy rate for holiday travel is assumed to be higher than that for normal commuter car travel, with Becken and Patterson (2006) estimating 3.4 people per vehicle (rounded to 3 people per vehicle here). This makes the car travel energy-to-km conversion $1.32 \mathrm{MJ} / \mathrm{pkm}$. Using Becken's calculations for car, bus and coach travel, the EF is $124,846 \mathrm{ha}$. The total holiday transport EF is $406,583 \mathrm{ha}$. The majority $(62 \%)$ is international flights with cars and vans forming $29 \%$ of the total NZ holiday transport EF.

NZ businesses supply New Zealanders (and export markets) with consumer goods and services. Carrying out business often requires travel. Government and services categories also require transport as part of the running of these organisations. The non-holiday portion of air travel is here used by business. The footprints of international and national business travel by air in 2007 were $84,086 \mathrm{ha}$ and $9,826 \mathrm{ha}$, respectively, totalling $93,912 \mathrm{ha}$. Travel by car and van was also used by food, consumer goods, government, and services sectors and is discussed in each of these 
sections. Total business travel in 2007 by car and van was 1,301 million vkm with an EF of 34,271 ha. The total combined business travel footprint by car, van and plane was 125,788 ha, of which $75 \%$ was for flights.

Table 4.28: Transport reallocated to other components of the NZ EF

\begin{tabular}{|lcc|}
\hline \multirow{2}{*}{$\begin{array}{c}\text { Transport } \\
\text { purpose }\end{array}$} & NZ energy & NZ EF \\
\cline { 2 - 3 } & GJ & NZha \\
\hline Holidays & $60,987,427$ & 406,583 \\
\hline Shopping & $17,473,984$ & 116,493 \\
\hline Business & $19,227,545$ & 128,184 \\
\hline Tourists & $4,308,652$ & $\mathbf{2 8 , 7 2 4}$ \\
\hline Total & $\mathbf{1 0 1 , 9 9 7 , 6 0 8}$ & $\mathbf{6 7 9 , 9 8 4}$ \\
\hline
\end{tabular}

Table 4.28 provides a summary of transport energy reallocated to other EF categories. The total that has been reallocated is 101.99 million GJ with an EF of 679,984 ha of energy land.

\subsubsection{Total Reallocated Travel EF}

The transport footprint minus travel required for the purchase of goods and services, holidays, tourist activity and business-associated travel (including flights) becomes 119.8 million GJ with a footprint of 798,707 ha (table 4.29 ).

Table 4.29: EF of land and water transport in 2007

\begin{tabular}{|lcccc|}
\hline \multirow{2}{*}{ Total travel } & $\begin{array}{c}\text { Total transport } \\
\text { energy }\end{array}$ & $\begin{array}{c}\text { Reallocated } \\
\text { energy }\end{array}$ & $\begin{array}{c}\text { Remaining } \\
\text { energy }\end{array}$ & NZ EF \\
\cline { 2 - 5 } & GJ & GJ & GJ & NZha \\
\hline Total land travel & $129,438,495$ & $\mathbf{2 7 , 6 8 7 , 0 7 5}$ & $101,751,420$ & 678,343 \\
\hline $\begin{array}{l}\text { Total water } \\
\text { travel }\end{array}$ & $\mathbf{1 8 , 6 6 0 , 2 7 5}$ & $\mathbf{6 0 5 , 6 1 4}$ & $\mathbf{1 8 , 0 5 4 , 6 6 2}$ & 120,364 \\
\hline Total travel & $\mathbf{1 4 8 , 0 9 8 , 7 7 0}$ & $\mathbf{2 8 , 2 9 2 , 6 8 8}$ & $\mathbf{1 1 9 , 8 0 6 , 0 8 1}$ & $\mathbf{7 9 8 , 7 0 7}$ \\
\hline
\end{tabular}




\subsection{New Zealand Consumer Goods Footprint}

This section estimates the EF of consumer goods in 2007 in NZ. These include all products and services that are not food, household materials, or services supplied by government. The Consumer Goods Footprint Map in figure 4.9 shows the elements included in this footprint. These EF calculations have two major limitations:

1. Data only provide information on consumer goods produced or imported in a year, rather than all consumer products that are in use; and

2. The majority of the available data only include the embodied manufacturing energy of the product, and not the embodied land.

A number of top-down methods are used to quantify the EF of consumer goods. The final consumer goods EF is 2.6 million hectares, slightly more than the food EF (excluding fishing land). This is probably a considerable underestimate for two reasons.

Calculations in the food and transport sections have used a top-down and bottom-up approach for many calculations, providing the opportunity to compare results to justify a 'best-fit' quantity. The consumer goods section is less straight-forward because of the significant number of consumer products in use by New Zealanders, the complex calculations, and lack of available data. In comparison to the top-down approach for food, the consumer goods imported into the country in 2007 are not the only consumer goods that New Zealanders 'consume'. There are a considerable number of consumer goods in NZ households and offices that were acquired prior to 2007 that are excluded by these calculations. A bottom-up calculation would need an audit of NZ homes and offices to list all consumer goods used by New Zealanders and their useful life, to give a value of the annual 'consumption' of that product. 


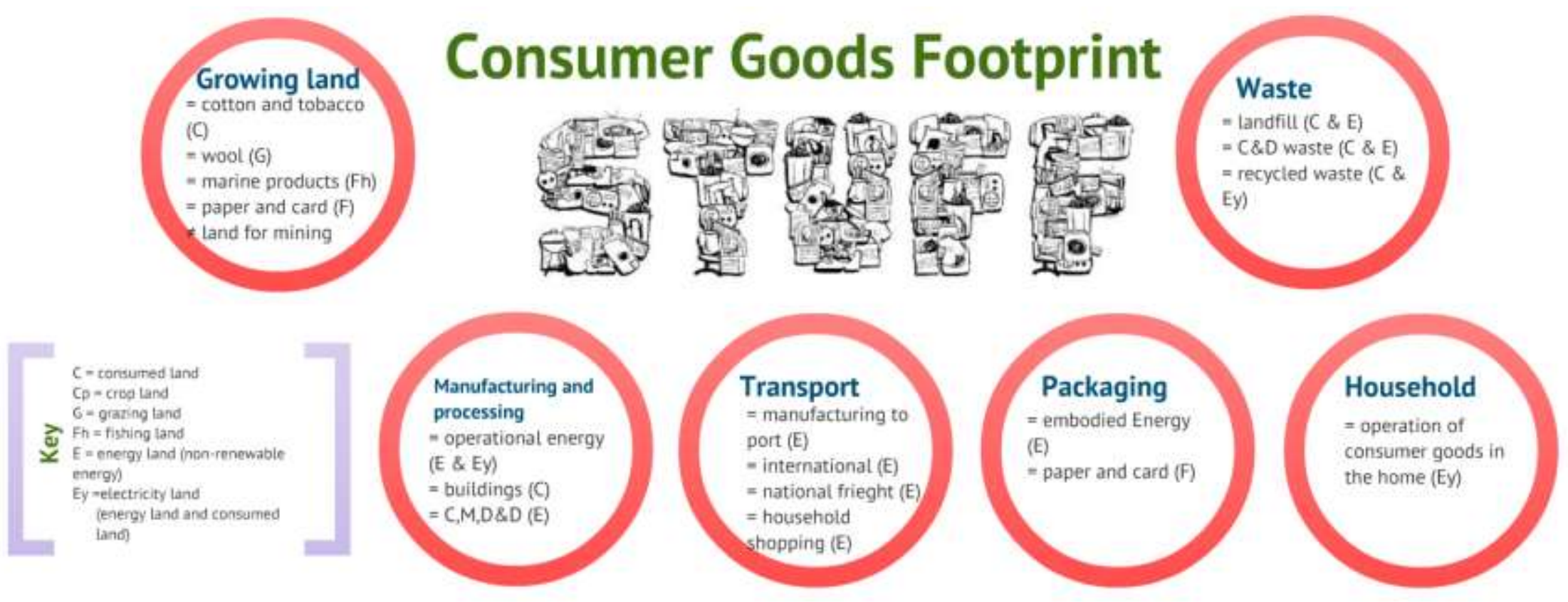

Figure 4.9: The Consumer Goods Footprint Map. 
As well as a top-down analysis underestimating the total number of consumer goods used by New Zealanders in 2007, there is also an underestimate of the land required to produce the products. Although data on the embodied energy and $\mathrm{CO}_{2}$ of consumer goods are increasingly available, there are seldom data detailing the crop, grazing, fishing, forest, and consumed land used to produce consumer products. For many products, particularly imports, the footprint only includes the embodied energy. Here, efforts have been made to account for the growing land required by cotton, tobacco, wool, paper products, and pets. In addition the detailed data needed for a full Life Cycle Energy Assessment (LCEA) of a product is rare. In an LCEA all energy inputs to a product are accounted for, including the energy for the production of the materials to make the goods, the manufacturing of the components of goods, and the materials and services for the manufacturing process. Many of the calculations here only include the energy for some of these inputs and therefore do not account for the entire life-cycle energy.

Three top-down approaches were compared for estimating the consumer goods footprint, considered under the following sectors:

1. Embodied manufacturing energy

2. Wool, tobacco, cotton

3. Pets

4. Consumer goods buildings

5. Transport of consumer goods

6. Household operation

7. Forest land associated with consumer goods

8. Consumer goods waste

9. Packaging associated with consumer goods

An additional level of complexity lies in differentiating between consumer goods used by 'households', including the businesses that supply those goods and services, and the goods and services required by the 'government and service' sector, such as energy suppliers, hospitals, and police. 


\subsubsection{Embodied Manufacturing Energy of Consumer Goods}

The aim of this section is to account for the embodied manufacturing energy of all consumer goods consumed by New Zealanders in 2007. Four methods (table 4.30) of calculating the embodied energy of NZ's consumer goods were investigated (EECA, 2007; Global Footprint Network, 2011; Ministry of Economic Development, 2010a; Statistics New Zealand, 2007c, 2008a).

Table 4.30: Consumer goods embodied manufacturing energy

Energy method
What does it measure?

-

Top-down, buildings, processing and transport energy

Bottom-up, buildings, processing and transport energy

Top-down, buildings, processing and transport energy

Top-down, life-cycle $\mathrm{CO}_{2}$ of products
NZ EF

NZha

\begin{tabular}{|c|c|c|}
\hline 1. Energy Data File 2007 & $\begin{array}{c}\text { Top-down, buildings, processing and transport } \\
\text { energy }\end{array}$ & 660,394 \\
\hline 2. Household Expenditure & $\begin{array}{c}\text { Bottom-up, buildings, processing and transport } \\
\text { energy }\end{array}$ & 137,961 \\
\hline 3. EECA End-Use Database & $\begin{array}{c}\text { Top-down, buildings, processing and transport } \\
\text { energy }\end{array}$ & 595,245 \\
\hline
\end{tabular}

4. GFN National EF Accounts

Three of the four case studies in table 4.30 were similar in their outcomes whereas the 'Household Expenditure and Energy and Economy' case study only estimated 137,961ha. The EECA End-Use database could be considered an effective method for the embodied EF of consumer products, but only considers consumer goods produced in NZ and further detail regarding total production, imports and exports is required. Using this figure would assume the embodied energy of exported consumer products is the same as the embodied energy in imports. Although the GFN calculation provides the highest estimate, it is used here as it is considered to be the most reliable. Life-cycle data used by GFN is based on overseas goods, but since considerable quantities of NZ's consumer goods are imported the figures are likely to be adequate. It is assumed the GFN calculations for consumer goods include transport energy, so the transport energy as calculated by EECA will be subtracted and added to the consumer goods transport section (4.5.5). The total consumer goods transport footprint was 71,766ha, less 18,466ha for domestic air travel which has been accounted for in section 4.4 .12 and will be 
included separately below. The total EF for the embodied energy of consumer goods is therefore 605,691ha.

\subsubsection{Wool, Tobacco and Cotton}

Crop and grazing land is required to supply tobacco, cotton and wool products to the market. Other products also require crop and grazing land, such as leather and hide products, fur, silk, and bamboo. However, there is a lack of life-cycle data, and such few products are consumed they would be insignificant to the total NZ EF. As a result only wool, cotton and tobacco are included here.

Wool is used for clothing, carpets, and household insulation. Data for the total wool consumed in NZ in 2007 varied. FAOSTAT (FAO, 2007) reported twice the wool production of local sources such as New Zealand Meat and Wool (Statistics New Zealand, 2008d) and Beef New Zealand (2008). The more conservative local data from New Zealand Meat and Wool, of 147,462t for the year July 2007 to June 2008, were used here, of which $89 \%$ was produced for export (M\&W NZ, 2008). As a result New Zealanders only consumed 16,221t in 2007. The average yield for wool is $5.4 \mathrm{~kg} /$ animal (Statistics New Zealand, 2010c). Using an average 19.23 sheep/ha/year (Richardson, 2012) gives $103.84 \mathrm{~kg} /$ ha of greasy wool. The footprint of wool consumed in NZ in 2007 was 156,211ha. This is likely to include some double-counting because though adult sheep are kept for wool they are often also used to produce lamb for meat which was accounted for in section 4.2.2. The additional processing energy to degrease the wool is likely to have been included in the embodied energy calculations (section 4.5.1)

Data for imported tobacco were taken from the FAOSTAT database. This showed that, in 2007, NZ imported 4,127t of tobacco and exported 1,079t as tobacco products (FAO, 2007), giving a domestic consumption of 3,048t. NZ imports the majority of its tobacco from Australia and Brazil (FAO, 2007). The production yields for these countries are $2,308 \mathrm{~kg}$ and $1,978 \mathrm{~kg}$ per hectare respectively, averaging $2,143 \mathrm{~kg} /$ hectare. Tobacco consumed by New Zealanders has an EF of 1,422ha (table 4.31). 
Cotton is integral to the goods and services New Zealanders consume on a daily basis, being used in clothes, furniture, bedding, children's toys, and sports goods. According to FAOSTAT, NZ imports 13t (FAO, 2007) of 'unprocessed' cotton, which leaves a very large amount of processed cotton unaccounted for. Two cotton calculations were compared, producing similar results. The UNComtrade calculations (Cotton Incorporated, 2011; ICAC, 2010; United Nations, 2011, New Zealand-cotton-exports-world-2007) resulted in a cotton EF of 6,495ha, compared with a Japanese case study result of 4,420ha (Cotton Incorporated, 2011; e-Stat, 2008; Statistics Bureau, 2010). The UNComtrade figures are used here because they are probably a more reliable account of NZ imports, although they could be an overestimate as they include other associated fabrics.

\section{Total Crop and Grazing Land}

A top-down approach was used to calculate the total land required for the growing of wool, tobacco and cotton consumed by New Zealanders (table 4.31).

Table 4.31: Grazing and crop land required for the EF of three products

\begin{tabular}{|lccc|}
\hline \multirow{2}{*}{ Crop and grazing } & \multirow{2}{*}{ Domestic supply } & Yield & NZ EF \\
\cline { 2 - 4 } & Tonnes & $\mathrm{kg} / \mathrm{ha}$ & NZha \\
\hline Wool & 16,221 & 104 & 156,207 \\
\hline Tobacco & 3,048 & $2,143^{1}$ & 1,422 \\
\hline Cotton & 4,852 & $\mathbf{7 4 7 ^ { 2 }}$ & 6,495 \\
\hline Total & $\mathbf{2 3 , 0 4 2}$ & $\mathbf{N} / \mathbf{A}$ & $\mathbf{1 6 4 , 1 2 5 ^ { 3 }}$ \\
\hline
\end{tabular}

1. FAOSTAT - Production Yields - 2007 - yield average, Australian and Brazilian

2. World average cotton yield (Cotton Incorporated, 2011)

3. Numbers may not add up due to rounding

The NZ EF for consumer goods crop and grazing land is 164,125 ha for wool, tobacco and cotton products, of which $95 \%$ is for grazing sheep and the production of wool.

\subsubsection{Pets}

NZ has one of the highest rates of pet ownership in the world, well ahead of the USA, the UK and Australia (Swarbrick, 2009). A 2007 survey by Swarbrick (2009) revealed that 52\% of NZ households had a cat and nearly $30 \%$ a dog, claiming that in 2008 the NZ pet industry was worth 
$\$ 400$ million annually. There are a number of reasons why including the footprint of pets is difficult due to the potential for 'double counting'.

The EF of pets is predominantly determined by the type of food they eat (Vale \& Vale, 2009, p. 252). Whether they eat meat or graze for themselves requires grazing land. Energy land is also needed to process and transport the food. For some pets, housing and exercise space should also be considered. It seems pet food was not included in the FAO food calculations (FAOSTAT, 2011) (section 4.3) and that food for pets is often in direct competition with food that could be fed to humans (Bowden, 2010; S. Collins, 2012; Jolley, 2012). The following section looks at the two most popular household pets in NZ-cats and dogs-and one other high-footprint pet, the horse.

\section{Dogs}

The National Dog Database has 475,072 registered dogs (New Zealand Dog Safety, 2011; New Zealand Petfood Manufacturers Association, 2011; Swarbrick, 2009). Using NZ yields, if all dogs were fed a chicken/grain-based diet their annual EF would be 147,086ha/year, and if fed on beef/grain, 229,609ha/year. A large portion of NZ pet food is imported, and these meat and grain yields are probably lower from lower grazing/crop land productivity. Therefore, the beef calculations are used here (Ewing, Reed, et al., 2010). According to the food figure (4.6), growing land is $73 \%$ of the food footprint and non-growing land is $26 \%$ (transport, processing, waste and packaging of food). This same split is used for pet food, making the total footprint of dog food (growing land and energy land) 310,282ha.

\section{Cats}

Unlike dogs in NZ, cats are not registered. According to Dalton (n.d.) there are 1.1 million domesticated cats and the New Zealand Department of Conservation (Department of Conservation, n.d.) estimate an additional 0.9 million feral cats, totalling 2 million cats in NZ. Vale and Vale $(2009$, p. 253) calculate the EF of a cat is $0.13 \mathrm{ha} /$ year to which is added $0.05 \mathrm{ha} /$ year to cover the energy required by the New Zealand Department of Conservation for trapping and 
killing wild cats and restocking areas with native fauna eaten by them. The total EF of NZ cats is 188,000ha.

\section{Horses}

Horses are used for a range of sports and leisure activities, including racing, polo, jousting, rodeos, and competitive equestrian sports such as gymkhanas and 3-day events. The AgriBase's Biosecurity database (AsureQuality, 2012) reported 120,000 registered horses in NZ. As with cats, this will be an underestimate as there are many unregistered horses. Horses require grazing and crop land for their food, and energy land for transport and tack (riding gear). Horses require 6-12 stock units of food depending on the "amount of physical exercise the horse is doing" (Animal Welfare Advisory Committee, 1993, p. 7). One stock unit equates to $1,040 \mathrm{~kg}$ of green matter (Barlow, 1987, p. 53; Bell, 2006; Statisitcs New Zealand, n.d.) and has an EF of 0.1891ha. The total growing land for an average NZ horse is 1.8ha/year.

Many services and products are required for the upkeep of horses, depending on their use. Dostine (2011a, 2011b) found equestrian competitors spent just under $\$ 13,000 /$ year/horse. The biggest single expenditure was travel at $0.5372 \mathrm{ha} /$ horse, with additional horse riding gear at $0.0054 \mathrm{ha} /$ horse. This gives a total EF of 2.34ha/year. Applying this to all NZ horses gives $280,676 \mathrm{ha}, 77 \%$ of which is grazing land and $23 \%$ transport.

\section{Total Pets}

Only three pets are included and more data are required to calculate the EF of NZ's remaining pets including birds, rodents and fish, so the pet footprint will be an underestimate at 730,219ha. The EF is 57,677ha of grazing land, 8,075ha of crop land, 91,528ha of energy land, and 53,842ha of consumed land.

\subsubsection{Consumer Goods Buildings}

Consumer goods require industrial buildings for their production, and offices for the management of businesses that produce and transport the goods. The following section 
calculates the EF of the consumed land related to these buildings and the energy land required for their construction, maintenance, demolition and disposal. The operational energy for consumer goods buildings was accounted for in the embodied energy section (4.5.1). Two methods are used. The first used the EECA End-Use Datasets (EECA, 2007) and information on lighting energy per $\mathrm{m}^{2}$ (Saville-Smith et al., 2010, p. 77). This method concluded a footprint of 2,092ha. The second is a top-down analysis of NZ's built-up area (MfE, 2009b). The total built-up land, less the area calculated for households, government, services and infrastructure, was 118,508 ha. If this figure were correct, consumer goods buildings would require almost three times the area of built-up residential land. One way the considerable difference in data could be interpreted is that the total floor area of consumer goods buildings is $2,092 \mathrm{ha}\left(5 \mathrm{~m}^{2}\right.$ per New Zealander) whilst the total 'consumed' area required for commercial activity is $118,508 \mathrm{ha}\left(300 \mathrm{~m}^{2}\right.$ per New Zealander). Consumer goods buildings only require $2 \%$ of the consumer goods land. Both these figures will be used here but, without any additional information, these figures are only an estimate.

The construction, maintenance, demolition and disposal of buildings require energy. The average of figures from two references (Lawson, 1995; Lukaszyk, n.d.) gave 2.9GJ/m² which will be used for industrial buildings and warehouses, and $6.64 \mathrm{GJ} / \mathrm{m}^{2}$ for offices. As before, construction is assumed to make up $60 \%$ of total energy, maintenance $34 \%$ and demolition and disposal $6 \%$. Without any data to verify this, a 40\%:60\% spilt between offices and warehouses has been used. This makes the construction footprint 10,441 ha/year, maintenance 5,916ha/year and demolition and disposal 1,044ha/year, totalling 17,401ha/year.

\subsubsection{Transport}

Consumer goods travel from international distribution points to NZ, around NZ to wholesale and retail stores, and from stores to households. The following section quantifies this travel into five parts: household travel, national freight, business travel related to consumer goods businesses, international transport, and transport within the exporter country. 


\section{Household Travel}

The energy required for householders to go shopping in order to buy consumer goods was calculated using the Ministry for Transport's (2008) Household Travel Survey. The survey showed that the transport required for moving products from the places of purchase to the household totals an estimated 12.6 million GJ, with a footprint of 83,875 hectares.

\section{National Freight}

According to the data from the EECA End-Use Database (2007) the embodied energy EF of consumer goods was $595,245 \mathrm{ha}$, of which $71,766 \mathrm{ha}(12 \%)$ was for transport. Of this, 52,931ha (74\%) was for freight. This is similar to consumer goods freight transport calculations by Richard Paling (2008) with an EF of 56,453ha. The EECA value is used here.

\section{National Business Travel}

Data from the EECA End-Use Database (EECA, 2007) show business travel by car related to consumer goods had an EF of $18,466 \mathrm{ha}, 26 \%$ of the total consumer goods transport EF. Working back from an MfE case study in section 4.9.2, government domestic air travel was $63 \%$ of all national business flights, with a footprint of 6,154ha. The remaining flights were divided between services, infrastructure and consumer goods based on the respective building floor areas. Consumer goods were therefore responsible for $82 \%$ of the remaining national business air travel with an EF of 3,606ha. The total national business travel EF is 22,072ha of energy land.

\section{International Freight}

A number of datasets were used to calculate the tkm travelled by imported consumer goods (IMO Library Services, 2006; Richard Paling Consulting, 2008; Statistics New Zealand, 2011b) although these estimates should be used with caution. They show that imported consumer products travelled 78,749 million tkm by ocean freighters which consume $0.12 \mathrm{MJ} / \mathrm{tkm}$ (Vale \& Vale, 2009, p. 43). The transport footprint for imported consumer goods is $62,999 \mathrm{ha}$. 


\section{International Business Travel}

Section 4.4 .7 showed that $25 \%$ of international trips were for business (Ministry for Tourism, 2008), with an EF of 84,086 ha. International business travel was again split between business, services and government, based on the office space required by each. Consumer goods were thus responsible for $49 \%$ of international business travel $(36,466 \mathrm{ha})$.

\section{Production to Port}

Section 4.2.5 found food travelled on average $878 \mathrm{~km}$ from farm to port. Here it is assumed that the majority of consumer products are produced in coastal industrial cities with purpose-built facilities for getting goods to port, consequently lowering the average travelling distance. Since China and the USA are two of NZ's major trade partners, providing a total of $43 \%$ of NZ's imports in 2008 (Statistics New Zealand, 2008b), case studies from these countries were used to indicate the distance consumer goods travel from factory to port (IBIS World, 2011; RITA, 2007). These studies indicated a consumer goods production to port EF of $9,802 \mathrm{ha}$, which is only $4 \%$ of the total consumer goods transport EF and is lower than expected.

\section{Total Consumer Goods Travel Footprint}

Table 4.32 provides a summary of the travel EF of consumer goods.

Table 4.32: Consumer goods transport EF 2007

\begin{tabular}{|lc|}
\hline \multirow{2}{*}{\multicolumn{1}{|c|}{ Transport }} & NZ EF \\
\cline { 2 - 2 } & NZha \\
\hline Household & 83,875 \\
\hline National freight & 52,931 \\
\hline National business & 22,072 \\
\hline International import & 62,999 \\
\hline International business & 36,466 \\
\hline Production to port & 9,802 \\
\hline Total & $\mathbf{2 6 8 , 1 4 5}$ \\
\hline
\end{tabular}


The EF of consumer goods transport from manufacturing to household is 268,145ha. Transporting goods from place of purchase to the house forms the largest portion at $31 \%$. National freight of goods is $20 \%$, international import is $23 \%$, international business $14 \%$, and transport from production to port only $4 \%$.

\subsubsection{Household Operational Energy}

Many consumer goods require energy to operate. Data from the HEEP project (Issacs et al., 2010, p. $9 \& 20)$ showed the operation of household appliances, other than those used in the kitchen, required $15 \%$ of NZ's total household electricity. This gives an EF of 19,001 ha, $23 \%$ of which is consumed land.

\subsubsection{Forest land}

Forest land is used to calculate the land needed for the production timber and paper and card consumer products and packaging.

\section{Paper}

Calculations in section 4.3.7 found NZ produced 758,200t of waste paper in 2007 (FAOSTAT, 2007), 54\% of which related to consumer goods (CSIRO, 1998). The resulting $348,772 t$ is split between households, business, government and services. COVEC (2007) reported that 36\% of paper and card is used in households $(125,558 \mathrm{t})$ and $64 \%$ in commerce. Calculations in section 4.9.2 found that, annually, central and local NZ governments required 5,205t of paper. The remaining 218,009 t will be split $51 \%$ to business and $49 \%$ to services, based on floor area.

The mean annual harvest increment for NZ forests is $18 \mathrm{~m}^{3} / \mathrm{ha}$ /year (New Zealand Forest Industries Council, 2010). Assuming 38\% of paper is from recycled materials, the paper-to-forestland conversion is $0.2092 \mathrm{ha} / \mathrm{t}$. The household paper footprint is therefore $26,267 \mathrm{ha}$ and that of commerce $23,083 \mathrm{ha}$, totalling 49,350 ha of forest land. 


\section{Wooden consumer goods}

FAOSTAT forestry production, import and export data (FAOSTAT, 2007) were used to calculate NZ's total 2007 wood consumption of 28.8 million $\mathrm{m}^{3}$. Of this, 21.1 million $\mathrm{m}^{3}$ was for household construction and maintenance (section 4.6.6), leaving $7,668,616 \mathrm{~m}^{3}$ for wood products with a forest EF of 426,034ha. Again splitting this based on national floor area, the results are that households account for $91 \%$, commerce $4 \%$, services $4 \%$ and government less than $1 \%$. The EF for wood products in households is therefore 387,186 ha, with 18,950 ha for business.

\subsubsection{Waste}

Consumer products and their packaging form a large portion of landfill and recycling waste (section 4.2). Section 4.2.3 shows that in 2007 C\&D waste related to consumer goods had a consumed land EF of 208ha and an energy land EF of 521ha, totalling 729ha. Of the money spent on building consents, 35\% was for commercial buildings (Statistics New Zealand, 2007a). Assuming, therefore, that commercial buildings are responsible for $35 \%$ of the footprint gives an EF of 255ha.

Organic waste made up 28\%, or 686,051t, of waste to landfill in 2007 (MfE, 2009c). Of this, garden waste was 39\% (MfE, 2007c, p. 34; Waste Not Consulting, 2006), with an EF of 621ha.

Consumables waste to landfill (section 4.2) was 127,325t from households and 432,846t from industry. The total EF of consumer goods household waste to landfill is 219 ha of consumed land and 1,490ha of energy land.

In 2007, 1,098,636t of waste was recycled, of which $71 \%$ was non-residential and $29 \%$ residential (COVEC, 2007). 50\% of this waste was associated with food (Lee et al., 2010). NZ consumer goods are therefore responsible for $549,318 \mathrm{t}$ of recyclables, with an EF of $594 \mathrm{ha}$. This is split into $172 \mathrm{ha}$ for households and 422ha for commerce. 
Table 4.33: Waste EF of NZ consumer goods in 2007

\begin{tabular}{|c|c|c|c|c|}
\hline \multirow{2}{*}{ Consumables waste } & NZ total & Energy & Consumed & NZ EF \\
\hline & tonnes & NZha & NZha & NZha \\
\hline C\&D waste & 72,893 & 48 & 80 & 129 \\
\hline Garden waste & 267,560 & 396 & 225 & 621 \\
\hline Residential consumables & 127,325 & 121 & 98 & 219 \\
\hline Non-residential consumables & 432,846 & 450 & 300 & 751 \\
\hline Residential recycling & 159,302 & 122 & 50 & 172 \\
\hline Non-residential recycling & 390,016 & 300 & 122 & 422 \\
\hline Total & $1,449,941$ & 1,466 & 886 & 2,352 \\
\hline
\end{tabular}

Non-residential C\&D waste and general waste to landfill are then further divided into services, government and business. Previous calculations using floor area show that $50 \%$ of these two waste streams is the result of non-residential activities, $49 \%$ the result of services and less than $1 \%$ is from government.

Consumer goods waste totals $1,449,941$ t with an EF of 2,352ha. Of this, $62 \%$ is energy land and $38 \%$ is consumed land.

\subsubsection{Packaging of Consumer Products}

Paper and card packing for consumer goods requires forest land, and plastic packaging needs embodied energy land. Of the 758,200t of paper packaging (COVEC, 2007), 348,772t were associated with consumer products with a forest land EF of 72,963ha. For non-wood-based packaging, the combined consumer goods landfill and recycled waste is $518,895 \mathrm{t}$, with an EF of $67,506 h a$.

\subsubsection{Consumer Goods Summary}

Consumer goods include all products not included in the food, housing, government, services and infrastructure sections. The consumer products category is large and would be larger if the total embodied land of all products were also included.

Table 4.34 shows NZ's consumer goods EF is 2.39 million hectares. Pets make up the single largest contribution at $31 \%$, with embodied energy at $25 \%$ and wood and paper products $19 \%$. Of the 
remainder, transport is $11 \%$, cotton, wool and tobacco $7 \%$, packaging $6 \%$, operation $1 \%$ and waste less than $1 \%$.

Table 4.34: EF of NZ consumer goods 2007

\begin{tabular}{|c|c|c|c|c|c|c|}
\hline Consumer goods & $\begin{array}{l}\text { Consumed } \\
\text { land }\end{array}$ & $\begin{array}{l}\text { Crop } \\
\text { land }\end{array}$ & $\begin{array}{l}\text { Grazing } \\
\text { land }\end{array}$ & $\begin{array}{l}\text { Forest } \\
\text { land }\end{array}$ & $\begin{array}{l}\text { Energy } \\
\text { land }\end{array}$ & NZ EF \\
\hline & NZha & NZha & NZha & NZha & NZha & NZha \\
\hline $\begin{array}{l}\text { Embodied } \\
\text { manufacturing } \\
\text { energy }\end{array}$ & & & & & 605,691 & 605,691 \\
\hline $\begin{array}{l}\text { Tobacco, cotton and } \\
\text { wool }\end{array}$ & & 7,918 & 156,207 & & & 164,125 \\
\hline $\begin{array}{l}\text { Paper and wood } \\
\text { products }\end{array}$ & & & & 455,486 & & 455,486 \\
\hline $\begin{array}{l}\text { Buildings and } \\
\text { manufacturing }\end{array}$ & 4,172 & & & & 24,323 & 28,494 \\
\hline Transport energy & & & & & 266,339 & 266,339 \\
\hline $\begin{array}{l}\text { Recycling and waste } \\
\text { energy }\end{array}$ & 886 & & & & 1,466 & 2,352 \\
\hline Pets & 53,842 & 8,075 & 576,774 & & 91,528 & 730,219 \\
\hline Packaging & & & & 72,963 & 67,506 & 140,469 \\
\hline Total & 58,899 & 15,993 & 732,981 & 528,449 & $1,056,853$ & $2,393,176$ \\
\hline
\end{tabular}




\subsection{New Zealand Holiday Footprint}

The United Nations World Tourism Organisation defines tourism as the "activities of persons travelling to and staying in places outside their usual environment". Tourists are the sum of sameday and overnight visitors (UNWTO, 2012). The components of both domestic and international holiday EF will be explored using the following categories:

1. Air transport;

2. Transport by land and sea;

3. Accommodation; and

4. Attractions.

The food and drink, eating out, and waste EF whilst on holiday are not included here. The food EF of tourists was explored in section 4.3. The NZ Holiday Footprint Map is shown in figure 4.10.

\subsubsection{Domestic Tourism}

Becken and Patterson (2006) state that domestic tourism was responsible for $74 \%$ of tourism's direct energy use and associated $\mathrm{CO}_{2}$ emissions, excluding international travel. Domestic tourists spent $\$ 7.39$ billion for the year ending June 2008; for the same period international tourists spent $\$ 6.18$ billion (Ministry for Tourism, 2008). Domestic tourism is an important part of NZ's economy and a significant part of its total EF. Domestic tourism includes all trips over $40 \mathrm{~km}$ outside the 'usual environment' (Becken, 2009).

\section{Domestic Tourist Transport}

The distance New Zealanders travel on holiday varies with lifestyle, money and family situation (Angus \& Associates, The Knowledge Warehouse, \& Tourism Resource Consultants, 2010).

Domestic tourists spend, on average, three nights away from home, meaning their holidays are characterised by a high transport component. Total emissions for tourism EF were 1.85 million $\mathrm{tCO}_{2}$-e (Angus \& Associates, The Knowledge Warehouse, \& Tourism Resource Consultants, 2010, p. 21). Data in Becken and Patterson (2006) were used to generate table 4.35. Car and van holiday 


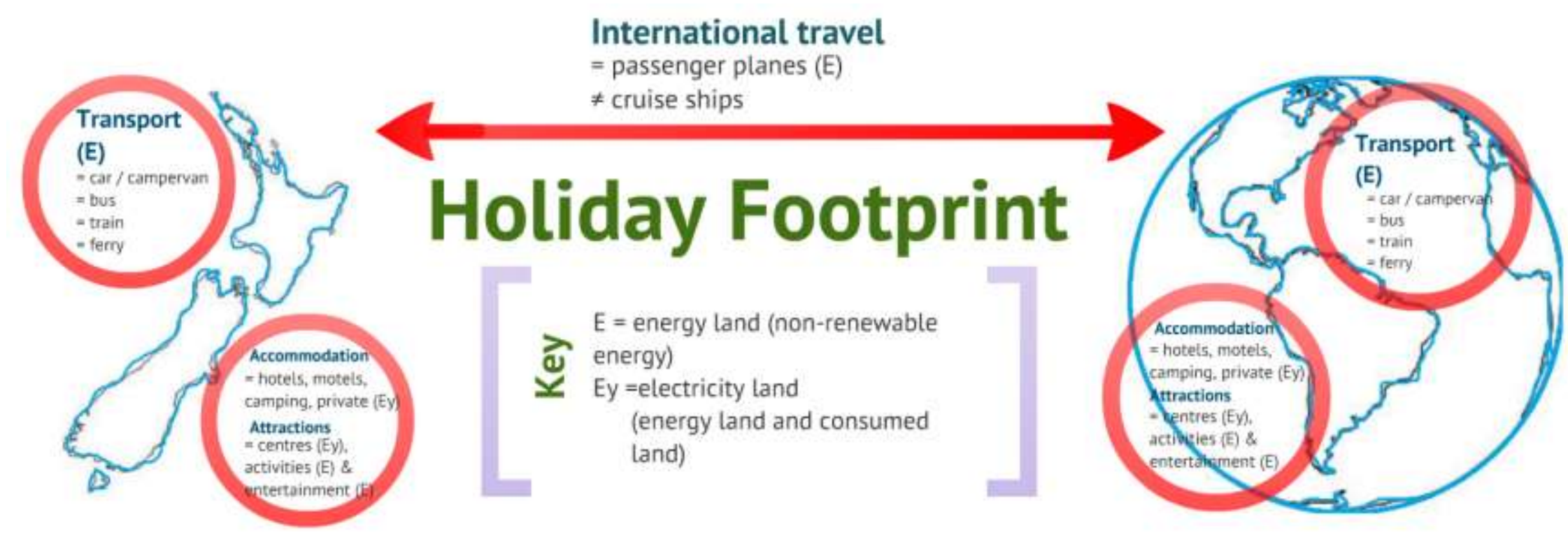

Figure 4.10: The Holiday Footprint Map. 
travel was 13,587 million pkm in 2007, with an EF of 119,265ha. Coaches and buses travelled 463 million pkms with a footprint of 5,581ha. Domestic flights taken by New Zealanders for holidays were 2,159 million pkm with a footprint of 29,478ha.

Table 4.35: Domestic holiday transport EF for 2007

\begin{tabular}{|lcccc|}
\hline \multirow{2}{*}{ Travel mode } & Passenger km & Energy/pkm & NZ energy & \multirow{2}{*}{ NZ EF } \\
\cline { 2 - 5 } & pkm (million) & MJ/pkm & GJ & NZha \\
\hline Cars and vans & 13,587 & $1.32^{1}$ & $17,889,730$ & 119,265 \\
\hline Domestic flights & 2,159 & 2.73 & $4,421,678$ & 29,478 \\
\hline Coach/bus & 463 & 1.81 & 837,125 & 5,581 \\
\hline Total & $\mathbf{1 6 , 2 0 9}$ & n/a & $\mathbf{2 3 , 1 4 8 , 5 3 3}$ & $\mathbf{1 5 4 , 3 2 4}$ \\
\hline
\end{tabular}

1. Becken and Patterson (2006) estimated 3.4 persons/car on holiday (rounded down to 3) giving a car energy-to-km conversion of $1.32 \mathrm{MJ} / \mathrm{pkm}$.

Table 4.35 shows that, in 2007, New Zealanders required 154,324ha of energy land for domestic holiday travel. Car and van travel is $77 \%$ of the NZ holiday transport EF. This is supported by research by Becken (2009, p. 25): “the main cause of domestic tourism's emissions is the car with 1.1 million tonnes of $\mathrm{CO}_{2}$-e emitted in 2007".

\section{Domestic Tourist Accommodation}

NZ Ministry for Tourism research was used to create the split in domestic tourist accommodation in table 4.36 (Angus \& Associates, The Knowledge Warehouse, \& Tourism Resource Consultants, 2010). The most popular form of accommodation for domestic tourists is 'other accommodation' (24 million nights) which includes 'rental accommodation', assumed here to be rented baches (cribs), holiday homes and apartments. The second most popular form is campgrounds and Department of Conservation huts (5.7 million nights). The energy use per night for all but 'other' accommodation was taken from Becken (2001, p. 377). The EF of domestic holiday accommodation is 3,731 ha, of which $77 \%$ is energy land. 
Table 4.36: The EF of NZ domestic tourist accommodation

\begin{tabular}{|lcccc|}
\hline \multirow{2}{*}{ Accommodation } & Total nights & Energy per night & NZ energy & NZ EF \\
\cline { 2 - 5 } & $\#$ & MJ/night & GJ & NZha \\
\hline Other & $\mathbf{2 4 , 5 4 2 , 4 6 8}$ & $26^{1}$ & 638,104 & 1,842 \\
\hline Hotel & $1,280,364$ & 155 & 198,456 & 573 \\
\hline Motel & 265,742 & 32 & 8,504 & 25 \\
\hline DOC/Camping & $5,700,000$ & 25 & 142,500 & 411 \\
\hline Hostel & $4,171,651$ & 39 & 162,694 & 470 \\
\hline Private & $1,291,709$ & 110 & 142,088 & 410 \\
\hline Total & $\mathbf{3 7 , 2 5 1 , 9 3 4}$ & $\mathbf{2 6}$ & $\mathbf{1 , 2 9 2 , 3 4 7}$ & $\mathbf{3 , 7 3 1}$ \\
\hline \multicolumn{1}{c}{ 1. Based on halving the total residential energy per year (Isaacs et al., 2010) to 26MJ/night. }
\end{tabular}

Domestic Tourist Attractions

Domestic tourists use entertainment, activities and attractions whilst on holiday. The embodied energy figures in research by Becken and Simmons (2002) were used here. Activity involvement was based on international tourist figures from the same research. Only embodied and operational energy land is included. The domestic tourist activity footprint is 4.4 million GJ with an EF of 28,612ha. Attractions were assumed to use NZ electricity, with activities and entertainment using non-renewable energy.

\subsubsection{International NZ Tourism}

In 2007, 1.98 million NZ permanent residents travelled overseas (Ministry of Tourism, 2009) for an average of 13 nights (Tourism Australia, 2008). The most popular destinations were Australia, Europe, and Fiji (Becken, 2009, p. 8). Huang (2011; p. 220 \& 223) found cruise ships accounted for less than $1 \%$ of the Auckland transport EF and these have therefore been excluded here. Pearce, Reid and Schott (2009) and Becken and Gnoth (2004) show three distinct types of New Zealander traveller; those using international travel packages (10.6\%) for an average 11.7 days, independent travellers (69.5\%) for an average 20.5 days, and package-plus travellers, who combine a package with other travel (19.9\%) for an average 20.8 days. 


\section{International Tourist Transport}

As described in section 4.3.7, the international air travel EF of New Zealanders is 336,346ha of energy land, 75\% of which was for holidays and visiting friends and relatives. The EF of NZ international holiday travel by air is therefore 252,259 ha.

Once New Zealanders reach their international travel destinations they normally use trains and buses for moving around (Europa, 2012) although an increasing number of low cost airlines offer flight opportunities abroad (Swartz, 2011). Based on this, the total international land and sea travel for NZ tourists is $47,123 \mathrm{ha}$.

\section{International Tourist Accommodation}

International NZ holiday-makers stay in a range of accommodation types (Pearce, Reid, \& Schott, 2009). Using the same breakdown as previously, New Zealanders required 44.4 million nights of international accommodation in 2007. Accommodation was assumed to use electricity based on the world average mix of $19 \%$ renewables (REN21, 2011). As a result, accommodation required by New Zealanders on international holidays in 2007 was 14,342ha, 3.4\% of which was consumed land.

\section{International Tourist Attractions}

The same breakdown suggests $27 \%$ of tourists visit tourist attractions, $2 \%$ take part in an activity, and $71 \%$ take part in entertainment whilst on holiday overseas. The energy-per-activity figures of Becken and Simmons (2004) were used to analyse attraction participation by international NZ tourists, giving an EF of 8,429ha.

\subsubsection{Total Holiday Footprint}

Table 4.37 summarises the impact of New Zealanders on holiday, which is 76.4 million GJ with an EF of 494,727 ha, mainly energy land. International flights are $50 \%$ of the total holiday EF, and national transport, including national flights, is $30 \%$. The transport EF of travel when overseas is 
9\%. Taking national and international holidays together, activities are $8 \%$ of the EF, and accommodation $4 \%$.

Table 4.37: EF of NZ holidays in 2007

\begin{tabular}{|c|c|c|c|c|}
\hline \multicolumn{2}{|c|}{ Holiday components } & NZ energy & NZEF & Portion of holiday EF \\
\hline & & GJ & NZha & $\%$ \\
\hline \multirow{4}{*}{ International holidays } & International flights & $37,838,894$ & 252,259 & $50 \%$ \\
\hline & Accommodation & $2,565,631$ & 14,342 & $3 \%$ \\
\hline & Transport & $6,626,475$ & 47,123 & $9 \%$ \\
\hline & Activities & $1,284,550$ & 8,429 & $2 \%$ \\
\hline \multirow{4}{*}{ Domestic holidays } & Transport & $24,215,841$ & 119,265 & $30 \%$ \\
\hline & Accommodation & $1,292,347$ & 3,731 & $1 \%$ \\
\hline & Activities & $4,414,790$ & 28,612 & $6 \%$ \\
\hline & Total & $78,682,009$ & 508,820 & \\
\hline
\end{tabular}




\subsection{New Zealand Household Energy Footprint}

The first part of the household energy section investigates the number and types of dwellings in $\mathrm{NZ}$ in 2007. The second part compares top-down and bottom-up data to understand where and how operational energy is used in the home. The Household Energy Footprint Map is shown in figure 4.11 .

\subsubsection{Household Count and Types}

In 2006 Statistics New Zealand (2006d) reported there were 1,651,542 dwellings in NZ. Of the 1,651,542 dwellings (Statistics New Zealand, 2006d), 1,641,459 were permanent. In 2007, 25,740 residential housing consents were issued. Of these, $9 \%$ were for apartments and the remainder for 'dwellings - excluding apartments' (Statistics New Zealand, 2011a). Data for the number of dwellings demolished each year could not be located but the number is assumed to be small. By the end of 2007 there were an assumed total of 1,667,205 dwellings in NZ (table 4.39).

For the purposes of this research 'unoccupied dwellings' are assumed to be 'separate houses' and 'occupied non-private dwellings' are assumed to be 'flats/apartments/units'. The final figures are 1,330,047 'separate houses', 262,824 'apartments', and 74,334 'baches'.

\subsubsection{Household Operational Energy}

Two approaches to calculating the energy required by NZ households in 2007 were compared. The first uses Household Energy End-Use Project (HEEP) estimates (Isaacs et al., 2010, p. 13) for a bottom-up approach, and the second uses national figures from the Ministry of Economic Development (MED) (Ministry of Economic Development, 2010a) for a top-down estimate. Residential energy includes electricity, non-renewable fuels and wood. As calculated in chapter 3.5.1 NZ's electricity has a split energy-to-land conversion of 1,000GJ/ha for the renewable $66.7 \%$ that requires consumed land, and 150GJ/ha for the non-renewable 33.3\% that requires energy land. The conversion of $150 \mathrm{GJ} /$ ha is used for non-renewable sources such as gas and coal. The wood footprint is $115.5 \mathrm{GJ} / \mathrm{ha}$. 


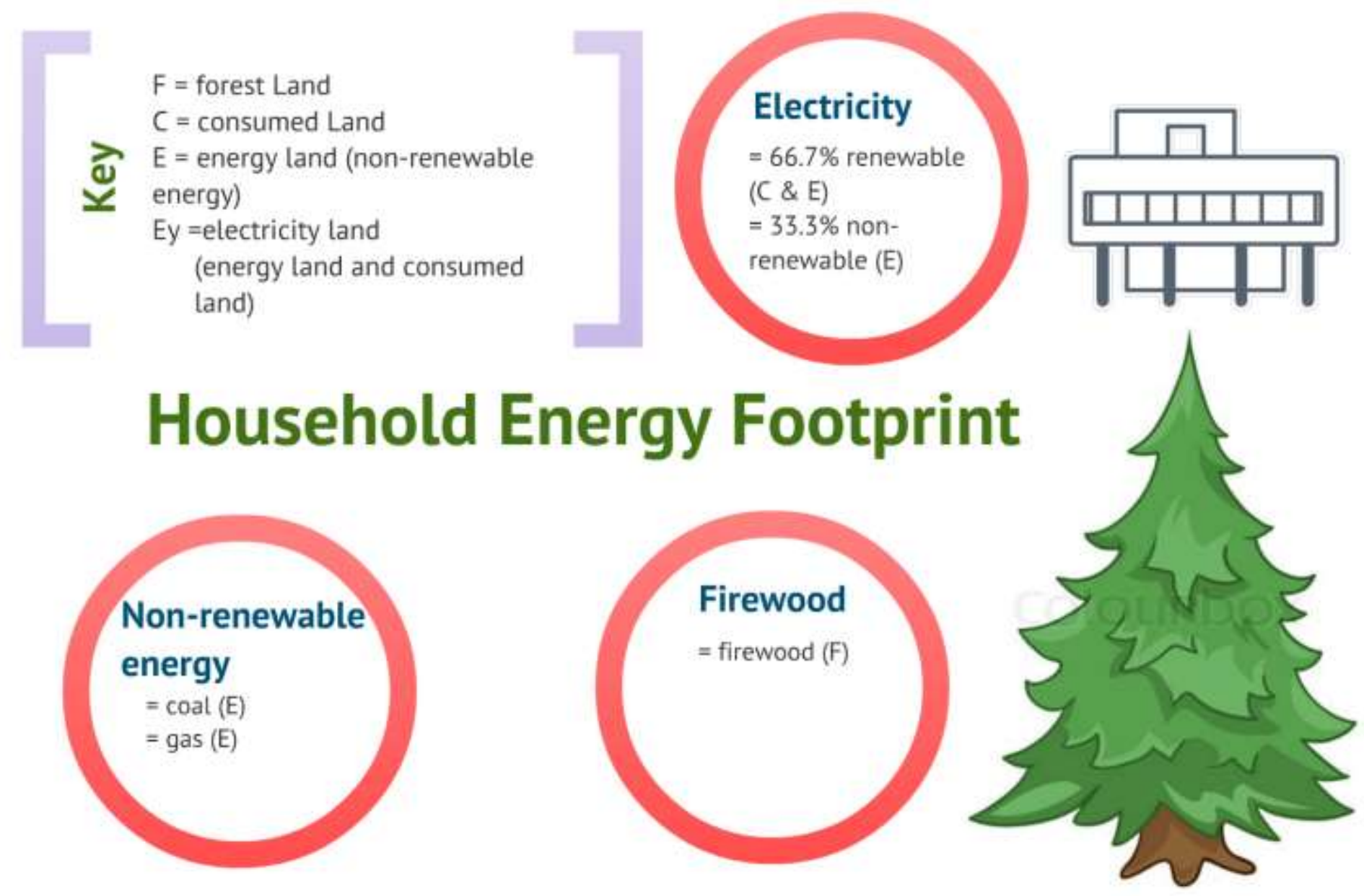

Figure 4.11: The Household Energy Footprint Map. 
According to HEEP, NZ households use 41.1GJ (11,410kWh) of energy per year (Isaacs et al. 2010, p.14), approximately half of which is electricity (28.08GJ or 7,800kWh) (Isaacs et al. 2010, table 6). Using the 2007 figure of 1,667,205 dwellings, NZ used 46.81 million GJ of electricity. MED's (2010) top-down figures for electricity are similar at 44.84 million GJ or, divided equally amongst households, 26.90GJ/dwelling. The balance of the operational energy is considered to be solid fuel.

\section{Energy for cooking and appliances}

HEEP found electrical appliances consume 37\% of all electricity (Isaacs et al. 2010, figures 14 \& 18 ), totalling $10.39 \mathrm{GJ}$. Of this, refrigeration is $27 \%$ or $2.81 \mathrm{GJ}$, the kitchen consumes $9 \%$ or $0.94 \mathrm{GJ}$, and entertainment is $18 \%$ or $1.87 \mathrm{GJ}$. In total, food and consumer goods required 5.61GJ making up $20 \%$ of the total household electricity. The remaining $80 \%$ of electricity is for hot water, lighting and heating, totalling $22.47 \mathrm{GJ} /$ dwelling or 37.5 million GJ of electricity for all NZ households.

\section{Solid Fuel}

HEEP research found that previous MED calculations for the average household use of solid fuel were an underestimate (13.7 million GJ compared to 8.35 million GJ) (Isaacs et al. 2010, p. 22; Ministry for Economic Development, 2010 p. 22-23). Data suggest that $85 \%$ of solid fuel used in the home is wood and 15\% coal (Isaacs et al., 2010, p. 22 and 160; Statistics New Zealand, 2006b). According to HEEP, NZ consumes the equivalent of $6.98 \mathrm{GJ}$ of wood energy per household with a forest footprint of 100,796ha, and 1.23GJ of coal per year with an EF of 63,917ha of energy land. However, the wood EF is likely to be a slight over-estimate as the firewood is assumed to be grown in a plantation forest (section 3.5.1).

\subsubsection{Total Household Energy}

Table 4.38 shows the energy use of NZ households. The electricity for the operation of consumer goods and food-related consumer goods has been subtracted from the total amount, so table 4.38 should not be used as the actual average annual household energy EF. 
Table 4.38: Annual household energy use

\begin{tabular}{|lcccc|}
\hline \multicolumn{1}{|c}{ Fuel type } & $\begin{array}{c}\text { Household energy } \\
\text { consumption }\end{array}$ & $\begin{array}{c}\text { NZ energy } \\
\text { consumption }\end{array}$ & $\begin{array}{c}\text { EF per } \\
\text { house }\end{array}$ & NZ EF \\
\cline { 2 - 5 } & GJ & GJ & NZha & NZha \\
\hline Electricity & $\mathbf{2 8 . 0 8}$ & $46,815,116$ & 0.0811 & 135,155 \\
\hline $\begin{array}{l}\text { Consumer goods and } \\
\text { food energy }\end{array}$ & 5.61 & $9,353,660$ & 0.0162 & 108,151 \\
\hline Electricity sub-total & $\mathbf{2 2 . 4 7}$ & $\mathbf{3 7 , 4 6 1 , 4 5 6}$ & $\mathbf{0 . 0 6 4 9}$ & $\mathbf{1 0 8 , 1 5 1}$ \\
\hline Non-renewable fuels & 5.75 & $19,859,813$ & 0.0383 & 63,917 \\
\hline Wood & 6.98 & $11,641,959$ & 0.0605 & 100,796 \\
\hline Total & $\mathbf{3 5 . 2 0}$ & $\mathbf{6 8 , 9 6 3 , 2 2 8}$ & $\mathbf{0 . 1 6 3 7}$ & $\mathbf{2 7 2 , 8 6 4}$ \\
\hline
\end{tabular}

NZ required 272,864ha of land for household energy consumption in 2007. Of this, the renewable electricity EF (66.7\%) is consumed land totalling 24,987 ha, the wood footprint is 100,796 ha of forest land, and the remaining 147,081 ha is energy land. 


\subsection{New Zealand Housing Footprint}

NZ has 1,651,542 dwellings (Statistics New Zealand, 2006d), here considered as separate houses, apartments and baches. The housing EF has six parts: physical area, impervious services, garden space, embodied energy, construction and demolition waste, and timber building materials, requiring three land types:

1. Consumed land of the dwelling EF, additional impervious structures and garden land. Land is also required for the landfill for construction and demolition waste from housing;

2. Energy land for the construction, maintenance, demolition and disposal of housing and the embodied energy in the material of the dwelling; and

3. Forest land for the construction wood.

The Housing Footprint Map is shown in figure 4.12.

\subsubsection{Housing Types}

In 2008 the NZ MfE reported that 163,438ha were covered in built-up structures; however there is no breakdown of this between buildings and other impervious surfaces, such as driveways. An alternative option is to use bottom-up data. To do this, the average areas of a NZ section and dwelling, driveway and other impervious areas are multiplied by the total housing stock.

New houses in NZ have increased from $121 \mathrm{~m}^{2}$ in 1976 (Dudding, 2010) to $218 \mathrm{~m}^{2}$ in 2007 (Statistics New Zealand, 2011a). Conversely, the average number of people per household is predicted to fall to 2.4 by 2031 (Statistics New Zealand, 2009b) meaning increased floor space per person. The average size of the NZ housing stock also varies by region (Ghosh \& Vale, 2009; Isaacs et al., 2010). The official Quotable Value New Zealand (QV) website (QV New Zealand, 2011) suggests an average floor area of $149 \mathrm{~m}^{2}$. 


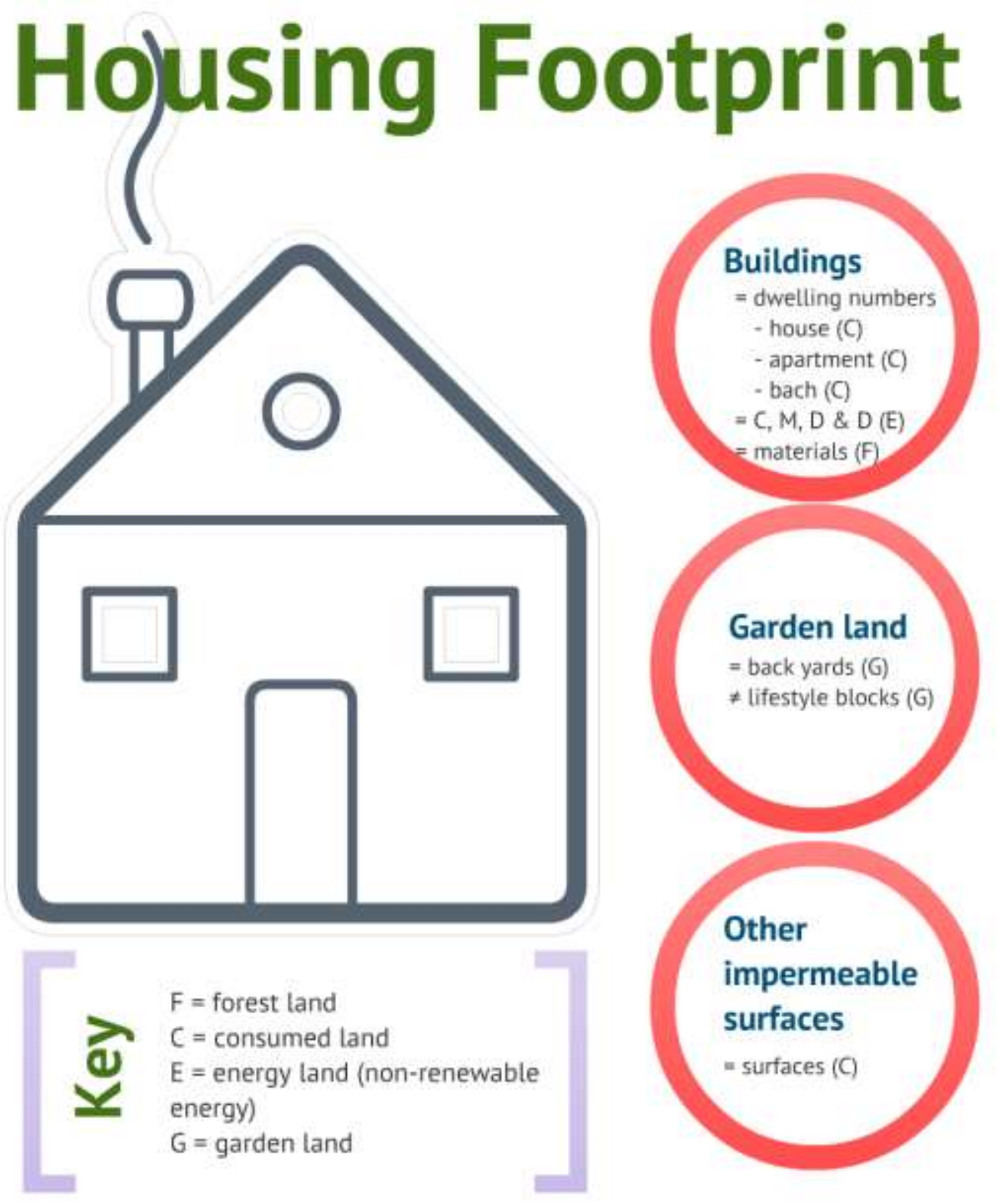

Figure 4.12: The Housing Footprint Map. 


\subsubsection{Physical Land}

The average size of an apartment is $118 \mathrm{~m}^{2}$ (Ghosh and Vale, 2009) and the NZ bach is estimated at $74 \mathrm{~m}^{2}$. All separate houses and baches are assumed to be single storey, and apartment blocks an average of five storeys. For the category 'separate houses' this will produce a small overestimate as there are increasing numbers of two storey houses (Immigration NZ, 2010) (table 4.39).

Table 4.39: Land occupied by residential buildings in 2007

\begin{tabular}{|lccc|}
\hline \multirow{2}{*}{ Floor area } & Number of dwellings & Average floor area & NZ EF \\
\cline { 2 - 4 } & & $\mathrm{m}^{2}$ & ha \\
\hline Separate houses & $1,330,047$ & 149 & 19,818 \\
\hline Apartments & 262,824 & 118 & 620 \\
\hline Baches & 74,334 & 74 & 5,501 \\
\hline Total & $\mathbf{1 , 6 6 7 , 2 0 5}$ & n/a & $\mathbf{2 5 , 9 3 9}$ \\
\hline
\end{tabular}

\subsubsection{Impervious Surfaces}

Ghosh and Vale (2009; table 3) measured the area of impervious land in five Auckland suburbs (using aerial photographs) to average $105 \mathrm{~m}^{2}$ per detached house, $74 \mathrm{~m}^{2}$ per apartment, and $112 \mathrm{~m}^{2}$ per bach. Using these values along with the number of dwellings (table 4.39) NZ residential buildings consume 16,795 ha of impervious surfaces such as driveways, garages, sheds and decking.

\subsubsection{Garden Land}

Here garden land is all residential land not used for the commercial growing of food, forests, or rearing livestock, and not included in the 'consumed land' category (buildings or other impervious surfaces). There is little information regarding the extent of garden land in NZ, although the average size of a NZ garden is decreasing (Emigrate New Zealand, 2011). The total garden EF was calculated using the average section size for different dwelling types, and then subtracting the area consumed by dwellings and impervious surfaces. The average garden area is $508 \mathrm{~m}^{2}$ for 
detached houses, $141 \mathrm{~m}^{2}$ for apartments and $701 \mathrm{~m}^{2}$ for baches. In 2007 there were 76,483ha of garden land.

\section{Lifestyle Blocks}

Paterson (2005, p. 1) describes a lifestyle block as "a rural smallholding attractive to people who wished to live in a rural lifestyle but whose income was derived from non-farming activities". This definition suggests a lifestyle block is garden land. A Kapiti Coast District Council (2010, p. 10) report supports this, noting that although some land defined as lifestyle block is likely to be used for crop, grazing or forest land, most falls into the category of garden land. In 2007 lifestyle blocks occupied 862,812ha of land (Paterson, 2005, citing Sanson, Cook and Fairweather, 2004); more than 20 times the total area required by dwellings and related impervious land.

This research does not account for lifestyle blocks as garden land. This is because although the land is in private ownership and therefore 'consumed' it is productive land that could be used in the future.

\subsubsection{Housing Construction and Demolition Waste}

Residential C\&D waste was $65 \%$ of C\&D waste making 270,745 t of waste to landfill each year. The conversion factor for high density waste is 0.00013 hectares of consumed land per tonne of waste (MfE, 2009a) and 0.00079 hectares of energy land per tonne of waste (Barrett \& Simmons, 2003). The residential EF for C\&D waste is 249ha/year.

\subsubsection{Timber Building Materials}

Forest land produces wood and paper products and timber for the construction of NZ buildings. In this research it is assumed that $100 \%$ of NZ's residential housing stock is timber frame, although alternative materials are increasingly being used (Page, 2008).

The total volume of timber in NZ houses was calculated; both for the average house/bach/apartment with timber floors and for a house with a concrete slab floor. Data from the Canberra EF report (CSIRO, 1998) with average NZ house sizes produced an estimate of $17 \mathrm{~m}^{3}$ 
of wood for a detached house with wooden floors, $14 \mathrm{~m}^{3}$ for a house with a concrete slab floor, $8.5 \mathrm{~m}^{3}$ for a bach, and $5 \mathrm{~m}^{3}$ for an apartment. The CSIRO suggests an additional $39 \%$ of timber is required for maintenance, repairs and alterations over the life of a house (CSIRO, 1998). Pinus radiata is the most commonly-used wood for housing construction and grows between $18 \mathrm{~m}^{3} /$ ha/year (New Zealand Forest Industries Council, 2010) and $25 \mathrm{~m}^{3} /$ ha/year (Evergreen Forests Limited, 1996). The more conservative estimate of $18 \mathrm{~m}^{3} /$ ha/year has been used. The minimum useful life for dwellings is 50 years $(\mathrm{DBH}, 2011)$ and the economic life 100 years (Mithraratne, Vale, \& Vale, 2007). An average of 75 years is used here. Page (2009, p. 35) found $88 \%$ of NZ houses (including baches) have timber frames with concrete floor slabs and $12 \%$ are timber frame with timber floors. This figure is for new houses, but is used in in the absence of more detailed data on the proportion of concrete floors in the general housing stock. Detached houses with timber floors have a forest EF of $179 \mathrm{~m}^{2} /$ year, those with concrete slab floors a footprint of $0.0145 \mathrm{ha} /$ year, baches a footprint of $89 \mathrm{~m}^{2} /$ year, and apartments $51 \mathrm{~m}^{2} /$ year. The estimated total forest EF needed for the construction and maintenance of NZ's housing stock in 2007 is 21,718 ha of forest land.

\subsubsection{Embodied Energy of Housing}

The construction, maintenance, demolition and disposal of houses require energy for the transportation of building materials, earth works and machinery. The following section is based on an assumed 75-year life for a NZ dwelling.

The embodied energy in the initial construction of a 'light construction type' timber frame house in NZ, including the foundation, floor, walls, roof, joinery, electrical work, plumbing and finishes, is $1.80 \mathrm{GJ} / \mathrm{m}^{2}$ (Mithraratne, Vale and Vale, 2007, table 7.7). Maintenance energy over 75 years increases the embodied energy by $0.94 \mathrm{GJ} / \mathrm{m}^{2}$ (Mithraratne, Vale and Vale, 2007, figure 7.3). Adalberth (1997, table 3) established that the energy for the demolition of a house is $0.04 \mathrm{GJ} / \mathrm{m}^{2}$ and for its disposal is $0.11 \mathrm{GJ} / \mathrm{m}^{2}$. The annual total embodied energy (including construction, maintenance, demolition and disposal) is thus $0.0385 \mathrm{GJ} / \mathrm{m}^{2} /$ year. Using the average dwelling sizes in table 4.39 , a detached house has a footprint of $383 \mathrm{~m}^{2} /$ year, a bach $303 \mathrm{~m}^{2} /$ year, and an 
apartment $190 \mathrm{~m}^{2} /$ year. The total embodied energy EF for NZ's housing stock is therefore $58,159 h a / y e a r$.

\subsubsection{Total Housing EF}

In 2007, NZ's total housing EF was 199,343ha, of which $38 \%$ was garden land, $29 \%$ energy land, $22 \%$ consumed land, and $11 \%$ forest land (table 40 ).

Table 4.40: EF and corresponding land for NZ housing and household energy in 2007

\begin{tabular}{|c|c|c|c|c|c|}
\hline Comnonent & Consumed land & Garden land & Forest land & Energy land & NZ EF \\
\hline & NZha & NZha & NZha & NZha & NZha \\
\hline Buildings & 42,734 & 76,483 & & & 119,217 \\
\hline C\&D waste & 35 & & & 214 & 249 \\
\hline Construction timber & & & 21,718 & & 21,718 \\
\hline Embodied energy & & & & 58,159 & 58,159 \\
\hline Total & 42,769 & 76,483 & 21,718 & 58,373 & 199,343 \\
\hline
\end{tabular}




\subsection{New Zealand Infrastructure Footprint}

Infrastructure is one of the three categories in the NZ citizenship footprint, which includes all goods and services supplied by the government or state agencies, and which can be defined as those services received in return for taxes. Figure 4.13 is the Citizenship Footprint Map.

The infrastructure discussed here is publicly owned or owned and operated in a public/private partnership, whereby the construction and maintenance is paid for through national and regional taxes (The Treasury, 2011). Some smaller infrastructure was not included, such as bridges and bicycle paths, but these are not considered to contribute significantly to the infrastructure EF.

\subsubsection{Roading and Walkway Infrastructure}

The NZ MfE (2009b) reported there were 6,519ha of land for transport infrastructure in 2009. Roading and pedestrian walkways consume the physical land they are built on, and use energy land for their embodied and operational energy (e.g. traffic and street lights). The length of road per person in NZ is one of the highest in the world (New Zealand Transport Authority, 2011) at $22 \mathrm{~m}$ per person (the total length of roading is 94 million metres). Table 4.41 shows the breakdown of different types of roads, ranging from $199 \mathrm{~km}$ of motorway carrying $10 \%$ of NZ's traffic, to $65,601 \mathrm{~km}$ of rural roading (Huang, 2010). Roads widths vary between $10 \mathrm{~m}$ and $20 \mathrm{~m}$ (Transit New Zealand, 1999, 2002).

Table 4.41: Roading the NZ EF for 2007

\begin{tabular}{|lccccc|}
\hline \multirow{2}{*}{ Roading } & Length & Average width & Portion paved & Consumed EF & Energy EF \\
\cline { 2 - 6 } & $\mathrm{m}$ & $\mathrm{m}$ & $\%$ & NZha & NZha \\
\hline Motorways & 199,000 & 20 & 100 & 398 & 362 \\
\hline State highways & $10,906,000$ & 12 & 99.5 & 15,087 & 11,987 \\
\hline Urban road & $17,298,000$ & 12 & 100 & 20,758 & 10,558 \\
\hline Rural roads & $65,601,000$ & 10 & 61 & 65,601 & 22,394 \\
\hline Footpaths & $34,596,000$ & 1.8 & 100 & 6,227 & 5,668 \\
\hline Total & $\mathbf{1 2 8 , 6 0 0 , 0 0 0}$ & n/a & n/a & $\mathbf{1 0 8 , 0 7 1}$ & $\mathbf{5 0 , 9 7 0}$ \\
\hline
\end{tabular}




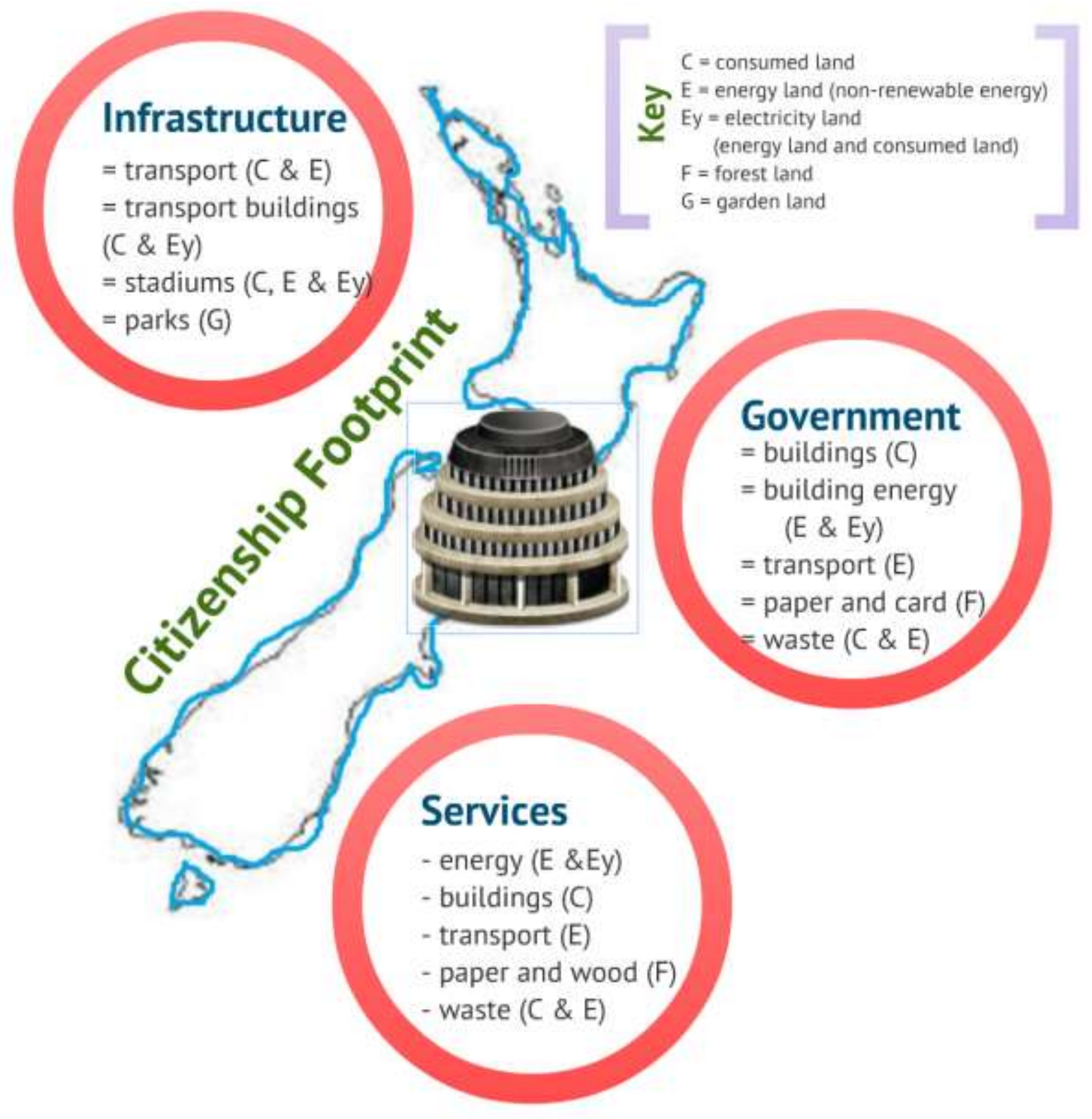

Figure 4.13: The Citizenship Footprint Map. 
The area covered by NZ roads and footpaths in 2007 was 108,071ha, of which Auckland roads comprise $15.8 \%$ (Huang, 2010) but service one-third of the population. Of the area covered by NZ roads $74 \%$ is paved, with $75 \%$ chipseal, $24 \%$ asphalt concrete mix, and $0.7 \%$ other forms of paving such as bricks (Land Transport Safety Authority, 2004, p. 3).

A range of data sources were used to calculate the embodied energy of three types of road surfacing (Huang, 2010; Alcorn, 2003; Mithraratne, 2011) assuming an optimistic life of 30 years. Estimates of the embodied $\mathrm{CO}_{2}$ of roads in Huang (2010, p.239) were used to calculate the embodied energy of different roading types. The asphalt-concrete mix and 'other' surfacing have an embodied energy of $0.41 \mathrm{GJ} / \mathrm{m}^{2}$, chipseal $0.18 \mathrm{GJ} / \mathrm{m}^{2}$ and unpaved $0.10 \mathrm{GJ} / \mathrm{m}^{2}$. The total embodied energy EF for all NZ roads and footpaths in 2007 was 50,970ha of energy land.

\subsubsection{Railway Infrastructure}

Railway infrastructure was divided into three components: tracks, platforms and buildings. The Ministry for Transport (2009c, p. 21) reports there are 4,000km of railway track in NZ although only 44\% (Wikipedia, 2011b) is used to transport people (the remainder carries only freight). The width allowed for a single train is only 3 metres (Smith, 2003), however a digital map of NZ shows the railway corridor is typically 20 metres wide (Koordinates, 2010). NZ railways therefore cover an area of 826ha. Huang (2010) estimated the embodied energy of the steel track, sleepers and crushed stone ballast had an annual EF of $0.0037 \mathrm{ha} / \mathrm{m}(0.55 \mathrm{GJ} / \mathrm{m})$, totalling $14,707 \mathrm{ha}$ of energy land for 2007.

Only the consumed land of Auckland and Wellington's railway buildings was included here, because these calculations are time consuming and unlikely to influence the overall EF. McCracken (2008) noted the Wellington railway station (yards, sheds and buildings) covered 28ha, and Google Maps (Google, 2012) show the Auckland Britomart block is 0.5ha. There are 49 railway stations in Wellington and 37 stations in Auckland, totalling 86 platforms. Platforms are approximately $1,000 \mathrm{~m}^{2}$ and therefore occupy 8.6 hectares of consumed land. The total consumed land EF of NZ railway infrastructure is $863 \mathrm{ha}$. 


\subsubsection{Aviation Infrastructure}

There are 36 commercial airports in NZ. Auckland and Christchurch are categorised as 'full size', and a further four are 'international' because they can host international flights (Wikipedia, 2011a). The remainder are 'small' airports. A number of airports across these categories were sampled for their total area, runway dimensions, operational energy and embodied energy of their buildings. These were used to inform the airport calculations.

The total area of airports in NZ is 8,224ha, of which $97 \%$ is grassed, $3 \%$ runways and $<1 \%$ buildings. Airport buildings are assumed to last 50 years and require $5 \mathrm{GJ} / \mathrm{m}^{2}$ of initial construction energy (CSIRO, 1998), with a total construction EF of 193ha. Previously it was established that initial construction is $60 \%$ of overall embodied energy, bringing the total EF to 322 ha (table 4.42 ).

In 2007 the total $\mathrm{CO}_{2}$ emissions from operation of the main buildings of NZ's two largest airports was $16,596 \mathrm{t}$ with an EF of $1,596 \mathrm{ha}$, which is $0.0100 \mathrm{ha} / \mathrm{m}^{2}$. It is assumed that smaller airport buildings will have lower emissions. Medium airports are assumed to have half the EF and small airports one fifth of that of large airport buildings. The operation footprint of NZ's airports is 2,885ha.

Table 4.42: Data from sample airports used for the aviation infrastructure EF

\begin{tabular}{|c|c|c|c|c|c|c|c|}
\hline Airport type & $\begin{array}{c}\text { Garden } \\
\text { land }\end{array}$ & $\begin{array}{l}\text { Area of } \\
\text { runway }\end{array}$ & $\begin{array}{l}\text { Area of } \\
\text { buildings }\end{array}$ & $\begin{array}{c}\text { Operational } \\
\text { energy of } \\
\text { buildings }\end{array}$ & $\begin{array}{l}\text { Embodied } \\
\text { energy EF } \\
\text { of } \\
\text { buildings }\end{array}$ & $\begin{array}{c}\text { Embodied } \\
\text { energy of } \\
\text { runways }\end{array}$ & NZEF \\
\hline & NZha & NZha & NZha & NZha & NZha & NZha & NZha \\
\hline Full size $^{1}$ & 3,000 & 55 & 10 & 1,512 & 111 & 100 & 4,723 \\
\hline International $^{2}$ & 744 & 41 & 17 & 1,343 & 197 & 75 & 2,359 \\
\hline Small $^{3}$ & 4,800 & 140 & 1 & 30 & 11 & 255 & 5,096 \\
\hline Total full size & 8,544 & 235 & 29 & 2,885 & 320 & 430 & 12,178 \\
\hline
\end{tabular}


Airports are assumed to be paved with asphalt $\left(0.4057 \mathrm{GJ} / \mathrm{m}^{2}\right)$. There is $2,353,500 \mathrm{~m}^{2}$ of airport runway in NZ with an EF of 430ha of energy land per year. Airports also have paved areas for parking and taxiways but these were ignored here because of lack of data.

The total EF of NZ's aviation infrastructure for 2007 is 12,178ha, of which 70\% is garden land.

\subsubsection{Sports Stadia}

A case study of the EF of the 2003/04 FA Cup final (Collins et al., 2007, p. 470) provides insight into the resources required by large events. The research showed that stadia required $0.104 \mathrm{gha} / \mathrm{day}$, with an expected lifespan of 100 years or $0.000001 \mathrm{gha} / \mathrm{visitor}$. Infrastructure was less than $1 \%$ of the EF. NZ has 66 multi-purpose stadia for sports, concerts, cultural events and community celebrations with a total seating capacity of 566,007 . The physical land that stadia require will be calculated in relation to seating capacity. The average from three case studies gives $1.39 \mathrm{~m}^{2} /$ person (Forsyth Barr, 2011; Suncorp Stadium, 2010; Waikato Stadium, 2011) and a total of 78.7 ha of consumed land.

\section{Energy Land}

Previous construction, maintenance, demolition and disposal figures were used to calculate the embodied energy of sports stadia. The figures for a warehouse and an office building were averaged, giving $5.12 \mathrm{GJ} / \mathrm{m}^{2}$ over a 50 year life. The initial embodied energy of stadia is thus 477 ha energy land, which becomes 597ha/year over the building life. The embodied energy of NZ stadia is $0.0008 \mathrm{ha} / \mathrm{m}^{2}$ of stadium.

As there were no data for the operational energy of any of NZ's sports stadia, so the energy requirements of three USA stadia were used (Glubiak, 2009; Meinhold, 2012; New York Yankees, 2010). The average energy consumption of these was $585 \mathrm{MJ} / \mathrm{m}^{2}$ which, when compared to the operational energy requirements for dwellings $\left(241 \mathrm{MJ} / \mathrm{m}^{2}\right)$, restaurants $\left(832.5 \mathrm{MJ} / \mathrm{m}^{2}\right)$ and warehouses $\left(1,048 \mathrm{MJ} / \mathrm{m}^{2}\right)$, seems realistic. The operational energy footprint of $\mathrm{NZ}$ stadia is 1,321ha, comprising $23 \%$ consumed land and $77 \%$ energy land. The total stadium EF for NZ is 1,996ha, $15 \%$ of which is consumed land and the remainder energy land. 


\subsubsection{Public Garden Land}

NZ has 17,000 protected areas, covering 8.6 million hectares, equivalent to $32 \%$ of NZ's land area (Molloy, 2009). These include conservation parks, nature reserves, conservation land and recreation (and other) reserves (MfE, 2010a). Taking a top-down approach to calculating 'garden' land has limitations because only land defined as bioproductive (capable of producing crops and other resources) should be included. Consequently only urban parklands are included here.

The MfE Land Cover Database (MfE, 2009b, table 1) reports that NZ has 40,164ha of urban parkland and open space. From a bottom-up perspective, the average area of city and regional 'reserves' set aside by Local Councils is 10.87 ha per 1,000 residents (Milne, 2006) totalling 45,962ha.

\subsubsection{Total Infrastructure Footprint}

Table 4.43 below provides a summary of the infrastructure footprint.

Table 4.43: Total energy and land required for NZ Infrastructure

\begin{tabular}{|lcccc|}
\hline \multirow{2}{*}{ Components } & Garden land & Consumed land & Energy land & NZ EF \\
\cline { 2 - 5 } & NZha & NZha & NZha & NZha \\
\hline Roads & & 99,844 & 33,449 & 133,292 \\
\hline Footpaths & & 6,227 & 5,668 & 11,895 \\
\hline Railways & & 864 & 14,707 & 15,570 \\
\hline Airports & 8,544 & & 3,635 & 12,179 \\
\hline Stadia & & 308 & 1,609 & 1,918 \\
\hline Parks & 45,962 & & & 45,962 \\
\hline Total & $\mathbf{5 4 , 5 0 6}$ & $\mathbf{1 5 3 , 2 0 4}$ & $\mathbf{7 0 , 9 2 2}$ & $\mathbf{2 3 2 , 6 7 0}$ \\
\hline
\end{tabular}

Unfortunately there are minimal data either for the infrastructure or the embedded energy within it, and further research is required for a detailed analysis. It is estimated here that NZ's infrastructure footprint for 2007 was 59,069ha, 73\% of which was consumed land. 


\subsection{New Zealand Government Footprint}

This research examines two areas of government: national and local (State Services Commission, 2011). Section 4.11 deals with the footprint of public and private services such as defence, police, health care, tertiary education, infrastructure management and postal services.

Four methods are used to calculate the footprint of NZ's national and local governments. The first two are bottom-up EF calculations from government case studies, based on resource use and $\mathrm{CO}_{2}$ emissions, and the second two are from top-down national datasets. Each method has a different set of parameters used to calculate the institutions' footprint and therefore results are not directly comparable (table 4.44). The final government EF has been pieced together using calculations from the different methods.

\subsubsection{The Size of Government}

Central and local government administration and the defence services are important employers in NZ. In 2007 central government agencies employed 64,150 people (Department of Labour, 2010) making 52,683 Full-Time Equivalent (FTE) positions (State Services Commission, 2009). In 2007 local government employed 15,842FTEs.

\subsubsection{Method 1: Resource Use Case Studies for Government}

Two case studies are used here, one from national government MfE and one from local government (Waitakere City).

In 2007, the only national government department to publish an 'environmental report' was the MfE (MfE, 2007b). MfE's resource requirements were broken down into FTEs. Resources/FTE are examined and then scaled-up to represent the whole of central government, assuming thereby that all central government departments have a similar EF, and that the size of their EF reflects the number of employees. However, at the time of the report, MfE probably had the most progressive policies for reducing their own EF, making it potentially lower than that of other ministries. 
The area of the MfE offices is 5,941 $\mathrm{m}^{2}$ (MfE, 2007b, p. 83). There were 265 FTE staff, making $22.42 \mathrm{~m}^{2} /$ FTE. The building in which the MfE staff have offices (Environment House) has eight levels (Smith, 2012) thus occupying 0.0743 ha of land in total, or $3 \mathrm{~m}^{2} /$ FTE. On this basis the total national government consumed land footprint would be $15 \mathrm{ha}$.

Total forest land should include all wood and paper products such as desks, bookshelves, stationery, however the following section only considers paper. MfE used 21t of paper in 2007 (79.87kg/FTE). The recycled content varied (MfE, 2007b, p. 80 and 81). Previous calculations (section 3.5) found that paper made from virgin wood required 0.38 ha of forest land per tonne and recycled paper 0.19ha per tonne. The MfE paper has an EF of 0.0183ha/FTE of forest land. The NZ national government would thus require 4,407t of paper with an annual footprint of 964ha of forest land. Calculations in section 4.5.7 found the NZ government's portion of wood products was very small at 174 ha of forest land.

The MfE recycled $132 \mathrm{~kg} /$ FTE of paper, $56 \mathrm{~kg} / \mathrm{FTE}$ of plastic bottles, aluminium cans and glass. Waste to landfill was $10 \mathrm{~kg} /$ FTE. The waste footprint conversions in section 4.2 were used to give the following footprint figures. The total government footprint for landfill waste is $14 \mathrm{ha}, 87 \%$ of which is energy land.

Electricity was the only energy reportedly used in the building. The Ministry used 706,926kWh of electricity in 2006/07 (MfE, 2007b, p. 83) (280m²/FTE), 23\% of which is consumed land, totalling $1,452 \mathrm{ha}$ for the whole of government. A mid-range initial construction figure for office buildings of $4.26 \mathrm{GJ} / \mathrm{m}^{2}$ (Camilleri \& Jaques, 2001; Lukaszyk, n.d.; Lawson, 1995) was used with a life of 50 years. Construction made up $60 \%$ of the total embodied energy of the building. The building operation and embodied energy footprint is $0.05 \mathrm{ha} / \mathrm{FTE}$, so is $3,342 \mathrm{ha}$ for the whole of government.

MfE staff travelled 20,665km/FTE: 67\% for international travel, 30\% for national flights and only $2 \%$ road travel. Using the conversion factors from section 4.3, staff travel equates to $3,100 \mathrm{~m}^{2} / \mathrm{FTE}$, totalling $16,233 \mathrm{ha}$ for the whole of government. 
The MfE case study shows that each FTE has a footprint of 0.35ha. If the MfE case study is representative of resource use by central government, the government footprint for 52,683 FTEs is 20,009 ha. The largest component of the footprint is travel (81\%), with operation energy at $7 \%$, and the embodied energy of buildings and forest products each $6 \%$.

Waitakere City in Auckland was known as the 'Green City' and was a leader in environmental reporting (Koveshnikova, 2010). Data from Waitakere's 2007 'triple bottom line' report is used here, though because the council aimed to reduce its EF for operating (Waitakere City Council, 2009, p. 55), this could be an underestimate of the impact of all local government. In 2007 Waitakere employed 987 FTEs. The following section covers the paper, physical land and travel EF of Waitakere in 2007.

Waitakere council used 50 t of paper in $2007,73 \%$ of which was recycled and the remainder went into reports and publications (Waitakere City Council, 2009, p. 55) (121 $\mathrm{m}^{2} / \mathrm{FTE}$ ). This gives a value for all local governments in NZ of 192ha of forest land. Waitakere's total energy use was $3,519 \mathrm{~m}^{2} /$ FTE of which $89 \%$ was energy land. The equivalent for the whole of local government is 5,575ha. Data on the physical size of the Waitakere buildings was not available so the MfE calculations were used as a guide, resulting in an estimated 5ha for the whole of local government. Waitakere is a mix of both urban and rural areas. As a result the travel footprint per FTE could be lower than for many rural local governments. The Waitakere EF for land-based travel was $684 \mathrm{~m}^{2} /$ FTE and $171 \mathrm{~m}^{2} /$ FTE for air travel. The total local government EF for travel is therefore 1,355ha. Because of the limited Waitakere data a conservative estimate of 7,127ha was calculated for 2007 EF of NZ local government, with 53\% being energy land, 14\% consumed land, and the remaining $4 \%$ forest land. The local government EF is $4,500 \mathrm{~m}^{2} / F T E$, higher than the national government EF of 3,500m²/FTE.

\subsubsection{Method 2: Government $\mathrm{CO}_{2}$ Case Studies}

The ICLEI_Local Government for Sustainability Initiative (previously known as the International Council for Local Environmental Initiatives) (ICLEI, 2012)-popularised carbon accounting in local 
government. Carbon dioxide data for one national ministry and three local government organisations has been used here.

According to MfE's 2007 annual report (MfE, 2007b) the Ministry generated 897tCO -equivalent in 2006/07, a $22 \%$ increase from 2005/06. Using the carbon-dioxide-to-energy-land conversion of $10.4 \mathrm{t} / \mathrm{ha}$, this is 86 ha or $3,300 \mathrm{~m}^{2} /$ FTE. The total EF for central government is thus $17,147 \mathrm{ha}$, similar to the total MfE EF above, where energy land made up $81 \%$ of the EF.

ICLEI (2012) requires local government members to report on their environmental impacts. Three $\mathrm{CO}_{2}$ emissions estimates were located, all from urban centres, which are therefore biased toward urban activities. FTE numbers were not available for all three case studies so the city population was used as appropriate.

Waitakere City Council emitted 5,230t $\mathrm{CO}_{2}$ in the year 2008/09 (Waitakere City Council, 2009, p. 41). The 'corporate' component of Waitakere City Council accounts for an EF of 0.0029ha per Waitakere resident. Greenhouse Gas Emission reports by Wellington and Hamilton City Councils both have much higher $\mathrm{CO}_{2}$ emissions than Waitakere. Wellington City Council (Wellington City Council, n.d.) reported $12,577 \mathrm{t} \mathrm{CO}_{2}$ from their corporate activity $\left(67 \mathrm{~m}^{2}\right.$ per Wellington resident). Hamilton reported 9,000t $\mathrm{CO}_{2}$ (Hamilton City Council, 2008) (0.0061ha per Hamilton resident. The average of the three calculations is $52 \mathrm{~m}^{2} /$ resident, giving a NZ EF of 21,931 ha.

\subsubsection{Method 3: Government National Accounts}

This method uses national expenditure (Statistics New Zealand, 2009a) and data on energy per dollar spent (Statistics New Zealand, 2008a) for calculating the EF of central and local governments in NZ. It only considers their energy use, excluding the forest land for paper products and physical land for buildings. The Energy and Economy report shows that every $\$ 1,000$ spent by central government equates to $1.2 \mathrm{GJ}$ (1.4GJ for local governments). National Accounts show central government spent $\$ 5,846$ million and local governments $\$ 2,063$ million in the year ending June 2009. Together they consumed 9.9 million GJ with a total EF of 53,678ha, or $127 \mathrm{~m}^{2} /$ New Zealander, of which $6 \%$ is consumed land. 


\subsubsection{Method 4: EECA Energy Use Database for Government}

The final method uses EECA's online Energy End-Use Database (EECA, 2007). Central government has a footprint of 4,769 ha, $24 \%$ of which is consumed land. The major energy end-uses are space heating (27\%), lighting (24\%), and land transport (21\%). Local government had an EF of 9,776ha, $15 \%$ of which is consumed land. Their major energy end-uses are land transport (49\%), lighting (27\%), and water heating (11\%). The EECA figures only include land transport and exclude air travel.

\subsubsection{Comparison of the four methods for the Government Footprint}

Table 4.44 summarises the results from the four methods.

Table 4.44: Comparison of the results of four methods for calculating the EF of national and local government

\begin{tabular}{|lccc|}
\hline \multirow{2}{*}{ Method } & National government EF & Local government EF & NZ EF \\
\cline { 2 - 4 } & NZha & NZha & NZha \\
\hline 1- Resource use & 20,009 & 7,127 & 27,136 \\
\hline 2- $\mathrm{CO}_{2}$ case studies & 17,147 & 21,931 & 39,078 \\
\hline 3 - National Accounts & 39,830 & 13,848 & 53,678 \\
\hline 4-EECA end-use & 4,769 & 9,776 & 14,545 \\
\hline Average & $\mathbf{2 0 , 4 3 9}$ & $\mathbf{1 3 , 1 7 0}$ & $\mathbf{3 3 , 6 0 9}$ \\
\hline
\end{tabular}

Table 4.44 shows considerable disparity in the results. For national government, the MfE resource use case study provided the most detailed account, although the $\mathrm{CO}_{2}$ calculations give a much higher result even without the embodied forest land for paper and consumed land for buildings. The results for method 1 , are just below the average of the four methods and this method will therefore be used for the government EF. Table 4.45 provides a breakdown of these, indicating where the Waitakere figures were used in the absence of MfE figures. 
Table 4.45: The EF of the NZ government

\begin{tabular}{|lcccc|}
\hline \multirow{2}{*}{\begin{tabular}{l} 
Component \\
\cline { 2 - 5 }
\end{tabular}} & Forest land & Consumed land & Energy land & NZ EF \\
\cline { 2 - 5 } & NZha & NZha & NZha & NZha \\
\hline Physical land & & 20 & & 20 \\
\hline Office paper and publications & 1,330 & & & 1,330 \\
\hline Waste $^{1}$ & & 2 & 15 & 18 \\
\hline Office energy & & 978 & 6,049 & 7,027 \\
\hline C,M,D \& D & & & 1,505 & 1,505 \\
\hline Travel & & & 17,588 & 17,588 \\
\hline Total & $\mathbf{1 , 3 3 0}$ & $\mathbf{1 , 0 0 0}$ & $\mathbf{2 5 , 1 5 8}$ & $\mathbf{2 7 , 4 8 8}$ \\
\hline
\end{tabular}

1. Waitakere figures used in the absence of MfE figures.

The NZ national and local government employ a combined 68,523 FTEs and have an estimated EF of 0.4NZha/FTE. These figures are probably an underestimate as, at that time, both the MfE and Waitakere City Council had strong corporate visions to lower their own footprints. Missing from the analysis is further detail about the office EF such as electronic equipment, stationery (minus paper) and office furniture. Waste created by the construction and demolition of government buildings should also be included though it will be very small. 


\subsection{New Zealand Services Footprint}

The state sector provides a range of services, including health care, education, finance, defence, police and the postal service. Each requires operational energy for buildings, physical land, embodied energy of buildings and offices, wood and paper products, transport, and waste services.

\subsubsection{Building Operational Energy for Services}

The EECA End-Use Database (EECA, 2007) was used to ascertain the total energy required by the services sector. The sectors included were:

1. Communication

2. Education services (1): Pre-school, primary and secondary

3. Education services (2): Tertiary education

4. Health and welfare services

5. Other social and related community services

6. Sanitary and cleaning services

7. Water works and supply

The total service energy footprint according to EECA is $71,227 \mathrm{ha}, 19 \%$ of which is consumed land and the remainder energy land. The transport component of these calculations, including car travel and freight had an EF of 11,321ha of energy land. Subtracting this gives a new total of 59,906 ha of which $23 \%$ is consumed land.

\subsubsection{Physical Land for Services}

There are two methods for calculating the area of land required by service buildings. The first uses the total energy for building lights (EECA, 2007) and the average lighting energy per $\mathrm{m}^{2}$; the other uses the total energy per $\mathrm{m}^{2}$ of commercial and industrial buildings provided by the Ministry for Economic Development (2010a). 
The Building Research Association New Zealand (BRANZ) Building Energy Use Study (BEES) found commercial buildings require $31 \mathrm{kWh} / \mathrm{m}^{2} /$ year in lighting energy (Saville-Smith et al., 2010, p. 77). In the EECA End-Use Database, the total electricity for service industry lighting was 3,795,831GJ (1,054 million kWh). This means service industries have an office space of 34 million $\mathrm{m}^{2}(3,401 \mathrm{ha})$. Assuming $60 \%$ of these buildings are multi-storey (average of 3-storey), the total physical land covered in service buildings is 20 million $\mathrm{m}^{2}$ or 2,041ha.

\subsubsection{Construction, Maintenance, Demolition and Disposal of Services Buildings}

From the building area calculations above, it is possible to use the lighting information to estimate the construction energy required by service buildings. As previously noted, the initial embodied energy for office buildings is $4.26 \mathrm{GJ} / \mathrm{m}^{2}$ and for warehouses is $2.9 \mathrm{GJ} / \mathrm{m}^{2}$. The EECA tables were used to estimate whether service buildings were more like office buildings or warehouses. The total construction energy for service buildings is 144.9 million GJ over 50 years. The embodied energy of service buildings has a total EF of 32,190ha/year.

\subsubsection{Services - Paper and Wood products}

As found in section 4.5.7, 223,214t of paper forms the non-residential EF to be apportioned between government, services and consumer goods. Consumer goods accounted for 110,342t and government 5,205t. Therefore the remaining $107,667 t$ are for services with an EF of 22,524 ha. Wood products were similarly divided with a services EF of 18,490 ha of forest land. The total paper and wood EF is 41,014 ha of forest land.

\subsubsection{Services - Transport}

The EECA End-Use Database found the service industries' transport footprint was 2,395ha, 21\% of which was travel by car. The remaining 'freight' travel is probably already included in consumer goods freight travel. Calculations for national and international flights found service industries

were responsible for less than $2 \%$ of the distances flown (EF of 1,320ha). The total transport footprint for services in 2007 is 3,715ha of energy land. 


\subsubsection{Waste}

The waste footprint for services was calculated in section 4.2. The general waste footprint was 822ha of C\&D and general waste, and 207ha of recycling waste.

\subsubsection{Total Services Footprint}

Table 4.46 provides the footprint of NZ's services industry.

Table 4.46: Total EF of the services industry in 2007

\begin{tabular}{|lcccc|}
\hline \multirow{2}{*}{ Services industry } & Forest land & Consumed land & Energy land & NZ EF \\
\cline { 2 - 5 } & NZha & NZha & NZha & NZha \\
\hline Building operation & & 13,840 & 46,066 & 59,906 \\
\hline Transport & & 3,715 & 3,715 \\
\hline Physical land & 2,041 & & 2,041 \\
\hline Building embodied energy & & & 32,190 & 32,190 \\
\hline Paper, card and wood products & 41,014 & & & 41,014 \\
\hline Waste & & 412 & 618 & 1,029 \\
\hline Total & $\mathbf{4 1 , 0 1 4}$ & $\mathbf{1 6 , 2 9 3}$ & $\mathbf{8 2 , 5 8 8}$ & $\mathbf{1 3 9 , 8 9 6}$ \\
\hline
\end{tabular}

The largest component of the services industry footprint is the operational energy of the buildings, followed by their embodied energy. There are probably a number of consumer items that have not been taken into consideration in these calculations, such as hospital equipment, and equipment and goods required by universities and research laboratories, although these are probably accounted for in the consumer goods section. The EF of services in NZ in 2007 was 139,896ha. 


\subsection{New Zealand's 2007 Ecological Footprint}

The NZ 2007 EF has nine categories: food and drink, travel, consumer goods, holidays, household energy, housing, infrastructure, government, and services. Waste was also calculated and incorporated. The results now are compared with other NZ and international footprint studies, in both local and global hectares.

\subsubsection{Total footprint results}

The 2007 EF of NZ was 10.53 million hectares of land (table 4.47). The 2007 population of NZ was $4,228,300$, making an average EF of 2.49 NZha/person. Of this footprint, $92 \%$ was related to lifestyle choice, $4 \%$ is housing and household energy, and $4 \%$ is the citizenship footprint.

Table 4.47: Summary EF for NZ (2007)

\begin{tabular}{|c|c|c|c|c|}
\hline \multicolumn{2}{|c|}{ NZ EF 2007} & NZ EF & NZ EF & Portion \\
\hline & & NZha & NZha & $\%$ \\
\hline \multirow{4}{*}{ Lifestyle Footprint } & Food and drink & $5,952,627$ & 1.4078 & \multirow{4}{*}{$92 \%$} \\
\hline & Transport & 798,707 & 0.1889 & \\
\hline & Consumer goods & $2,393,176$ & 0.5660 & \\
\hline & Holidays & 508,820 & 0.1203 & \\
\hline \multirow{2}{*}{ Household Footprint } & Household energy & 272,864 & 0.0645 & \multirow{2}{*}{$4 \%$} \\
\hline & Households & 199,343 & 0.0471 & \\
\hline \multirow{4}{*}{ Citizenship Footprint } & Infrastructure & 232,670 & 0.0550 & \multirow{3}{*}{$4 \%$} \\
\hline & Government & 27,488 & 0.0065 & \\
\hline & Services & 139,896 & 0.0331 & \\
\hline & Total & $10,525,590$ & 2.4893 & \\
\hline
\end{tabular}

The EF is shown in further detail in table 4.48. Growing land for food is a considerable portion of the EF. Fishing land, grazing land and crop land combined make up 58\%. Fishing land alone represents $35 \%$ of NZ'S EF. As discussed earlier a number of authors have recognised the limitations of including the fishing land in the footprint analysis. The fishing land is particularly difficult because it skews the results and causes other footprint components to look insignificant.

Figure 4.14 shows a breakdown of the NZ EF with fishing land removed. The energy land now makes up $47 \%$ of the total. Energy land is the total forested land required to sequester the $\mathrm{CO}_{2}$ 
released by New Zealanders into the earth's atmosphere, and includes both NZ plantation forests and indigenous forests.

Table 4.48: EF CLUM of NZ in 2007

\begin{tabular}{|c|c|c|c|c|c|c|c|}
\hline EF Category & $\begin{array}{l}\text { Fishing } \\
\text { land }\end{array}$ & $\begin{array}{c}\text { Energy } \\
\text { land }\end{array}$ & $\begin{array}{l}\text { Grazing } \\
\text { land }\end{array}$ & $\begin{array}{l}\text { Forest } \\
\text { land }\end{array}$ & $\begin{array}{l}\text { Crop } \\
\text { land }\end{array}$ & $\begin{array}{l}\text { Consumed } \\
\text { land }\end{array}$ & $\begin{array}{c}\text { Garden } \\
\text { land }\end{array}$ \\
\hline & NZha & NZha & NZha & NZha & NZha & NZha & NZha \\
\hline Food and drink & $3,700,167$ & 434,013 & $1,294,161$ & 85,652 & 412,264 & 26,369 & \\
\hline Transport & & 798,606 & & & & 101 & \\
\hline $\begin{array}{l}\text { Consumer } \\
\text { goods }\end{array}$ & & $1,056,853$ & 732,981 & 528,449 & 15,993 & 58,899 & \\
\hline Holidays & & 506,608 & & & & 2,212 & \\
\hline $\begin{array}{l}\text { Household } \\
\text { energy }\end{array}$ & & 147,081 & & 100,796 & & 24,987 & \\
\hline Housing & & 58,373 & & 21,718 & & 42,769 & 76,483 \\
\hline Infrastructure & & 70,922 & & & & 107,243 & 54,506 \\
\hline Government & & 25,158 & & 1,330 & & 1,000 & \\
\hline Services & & 82,588 & & 41,014 & & 16,293 & \\
\hline Total & $3,700,167$ & $3,180,202$ & $2,027,142$ & 778,960 & 428,257 & 279,873 & 130,989 \\
\hline
\end{tabular}

With fishing land subtracted, grazing land is $30 \%$ of the EF. Grazing land produces meat, dairy products, wool and grazing for pets. Forest land is the next largest at $11 \%$ of the footprint. Most forest land was for the production of paper and wood consumer products and packaging, and for firewood. Crop, consumed and garden land made up 6\%, $4 \%$ and $2 \%$ respectively.

Alternatively, the results of this research can be expressed in relation to each category's proportion of the total footprint. Different scenarios have been presented in table 4.49 depending on what footprint categories have been included or excluded. 


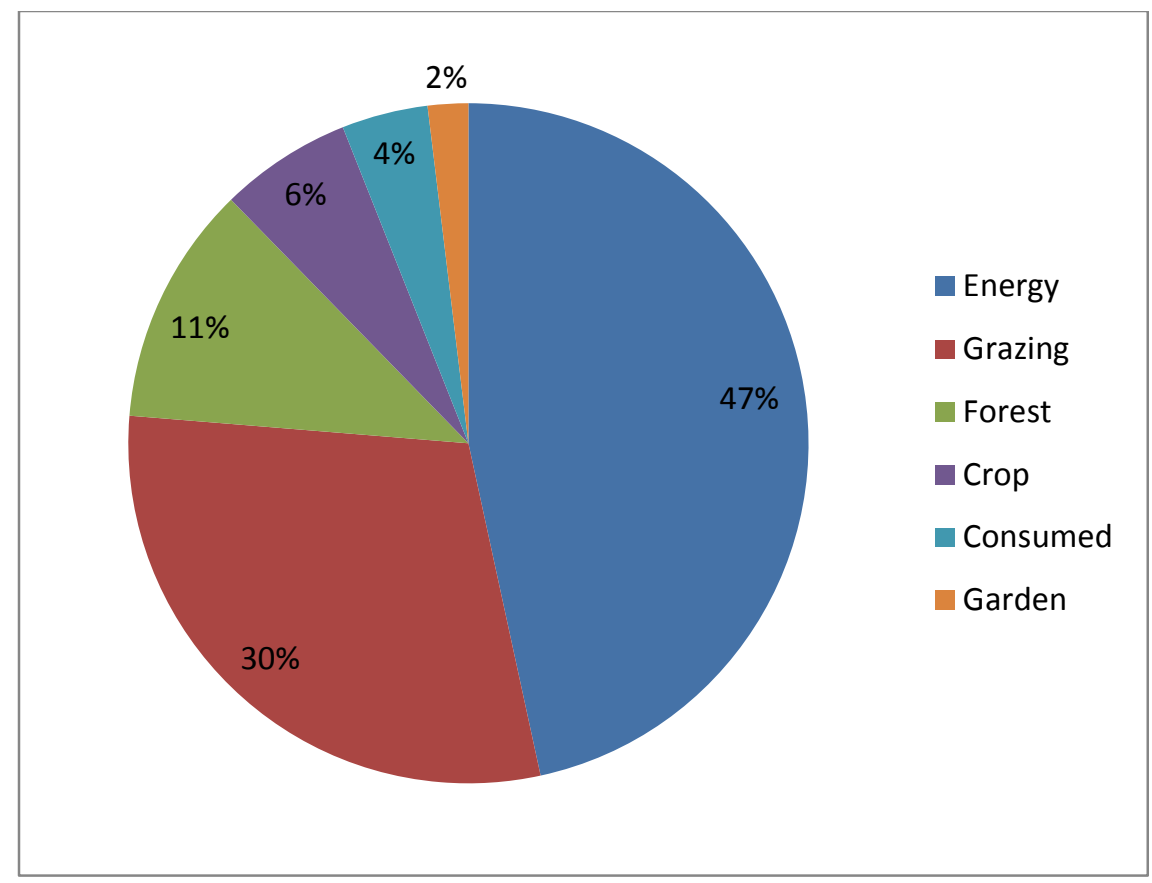

Figure 4.14: Distribution of the 2007 NZ EF by land type excluding fishing land.

The different EF category proportions in table 4.49 show how NZ EF calculations differ depending on what is and is not included. The review of a range of international case studies found many did not include a fishing land component. Removing fishing land from the current study reduces the food and drink EF by $24 \%$, increasing other sections by as much as $12 \%$. Pets contribute $28 \%$ of the consumer goods section and represent 7\% of NZ's total EF. This suggests they are an important component of the total EF and their impact needs to be considered in future resource accounting projects. If both pets and fishing are removed the EF looks different, with food and consumer goods contributing $34 \%$ and $28 \%$ respectively, transport $12 \%$, and housing and holidays $9 \%$ and $8 \%$ respectively.

Many EF projects report the total transport EF as one category, rather than including it in the other categories as here. Amalgamating the transport footprint for the current research did not change the distribution greatly. When all transport is in one category, and fishing and pets are removed, transport is $24 \%$ of the EF and consumer goods $22 \%$. 
Table 4.49: Comparison of different land category scenarios for the 2007 NZ EF

\begin{tabular}{|lcccccc|}
\hline \multirow{2}{*}{$\begin{array}{c}\text { Current } \\
\text { research EF }\end{array}$} & Total & $\begin{array}{c}\text { No } \\
\text { fishing }\end{array}$ & $\begin{array}{c}\text { No } \\
\text { pets }\end{array}$ & $\begin{array}{c}\text { No fish, no } \\
\text { pets }\end{array}$ & $\begin{array}{c}\text { All } \\
\text { transport }\end{array}$ & $\begin{array}{c}\text { All transport, no fish, } \\
\text { no pets }\end{array}$ \\
\cline { 2 - 7 } NZha & NZha & NZha & NZha & NZha & NZha \\
\hline Food and drink & $57 \%$ & $31 \%$ & $58 \%$ & $34 \%$ & $52 \%$ & $31 \%$ \\
\hline Transport & $8 \%$ & $11 \%$ & $8 \%$ & $12 \%$ & $15 \%$ & $24 \%$ \\
\hline $\begin{array}{l}\text { Consumer } \\
\text { goods }\end{array}$ & $23 \%$ & $35 \%$ & $18 \%$ & $28 \%$ & $20 \%$ & $22 \%$ \\
\hline Holidays & $5 \%$ & $7 \%$ & $5 \%$ & $8 \%$ & $0 \%$ & $1 \%$ \\
\hline $\begin{array}{l}\text { Household } \\
\text { energy }\end{array}$ & $3 \%$ & $3 \%$ & $2 \%$ & $3 \%$ & $6 \%$ & $10 \%$ \\
\hline Housing & $2 \%$ & $8 \%$ & $6 \%$ & $9 \%$ & $4 \%$ & $6 \%$ \\
\hline Citizenship & $4 \%$ & $5 \%$ & $4 \%$ & $6 \%$ & $3 \%$ & $6 \%$ \\
\hline Waste & $0.1 \%$ & & & & & \\
\hline
\end{tabular}

Also, as in a number of other case studies, waste was calculated separately, even though the waste $\mathrm{EF}$ is less than $1 \%$ of the total and does not affect the distribution of the footprint between categories.

The particular selection of land and EF categories to include in calculations makes a considerable difference to the total EF and the EF distribution.

\subsubsection{NZ's EF in Global Hectares}

The results above are presented in NZha, because NZ yields were used in the calculations. As discussed in chapter 3.4, not all land types are the same and conversions can be used to make them internationally comparable. The GFN created a EF method that allows for the comparison of consumption between countries (Ewing et al., 2010). Their EF calculations are based on world average yields, reflecting the interconnectedness of the world's trading systems. This method emphasises resource use within planetary boundaries. The GFN uses two conversions for each of the seven different land types: yield factors specific to a country, and equivalence factors. The local hectare results above are converted to global hectares by multiplying each land type by the corresponding equivalence factor and yield factor (table 3.1). The NZ EF becomes 16.5 million gha, or 3.9gha per New Zealander. If fishing land is subtracted, the final EF is 15.2 million gha or 3.6gha/person. The following section compares these results with other footprint projects 
involving NZ. Comparisons are made using local and global hectares and a range of scenarios for which components are included or excluded.

\subsubsection{Case Study Comparisons}

A number of projects have considered the NZ EF, including Bicknell et al. (1998), McDonald and Patterson (2003; 2004), Huang (2010), GFN (2010) and Field (2011). GFN includes NZ in their global comparison, expressing the results in global hectares, whilst some local footprint projects have used local hectares.

Perhaps the most well-known and widely used results are those from the GFN (GFN, 2011). Every three years GFN recalculates the NZ EF as part of a worldwide dataset (Ewing et al., 2010). The 2010 publication shows the 2007 NZ EF was 20.5 million gha (4.9gha/person), 30\% more than the result from the current project when expressed in gha.

The major differences are in the crop and grazing land. GFN results show that New Zealanders required 3 million gha of crop land and just under 1 million gha of grazing land. In comparison, this research found the reverse, with 1.1 million gha of crop land and 5 million gha of grazing land (table 4.50). Forest land is also quite different. The GFN total for forest land is 5.3 million gha compared with a wood and paper EF of 2.9 million gha in this research. The reason for the difference is not clear and GFN do not provide detailed information about the assumptions underpinning their global average yields.

However for a high productivity country like NZ, these global averages are probably very different from NZ yields. As an example, the global average yield for wood is $1.81 \mathrm{~m}^{3} / \mathrm{gha} /$ year whilst NZ's yield is between $18 \mathrm{~m}^{3}$ and $25 \mathrm{~m}^{3} / \mathrm{NZha}$ /year; showing NZ forest land to be 10 to 14 times more productive than the world average. Milk is another problematic product. The global average is 1,850kg/gha (GFN, 2011, livestock_intensity_n_grazing), whilst the NZ average is 9,960kg/NZha (Richardson, 2012). Milk production figures from other countries were difficult to attain, particularly for the world's five top milk producing nations (USA, India, China, Russia and Germany (Goff, 2009)). Figures for the UK, Spain and Sweden show milk yields in local hectares 
of $8,796 \mathrm{~kg} / \mathrm{ha}, 9,102 \mathrm{~kg} / \mathrm{ha}$ and $2,686 \mathrm{~kg} / \mathrm{ha}$, respectively; all being much higher than the GFN world average yield. These examples reconfirm that the use of global hectares for local decisionmaking is not adequate and local hectares are a better option.

NZ-based researchers have used a range of methods to calculate the NZ EF. The results of the EF projects are summarised in table 4.50. The case studies range from 3.49NZha/person/year from Bicknell et al., to 1.61NZha/person from this research. None of the case studies include fishing land, and the land categories have been re-aggregated to fit those of the Bicknell et al. and McDonald and Patterson case studies.

Bicknell et al. (1998) produced an early EF assessment and were also the first researchers to use input-output analysis for calculating footprints. They found NZ's $1991 \mathrm{EF}$ was 11.9 million NZha (3.49NZha/person). Input-output analysis relies on the flow of money through the economic system as a way of tracking resource flow. Using input-output analysis is an effective measure for footprinting unless current consumption behaviours rely on resources that do not pass through the economy. Calculations in this research found it was difficult to align the money spent at the household level with money spent at the national level due to the uncertain price of products and inconsistencies related to taxes and retailers' overhead costs.

McDonald and Patterson (2004, p.52) also used input-output analysis to calculate the NZ 1997/1998 ecological footprint, finding NZ required 11.7 million NZha. The total EF per person in 1997/98 was 3.08NZha/person. Field (2011) carried out a high level analysis for Wellington's EF based on 2006 data. Excluding fishing grounds, Field found that if all New Zealanders lived like Wellingtonians the total NZ EF would be 10.2 million ha (2.42ha/person). Finally the GFN (Ewing et al., 2010) case study is also included, with a result of $1.98 \mathrm{NZha/person} \mathrm{calculated} \mathrm{by} \mathrm{working}$ back from global hectares.

The largest variations in the land categories in table 4.50 are in the agricultural calculations. In Bicknell et al., McDonald and Patterson, and Field, the total crop and grazing land footprints are all well above $1 \mathrm{NZha} /$ person, while this research has a much lower result at $0.58 \mathrm{NZha} /$ person, aligning with the GFN. The forest land EF estimates from Bicknell et al., McDonald and Patterson, 
and Field's case studies are similar to that from this research, whilst the GFN calculations show double the forest land. The energy land calculations of Bicknell et al. and of McDonald and Patterson are much lower than those of this research, probably because they used a much higher energy-to-land conversion of $13.2 \mathrm{tCO}_{2} / \mathrm{NZha}$ (185GJ/NZha compared to $150 \mathrm{GJ} / \mathrm{NZha}$ in this research). It seems there is a range of possible EF estimates depending on the method used, the specific yields for each product and what is included or excluded in the calculations.

Table 4.50: A comparison of NZ EF in NZha from various case studies

\begin{tabular}{|l|ccccc|}
\hline \multirow{2}{*}{$\begin{array}{c}\text { Land } \\
\text { categories }\end{array}$} & $\begin{array}{c}\text { Bicknell et } \\
\text { al. }\end{array}$ & $\begin{array}{c}\text { McDonald } \\
\text { \& Patterson }\end{array}$ & Field & GFN & $\begin{array}{c}\text { 2012: this } \\
\text { thesis }\end{array}$ \\
\cline { 2 - 6 } & 1991 & $1997 / 98$ & 2006 & 2007 & 2007 \\
\hline Agricultural & 1.41 & 2.36 & 1.18 & 0.57 & 0.58 \\
\hline Forest & 0.28 & 0.22 & 0.07 & 0.49 & 0.18 \\
\hline Energy & 0.53 & 0.57 & 0.99 & 0.89 & 0.75 \\
\hline Degraded & 0.36 & 0.28 & 0.18 & 0.03 & 0.10 \\
\hline Imported & 0.91 & $\mathrm{n} / \mathrm{a}$ & $\mathrm{n} / \mathrm{a}$ & $\mathrm{n} / \mathrm{a}$ & $\mathrm{n} / \mathrm{a}$ \\
\hline Total & $\mathbf{3 . 4 9}$ & $\mathbf{3 . 4 3}$ & $\mathbf{2 . 4 2}$ & $\mathbf{1 . 9 8}$ & $\mathbf{1 . 6 1}$ \\
\hline
\end{tabular}

Table 4.51 shows a selection of EF projects published since 2002 from Australia, North America, the UK and Europe. The majority of these used the GFN methodology and its standardised world average yield values, equivalence factors and yield factors, giving results in global hectares (Ewing et al., 2010). The EF categories varied considerably between projects and amalgamation of certain categories was required. Whether the case study included fishing land is noted.

Of the 12 case studies in table 4.51, five had food and drink as the largest component of the footprint, at $23-49 \%$ of the total. Waste was the second most highly-ranked section with 3 out of 12 having it as the largest component of the footprint. Household energy was also consistently high.

The results from most of these case studies differ from those of the current study. For the latter, consumer goods were the largest component of the EF, then food and drink followed by transport. There are a number of reasons for this. For example, it seems that where international 
case studies included fishing land it helped to shift the food and drink category into first place. Also notable was the role household energy played in many of the footprints. NZ enjoys a much lower household EF due to the renewable energy contribution (67\%) in electricity generation (Ministry of Economic Development, 2010a), as compared with the world average of only $19 \%$ (REN21, 2011). Transport is not a high proportion of the EF in any of the case studies, but this might be because of the way transport is categorised, i.e. whether food transport is included in the food or transport section.

Tables 4.50 and 4.51 show support for the results of the footprint calculations in this thesis. Where there are differences these can usually be explained. Many are caused by particular decisions about yield factors or categories important to the outcome of each study, such as the pet footprint and holidays. It seems that the inclusion of fishing land skews the results of many case studies and it may be helpful to remove it from further EF calculations. It is concluded that the footprint calculations are reliable and justifications can be found in cases where the results differ from other NZ or international footprint projects. The NZ EF data from chapter 4 will be used as the basis for the NZ EF template discussed in chapter 5 . 
Table 4.51: Comparison of the NZ EF to international EF case studies

\begin{tabular}{|c|c|c|c|c|c|c|c|c|c|c|c|c|}
\hline & $\begin{array}{l}\text { Lawton } \\
\text { (2012) }\end{array}$ & $\begin{array}{c}\text { Victoria } \\
\text { (2008) }\end{array}$ & $\begin{array}{c}\text { Wales } \\
(2006)\end{array}$ & $\begin{array}{l}\text { Cardiff } \\
(2006)\end{array}$ & $\begin{array}{c}\text { York } \\
\text { (2002) }\end{array}$ & $\begin{array}{c}\text { Limerick } \\
\text { (2010) }\end{array}$ & $\begin{array}{l}\text { Belfast } \\
\text { (2010) }\end{array}$ & $\begin{array}{l}\text { London } \\
\text { (2002) }\end{array}$ & $\begin{array}{l}\text { Rural } \\
\text { Ireland } \\
(2004)\end{array}$ & $\begin{array}{c}\text { Piacenza } \\
\text { (2008) }\end{array}$ & $\begin{array}{c}\text { Alberta } \\
(2009)\end{array}$ & $\begin{array}{c}\text { North } \\
\text { America } \\
\text { (2009) }\end{array}$ \\
\hline Fish? & yes & yes & yes & yes & no & yes & yes & yes & no & yes & no & no \\
\hline $\begin{array}{l}\text { Food and } \\
\text { drink }\end{array}$ & $32 \%$ & $28 \%$ & $25 \%$ & $23 \%$ & $33 \%$ & $16 \%$ & $16 \%$ & $41 \%$ & $39 \%$ & $49 \%$ & $21 \%$ & $10 \%$ \\
\hline $\begin{array}{l}\text { Personal } \\
\text { transport }\end{array}$ & $20 \%$ & $10 \%$ & $14 \%$ & $18 \%$ & $23 \%$ & $13 \%$ & $14 \%$ & $5 \%$ & $19 \%$ & $12 \%$ & $9 \%$ & $17 \%$ \\
\hline $\begin{array}{l}\text { Consumer } \\
\text { goods }\end{array}$ & $33 \%$ & $14 \%$ & $12 \%$ & $12 \%$ & $9 \%$ & & & & & $15 \%$ & $14 \%$ & $12 \%$ \\
\hline $\begin{array}{l}\text { Household } \\
\text { energy }\end{array}$ & $3 \%$ & $16 \%$ & $17 \%$ & $17 \%$ & $50 \%$ & $34 \%$ & $39 \%$ & $10 \%$ & $24 \%$ & & $26 \%$ & $4 \%$ \\
\hline Housing & $7 \%$ & $5 \%$ & $3 \%$ & $3 \%$ & & $20 \%$ & $20 \%$ & & & $15 \%$ & $5 \%$ & $7 \%$ \\
\hline Citizenship & $6 \%$ & $27 \%$ & $14 \%$ & $14 \%$ & $4 \%$ & & & & & $9 \%$ & $36 \%$ & \\
\hline Waste & $(0.1 \%)$ & & & $13 \%$ & $20 \%$ & $37 \%$ & $31 \%$ & $44 \%$ & $20 \%$ & & & $49 \%$ \\
\hline
\end{tabular}




\section{Chapter 5: Community and Individual Footprints}

Continued growth is expected in NZ's population (Bascand, 2012), requiring either further expansion of its cities and towns or the development of new communities. The next part of this research uses the NZ data from chapter 4 to better understand the footprints of different urban forms and lifestyles. A calculator was created so that multiple variations on the NZ EF could be studied. A survey was administered to gather data from sample community populations. Individual community footprints were quantified using the calculator developed for the purpose.

Five communities accepted the invitation to take part in the project: three from the North Island (Waiheke, Waitakere and Kapiti Coast), and two from the South Island (Cromwell and Tarras). The communities each represent a different type of NZ urban form and together span a range of $\mathrm{NZ}$ lifestyles described by the 8 Tribes research (chapter 1.3).

The community survey data were analysed to tell a qualitative and quantitative story about the lifestyles of each community and the role of their urban form in the resource use intensity of their lifestyle decisions. SPSS was used to investigate the data within and between each community sample. ANOVA was used to determine whether there were significant differences between the community footprints, for both EF categories and single survey questions. Individual high and low footprints are also described to highlight the key components that contribute (or do not contribute) to individuals' total footprints.

\subsection{Footprint Calculator and Community Survey}

The calculator and survey results are required to calculate the community footprints. They were designed to focus on specific areas of the EF that were shown to have the heaviest footprint weighting, or common activities that were likely to decrease an individual's footprint.

The aim of the survey was to provide valid and reliable measures for converting an individual's daily activity into a quantifiable EF. It contained seven questions and 83 sub-questions 
covering seven footprint categories (food and drink, travel, consumer goods, pets, holidays, housing, and household energy). Also included are two lifestyle categories: barriers to reducing footprint, and 8 Tribes statements. The survey was completed during interviews which took 20-90 minutes depending on the enthusiasm and level of detail provided by the participants. Face-to-face hour-long interviews are not uncommon (Neuman, 1997, p. 245). The survey was designed to be flexible for gathering the footprint information of either an individual or of a household (see appendix 1).

The survey covered property and household questions as well as behavioural questions regarding resource consumption and waste production. It also included demographic data. More general attitude and lifestyle data were provided by statements, selected by the respondent from a list, that were used to define which of the 8 Tribes most fitted an individual (Caldwell \& Brown, 2010) (section 5.3.5).

A total of 178 individuals were surveyed, all living in NZ. The questions were designed to be clear, relevant and meaningful to all respondents (Neuman, 1997, p. 233).

Quantitative surveys are the most common means of calculating individual footprints online. Surveys based on interviews were chosen for use in this work, following Neuman (1997, p. 126) who recommends this as the most appropriate method for gathering information on self-reported beliefs or behaviours.

A large quantity of data had to be collected from a large number of people so, in order for the research to stay within the required timeframe, data needed to be streamlined and gathered quickly. The questions were multiple-choice, closed-ended questions which limited response options but provided enough choices to capture the majority of people's behaviours and preferences. In an effort to make the questions as clear as possible, the multi-choice options for a general frequency such as 'infrequently' or 'often' also included further explanatory detail such as 'once or twice a week'. There are a number of limitations to using closed-ended, multi-choice questions; particularly that misinterpretation of a question can go unnoticed, respondents can answer questions even if they do not know the answer, or they may be forced to give simplistic responses to complex issues. Multi-choice questions can also suggest ideas that the respondent would not otherwise have considered (Neuman, 1997, p. 241). 
However, by asking these questions during a face-to-face interview, respondents were able to ask for clarification if they were unsure about the question. Respondents were encouraged to take their time and to think about their average weekly activity before answering. There were few opportunities to take a position of 'non-attitude' or 'middle position', in an attempt to get all the information needed.

The survey was tested on 15 friends and colleagues throughout NZ, based on their socioeconomic backgrounds and high/low resource consumption tendencies. The survey went through a number of iterations, including the addition of a question about the alcohol people consumed. Both the pet and holiday questions required rewording and further information was added to clarify them. Many of the answer sets also needed to be broadened.

The calculator was created in Microsoft Excel as an easy-to-use option that could be altered and updated if further EF data or EF components were required. The calculator can be manipulated to calculate the footprint of either an individual or a household. A copy of the calculator is provided in the supplementary information folder accompanying this thesis. The Tarras survey results are included as an example.

The calculations showing the breakdown of the average NZ EF (chapter 4) provided a template for the manipulation of data to reflect the variation in footprint depending on an individual's house, consumption of goods and services, and production of waste. Freely-available webbased questionnaires and corresponding calculators (GFN, 2010; NZCEE, 2007; Redefining Progress, 2006; Stockholm Environment Institute, 2011) were reviewed to provide a baseline set of questions. All but one of these calculators (Redefining Progress, 2006) lacked any detailed information explaining how footprint calculations were made, why particular questions were asked, or how particular questions affected the calculation of an individual's EF.

Questions common to the EF calculators were highlighted and the effects of these on an individual's footprint noted. The NZ EF template provided detail about the areas of the NZ EF that had the greatest influence on an individual's EF. A number of new questions were added to those from the existing calculators to capture additional information on lifestyle choices. For example, "How much of the food that you eat has not been bought but either caught or 
gathered yourself, produced on your own land, or exchanged or bartered with others?" Many questions were reworded to reflect NZ values and use colloquial terminology and phrases.

The EF calculations have a sliding scale. Depending on the respondent's answer, the footprint result is either higher, lower or the same as the 'average' NZ EF. For example, on average, New Zealanders consume $0.66 \mathrm{~kg}$ of chicken per week $(34.41 \mathrm{~kg} /$ year $(F A O, 2007))$. The recommended serving size for chicken is $0.08 \mathrm{~kg} / \mathrm{meal}$ (Farner, 2012)). However, the average consumption is much higher than this because the majority of people eat more than they need (The Economist Online, 2012). It was assumed that, on average, New Zealanders eat about one and a half times the recommended serving size, which would be approximately $0.12 \mathrm{~kg}$ of chicken four-five times a week. Question (2iv) of the survey asks: How often do you eat animal based products?

Poultry (chicken, duck, turkey)

1. never (or very rarely)

2. infrequently (once every few weeks)

3. occasionally (one or two times per week)

4. often (three or more times a week)

5. all the time (most days most meals)

As suggested by Neuman $(1997$, p. 243$)$, answers to the questions were normally ordered from the least to most resource use with the average consumption in the middle of the multichoice list, though there were some exceptions. Further discussion about the specific questions and how they influence the footprint calculations is provided in section 5.3.3.

The final survey had pictures added and it was printed in colour. Effort was made to ensure that the survey was easy to read, well worded and aesthetically pleasing. Researchers were conscious of not making the respondents feel as though they were being tested. Feedback from respondents suggests that the survey was well received, however feedback also suggested there were a number of questions that need further clarification. The use of closedended, multi-choice questions was an effective way of gathering a large amount of footprint data. 
The total EF was calculated to reflect an individual's annual EF and is presented in a CLUM similar to table 4.48. The footprint calculator produced a CLUM for each respondent's results as well as a total community EF. All results are in NZha.

Ethics approval for the use of the survey in interviews was granted by the Standing Committee of the Victoria University of Wellington Human Ethics Committee on 10th January 2011.

\subsection{Gathering Community Data}

A range of methods was used to invite people to take part in the surveys and workshops, depending on the opportunities for engagement within each community. To go through the 'correct avenues' local councils and community boards were initially approached to gain acceptance of the project and they provided recommendations of potential community groups. Advertisements and stories were posted in the local newspapers to entice people to take part. For Otago the Polytechnic's contacts databases were also used to reach a diverse range of community members from Cromwell and Tarras. A complimentary drink was included with each interview as a way of enticing individuals to volunteer. Information about the research was provided to the respondents prior to the interview and they gave consent for the research project to use their results (see appendix 2). Once respondents had completed the survey, they were asked to leave their contact details and state whether they were interested in being involved in the community workshop or wanted a set of the results.

Efforts were made during research design and collection to minimise non-sampling errors. As described in detail below, the main concerns included the respondents' predisposition to lower footprints, household representation, incorrect personal data due to lack of trust, social desirability bias, and the timescale over which respondents were being asked to provide data.

Predisposition to lower footprints: Participants were mostly volunteers, and it was probable they volunteered because they were interested and already thinking about their resource use and waste creation. This predisposed them to having a lower EF than that of a random sample. As a result, the EF of the community samples could be lower than the overall community average. 
Household representation: Only one member of each household was asked to take part in the survey although different household members often have different roles. As a result some members of the household have better knowledge of resources consumed in some household roles. In addition, questions based on personal resource consumption may not be a good indication of household consumption, e.g. a car commuter will drive more than a stayat-home mum. The broader question of 'how far does your whole family travel each week?' would capture a truer household travel EF but is more difficult for people to answer because they have to estimate the travel of other family members.

Gaining trust: In an effort to provide a relaxing atmosphere, interviews were carried out in a place chosen by the respondent. This was often either the home or a local café. The interview questions were designed to ease people in, starting with the most straightforward (food and drink), and progressing to the harder and more personal questions (average household income and 8 Tribes statements).

Social desirability bias: Due to the types of questions it was possible that respondents might have tried to present a positive personal image instead of giving true answers. Respondents might give what they believe to be the normative or socially desirable answer. Wentworth (1993: p. 180, cited in Neuman 1997) notes people are likely to over-report being a good citizen (voting, knowing about issues), being well-informed and cultured, fulfilling moral responsibilities (having a job, giving to charity), or having a good family life (happy marriage and good relations with children). Having a lower footprint by consuming less may be similarly over-reported.

Timing of surveys: All communities were sampled at a similar time of the year to reduce discrepancies. However the chosen time of the year could have altered a person's perception of their consumption of specific resources. For example, the interviews were in autumn and one question was about the household annual wood consumption, which might be hard to recall from the previous winter.

Initial data were collected through transcribing interviews and transferring data into an Excel spread sheet. Data sets were amalgamated into SPSS. The data were cleaned to minimise the potential for erroneous data. 
A number of precautionary measures were included in the data-gathering process to minimise non-sampling errors, although some, such as the timing of interviews, were unavoidable, as discussed below.

\subsection{Survey Results}

Statistical analyses of the sample communities were carried out and community samples tested for significance in relation to the whole sample population. Survey results were compared between communities, and the similarity or difference between them was assessed along with a statistical level of confidence. Inter-sample group analysis was also carried out relative to differences in footprint categories.

The survey results are presented as a whole sample population (all five communities), and as individual community samples, using the headings below:

1. Demographics of the respondents

2. Community and urban form definitions

3. Survey footprint results

4. Community footprint differences

5. Survey lifestyle results

6. Individual footprint results.

\subsubsection{Demographics}

There were 178 survey respondents unevenly distributed amongst five NZ communities. Although the participants were self-selecting, diversity was similar when compared to the overall NZ demographic characteristics (table 5.1).

More females than males took part in the survey. The average overall age was skewed towards the 'over 35s' with almost 50\% of respondents aged 45-64. In 2011 Statistics New Zealand (2011d) reported that 78\% of New Zealanders identified themselves as NZ European, 13\% Māori, 4\% Pacific peoples and 10\% Asian. The sample has an over-representation of New Zealanders of European decent (NZ Pākehā) and an under-representation of other ethnicities. Much of this was because of the specific communities invited to take part in the research, 
since Tarras, Cromwell and Waiheke have a proportionally higher representation of NZ Pākehā (Statistics New Zealand, 2006c).

Table 5.1: Demographic characteristics of the whole sample

\begin{tabular}{|lcccccc|}
\hline Sex & \multicolumn{3}{c|}{ Male: $37 \%$} & \multicolumn{3}{c|}{ Female: $64 \%$} \\
\hline Age & $<25:$ & $25-34:$ & $35-44:$ & $45-54:$ & $55-64:$ & $\geq 65:$ \\
& $4 \%$ & $13 \%$ & $21 \%$ & $22 \%$ & $26 \%$ & $15 \%$ \\
\hline Ethnnicity & Pākehā: & Māori: & Pacific Island: & Asian: & Other: \\
& $87 \%$ & $2 \%$ & $3 \%$ & $1 \%$ & $7 \%$ \\
\hline Qualification & \multicolumn{2}{c}{ Tertiary: } & Professional: & No qualifications: \\
& $61 \%$ & $21 \%$ & $18 \%$ \\
\hline
\end{tabular}

As of March 2011, 20\% of the NZ population had no qualification, $60 \%$ had a certificate or diploma, and the remaining $20 \%$ had a tertiary qualification (Statistics New Zealand, 2011d). In the sample, $61 \%$ held tertiary qualifications, $21 \%$ a professional certificate or diploma, and $18 \%$ had no qualification. This means the sample group is a reasonable representation of people with no qualifications but an over-representation of people with tertiary qualifications.

Official information was retrieved from Statistics New Zealand (2006c) regarding the demographic make-up of four of the five communities. Tarras data was not available separately, being included in the data for Cromwell. Unfortunately this data was not sufficiently detailed to be useful to be useful for comparing the communities.

Because the research aimed to investigate statistically different communities their demographic data were compared. This analysis found that, other than by age (figure 5.1), the five communities were not statistically different.

There was a significant difference in age between the Cromwell and Tarras communities, as almost all Tarras participants were 55 years and older while the Cromwell sample had a broader representation of age groups. Waitakere was similarly skewed to Tarras, and Waiheke and Kapiti were more like Cromwell, although the whole sample was skewed towards the over 35s. 


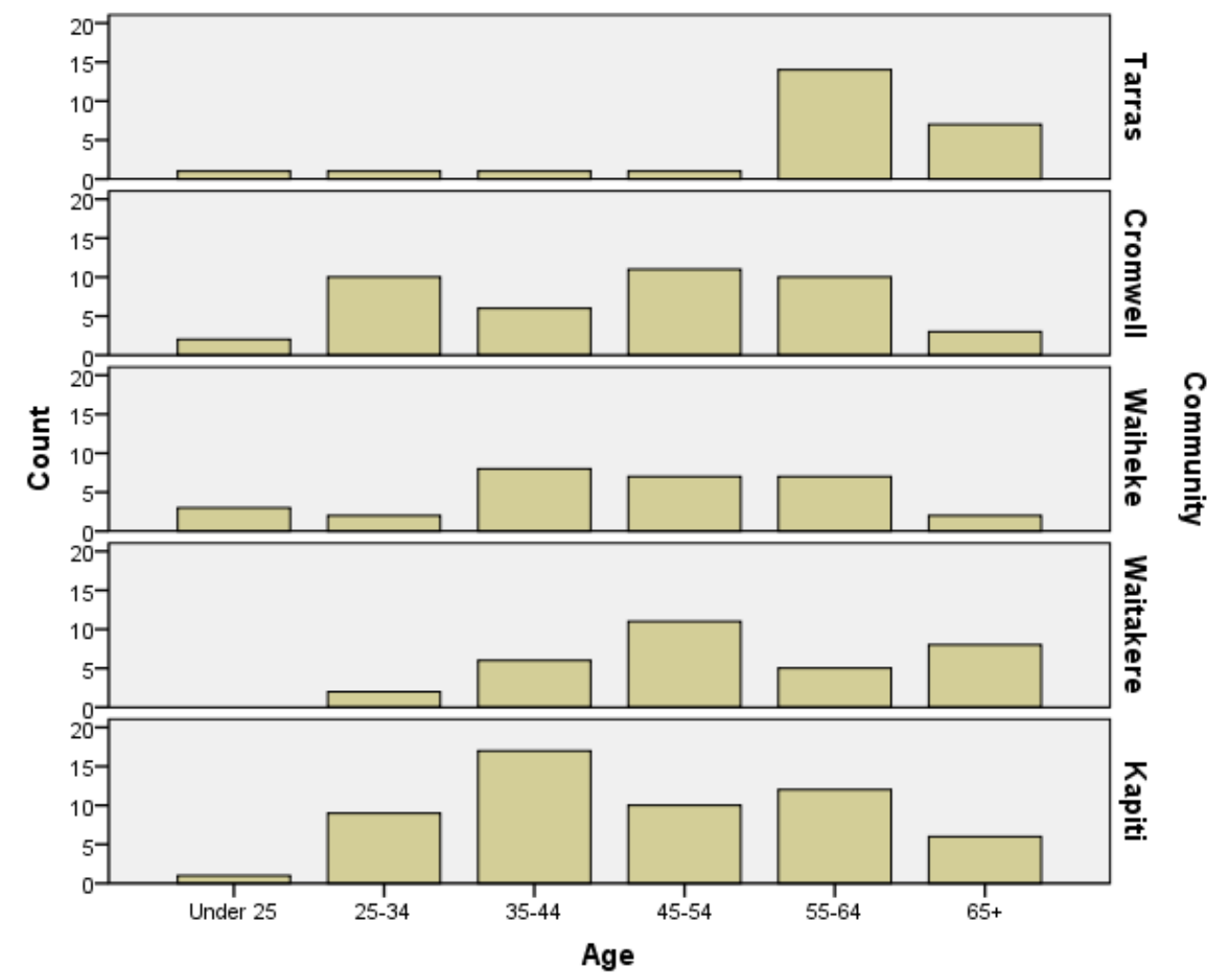

Figure 5.1: Age distribution of survey respondents by community.

Both Tarras and Cromwell have many fewer non-Pākehā members than the North Island communities, with Waitakere and Waiheke showing the most ethnic diversity. The sex and qualification statistics between the communities were not significantly different.

Household income is not directly included in the footprint calculations, although income is an important component of lifestyle that ultimately drives individual and community resource wants and needs. Survey respondents were given the option of 'no comment' and $13 \%$ chose this. Statistics New Zealand (2011c) report that the median annual household income in June 2011 was $\$ 67,028$. The overall income analysis of survey respondents showed a broad range of household income in the sample, with a slight tendency for higher incomes. Approximately $22 \%$ of households earned less than $\$ 40,000 /$ year, and $40 \%$ earned between $\$ 40,000$ and $\$ 80,000 /$ year, and $27 \%$ earned more than $\$ 80,000 /$ year. The remaining $13 \%$ chose not to comment. There was no significant difference in income levels between the five communities, although there were differences in income level between age groups. Incomes increased with age, peaking with $45-55$ year olds earning an average $\$ 60,001-\$ 80,000 /$ year, declining with 56-64 year olds at $\$ 40,001-\$ 60,000 /$ year, and over-65-year-olds at less than $\$ 40,000 /$ year. 


\subsubsection{Community Urban Form and Housing Definitions}

Statistics New Zealand's New Zealand: Urban/Rural profile categories (Statistics New Zealand, 2004) were used to assign an urban form to the communities, although the voluntary nature of the survey meant participants might not live in typical dwellings. The survey asked where people lived and about their housing type.

Four of the five communities were asked to describe the type of urban form, choosing from five categories: rural, rural-residential (the outskirts of town), suburban, urban, and inner city. The Kapiti respondents were not asked this question because they volunteered to take part in the survey on a street basis. Although the urban form of the street was noted, this data was not included in the analysis. For the whole sample, $68 \%$ identified with living in a suburban or rural-residential setting, $21 \%$ in a rural setting, and $11 \%$ in an urban or inner city setting. The community groups were compared to the official categories (section 2.3), as shown in table 5.2 .

Table 5.2: Official urban form categories for each community and survey results to 'where they live'

\begin{tabular}{|c|c|c|}
\hline & Official urban form categorisation & Survey results ${ }^{1}$ \\
\hline Waiheke & Satellite urban area & $\begin{array}{c}66 \% \text { rural-residential } \\
34 \% \text { suburban }\end{array}$ \\
\hline Waitakere & Satellite urban area & $\begin{array}{c}66 \% \text { suburban } \\
25 \% \text { rural-residential } \\
6 \% \text { urban and inner city }\end{array}$ \\
\hline Kapiti Coast & Main urban centre & \\
\hline Cromwell & Independent urban area & $\begin{array}{c}41 \% \text { suburban } \\
31 \% \text { rural-residential } \\
29 \% \text { urban }\end{array}$ \\
\hline Tarras & Highly rural remote area & $100 \%$ rural \\
\hline
\end{tabular}

1. Note percentages do not add up to $100 \%$ due to rounding.

The respondents surveyed were largely representative of the official urban form categories. The only community of concern is Waitakere with its broad range of property types, making it hard to generalise. The survey showed $25 \%$ live in a rural-residential area, including one person living in an apartment. From the survey, Waitakere is more like a 'rural area with high urban influence' rather than a 'satellite urban community'. Lack of clarity regarding its urban form has been considered when generalising urban form impacts on EF. 
The second of the household property-type questions was 'what best describes your property?' Respondents could choose from seven answers: high country farm, working farm (use significant area of farm to produce goods), lifestyle block ( 0.4 to 30 hectares - do not use significant area to produce goods), free standing house (FSH) on a large section $\left(1,000 \mathrm{~m}^{2}\right.$ to $4,000 \mathrm{~m}^{2}$ ), FSH on a small section (less than $1,000 \mathrm{~m}^{2}$ ), single storey apartment with no section, apartment in a multi-storey building. Generally there were mixed housing types within all communities, which is representative of NZ (figure 5.2).

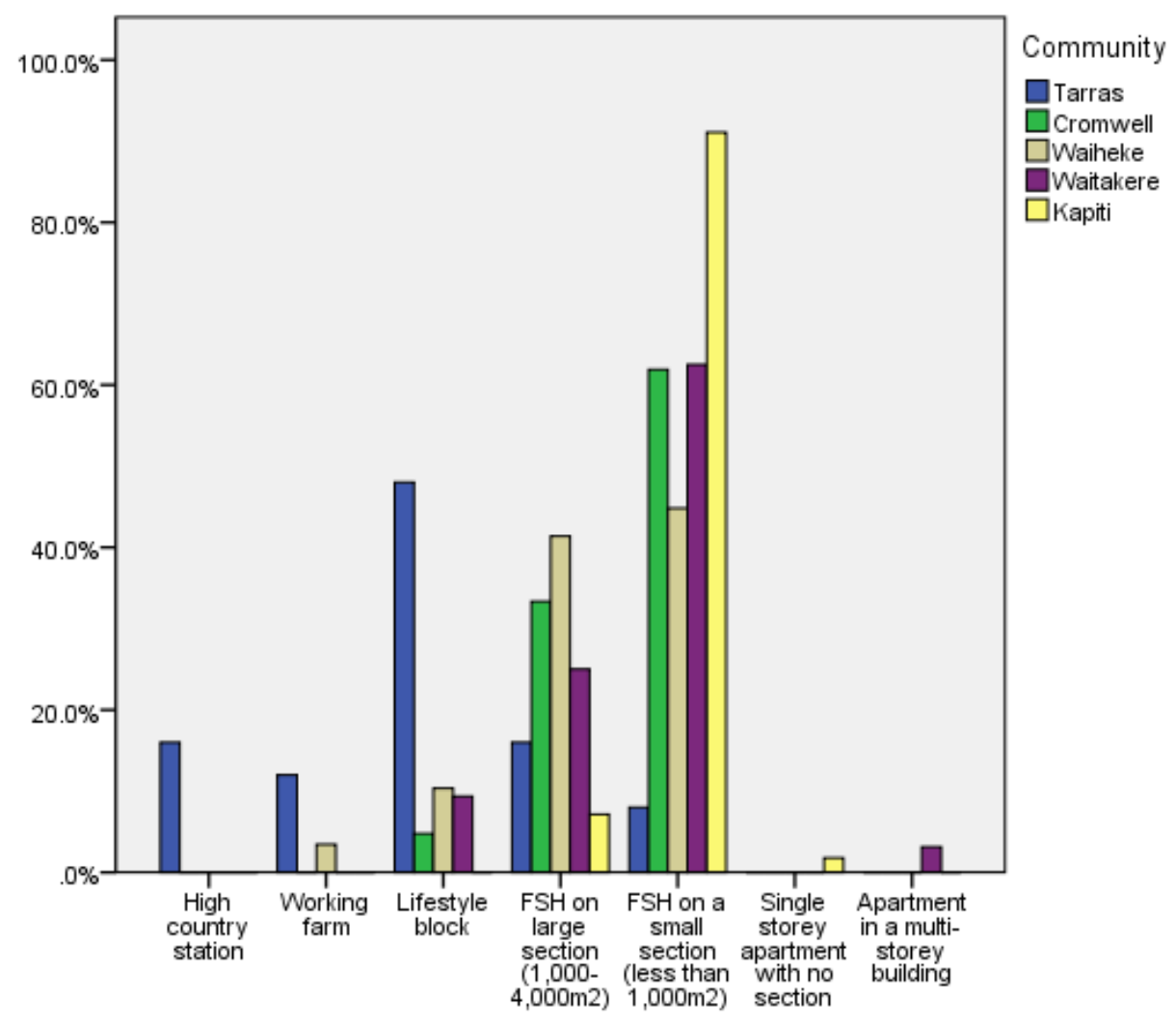

Figure 5.2: Household description.

Waiheke included four of the seven property descriptions; $14 \%$ described their property as a lifestyle block or working farm, although the majority (86\%) lived in a FSH on a small or large section. Waitakere had $10 \%$ of respondents on lifestyle blocks, $25 \%$ in houses with large sections, but most (67\%) living in a FSH on a small section. One person was in a multi-story apartment building. The majority of Kapiti residents (91\%) lived in a FSH with a small section, with $7 \%$ having large sections, and one person in an apartment with no section. Cromwell participants lived in houses on small and large sections (62\% and 33\% respectively) with 5\% on lifestyle blocks. Tarras had the broadest range of properties and was the only community 
to include high country farms (16\%). Working farms were $12 \%$ of the community, $48 \%$ lived on lifestyle blocks, $16 \%$ in FSH on large sections, and $8 \%$ on small sections.

The volunteering community members live in fairly representative situations to the official categories of community urban form, with the possible exception of Waitakere, making caution necessary for any broad conclusions regarding its EF as a satellite urban form.

\subsubsection{Survey Footprint Results}

One aim of this research is to determine the extent to which the EF of New Zealanders changes with the urban form of their community and the lifestyle choices they make. Data from five communities were used to calculate individual footprints and community sample averages. The EF categories are food and drink, travel, consumer goods, pets, holidays, household energy and housing. The infrastructure, government and services category forms the citizenship EF, the individual's share of which is added to the footprint. Statistical analysis was used to test for significant differences between community footprints. Where differences were found, further investigation was carried out to isolate the differences.

\section{Total Footprint}

Figure 5.3 shows that the average EF for the community sample was $2.75 \mathrm{NZha}$ and that the distribution of the data is relatively normal though there is a slight skew to the right, meaning the sample average EF is at the lower end of the footprint spectrum. The standard deviation is 0.81 , so most results are close to the average but there are individuals at the higher end of the EF results.

The distribution of data can be 'normalised' further by removing outliers from the dataset. These were identified using a stem and leaf plot analysis, and were all above the average EF. The outliers, their community groups and their footprints were Tarras $=7.16$, Waitakere $=$ 5.35, Tarras $=5.52$ and Tarras $=4.95$. 


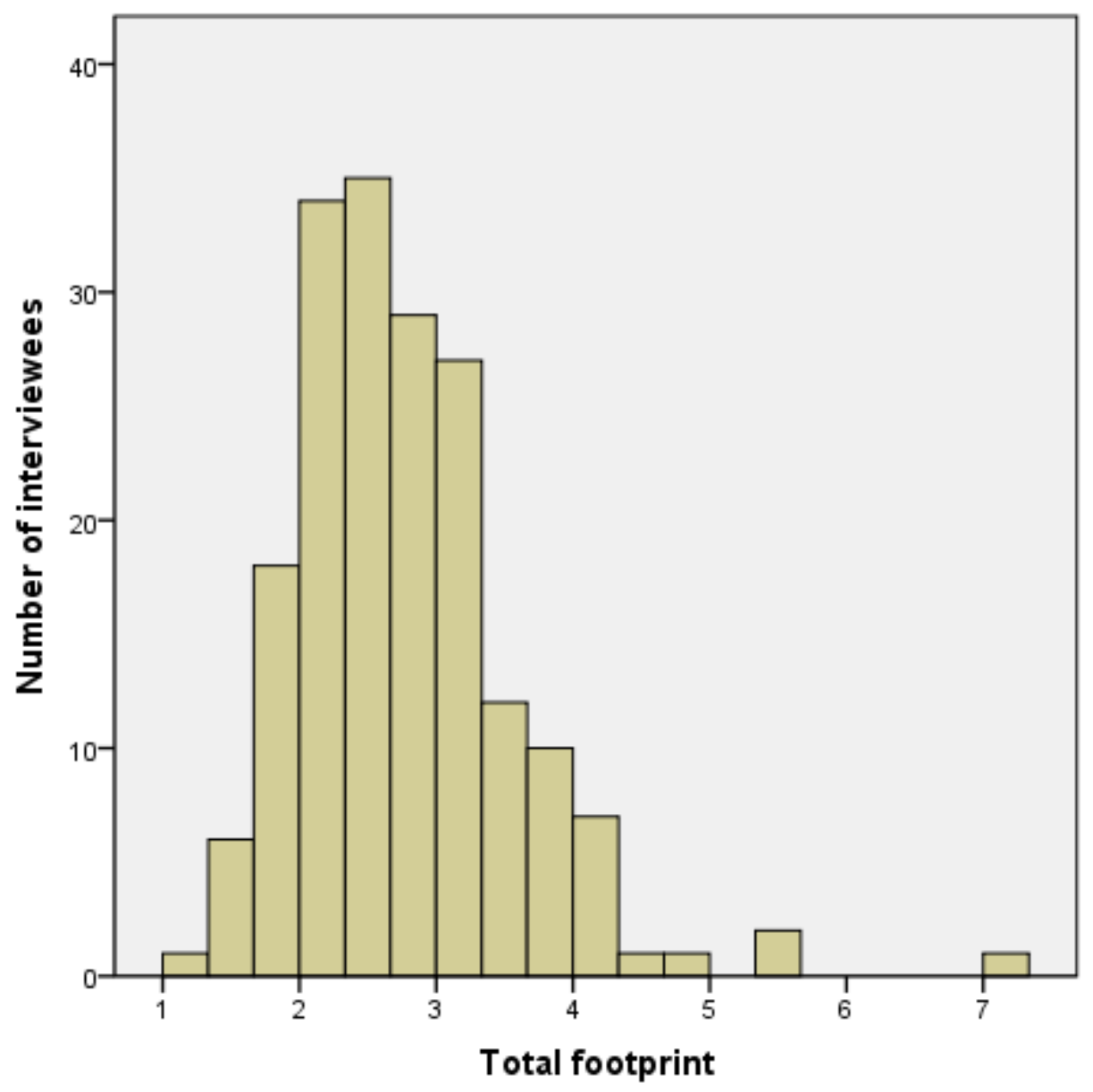

Figure 5.3: EF of the entire community sample.

The difference between communities is tested using ANOVA to see whether the variation of the EF or characteristics between communities is no greater than that due to normal variation (Washington State University, 2000). The aim is either to accept or reject the 'null' hypothesis that the averages for the five communities $(\mu)$ are all the same. The equation for the null hypothesis is:

$H_{0}: \mu_{1}=\mu_{2}=\mu_{3}=\mu_{4}=\mu_{5}$

There are two attributes to test before an ANOVA can be carried out; defining whether the data is a continuous variable, and whether it is normally distributed. ANOVA tests use the $F$ ratio and $p$-value to reject or accept the null hypothesis. A big F-ratio, with a small $p$-value, means that the null hypothesis is discredited, while a small F-ratio, with a big $p$-value indicates the means are not significantly different (Washington State University, 2000). 
Table 5.3 shows the results of the seven ANOVA tests, giving the mean and standard deviation of each community sample.

The EF samples were tested in both NZha and gha. The differences between the EF datasets were 'not significant' and the following analysis has only been carried out in NZha.

There was no difference between communities in the housing category and little in the food and drink and pets categories. Significant statistical differences occurred for transport, consumer goods, holidays and household energy.

Table 5.3: Statistical analysis of EF results

\begin{tabular}{|c|c|c|c|c|c|c|c|c|}
\hline \multicolumn{2}{|c|}{ EF and components } & \multirow{2}{*}{$\frac{\text { Tarras }}{\text { NZha }}$} & \multirow{2}{*}{$\frac{\text { Cromwell }}{\text { NZha }}$} & \multirow{2}{*}{$\frac{\text { Waiheke }}{\text { NZha }}$} & \multirow{2}{*}{$\frac{\text { Waitakere }}{\text { NZha }}$} & \multirow{2}{*}{$\frac{\text { Kapiti }}{\text { NZha }}$} & \multirow[t]{2}{*}{ F-ratio } & \multirow[t]{2}{*}{$\begin{array}{c}p \text { - } \\
\text { value }\end{array}$} \\
\hline & & & & & & & & \\
\hline \multirow{2}{*}{$\begin{array}{l}\text { Total } \\
\text { footprint }\end{array}$} & mean & 3.44 & 2.59 & 2.51 & 2.62 & 2.77 & 6.421 & 0.000 \\
\hline & $\begin{array}{l}+/- \\
\text { SD }\end{array}$ & 1.2 & 0.6 & 0.7 & 0.8 & 0.6 & & \\
\hline \multirow{2}{*}{$\begin{array}{l}\text { Food and } \\
\text { drink }\end{array}$} & mean & 0.93 & 0.99 & 1.05 & 1.12 & 1.13 & 2.418 & 0.050 \\
\hline & $\begin{array}{l}+/- \\
\text { SD }\end{array}$ & 0.3 & 0.3 & 0.4 & 0.4 & 0.3 & & \\
\hline \multirow[t]{2}{*}{ Transport } & mean & 0.37 & 0.20 & 0.32 & 0.18 & 0.28 & 3.367 & 0.011 \\
\hline & $\begin{array}{l}+/- \\
\text { SD }\end{array}$ & 0.3 & 0.2 & 0.3 & 0.2 & 0.3 & & \\
\hline \multirow{2}{*}{$\begin{array}{l}\text { Consumer } \\
\text { goods }\end{array}$} & mean & 0.38 & 0.36 & 0.30 & 0.35 & 0.36 & 3.522 & 0.009 \\
\hline & $\begin{array}{l}+/- \\
\text { SD }\end{array}$ & 0.9 & 1.0 & 0.8 & 0.9 & 0.4 & & \\
\hline \multirow[t]{2}{*}{ Pets } & mean & 0.81 & 0.44 & 0.33 & 0.53 & 0.58 & 2.368 & 0.054 \\
\hline & $\begin{array}{l}+/- \\
\text { SD } \\
\end{array}$ & 1.0 & 0.5 & 0.4 & 0.7 & 0.6 & & \\
\hline \multirow[t]{2}{*}{ Holidays } & mean & 0.58 & 0.29 & 0.25 & 0.20 & 0.20 & 9.646 & 0.000 \\
\hline & $\begin{array}{l}+/- \\
\text { SD }\end{array}$ & 0.4 & 0.3 & 0.2 & 0.2 & 0.2 & & \\
\hline \multirow[t]{2}{*}{ Housing } & mean & 0.22 & 0.15 & 0.15 & 0.18 & 0.12 & 0.195 & 0.941 \\
\hline & $\begin{array}{l}+/- \\
\text { SD }\end{array}$ & 0.8 & 0.4 & 0.4 & 0.6 & 0.4 & & \\
\hline \multirow{2}{*}{$\begin{array}{l}\text { Household } \\
\text { energy }\end{array}$} & mean & 0.14 & 0.09 & 0.05 & 0.07 & 0.08 & 28.650 & 0.000 \\
\hline & $\begin{array}{l}+/- \\
\text { SD }\end{array}$ & 0.05 & 0.04 & 0.03 & 0.02 & 0.03 & & \\
\hline
\end{tabular}

Tarras had the highest average total EF at 3.44NZha, and Waiheke the lowest at 2.51NZha. There is a statistically significant difference between Tarras and the other four communities 
because the $p$-value is very low and F-ratio high. Therefore, the footprints of the five communities were different and the null hypotheses could be rejected. However, there is no evidence of a significant difference between the total footprints of the other four communities.

Box and whisker plots for the five communities are shown in figure 5.4, providing an overview of the total footprint figures, including the highest, median and lowest footprints. The distribution of footprints is broadest in Tarras and most condensed in Cromwell, though there are outliers in the group. Tarras has the highest individual footprint of 7.16NZha and Waiheke the lowest of 1.01NZha. The low Waiheke footprints show it is possible to live within the fair earth share of 1.21NZha.

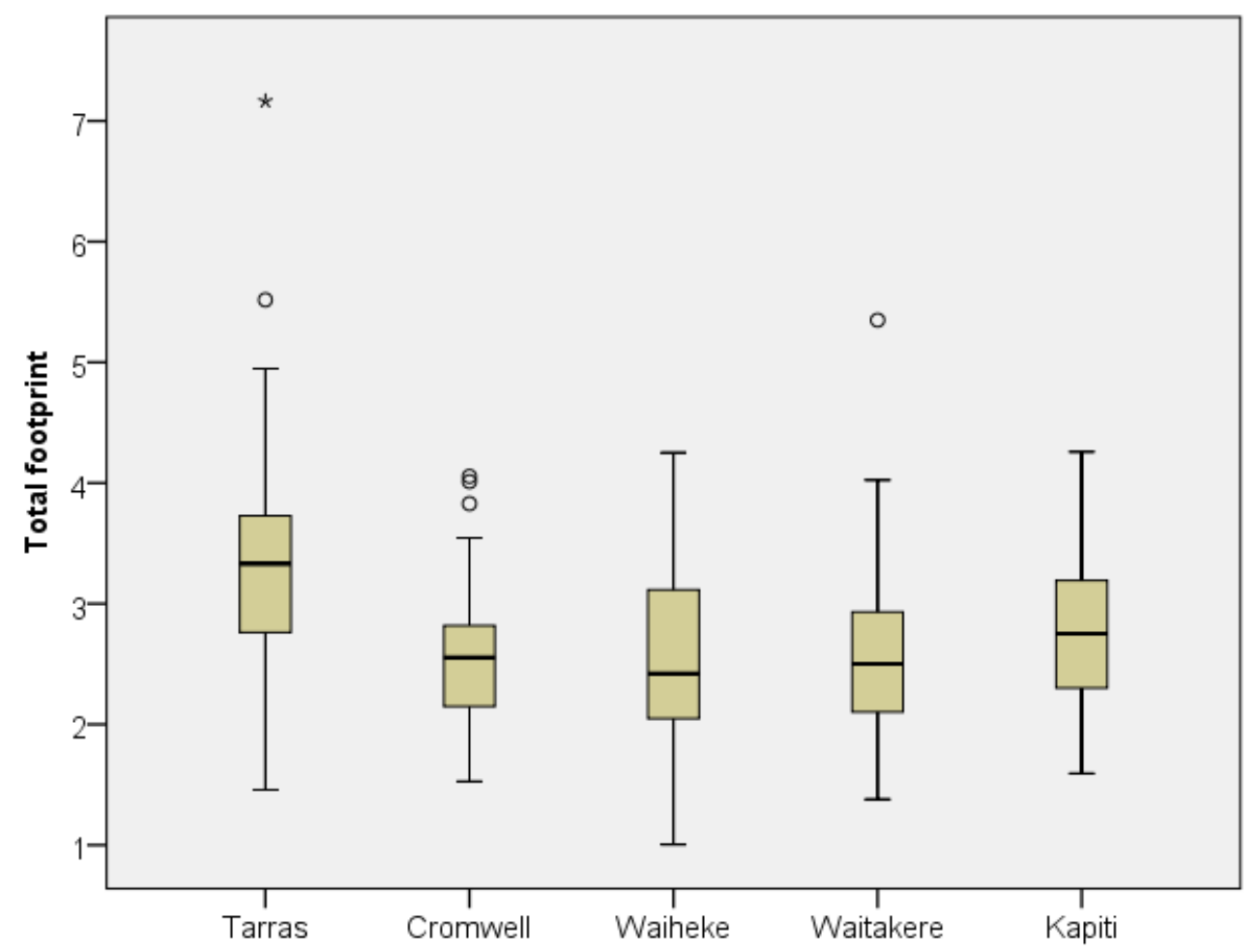

Figure 5.4: Box and whisker plots of the five community total footprints including outliers.

Table 5.4 summarises the EF by category. The breakdown shows the variation in each category in relation to others. For example, travel is $13 \%$ of the average Waiheke EF, $8 \%$ of the NZ average, and $10 \%$ of the survey average. This suggests that the Waiheke sample should concentrate on travel if aiming to lower their EF. 
As mentioned, the sample looks different from the NZ EF average. In the sample, all food and drink and consumer goods are lower whilst pets are significantly higher. Reasons for this include the possibility that the community samples do indeed have different footprints to other NZ communities, or that the food EF is lower because a portion of it is distributed elsewhere, such as to the pets category. Pet ownership amongst survey respondents could also be different from the NZ EF average because four of the five communities were rural or semi-rural, including a number of lifestyle blocks with large pets on them.

Table 5.4: EF by category (NZ average, sample average, and averages of the five communities)

\begin{tabular}{|lcccccccc|}
\hline \multirow{2}{*}{$\begin{array}{c}\text { Community } \\
\end{array}$} & $\begin{array}{c}\text { Food } \\
\text { and } \\
\text { drink }\end{array}$ & Travel & $\begin{array}{c}\text { Consumer } \\
\text { goods }\end{array}$ & Pets & Holidays & $\begin{array}{c}\text { Household } \\
\text { energy }\end{array}$ & Housing & Citizenship \\
\cline { 2 - 10 } & $\%$ & $\%$ & $\%$ & $\%$ & $\%$ & $\%$ & $\%$ & $\%$ \\
\hline NZ average & 57 & 8 & 16 & 7 & 5 & 3 & 2 & 4 \\
\hline $\begin{array}{l}\text { Survey } \\
\text { average }\end{array}$ & 38 & 10 & 13 & 19 & 11 & 3 & 3 & 3 \\
\hline Waiheke & 42 & 13 & 12 & 13 & 11 & 2 & 3 & 4 \\
\hline Waitakere & 43 & 7 & 14 & 20 & 8 & 2 & 3 & 3 \\
\hline Kapiti & 41 & 10 & 13 & 21 & 7 & 2 & 2 & 3 \\
\hline Cromwell & 38 & 8 & 14 & 17 & 12 & 3 & 4 & 4 \\
\hline Tarras & 27 & 11 & 11 & 23 & 17 & 4 & 3 & 3 \\
\hline
\end{tabular}

\section{Food and drink}

The average food and drink EF was 1.05NZha/person. Kapiti Coast had the highest average of 1.13NZha, closely followed by Waitakere at $1.12 \mathrm{ha}$. Tarras had the smallest average food EF with the broadest range of results and the smallest dataset. Food and drink was the only EF category for which Tarras received a low score. The highest individual food and drink EF was 1.71NZha (Waitakere) and the smallest was 0.30NZha (Cromwell). The complete food and drink EF dataset had an almost perfect normal distribution. No statistical difference was found amongst the five sample communities.

\section{Travel}

The average travel EF was $0.26 \mathrm{NZha}$. Tarras had the highest community average of $0.38 \mathrm{NZha}$, statistically different from Waitakere with the overall lowest of 0.18NZha and Cromwell with 
0.20NZha. Kapiti and Waiheke had slightly higher-than-average travel footprints but these were not shown to be statistically different from the other communities. The distribution of the travel EF was skewed to the left and included a number of very high outliers. The highest transport EF for a single person was 1.39NZha (Kapiti) and the lowest was 0.002NZha (Cromwell). Of the fourteen outliers in this category four are from Kapiti, four from Tarras and six from Waiheke.

\section{Consumer goods}

The consumer goods section of the survey was in two parts: consumer goods and waste, and pets. The average consumer goods (minus pets) EF was 0.35NZha. The highest average was Tarras (0.38NZha) and the lowest Waiheke (0.30NZha). As a group, the consumer goods EF is skewed to the left showing that the majority of people have lower consumer goods footprints. There were no outliers in the group. The lowest individual consumer goods EF was $0.17 \mathrm{ha}$ (Kapiti) and the highest 0.60ha (Cromwell).

The NZ-average pet EF is $29 \%$ of the total consumer goods EF (calculated in chapter 4.5 ), whereas pet EF of the sample was $61 \%$ of the total. It is unlikely that this dataset has a normal distribution because $38 \%$ of respondents had no pets. The average community pet EF was 0.53NZha. Waiheke had a very low pet EF of 0.33NZha, and was statistically different from Tarras with a high community pet EF of 0.81NZha. The highest single pet EF is from Tarras (3.54NZha).

\section{Holidays}

The average holiday footprint was 0.28NZha, with Tarras having the highest average community holiday EF (0.58NZha) and Waitakere the lowest (0.20NZha). Tarras is statistically different from the other four communities with a holiday EF more than twice that of Waiheke, Waitakere and Kapiti. The holiday EF category results are also skewed to the left. The majority of respondents had relatively small holiday footprints. However, the holiday EF dataset has the highest number of outliers at eight: four from Tarras, three from Cromwell and one from Kapiti. These individuals increase the average total holiday EF considerably. 


\section{Household energy}

The average household energy EF was 0.08NZha. Again Tarras had the highest community average $(0.14 \mathrm{ha})$, whilst the lowest was Waiheke $(0.05 \mathrm{NZha})$. There are considerable differences between the community household energy datasets shown by a very high F-ratio and low p-value. Of the five datasets, three were statistically different. Waiheke and Waitakere were similar but statistically different from Tarras. Kapiti and Cromwell were also similar and statistically different from Tarras. Not unexpectedly, the size of the household energy EF for each community increases going from north to south. Household energy distribution was relatively normal but still with a slight skew to the left. There are seven outliers; five from Tarras, one from Cromwell, and one from Kapiti. The highest individual household energy EF was 0.24NZha (Cromwell), and the lowest 0.02NZha (Kapiti).

\section{Housing}

The average housing EF was 0.16NZha with no difference between the communities, suggesting a broad range of house sizes irrespective of urban form. Overall the housing EF is small and the questions did not provide much detail, as the different options did not make a significant difference to the EF. The highest average community housing footprint is Tarras (0.22NZha) and the lowest Kapiti (0.12NZha). The distribution of the household EF was skewed to the left with ten outliers on the box-and-whisker plot. There are two groups of outliers, five just above the upper quartile and five with much higher footprints. The five with the highest footprints are spread between four of the five groups (Tarras, Waitakere, Kapiti and Cromwell).

\section{Summary}

Overall, Tarras had the highest EF for five of the seven categories, but had the lowest food and drink EF. Table 5.3 also shows Tarras had the highest standard deviation and therefore the broadest spread for its total EF, suggesting a range of high and low footprints within the community. Tarras is often the source of outliers showing that there are individuals within the community who have significantly large footprints. In other categories the lowest EF was shared between communities. Waitakere has the lowest average EF for transport, Waiheke for consumer goods, Waitakere and Kapiti for holidays, Kapiti for housing, and Waiheke for 
household energy. Cromwell consistently has the second lowest ( $4^{\text {th }}$ place) position for each category, resulting in the second lowest overall EF. There is a significant difference between the community footprints for most categories and therefore the null hypothesis can be rejected.

\subsubsection{Detailing the community differences}

In this section the results of each EF category and other potentially significant factors such as income were analysed. The survey questions that carried the largest footprints were considered in more detail. The EF results are also tested against individual and community ' 8 Tribes' results.

Highlighting the differences between the five communities shows that the most important factors for the overall EF are the amount of food a community consumes but does not buy, holiday travel, and the average number of pets in a community.

\section{Income}

Tests were carried out on the variation in household income between communities but no statistical significance was found. The average income varied a little between community samples. In Waiheke and Cromwell it was $\$ 60,000-\$ 80,000 /$ year. The income of Tarras households was just below average. Kapiti and Waitakere's average household income was $\$ 40,000-\$ 60,000 /$ year. The Kapiti sample had the overall lowest income with $47 \%$ of households earning less than $\$ 60,000 /$ year, closely followed by Waiheke with $45 \%$ earning less than $\$ 60,000 /$ year.

Income has been shown to be an important indicator of an individual's EF. The Canadian Centre for Policy Alternatives $(2008$, p. 1) found the "richest $10 \%$ of Canadians have a footprint $66 \%$ higher than the poorest $10 \% "$. It is assumed that a higher income increases an individual's ability to buy goods and services (such as long haul flights), thereby increasing their EF.

However, this research does not support this theory. There is no strong correlation between high EF and high income (figure 5.5). Interestingly some individuals with the highest footprints, the outliers, have the lowest incomes which is predominantly due to a large pet 
footprint. Those with footprints above 4NZha have incomes spread between the income categories.

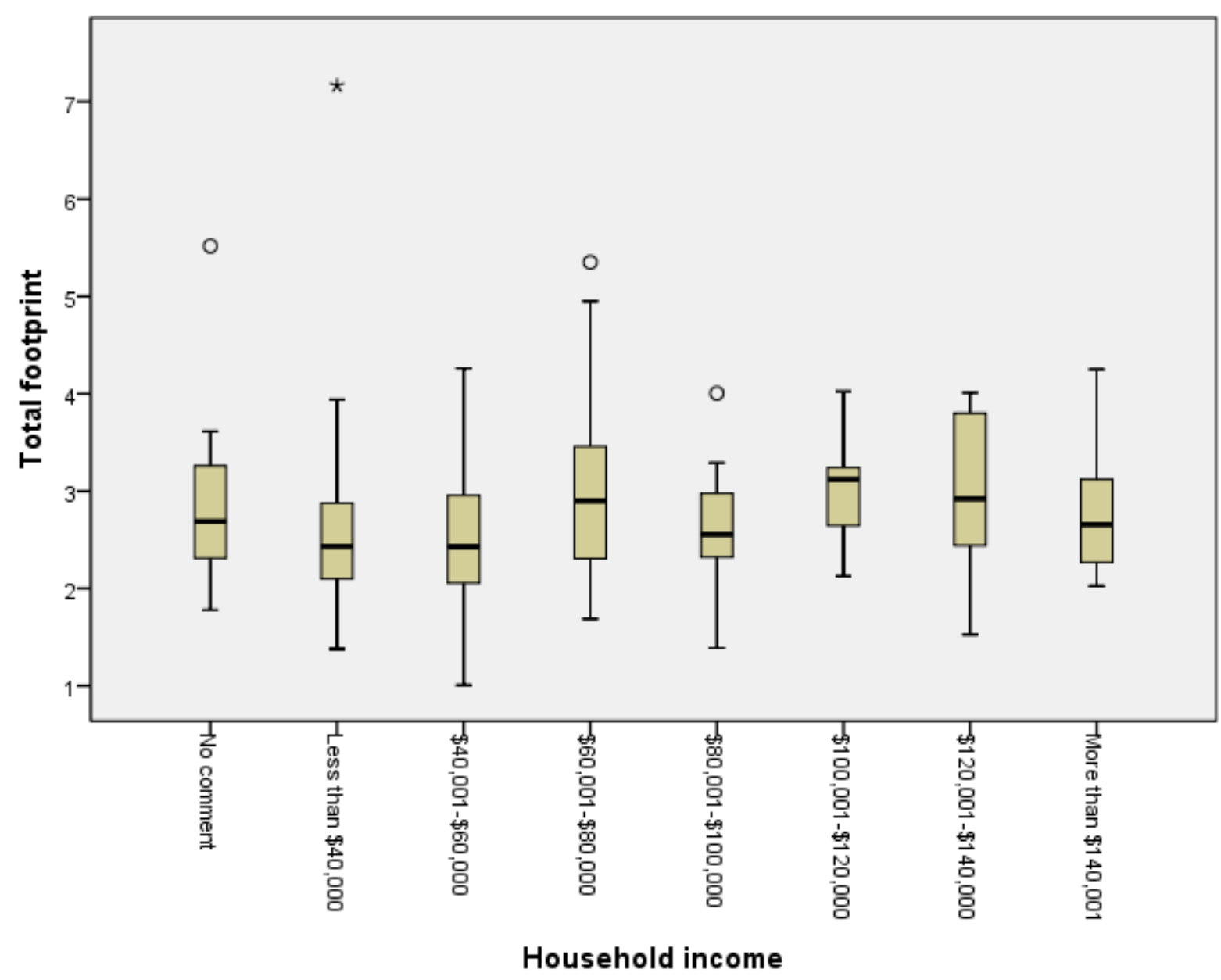

Figure 5.5: EF of household by income.

In the sample, $25 \%$ of respondents did not reveal their income, with Waitakere having the highest rate opting out (38\%). Tarras also had missing data. This missing data meant the EFincome correlation was limited.

Some households earning less than $\$ 40,000 /$ year have high footprints. The average individual EF for the group is 2.62NZha with a standard deviation of 0.98 . There are two outliers in the under $\$ 40,000 /$ year group; they are from Tarras where the very large EF is caused by pet ownership. If pets are subtracted their EF is lower than average.

A number of EF categories were compared with income to test for income dependency. Households with an income of less than $\$ 40,000 /$ year flew less and therefore had a lower 
holiday EF. In comparison households who earned $\$ 60,000-\$ 80,000$ flew more and, on average, had a higher holiday EF. However, as shown in figure 5.5, once participants earned over $\$ 120,000 /$ year the average holiday EF decreased. Some participants earning this amount stated they had no holidays. This suggests that earning more money may provide the opportunity for people to increase their holiday EF but over a certain amount, other drivers of $E F$, such as time and values, have greater impact. It is also likely to be relevant that individuals earning over $\$ 120,000$ per year travel more as part of their employment and therefore prefer to stay close to home during the remaining non-work related time.

No other EF category showed a clear correlation between income and EF. One possible reason is that annual income is not a sufficient measure of an individual's wealth, particularly for older respondents and people with their own businesses. These two groups may consume more resources and create more waste than their income buys because they have money or resources saved up. In retrospect this question should be changed to ask respondents how much their household spends each year, rather than their income. However, for many respondents this will be a difficult question to answer.

\section{Food and drink}

Food and drink formed the largest component of the survey, with seven sub-questions. The first two covered the quantity of food consumed by type. The next two questions asked about the proportion of organically-produced food consumed, and the proportion of food that was unprocessed and unpackaged, produced locally, and not bought from a shop. The fifth question was the amount of food people grew at home and why they grew food, the sixth was the average number of times people ate out in a week including takeaways and restaurants, and the seventh was the quantity of alcohol consumed.

To calculate the food footprint, the survey questions were based on the average amount of food consumed. The respondent's answer provided a quantity of food which was then multiplied by the average yield for each food group to give the growing land required. The onfarm energy per kg of food was calculated using conventional farming methods, and reduced according to the quantity organic food eaten. A similar process was used for processing energy, packaging, transport and food building energy. If respondents grew food in their 
garden, the amount they grew was subtracted from the cumulative total to this point. This assumed food grown at home has a near zero EF because no growing land is required and it has minimal on-farm energy, packaging and transport impacts.

Footprint calculations for food that is 'hunted', including foraging for plants and hunting animals, only considered the footprint of the related travel, not the embodied energy of equipment, such as the gun (assumed to be low relative to the travel EF). The distances travelled to 'hunt' food depended on where the person lived. The Tarras sample includes considerable food grown on household land, which is assumed not to involve much travel. Ryan (2011) stated "hunters in Wanaka generally travel about 30 minutes by sealed or gravel road to get to a farm track where they spend a considerably long time driving very slowly in low gear and not using much fuel". If a hunter travels two hours by truck to kill a wild deer, calculations suggest the EF per kg of meat would be lower than commercially produced meat.

When respondents eat out the embodied energy of this food was slightly increased. Lastly the footprint per glass of alcoholic beverage was calculated and multiplied by the amount a respondent consumed.

There was no statistical difference between the community food and drink footprints but there are differences within the results that affect the EF variations. Two areas have been explored to investigate this; the amount of grazing land and crop land required and where a community's food comes from. An effective way of lowering EF is to consume less shopbought food on the assumption home-produced food involves no commercial land, less travel, less packaging, less processing, and no food building EF.

The five communities were compared on the amount of animal-based products they consume, showing only minor dietary differences between communities. Waiheke ate the least beef, lamb and chicken and more pulses. Waitakere and Tarras ate more poultry. There was no significant difference in the amount of fish consumed in the communities despite the distance of some from the sea. As for crop land food, Tarras consumed significantly more vegetables than Cromwell, Kapiti more bread than Cromwell and Waitakere, and Kapiti less pasta than Waiheke or Cromwell. 
An analysis was also carried out on the consumption of organic food, fresh unpackaged food, locally grown food, food not bought from a shop, and food grown in gardens, revealing differences between the communities. Waiheke consumed more organic food than Cromwell. Kapiti consumed more processed food than the other communities, and Tarras more food that had not been bought. Tarras also grew more food than Waiheke. It seems from these results that although Tarras eats more meat, the food EF is lower than the other communities because a lot of food was not shop-bought but hunted, bartered, or grown at home.

\section{Food Grown at Home}

Growing food in the garden is an effective ways of lowering both the food EF, and the overall footprint. Figure 5.6 summarises the food that households grew on their own land.

In the whole sample only two individuals grew all of their own food, one from Tarras and one from Waiheke. $17 \%$ said they grew no food and $2 \%$ only grew herbs, meaning $81 \%$ of respondents grew at least some food at home. There was a statistically significant difference between the quantity of home-grown food in the Tarras and Waiheke communities.

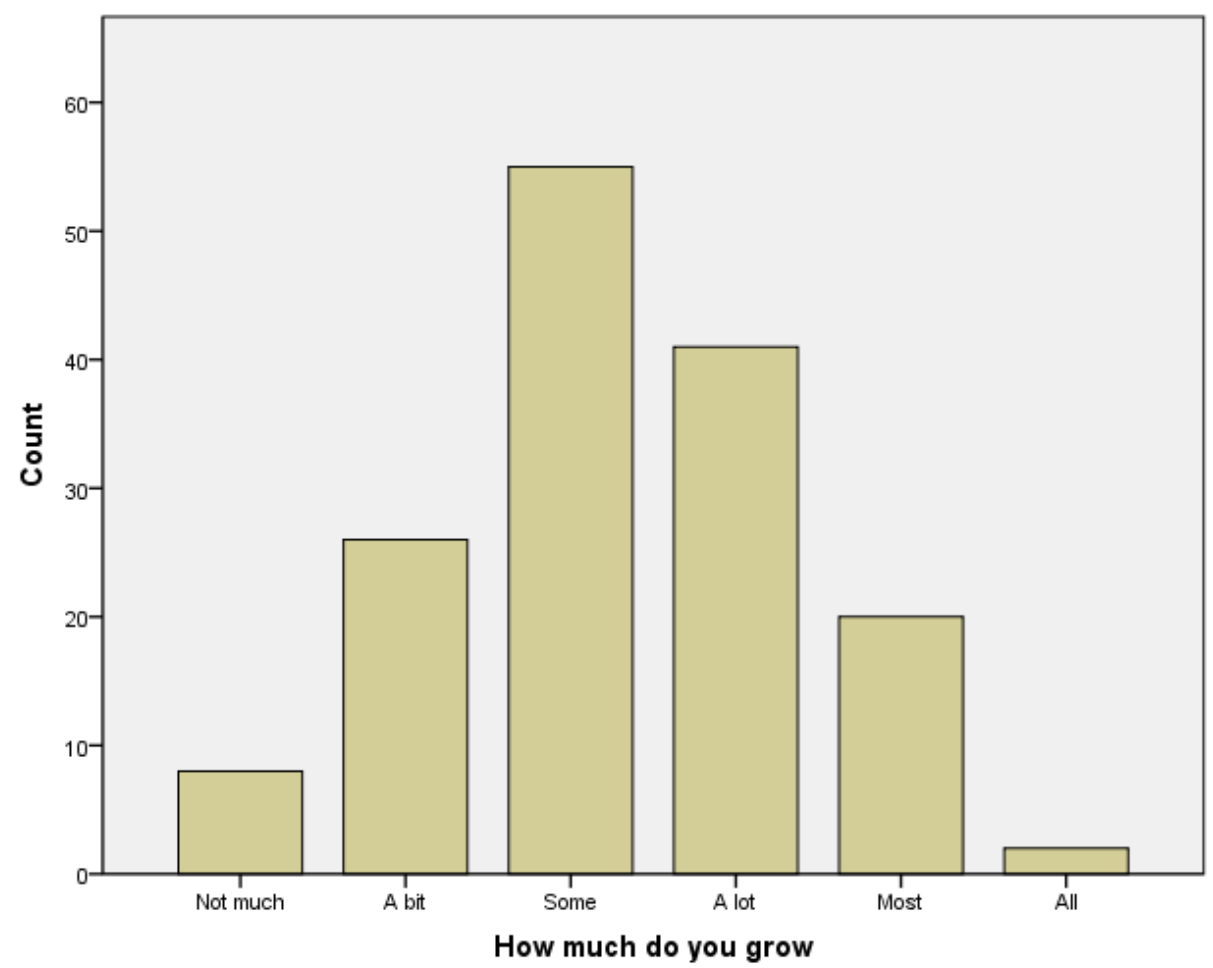

Figure 5.6: Distribution of food grown at home and land for growing food. 
Participants were asked why they grew their own food, with a selection of reasons to choose from. Figure 5.7 summarises the results, showing the top reason was 'Enjoy eating own food', second was 'therapeutic', and third was 'for my health'. Convenience and 'I always have' were the least likely reasons to grow food.

Overall, $50 \%$ considered the environment a good reason for growing food at home. The Tarras community found it less important with only $32 \%$ concerned, while $62 \%$ of the Waiheke community thought it was important. This is important information when considering how to entice more people to grow food. The two most important messages are that people enjoy eating food they have grown and that gardening is therapeutic.

There was no significant correlation between the amount of food individuals grew and the age groups, with only a slight trend for those who grew the most food being from the two older age brackets. Households that grew the most food lived in rural or rural-residential areas, and those that grew the least food were in suburban and rural-residential areas. There was no significant difference between a household's income and the amount of food they grew.

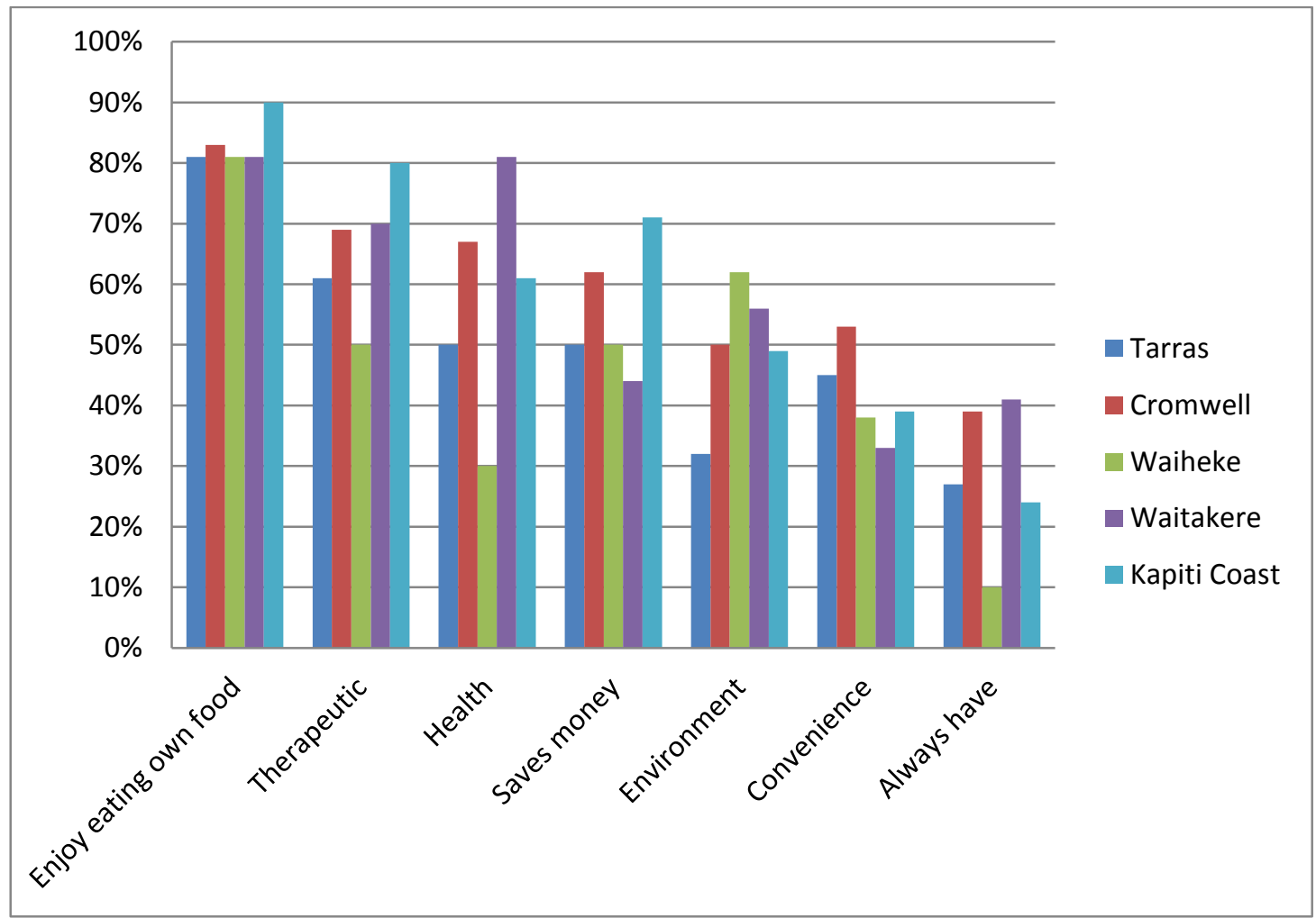

Figure 5.7: Reasons why people grow their own food, organised by community. 


\section{Food Eaten Out}

Eating food outside the home slightly increases an individual's food EF. The survey found 'takeaway food' and 'restaurant food' were almost normally distributed with a slight left skew. On average people eat out once a week, though a few individuals ate out a lot. People eat takeaways more often than eating at a restaurant. There were no significant differences in the amount of takeaway food or restaurant food eaten by the five communities. This would suggest people eat out a similar amount whether they live near to, or further away from, eating out places.

\section{Alcohol}

Of the total respondents, $27 \%$ did not drink at all, and $9 \%$ drank a lot. There were no significant differences between the drinking habits of the communities, or significant correlations to footprint or urban form.

\section{Summary}

The food and drink EF results suggest places with available rural land, such as Tarras and Cromwell, use this to reduce their food EF. Urban areas such as Kapiti and Waitakere consume more processed and packaged food, and less food not bought or grown in their garden. Waiheke eats the least meat.

\section{Travel}

The transport EF involves a number of questions asking about details of weekly personal vehicle transport, the level of walking and cycling, public transport use, and the other motorised vehicles the household owns (boats, jet skis or light aircraft/helicopters). The EF per kilometre travelled was calculated using data from section 4.3 and multiplied by the average distance for each answer, then converted to annual travel.

The 'car' section of the survey included questions regarding the size of car, the time people spent driving in urban and rural areas, and how often there was another person in the car. Respondents were asked to not include car travel for business or work. The distance travelled and size of car were used to calculate the $\mathrm{EF} / \mathrm{vkm}$ which was then varied depending on type 
of road most used and number of people in the car. The question with the biggest influence on the car footprint was the amount of time spent with more than one person in the car. Public transport questions were also based on footprint per pkm travelled, and these were multiplied by the pkm travelled per week by each mode.

There were significant differences between the community transport footprints; for example Tarras' transport footprint was significantly different and much higher than that of Waitakere and Cromwell. Because of the rural nature of Tarras there was less walking reported as a form of transport than in the other four communities, although people did not walk much in Waitakere. Respondents spent a similar amount of time walking and biking in Cromwell, Waiheke and Kapiti, supporting the idea urban areas have more potential for these modes.

Not unexpectedly, the Tarras community travelled considerably further by car than Waiheke residents. When it came to car occupancy, more than $50 \%$ of people interviewed reported they 'almost never' or 'very occasionally' travelled with anyone else in the car. The community with the highest single occupancy was Kapiti with $84 \%$ falling into these two categories, and Tarras was also high with $68 \%$ in the two categories. However, $45 \%$ of the sample reported 'always' or 'very often' travelling with other people, with Cromwell and Waiheke having the highest rates of multiple occupancy, at $50 \%$ and $38 \%$ respectively.

Almost the entire Tarras sample reported they spent $90 \%$ of their time driving on open roads, compared to Kapiti where $75 \%$ did more than $50 \%$ of driving on the open road. The majority of driving in Cromwell and Waitakere was in urban centres. The results of these two questions provide insight into the efficiency of personal transport in satellite communities. Cromwell and Waiheke both have service centres, meaning people do not need to leave the community to shop and work, and therefore travel less. The towns are small enough that everyone is going to the same place(s) and can share transport.

As expected, the respondents supported the notion that availability of public transport increases its use. There is no public transport in Tarras and Cromwell. In comparison, $40 \%$ of Waiheke, $34 \%$ of Kapiti and $23 \%$ of Waitakere residents used public transport. Table 5.5 shows the 
Of those using public transport in Kapiti, $12 \%$ of the Kapiti community caught the bus and 30\% caught the train. Kapiti residents commuting by train to Wellington for work each day $(a 98 \mathrm{~km}$ round trip) have high train usage. Waitakere residents travelled mostly by bus (58\%) and more than half the Waitakere sample used the train (table 5.5).

Of the Waiheke public transport users, 70\% used the bus service, 12\% used trains (Auckland commuters) and $36 \%$ travelled by ferry. Waiheke was the only community to have high ferry use, with only $24 \%$ reporting they did not travel regularly on the ferry. The overall transport EF is influenced by ferry travel due to its high EF.

Table 5.5: The percentage of respondents who caught each mode of public transport and the distance they travelled

\begin{tabular}{|c|c|c|c|c|c|c|}
\hline \multicolumn{2}{|c|}{ Mode and Distance } & \multirow{2}{*}{$\begin{array}{c}\text { Waiheke } \\
38 \%\end{array}$} & \multirow{2}{*}{$\begin{array}{c}\text { Waitakere } \\
83 \%\end{array}$} & \multirow{2}{*}{$\begin{array}{c}\text { Kapiti } \\
88 \%\end{array}$} & \multirow{2}{*}{$\begin{array}{c}\text { Cromwell } \\
0 \%\end{array}$} & \multirow{2}{*}{$\begin{array}{c}\text { Tarras } \\
0 \%\end{array}$} \\
\hline Bus & $0 \mathrm{~km}$ & & & & & \\
\hline & $1-10 \mathrm{~km}$ & $41 \%$ & $13 \%$ & $11 \%$ & $0 \%$ & $0 \%$ \\
\hline & $11-25 \mathrm{~km}$ & $10 \%$ & $6 \%$ & $0 \%$ & $0 \%$ & $0 \%$ \\
\hline & $26-100 \mathrm{~km}$ & $10 \%$ & $3 \%$ & $0 \%$ & $0 \%$ & $4 \%$ \\
\hline & More than $100 \mathrm{~km}$ & $0 \%$ & $0 \%$ & $2 \%$ & $0 \%$ & $0 \%$ \\
\hline \multirow[t]{5}{*}{ Train } & $0 \mathrm{~km}$ & $90 \%$ & $78 \%$ & $70 \%$ & $0 \%$ & $0 \%$ \\
\hline & $1-10 \mathrm{~km}$ & $7 \%$ & $6 \%$ & $7 \%$ & $0 \%$ & $0 \%$ \\
\hline & $11-25 \mathrm{~km}$ & $3 \%$ & $13 \%$ & $5 \%$ & $0 \%$ & $0 \%$ \\
\hline & $26-100 \mathrm{~km}$ & $0 \%$ & $3 \%$ & $7 \%$ & $0 \%$ & $0 \%$ \\
\hline & More than $100 \mathrm{~km}$ & $0 \%$ & $0 \%$ & $11 \%$ & $0 \%$ & $0 \%$ \\
\hline \multirow[t]{5}{*}{ Ferry } & $0 \mathrm{~km}$ & $38 \%$ & $83 \%$ & $88 \%$ & $0 \%$ & $0 \%$ \\
\hline & $1-10 \mathrm{~km}$ & $41 \%$ & $13 \%$ & $11 \%$ & $0 \%$ & $0 \%$ \\
\hline & $11-25 \mathrm{~km}$ & $10 \%$ & $6 \%$ & $0 \%$ & $0 \%$ & $0 \%$ \\
\hline & $26-100 \mathrm{~km}$ & $10 \%$ & $3 \%$ & $0 \%$ & $0 \%$ & $4 \%$ \\
\hline & More than $100 \mathrm{~km}$ & $0 \%$ & $0 \%$ & $2 \%$ & $0 \%$ & $0 \%$ \\
\hline
\end{tabular}

It would have been useful to show the transport footprint broken down into individual questions regarding the various transport options. Unfortunately a design flaw in the calculator did not allow for this. Even without this analysis, sole car occupancy and longer travel distances are the two biggest contributors to a large personal transport EF, and ferry travel is the largest contributor to a large public transport footprint. As a result Tarras and Kapiti have the largest personal transport footprints and Waiheke the largest public transport EF. Removing the Waiheke ferry footprint gives Waiheke one of the lowest transport 
footprints. Cromwell had the smallest travel EF even without the support of public transport, and Waitakere's travel EF was also small, because although residents travelled further they used low EF public transport options.

The Cromwell travel EF was probably low because Cromwell is a self-contained urban environment where people can work, shop for commercial goods and services, and eat out. Waiheke would be similar were it not for the ferry transport.

\section{Pets}

The question about pets was in five parts, asking the number of 'very low', 'low', 'medium' and 'high' resource pets, as well as whether people owned a large pet (that they did not eat) such as a horse, sheep, pig or cow. The average footprint for each pet category was multiplied by the number of pets and the results totalled.

Tarras had the highest community pet EF and Waiheke the lowest, although $52 \%$ of the Tarras sample had no pets. This was outweighed by a number of individuals with a significant number of pets. Individual pet footprints for Tarras were the highest, up to 3.5NZha, much greater that the average NZ pet EF. A number of Waitakere residents also had high pet footprints, the largest being 3.1NZha. The annual EF of a large pet is $0.81 \mathrm{NZha}$, so having a large pet was significant given that this is twice the size of an average transport EF. Waiheke had a lower pet EF than Tarras, because of the pet types rather than their number. In Tarras $73 \%$ of pets were medium or high resource ones. As well as the high resource pets, $28 \%$ of Tarras households had at least one large pet (that they did not eat), such as a pig, sheep or horse. In Waitakere, $12 \%$ of households had at least one pet, with $65 \%$ having only one pet, and $70 \%$ of all pets being either small dogs or cats. There were far fewer pets in Waitakere.

The pet results show that rural communities have more pets, especially large ones. Urban communities (Waiheke, Cromwell) have similar pet numbers but the pets are smaller.

\section{Consumer goods}

The contribution of pets to the consumer goods EF was removed from the analysis of the latter to better understand the effects of other consumer goods on the total household EF. 
The first part of the consumer goods question concerned the quantity of new consumer goods purchased by each household. The questions covered electronics, furnishings, clothing, reading material and appliances. The second part related to the waste produced by the household and the amount that people recycled.

The EF calculations were developed using the average embodied energy and additional growing land for each type of consumer product. All consumer goods questions allowed the respondent to choose an option of buying very few products new, or buying mainly secondhand products. Second-hand products have a low EF on the assumption that the EF belongs to the person who first bought them. It is also assumed that most second-hand products have been in use for a number of years, with the embodied energy of the product shared across them. If the product is motorised, the operational energy will be accounted for in the household energy or food and drink categories.

Most respondents did not buy many new consumer products. On average, reading material was bought most often, whilst 'furnishings' were most often bought new. These findings are surprising in the light of the number of goods and services shops. Key findings are listed below:

1. Tarras bought the most electronic goods and Cromwell the least, but there was no significant difference in electronic goods bought by the other three communities.

2. Waiheke purchased significantly less clothing than Tarras.

3. All communities purchased approximately the same amount of furnishings and appliances.

4. Waiheke bought the least amount of reading material.

The second part of the consumer goods question related to waste and recycling. Cromwell had a larger waste EF than any of the other communities. Waiheke had the lowest waste EF and recycled the most materials. Waiheke and Waitakere's recycling footprints are different from Cromwell's where recycling of materials is least.

The Waiheke respondents were the most likely to consider waste when buying products. Tarras and Kapiti did not consider waste much. There was no significant difference between 
the various communities in relation to the purchasing of consumer products that are labelled 'green' or 'eco', as all paid some attention to the labelling of products.

Living in a rural setting and further from shops does not seem to reduce a community's consumer goods footprint, with Tarras consuming more electronics and reading material. Although Waiheke and Cromwell have the same urban form, Waiheke consumed fewer consumer goods and recycled more.

\section{Holidays}

Holidays were defined as any overnight travel that was not 'work'. Respondents were asked to not include any work travel in their EF calculations. Two aspects of the holiday EF are considered here; the travel required in getting people to their holiday destination of choice, and the EF associated with land and water travel, accommodation and activities. The holiday question was as follows:

1. How often do you go on holiday each year?

2. How far do you travel to go on holiday?

3. What are your main activities when you go on holiday?

4. What are your reasons for going on holiday?

Of the respondents, $10 \%$ never went on holiday for any length of time. The greatest portion $(40 \%)$ of respondents went on a 'long holiday' either during summer or winter. Many interviewees reported that they went away for weekends (36\%) and a quarter of the respondents (26\%) reported that they went away for multiple weekends during the year.

The holiday calculation was carried out using the average distance travelled by car to go on holiday, multiplied by the size of the car noted earlier and an average occupancy of three people. This was then multiplied by the average distance driven and number of holiday occasions. For example, if a respondent 'travelled by car more than $400 \mathrm{pkm}$ ' and holidayed 'multiple weekends during the year' the distance was multiplied by two (return trip) for 18 weekends (assumption for multiple weekends). This is probably an overestimate for the travel distance. Selected accommodation and activity energy was also added, as spending a lot of time in hotels could increase the holiday footprint. 
It was assumed that all household flights were for holidays. Interviewees were asked to not include business-related flights. There was considerable variation in flying of different communities. Overall $11 \%$ of the sample had not flown in the last two years: $25 \%$ of interviewees never flew nationally, and $25 \%$ flew less than $800 \mathrm{pkm} /$ year nationally. Overall $27 \%$ said they did not fly internationally and $37 \%$ said they flew less than 9,000 pkm internationally, the equivalent of two Auckland-Sydney return trips. Overall more people had flown to Australia than within NZ.

Kapiti residents flew the least. Tarras did more national flying ( $88 \%$ of the community) than Waiheke, Waitakere or Kapiti, and more international flying (also $88 \%$ of the community) than Waitakere, Cromwell and Kapiti. Over half of the Tarras sample flew more than $3,000 \mathrm{pkm} /$ year domestically (equivalent to one return flight Queenstown-Auckland, or three return flights from Queenstown-Wellington), and half flew more than 15,000pkm/year internationally (NZ-East Coast USA, or Singapore-NZ return).

The most popular holidays (37\%) were travel of more than $400 \mathrm{pkm}$ by car and the second most popular (32\%) driving 100-400pkm (one way trip). Third was travelling to Australia by plane (31\%). Table 5.6 shows the most and least likely reasons the communities went on holiday. Waiheke were most likely to holiday to see new places but also spent time with friends and family. Waiheke was least likely to go on holiday for a sports event or to gather food. They were not likely to take part in four-wheel driving and boating or visiting their bach. Waitakere went on holiday specifically to spend time with friends and family, to relax, and for road-tripping, but did not go four-wheel driving and boating, camping, or visiting the bach.

Cromwell residents also went on holiday to spend time with friends and family and see new places, and went road-tripping whilst away. They were least likely to go on holiday to gather food or attend a sports event. Tarras was different, with their main reason for going on holiday being to relax and then to gather food. They often went to the bach and went fourwheel driving and boating, and were least likely to go camping or eat out. The results for Tarras seem to contradict their preference for travelling to Europe, which implies seeing new places. Urban form does not seem to play a significant role in holiday choice. All communities travel to spend time with family and friends. Cromwell and Kapiti's larger holiday footprint, unlike that of Tarras, is linked with travelling further to see new places. 
Table 5.6: Reasons why communities go on holiday and the activities they undertake

\begin{tabular}{|c|c|c|c|c|c|c|c|}
\hline Community & $\begin{array}{l}\text { Spending } \\
\text { time } \\
\text { with } \\
\text { friends } \\
\text { and } \\
\text { family }\end{array}$ & $\begin{array}{c}\text { Visiting } \\
\text { new } \\
\text { places }\end{array}$ & Relaxing & $\begin{array}{l}\text { Gathering } \\
\text { food }\end{array}$ & $\begin{array}{l}\text { Sports } \\
\text { events }\end{array}$ & $\begin{array}{c}\text { Reason } \\
\text { changes each } \\
\text { year }\end{array}$ & \\
\hline \multicolumn{7}{|l|}{ Waiheke } & \\
\hline \multicolumn{7}{|l|}{ Waitakere } & \\
\hline \multicolumn{7}{|l|}{ Kapiti } & \\
\hline \multicolumn{7}{|l|}{ Tarras } & \\
\hline \multicolumn{8}{|l|}{ Cromwell } \\
\hline & Camping & Fishing & $\begin{array}{l}\text { Go to } \\
\text { the } \\
\text { bach }\end{array}$ & VFR & $\begin{array}{l}\text { Road- } \\
\text { trip }\end{array}$ & 4WD/boating & $\begin{array}{c}\text { Eating } \\
\text { out }\end{array}$ \\
\hline \multicolumn{8}{|l|}{ Waiheke } \\
\hline \multicolumn{8}{|l|}{ Waitakere } \\
\hline \multicolumn{8}{|l|}{ Kapiti } \\
\hline \multicolumn{8}{|l|}{ Tarras } \\
\hline Cromwell & & & & & & & \\
\hline
\end{tabular}

\begin{tabular}{|l|llll|}
\hline KEY & Most likely & Second most likely & Second least likely & Least Likely \\
\hline
\end{tabular}

Cromwell residents also went on holiday to spend time with friends and family and see new places, and went road-tripping whilst away. They were least likely to go on holiday to gather food or attend a sports event. Tarras was different, with their main reason for going on holiday being to relax and then to gather food. They often went to the bach and went fourwheel driving and boating, and were least likely to go camping or eat out. The results for Tarras seem to contradict their preference for travelling to Europe, which implies seeing new places. Urban form does not seem to play a significant role in holiday choice. All communities travel to spend time with family and friends. Cromwell and Kapiti's larger holiday footprint, unlike that of Tarras, is linked with travelling further to see new places.

\section{Household Energy}

The four household energy questions included the total spending on electricity, natural gas/diesel and coal per month, and a question asking about the total amount of wood consumed per year. The electricity footprint was calculated using the average energy (MJ) per dollar as reported by the major NZ energy suppliers, then converted to hectares. For other 
fuels, gas/diesel were lumped together because their footprints per dollar spent were comparable, although this meant the results were less clear. The monthly energy footprints were calculated for the year. The EF calculation for wood (section 4.7.2) gave a forest EF per household per year, which was then divided by the number of people living in the house.

For electricity Waiheke was different from all other communities, spending $\$ 51-100 /$ month on electricity. The other four community averages were in the range $\$ 101-150 /$ month (going from lowest to higher spending, the order was Waitakere, Cromwell, Tarras, and Kapiti). Only $2 \%$ of homes were off the grid (one household in each of Tarras, Waiheke and Kapiti). Tarras, Waitakere and Kapiti all had households consuming over $\$ 250$ of electricity/month. Waitakere had the broadest spread for the amount spent and Waiheke the least.

More than half of those sampled did not use gas or diesel. Of those using these fuels, half used less than $\$ 25 /$ month. Of those who did use gas, $69 \%$ were from Waiheke, but overall there was no significant difference between gas and diesel use in the communities.

Overall $94 \%$ did not use coal. Tarras was most likely to use coal, with $12 \%$ spending under $\$ 100 /$ month and $4 \%$ over $\$ 100 /$ month. Cromwell and Kapiti also use coal at $12 \%$ and $4 \%$ respectively, spending less than $\$ 100 /$ month. The further south respondents lived the more likely they were to use coal. The coal used by households increased the household energy EF, particularly for those consuming over $\$ 100 /$ month.

Overall $68 \%$ of the sample used wood, averaging $4-7 \mathrm{~m}^{3} /$ year (table 5.7 ). The most likely community to use wood was Tarras where $96 \%$ of the community burned wood. $64 \%$ of Cromwell, $62 \%$ of Waiheke, $56 \%$ of Waitakere and $53 \%$ of Kapiti used wood. The use of wood in Tarras and Cromwell is significantly different from Kapiti, Waitakere and Waiheke.

Table 5.7: Wood use by community respondents

\begin{tabular}{|lccccc|}
\hline Wood & Tarras & Cromwell & Waiheke & Waitakere & Kapiti \\
\hline $0-2 m^{3}$ & $0 \%$ & $2 \%$ & $38 \%$ & $12 \%$ & $14 \%$ \\
\hline $3-5 m^{3}$ & $20 \%$ & $14 \%$ & $21 \%$ & $24 \%$ & $32 \%$ \\
\hline $6-10 m^{3}$ & $32 \%$ & $29 \%$ & $0 \%$ & $7 \%$ & $14 \%$ \\
\hline $11-15 m^{3}$ & $16 \%$ & $7 \%$ & $0 \%$ & $0 \%$ & $7 \%$ \\
\hline$+15 m^{3}$ & $28 \%$ & $12 \%$ & $3 \%$ & $0 \%$ & $0 \%$ \\
\hline
\end{tabular}


In only three cases was there a high use of both wood and coal, all from Tarras. Two of the three high wood- and coal-consuming households also spent more than $\$ 200 /$ month on electricity. There were a number of households (20) who spent less than $\$ 100 /$ month on electricity and also did not use gas, diesel, coal or wood. Of these, $40 \%$ were from Kapiti, $25 \%$ from Cromwell, 25\% from Waitakere, and 10\% from Waiheke. Of the 25 lowest energy footprints $(<0.2 \mathrm{NZha}), 12$ were from Waiheke, 6 from Waitakere, 5 from Kapiti and 2 from Cromwell. Of these same households, $40 \%$ used gas and $36 \%$ wood, all using less than $5 \mathrm{~m}^{3} /$ year, and electricity use averaged $\$ 101-150 /$ month. Only one of the three off-the-grid households had an energy EF of less than 0.2NZha.

This analysis suggests that a low household energy EF in NZ means having an average electricity use together with a small amount of wood, gas or coal. Here firewood is assumed to be grown on purpose-specific land. Alternatively, if land can grow firewood and also be used for another purpose (such as shade for stock) then firewood becomes a better option, not unlike using waste from timber grown for construction, as plantation-grown firewood has a similar energy EF to using gas. Coal on the other hand has the largest EF of any fuel (table 3.3 above). It also has the additional impacts of increased particulate matter in the air which are tied to increased health problems. The size of the house and the number of people sharing the energy must be considered when assessing the EF of household energy (table 5.8).

\section{Housing}

Housing questions asked about the number of people in the household, ownership, house size, the impervious surface coverage, and the construction materials used.

Overall $58 \%$ of respondents owned their own home, with the remainder renting. In the Kapiti sample $84 \%$ rented, the highest proportion of renters, with Tarras having the highest ownership at $92 \%$. There was a significant difference between the housing footprints of Tarras and Cromwell versus those of Waitakere, Kapiti and Waiheke. An analysis was carried out on the entire dataset to look for relationships between age and number of people in a household. The average for the latter was 2.87 people, varying considerably between the communities. Tarras was lowest at 2.04 people/household and Waiheke the highest at 3.17 people/household. The ANOVA showed a significant correlation between age group and the 
number of people/household. The $65+$ group was most likely to have the lowest number of people/household, and the under-25 and 35-44 groups the highest number of people/household.

There were significant differences in the size of houses between the five communities. The average was $101-150 \mathrm{~m}^{2}$ with the median higher at $151-200 \mathrm{~m}^{2}$. This shows that, although smaller houses form the bulk of the sample, there were a significant number of large houses. On average Kapiti had the smallest houses (101-150m²) and Tarras the largest (151-200m²). Tarras also had the smallest average number of people living in the house (table 5.8).

The area of impervious surface needs to be considered along with the size of the section, and it would have been better to have asked about the percentage of each property covered in impervious surface rather than the area of the section. Waiheke had the least impervious surface but also some of the smallest houses. Waiheke and Kapiti were noticeably different from Tarras, Cromwell and Waitakere (table 5.8).

The results in table 5.8 give support to the assumption that more urban communities have smaller housing footprints, although this does depend on occupancy. Cromwell and Tarras have low inhabitant numbers, use considerable household energy, and have big houses, and as a result have the highest housing and household energy footprints.

In the final question about the materials of which the house was made, by allowing the respondents to tick more than one material(s) unfortunately their responses no longer reflected the footprint calculations in section 4.6. Despite this problem, timber frame is the most common material for the whole of the NZ housing stock and this was supported by the survey where $86 \%$ of respondents answered 'timber frame'. A further $10 \%$ answered clay brick, $2 \%$ were mud brick and $2 \%$ did not know. For the EF calculation, all participants were assumed to have timber-framed houses with concrete floors though this is truer for new houses. 
Table 5.8: Comparison of urban categorisation, number of people per household, average house size, average impervious surface, most popular housing type, and average housing

EF

\begin{tabular}{|c|c|c|c|c|c|c|c|}
\hline Community & $\begin{array}{l}\text { Official urban } \\
\text { categorisation }\end{array}$ & $\begin{array}{l}\text { People } \\
\text { per } \\
\text { house }\end{array}$ & $\begin{array}{l}\text { Average } \\
\text { house } \\
\text { size }\end{array}$ & $\begin{array}{l}\text { Average } \\
\text { impervious } \\
\text { surface }\end{array}$ & $\begin{array}{c}\text { Most } \\
\text { popular } \\
\text { property } \\
\text { type }\end{array}$ & $\begin{array}{c}\text { Average } \\
\text { housing } \\
\text { EF }\end{array}$ & $\begin{array}{l}\text { Average } \\
\text { household } \\
\text { energy EF }\end{array}$ \\
\hline & & & $m^{2}$ & $m^{2}$ & & $m^{2}$ & $m^{2}$ \\
\hline Kapiti & $\begin{array}{c}\text { Main urban } \\
\text { area }\end{array}$ & 3.14 & 108 & 27 & $\begin{array}{l}\text { FSH on } \\
\text { small } \\
\text { section }\end{array}$ & 1,229 & 2,000 \\
\hline Waitakere & $\begin{array}{c}\text { Satellite } \\
\text { urban area }\end{array}$ & 3.09 & 132 & 32 & $\begin{array}{l}\text { FSH on } \\
\text { small } \\
\text { section }\end{array}$ & 1,803 & 2,000 \\
\hline Waiheke & $\begin{array}{l}\text { Satellite } \\
\text { urban area }\end{array}$ & 3.17 & 131 & 14 & $\begin{array}{l}\text { FSH on } \\
\text { small } \\
\text { and } \\
\text { large } \\
\text { sections }\end{array}$ & 1,486 & 2,500 \\
\hline Cromwell & $\begin{array}{c}\text { Independent } \\
\text { urban } \\
\text { community }\end{array}$ & 2.62 & 156 & 28 & $\begin{array}{l}\text { FSH on } \\
\text { small } \\
\text { section }\end{array}$ & 1,537 & 2,900 \\
\hline Tarras & $\begin{array}{l}\text { Highly rural } \\
\text { remote area }\end{array}$ & 2.04 & 170 & 22 & $\begin{array}{l}\text { Lifestyle } \\
\text { block }\end{array}$ & 2,154 & 5,800 \\
\hline
\end{tabular}

Individuals with the smallest housing footprints have different housing characteristics. Of the five that had a housing EF below 0.6NZha, one lived in an apartment and four lived in a FSH on a section smaller than $1,000 \mathrm{~m}^{2}$. Three of these had a small house between $51-100 \mathrm{~m}^{2}$, however, one house was $201-250 \mathrm{~m}^{2}$ but still on a small section.

\section{Summary}

The survey results showed a number of clear correlations between a community's urban form and footprint, as listed below, where the community names have been replaced by their urban forms.

1. A low food EF was closely aligned with growing, gathering, or bartering a large quantity of food, or with eating fewer animal products. Both seemed to have a similar weighting. The food EF increased as the community became more urbanised, had 
smaller sections and gardened less. Urban centres also consumed more processed food.

2. A low travel footprint occurred in satellite and independent urban centres where people could walk and bike, did not need to travel so far, and tended to have multiple car occupancy. Being able to use public transport, again a characteristic of satellite and independent urban centres, also lowers the travel EF. However only about half of the 'main urban centre' sample used public transport, with half driving their cars long distances with single occupancy. This result does not support the commonly held perception that the densest areas have the lowest travel footprints. An individual's travel EF seems to depend on distance to the most used destination (place of work or study) and proximity to services, alongside a mixture of the lifestyle drivers of consumption values, income and time.

3. A low consumer goods footprint is achieved by not buying new products, including reading material. There seemed no clear correlation between consumer goods and urban form, with residents in the remote rural areas consumed more, even though they are further from the stores. More spending on consumer goods would suggest either increased disposable income or that the disposable income is spent differently. Half of the interviewees from the rural community did not disclose their household income and as a result the data cannot be used to verify this. However as suggested in the food and drink category the additional land available for growing food would also help to supplement food costs leaving more disposal income for consumer goods. The two communities with the least access to recycling facilities were the least likely to recycle.

4. Rural areas, working farms and lifestyle blocks have high footprint pets. However main urban centres also have a high number of medium-resource pets, whilst other areas had high numbers of low-resource pets.

5. Correlations between holidays and urban form are not clear. The communities in the southern part of NZ have higher holiday travel footprints, as does Waiheke in the north. Here, distance from other attractions is the reason (ferry travel has a high EF). 
6. Urban areas and satellite urban centres have the smallest houses with the largest number of people living in them, giving the lowest housing and household energy footprints.

Overall, urban form does play a role in the size of a community's EF, particularly in relation to food, travel, pets, housing and household energy.

\subsubsection{Lifestyle EF Results}

Lifestyle choices can affect the quantity and type of resources an individual or household consumes, and personal values are a big driver of lifestyle choices. The following section analyses the survey to identify lifestyle types.

\section{Barriers to having a less resource-intensive lifestyle}

The first of the lifestyle questions was for the respondent to identify the 'major barriers to having a less resource-intensive lifestyle'. This 'barriers' question was not included in the Kapiti survey as it was not considered 'appropriate' by the project manager for his group. The results found cost the major barrier, followed by not wanting, or being unable, to change a habit, with the third barrier being community infrastructure (table 5.9).

Table 5.9: Perceived barriers to having a less resource-intensive lifestyle (four communities) including barriers for individuals with footprints over 4NZha

\begin{tabular}{|lcccccc|}
\hline \multicolumn{1}{|c}{$\begin{array}{c}\text { Barriers } \\
\end{array}$} & & & & & & $\begin{array}{c}\text { Footprints } \\
\text { more than } \\
\text { 4NZha }\end{array}$ \\
\hline Cost & $42 \%$ & $41 \%$ & $56 \%$ & $46 \%$ & $16 \%$ & $20 \%$ \\
\hline Change of habit & $41 \%$ & $39 \%$ & $41 \%$ & $49 \%$ & $32 \%$ & $50 \%$ \\
\hline $\begin{array}{l}\text { Community } \\
\text { infrastructure }\end{array}$ & $40 \%$ & $36 \%$ & $54 \%$ & $28 \%$ & $38 \%$ & $70 \%$ \\
\hline Responsibility & $31 \%$ & $7 \%$ & $47 \%$ & $24 \%$ & $36 \%$ & $10 \%$ \\
\hline Defiant & $7 \%$ & $14 \%$ & $3 \%$ & $5 \%$ & $8 \%$ & $20 \%$ \\
\hline Not interested & $6 \%$ & $0 \%$ & $9 \%$ & $5 \%$ & $9 \%$ & $0 \%$ \\
\hline Other & $5 \%$ & $3 \%$ & $0 \%$ & $2 \%$ & $16 \%$ & $10 \%$ \\
\hline Lack of support & $5 \%$ & $3 \%$ & $6 \%$ & $5 \%$ & $4 \%$ & $0 \%$ \\
\hline
\end{tabular}

Cost was the biggest barrier for Waitakere, the community with the lowest average income. Infrastructure was of least concern for Cromwell and Tarras, communities with the lowest 
level of infrastructure. For the individuals with large footprints, infrastructure was the biggest barrier and change of habit was the next. Very few respondents were not interested, but the few were mostly from Waitakere and Tarras.

\section{Tribes Lifestyles}

As discussed in chapter 2, the NZ 8 Tribes were used here to help identify different types of NZ lifestyles, and whether certain lifestyles have similar footprint characteristics. The 8 Tribes used in this analysis are Grey Lynn, Raglan, Otara, Papatoetoe, Balclutha and North Shore. Cuba Street and Remuera tribes are omitted because the number of profiles for them was too low for analysis. The survey results are examined from three perspectives. The first shows the 8 Tribes results by tribe, total EF and income to investigate whether the initial 8 Tribes research was correct. The second identifies the most prominent tribes within each community. The third looks at statements in the 8 Tribes survey to highlight high and low footprints.

Initial 8 Tribes research (Lawton, in press; Lawton, Vale, \& Vale, 2010) used the characteristics of each tribe to carry out footprint calculations, and also looked at average income, with the following results:

1. The North Shore tribe has high incomes and large footprints because they 'have more stuff' and 'keep up with the Joneses'.

2. Remuera has 'old money', used for long international holidays, and expensive tastes.

3. Grey Lynn likes to 'think green' and has high incomes, allowing them to 'buy green'. However, they buy too much and travel extensively. Grey Lynn members often suffer from time poverty which restricts options for reducing their footprint, such as growing food.

4. The Balclutha tribe is 'small town' at heart, and historically would have grown their own and made their own, producing a low footprint. However, some of these values are being lost as the tribe becomes urbanised and incomes increase, meaning they buy and fly more.

5. Cuba Street tribe tends to have higher incomes and work in 'new industries'. They like 'gadgets' and travel extensively. 
6. Papatoetoe households earn the average wage or just below. They work hard and live simply. They might have a higher footprint if they could afford it.

7. Raglan like to live simply and have earthly values. They have the most diverse range of incomes, suggesting their footprint could be increased by extensive international travel.

8. The Otara tribe is likely to have the lowest footprint, living on less than the average wage. The majority of the Otara tribe are immigrants whose lifestyle revolves around the church and family.

It was noted during this initial research that an individual's lifestyle characteristics are often expressed through multiple tribes, making a direct link with footprint more difficult. Some tribes have a mix of EF components and incomes depending on the satisfiers they choose.

The 8 Tribes section of the survey contains numerous statements with which respondents could choose to agree or disagree. Each question has a positive or negative weighting corresponding with one or more of the 8 Tribes. The weightings of the statements with which a respondent agrees are summed, resulting in an overall weighting for or against each tribe. This is why a particular person can show the characteristics of numerous tribes and strongly disagree with others. The Footprint Calculator assigned each person a tribal affiliation, based on a ranking of their associated tribes. Due to the sheer amount of data, the following discussion only considers the primary and secondary tribe selection for each respondent.

Grey Lynn tribe was the most common tribe at $43 \%$ of all respondents. Balclutha was second (23\%), Papatoetoe third (15\%), closely followed by Raglan (12\%). Otara and North Shore were both $3 \%$.

The tribes were compared to the average EF from the initial 8 Tribes research (gha), the average EF for each tribe from the sample (NZha), the standard deviation for the EF, and average income for the tribe. The NZ average income is also presented for comparison (table 5.10). The average EF of each tribe follows a similar trend to the initial research and the standard deviation suggests considerable variation within some of the tribes. The results for the Otara and North Shore tribes must be used with caution due to the very small sample sets (five and six respondents, respectively). 
Balclutha and North Shore have similarly high average footprints of 3.00 and 2.98NZha. Balclutha also had a very diverse range of footprints as shown by the high standard deviation. The highest individual EF is included in this tribe. North Shore supported the 8 Tribes concept of having the highest income on average. Of those who represented the North Shore tribe, none had a low EF. Grey Lynn has the third highest EF, which is very similar to the average footprint for the whole community. This ranking supports the findings from the initial 8 Tribes research. Grey Lynn's average income range was slightly lower than previously reported. Raglan has the next footprint at 2.59NZha and the standard deviation is small. The average income bracket is a little high, but has the highest income standard deviation, suggesting that income is not a good indicator for this group. The Papatoetoe tribe footprint is less than the average EF, as initially suggested, though the standard deviation is high, showing variability. Their average income also has a high standard deviation, with 11 of the 27 households earning more than $\$ 80,000$ per year. Finally, the Otara tribe have by far the lowest EF with a low standard deviation. Their average income is much higher than previously reported, pulled up by a Cromwell respondent with an income of $\$ 60,000-\$ 80,000$. Overall the 8 Tribes survey findings support the initial research, suggesting this method could provide some indication of the footprints found in NZ communities.

Table 5.10: Comparison of 8 Tribes in the survey with average EF, standard deviation of survey $\mathrm{EF}$, and average household income

\begin{tabular}{|c|c|c|c|c|c|}
\hline 8 Tribes & $\begin{array}{l}\text { Primary } \\
\text { tribe }\end{array}$ & $\begin{array}{c}\text { NZ } \\
\text { average } \\
\text { EF }\end{array}$ & $\begin{array}{l}\text { Average } \\
\text { survey EF }\end{array}$ & $\begin{array}{l}\text { Survey EF } \\
\text { standard } \\
\text { deviation }\end{array}$ & Average Income \\
\hline & $\%$ & gha $^{1}$ & NZha & & $\$$ \\
\hline Grey Lynn & $43 \%$ & 5.81 & 2.76 & 0.66 & $\$ 40,000-\$ 60,000$ \\
\hline Balclutha & $23 \%$ & 5.32 & 3.00 & 1.01 & $\$ 40,000-\$ 60,000$ \\
\hline Papatoetoe & $15 \%$ & 3.76 & 2.54 & 0.81 & $\begin{array}{l}\text { Less than } \\
\$ 40,000\end{array}$ \\
\hline Raglan & $12 \%$ & 3.22 & 2.59 & 0.68 & $\$ 60,000-\$ 80,000$ \\
\hline Otara & $3 \%$ & 3.16 & 2.36 & 0.37 & $\$ 40,000-\$ 60,000$ \\
\hline $\begin{array}{l}\text { North } \\
\text { Shore }\end{array}$ & $3 \%$ & 6.56 & 2.98 & 0.51 & $\$ 60,000-\$ 80,000$ \\
\hline NZ average & & & 2.49 & & $\$ 67,028^{2}$ \\
\hline
\end{tabular}

1. The initial 8 Tribes research was carried out using a different footprint calculator which provided results in global hectares (Redefining Progress, 2006). The results are shown here not as a direct comparison but to show trends and differences in footprint between tribes.

2. Average household income June 2011 (Statistics New Zealand, 2011c) 
Table 5.11 gives the total number of times the Tribes were represented as either a primary or secondary tribe in the community lifestyle results. The results do not add up to $100 \%$ because of the exclusion of the Remuera and Cuba Street tribes. As discussed above, Grey Lynn is the most common tribe, but in relation to the communities this was only true for Waiheke and Waitakere.

Balclutha was the most common tribe for Tarras and Cromwell, which is not surprising given that these are both representative of 'small town' NZ. Also significant to Tarras and Cromwell is a high portion of Grey Lynn and Papatoetoe tribes. This makes an interesting mix of small town values, highly qualified individuals who exude 'green values', and those who do manual work. The biggest difference between Tarras and Cromwell is the additional mix of North Shore and Raglan tribes in the Cromwell community, showing broader extremes of respondents who put both more and less value on material belongings. Tarras was also unique, as when the primary tribe affiliations were considered, they only included Grey Lynn (40\%), Balclutha (24\%), Papatoetoe (20\%) and Raglan (16\%). Including both primary and secondary affiliations changed the proportion of the Balclutha tribe and reduced the Raglan tribe, showing that although Raglan was the dominant tribe for many, Balclutha often came in as a secondary tribe and was more dominant overall.

Table 5.11: Tribe and community association

\begin{tabular}{|lccccc|}
\hline & Tarras & Cromwell & Waiheke & Waitakere & Kapiti \\
\hline Grey Lynn & $30 \%$ & $24 \%$ & $40 \%$ & $27 \%$ & $35 \%$ \\
\hline Raglan & $8 \%$ & $18 \%$ & $16 \%$ & $13 \%$ & $19 \%$ \\
\hline Otara & $4 \%$ & $2 \%$ & $2 \%$ & $13 \%$ & $4 \%$ \\
\hline Papatoetoe & $20 \%$ & $16 \%$ & $16 \%$ & $21 \%$ & $14 \%$ \\
\hline Balclutha & $37 \%$ & $32 \%$ & $25 \%$ & $24 \%$ & $21 \%$ \\
\hline North Shore & $0 \%$ & $7 \%$ & $2 \%$ & $2 \%$ & $7 \%$ \\
\hline
\end{tabular}

The Waiheke results are similar to Cromwell. Waiheke had the highest representation of the Grey Lynn tribe and a significant portion from Balclutha. Kapiti had the highest representation of the Raglan tribe which was not expected given that it is a main urban centre. Waitakere had the highest portion of the Papatoetoe and Otara tribes meaning it had a distinctly different make-up in comparison to the other communities. This high representation of less common tribes could help explain some of the anomalies found in the Waitakere EF results. 
The following section explores whether EF or urban form could be predicted by a respondent 'agreeing' or 'disagreeing' to a particular statement or set of statements. The most common statements people agreed with were 'it's important to take responsibility for the social and environmental effects of your lifestyle choices' (136 people, $74 \%$ ), 'acting ethically is so much more important than financial gain' (113 people, 61\%), 'possessions are pretty unimportant in the scheme of things' (105 people, 57\%), 'I identify with the down to earth people you find in country areas' (97 people, 53\%), and 'we must change the way we live our individual lives, so we can change the world' (94 people, 51\%). The least common were 'I would die if I had to live in the provinces - the inner city is my heartland' ( 2 people, $1.1 \%$ ), 'my private school education has connected me with important social networks' (5 people, $2.7 \%$ ), 'most people haven't heard the music l'm into' (6 people, 3.3\%), 'old money has class, new money is crass' (9 people, 4.9\%). A full summary of all statements and selections is provided in appendix $5 . \mathrm{A}$ breakdown of the selection of these statements by community is shown in table 5.12 .

Table 5.12: Five highest-scoring ' 8 Tribes' statements, by community

\begin{tabular}{|c|c|c|c|c|c|c|}
\hline & Overall & Waiheke & Waitakere & Kapiti & Cromwell & Tarras \\
\hline $\begin{array}{l}\text { It's important to take } \\
\text { responsibility for the social } \\
\text { and environmental effects } \\
\text { of your lifestyle choices }\end{array}$ & $74 \%$ & $72 \%$ & $72 \%$ & $70 \%$ & $79 \%$ & $84 \%$ \\
\hline $\begin{array}{l}\text { Acting ethically is so much } \\
\text { more important than } \\
\text { financial gain }\end{array}$ & $61 \%$ & $69 \%$ & $60 \%$ & $57 \%$ & $62 \%$ & $68 \%$ \\
\hline $\begin{array}{l}\text { Possessions are pretty } \\
\text { unimportant in the scheme } \\
\text { of things }\end{array}$ & $57 \%$ & $62 \%$ & $63 \%$ & $59 \%$ & $55 \%$ & $48 \%$ \\
\hline $\begin{array}{l}\text { I identify with the down to } \\
\text { earth people you find in } \\
\text { country areas }\end{array}$ & $53 \%$ & $38 \%$ & $56 \%$ & $35 \%$ & $62 \%$ & $92 \%$ \\
\hline $\begin{array}{l}\text { We must change the way } \\
\text { we live our individual lives, } \\
\text { so we can change the world }\end{array}$ & $51 \%$ & $59 \%$ & $59 \%$ & $41 \%$ & $50 \%$ & $48 \%$ \\
\hline
\end{tabular}

All communities scored highly for the statement 'it's important to take responsibility for the social and environmental effects of your lifestyle choices'. Tarras and Cromwell had the highest proportion, above the overall average, choosing this statement. Both communities are rural 'small towns' with a high number of Balclutha, Grey Lynn and Raglan tribes. Tarras 
and Waiheke were most likely to choose 'acting ethically is so much more important than financial gain'. 'Possessions are pretty unimportant' was the third most popular statement, and most important for Waitakere and Waiheke. 'I identify with the down to earth people you find in country areas' was supported by Tarras. Finally 'we must change the way we live our individual lives, so we can change the world' was selected by half of all respondents, with the highest selections in Waiheke and Waitakere, the least Kapiti. Kapiti had a low response rate for four of the five questions which may suggest that Kapiti has a lower EF without the 'eco' tendencies found in the other communities.

Four statements were also selected as representative of things you might expect high EF people to believe and tested for whether they were high EF statements. A summary is provided in table 5.13 of the proportion of all respondents selecting a statement, the proportion of each community, and the average EF of those selecting a statement. Of the four statements, only 'getting rich is one of my goals in life' has a below-average EF of 2.75NZha. 'The things I own show what I've achieved so far' has the highest average footprint of 3.03NZha. The statement 'buying new stuff is one of the great joys of life' was selected by $25 \%$ of the Tarras community (community with the highest average EF), whilst it was not selected by any Waiheke respondents (community with the lowest total average NZ). This suggests these statements may be a good indicator of EF.

Table 5.13: Selection of possible high EF statements, and associated EF

\begin{tabular}{|c|c|c|c|c|c|c|c|}
\hline $\begin{array}{c}\text { High EF } \\
\text { Statements }\end{array}$ & Overall & Waiheke & Waitakere & Kapiti & Cromwell & Tarras & $\begin{array}{c}\text { Average } \\
\text { EF }\end{array}$ \\
\hline $\begin{array}{l}\text { Buying new stuff is } \\
\text { one of the great } \\
\text { joys of life }\end{array}$ & $12 \%$ & $0 \%$ & $9 \%$ & $11 \%$ & $17 \%$ & $24 \%$ & 2.93 \\
\hline $\begin{array}{l}\text { The things I own } \\
\text { show what I've } \\
\text { achieved so far }\end{array}$ & $11 \%$ & $3 \%$ & $3 \%$ & $10 \%$ & $17 \%$ & $12 \%$ & 3.03 \\
\hline $\begin{array}{l}\text { Getting rich is one } \\
\text { of my goals in life }\end{array}$ & $9 \%$ & $10 \%$ & $9 \%$ & $9 \%$ & $10 \%$ & $4 \%$ & 2.68 \\
\hline $\begin{array}{l}\text { I strive to get the } \\
\text { best house and car } \\
\text { I can afford }\end{array}$ & $6 \%$ & $7 \%$ & $9 \%$ & $4 \%$ & $7 \%$ & $4 \%$ & 2.97 \\
\hline
\end{tabular}

In the following section, the EF results of activities likely to increase EF are discussed, by community and tribe, to look for trends. 


\section{Tribes that most like to fly}

All respondents who annually flew more than $1,600 \mathrm{pkm}$ nationally and $9,000 \mathrm{pkm}$ internationally were selected for analysis. Only $22 \%$ of respondents travel this much and, of these, $52 \%$ were from Tarras and $25 \%$ were from Kapiti, significantly higher than the other three communities. There was no clear trend between flying and the primary tribe. Of those who selected North Shore as their first tribe choice, 33\% flew a lot. Of the rest, $24 \%$ of Grey Lynn flew a lot, $20 \%$ of Otara, and approximately $19 \%$ of Balclutha, Papatoetoe and Raglan tribes.

\section{Tribe most likely to have a high pet EF}

Only $15 \%$ of all respondents have a pet EF larger than one hectare, and this is most likely to occur within the Balclutha tribe ( $24 \%$ of the tribe). For those who chose Otara as their first choice tribe, $20 \%$ had a large pet EF (only one person). The Grey Lynn tribe had 11 people out of 80 with a high pet EF (14\%). Raglan also had $14 \%$ with a high pet EF.

\section{Tribes most likely to grow food}

Overall, $34 \%$ of respondents grew more than 'some' food in their garden. Of these, the majority came from Tarras (60\%). Cromwell had 38\%, then Kapiti, Waitakere and Waiheke at $29 \%, 26 \%$ and $25 \%$ respectively. Of the total Balclutha population, $38 \%$ grow a significant amount of their food, with Grey Lynn at 37\%. Of the Raglan tribe 32\% grow a lot of their own food, with $26 \%$ in the Papatoetoe tribe and only $16 \%$ in the North Shore tribe.

\section{Summary}

Balclutha tribe and Grey Lynn tribe were the most dominant tribes and cost was perceived as the major barrier to respondents reducing their footprint. Each of the five sample communities had a different tribal make-up. The small-town Balclutha tribe was most heavily represented by Tarras, then Cromwell, whilst the Grey Lynn tribe was Waiheke and Kapiti. The most prominent tribe for Waitakere was also Grey Lynn, but only just ahead of the Balclutha and Papatoetoe tribes. 'It's important to take responsibility for the social and 
environmental effects of your lifestyle choices' was the most supported statement, particularly by Tarras.

\subsection{Lowest individual EF results}

Looking at the lowest footprints will help in better understanding the mix of urban form and lifestyles choices which achieve low EF living. One respondent had a footprint below the NZ fair earth share, and their lifestyle is described.

Table 5.14 summarises the lowest EF from each of the five communities. The average EF for each category is included for comparison. The individual's EF ranking (out of all respondents, ranked from lowest to highest EF) is also given in the table. The EF is shown by footprint category to highlight how the EF can change between individuals, with low EF categories for some respondents being very different from others (within an overall low EF).

Table 5.14: Comparison of the lowest EF individual from each community with the NZ average

\begin{tabular}{|c|c|c|c|c|c|c|c|c|c|}
\hline Community & & $\begin{array}{l}\text { Overall } \\
\text { EF } \\
\text { ranking }\end{array}$ & Total & $\begin{array}{l}\text { Food } \\
\text { and } \\
\text { drink }\end{array}$ & Travel & $\begin{array}{l}\text { Consumer } \\
\text { goods }\end{array}$ & Pets & Holidays & $\begin{array}{l}\text { Housing } \\
\text { and } \\
\text { Household } \\
\text { energy }\end{array}$ \\
\hline & & NZha & NZha & NZha & NZha & NZha & NZha & NZha & NZha \\
\hline $\begin{array}{l}\mathrm{NZ} \\
\text { average }\end{array}$ & & 2.75 & 1.05 & 0.26 & 0.35 & 0.44 & 0.58 & 0.16 & 0.77 \\
\hline Waiheke & 1 & 1.01 & 0.31 & 0.08 & 0.24 & 0.00 & 0.18 & 0.04 & 0.06 \\
\hline Waitakere & 2 & 1.38 & 0.38 & 0.08 & 0.39 & 0.36 & 0.00 & 0.03 & 0.04 \\
\hline Tarras & 5 & 1.46 & 0.62 & 0.08 & 0.31 & 0.12 & 0.00 & 0.15 & 0.09 \\
\hline Cromwell & 6 & 1.59 & 0.69 & 0.05 & 0.40 & 0.00 & 0.17 & 0.07 & 0.06 \\
\hline Kapiti & 7 & 1.53 & 0.78 & 0.11 & 0.44 & 0.00 & 0.00 & 0.08 & 0.09 \\
\hline
\end{tabular}

Each of the EF categories for the Waiheke respondent is much lower than the average. The Waitakere respondent's footprint is only slightly higher than the fair earth share. This respondent has pets and a higher-than-average consumer goods EF, but does not travel to go on holiday. The Tarras resident is still typically Tarras with an above-average household energy footprint and a few pets. However, unlike many other respondents from Tarras they did not travel to go on holiday. The Cromwell respondent has an above-average consumer goods EF and no pets. Finally, the Kapiti resident does not go on holiday or have pets, but has 
the highest consumer goods, travel and food and drink EF. Further detail about the specific lifestyles of these individuals is provided below.

Table 5.14 shows that for a low overall EF, not all EF components need to be very small, but at least one needs be minimal and the rest reasonably small. Having no pets and no holidays is a good way to reduce individual EF, although having small food and travel footprints also helps.

One survey respondent had an EF below the NZ fair earth share of 1.21NZha, and was under this by 0.29 NZha, or approximately the average travel EF. The respondent lived in Waiheke, a satellite urban area, but did not commute to Auckland for work, saving a considerable proportion of footprint compared to commuting Waiheke respondents. The respondent did not eat meat and bought few consumer goods (table 5.15).

The other four respondents with the lowest low footprints (see appendix 6) all limit the meat they eat, or eat no fish or red meat, thus lowering the commercial growing land required. Some, but not all, grow their own food or consume food which had not been bought. None rely on public transport, and they all drove 1-100pkm/week.

Three of the four infrequently buy consumer goods but some buy reading material. Two of the four have pets, one with multiple small pets and one with a medium-sized pet. Two of the four never fly whilst two fly some distance both nationally and internationally. One never goes on holiday. Their incomes range from less than $\$ 40,000 /$ year up to $\$ 140,000$. One of the households has a large home, spending up to $\$ 250 /$ month on electricity, uses a small amount of coal and burns up to $11 \mathrm{~m}^{3} /$ year of wood. However, this energy is shared between four people, still resulting in a small EF. The others spend much less on electricity and use fewer other forms of energy. 
Table 5.15: Summary of a respondent's NZ fair earth share EF

Waiheke - 1.01NZha/year. 35-44 years of age with 2 people living in the house. European/Pākehā with a tertiary qualification.

Food

- Eats no meat or fish, consumes dairy daily but very few eggs. Eats a lot of vegetables, fruit, bread and pulses. Has rice more than three times a week but only some pasta.

- Eats mostly organic food, does not consume processed foods. Most food is bought but some comes from the garden in summer.

- They eat out very rarely and do not drink.

Travel

- Walk almost all the time.

- Drive less than $100 \mathrm{pkm}$ each week in a dense urban environment and often has someone else in the car.

- They never take public transport.

\section{Consumer Goods}

- They do not have pets.

- Rarely buy anything, other than a few new furnishings each year.

- They have very little waste and recycle all the waste they generate.

- Buying 'eco' labelled goods is not a priority but waste is always considered when buying products.

Holidays

- They take long holidays and weekend holidays once a month, driving 100-400pkm per trip or flying.

- For holidays they fly less than $800 \mathrm{~km} /$ year nationally and $9,000 \mathrm{~km} / \mathrm{year}$ internationally.

- The purpose of holidaying is to spend time with family and friends, see new places and to relax. The activities they take part in are camping and staying at the bach.

\section{Household}

- There are two people living in a house of $50-100 \mathrm{~m}^{2}$ with no additional impermeable surfaces.

- Their household income is in the range $\$ 40,000-\$ 60,000$ per year.

- They spend \$101-150/month on electricity with no additional energy, and consume less water than average.

\section{Values}

- They indicate no barriers to living a less resource-intensive lifestyle.

- Their ' 8 Tribe' make-up was mainly Raglan with some Grey Lynn, Papatoetoe and Otara characteristics. They are not Remuera, Balclutha and Cuba Street.

- From the ' 8 Tribe' statements they believe in making things, are more at home in their own culture than kiwi culture, connect with down to earth people, take responsibility for their actions, are good at practical things, think possessions are unimportant, feel less mainstream as they get older, and they agree that they can play a part in changing the world. Most importantly they feel they must act ethically and take responsibility for their environmental and social actions. 
Responsibility and cost are the barriers stopping these low footprint respondents from reducing their footprints further. Papatoetoe or Raglan tribes appear most often in their ' 8 Tribes' profile, with one of these two being a primary choice for each. This suggests that low footprint living could be one of two things: either wanting to live simply or living simply due to low income; or being practical and making do. It could also be both.

\subsection{Results Summary}

Lifestyle decisions impact on an individual's EF, but lifestyle must be considered in relation to the urban form in which people live. The results of the lifestyle survey show that low footprints can come from being very conscientious when it comes to consumption and travel choices, but other low footprints seem more the result of being efficient, living together and sharing resources.

\subsubsection{Remote Rural Living}

Living in a remote rural community seems to encourage high EF living, although most of this high EF is related to individual lifestyle choices. The total EF of 'remote rural living' is statistically different from the other communities. The community is generally an ageing population predominantly made up of Balclutha tribe characteristics. As a result they have hands-on, do-it-yourself skills and knowledge about making 'stuff'. There is also a high proportion of Grey Lynn tribe, who are well-educated and 'buy green', but 'buying new stuff is one of the great joys of life', leading them to consume a lot of green stuff, which results in a high EF.

A rural setting with plenty of land supports healthy, local, home-grown food systems, as $60 \%$ of households grow much of their food or procure wild food. Rural communities are the most reserved and least likely to reveal how much money they earn. Those who revealed this had incomes that varied with age and most also had land from which they can substitute income with their own products. The household energy bills are high, compounded by a lower number of people per house, but bigger dwellings with more space to power. The community 'work hard and play hard'; the average holiday footprint is twice that of any other community. They tend to 'relax' either somewhere exotic, or stay at the bach to hunt, fish and spend time with the family. 


\subsubsection{Independent Urban Centre}

Independent urban centres are made up of a range of people from different socio-economic, but similar ethnic, backgrounds; the footprints vary considerably. The tribal make-up is predominantly Balclutha but includes a lot of Grey Lynn and Papatoetoe and a little North Shore and Raglan tribes. This mix means people generally 'do it themselves' but as incomes increase to some of the highest averages in the country, many 'just buy it'. And 'buying new stuff is one of the greatest joys in life'. Those who have continued to 'do it themselves' have kept their footprints low. There are a lot of new houses on bigger sections, so the average house size is larger than the NZ average. As the houses get bigger, so do the household energy costs. This community's most redeeming features are that they are largely self-contained for services and employment. As a result they have some of the lowest travel footprints in the country, both due to people not needing to drive far and taking someone else if they do drive. On the other hand, the town is small, leading to the fact that people still love to holiday, often overseas to 'see new places'.

\subsubsection{Satellite Urban Centres}

Satellite urban centres provide living spaces for the majority of the NZ population, defining the suburban outskirts of NZ's cities. The majority connect with Grey Lynn and Papatoetoe tribe values but there is also a strong connection with Balclutha, Raglan and Otara. These centres house an ethnically diverse population, including many minorities, and some of the poorest and wealthiest of NZ society live here.

Satellite urban centres are often a mix of housing types with older, smaller houses next door to larger new homes, which are often adjacent to lifestyle blocks. With this diversity of property types, overall there is available land for growing food. However, currently, growing food is not very popular except on lifestyle blocks and working farms, and little of the food consumed is wild or not bought. These centres have low travel footprints due to the ability to share transport, either public or private. In common with the overall trend for urban forms, as the houses get bigger, the consumption of goods and energy increases, with fewer people sharing them. 


\subsubsection{Main Urban Centres}

Main urban centres are the least likely place to find the Balclutha tribe and people that 'identify with the down to earth people you find in country areas'. These areas are full of Grey Lynn, Papatoetoe and Raglan tribes. Incomes are generally average, and extravagant holidays are not a priority. There are a high proportion of people renting rather than owning homes. The majority of dwellings are FSH on small sections with more than three people living in them, which reduces household energy footprints. This group were the least likely to feel their individual actions could change the world, and least likely to agree with the 'eco' orientated ' 8 Tribes' statements. They were the least likely to grow food, eat organic food and share private transport. The latter finding overturns many of the common arguments for intensification as a way of reducing travel footprints. It seems that smaller footprints are a result of income level and general lifestyle tendencies.

\subsubsection{Summary}

It appears that urban form influences community footprint to some extent, but that the lifestyle choices of the people within the various urban forms has a greater impact, particularly in relation to the food people eat, where they holiday, and the types of pets they keep.

Results from the sample communities support a generally-accepted assumption that more intensified urban areas have lower housing footprints and lower household energy footprints. However, the lower household energy also occurs because the number of people per household is higher in urban areas, which is not an attribute of urban form. Kapiti, the 'main urban centre' in this research, did not have a lower travel EF. It is not clear from the results whether this is from a lack of public transport or a lack of desire by the respondents to take public transport. Together Kapiti, Waiheke and Waitakere (the latter two being satellite urban centres), show that travel EF is not lower in urbanised areas unless people choose to reduce their car use.

In comparison, rural and semi-rural areas fit many of the stereotypes, particularly high car use. However the increase in availability of land seems to support more local food production. The results suggest that lifestyles that are likely to grow food, such as Raglan and Balclutha, 
are more likely to occur in rural areas, but there is insufficient evidence to know whether those living in denser urban areas would grow food if they had land available. Those living in rural areas also had more pets.

NZ communities are a cosmopolitan mix of different lifestyle types with varying levels of income, real or perceived barriers to lowering their EF, and tendencies for fulfilling their needs with high or low EF satisfiers. This makes identifying average footprints for particular communities difficult but not impossible. It seems that the technique of identifying the lifestyle of a community could be as good as, or better than, using household income as an indicator. 


\section{Chapter 6: Fair Earth Share Futures}

Having quantified the current EF of New Zealanders, the second aim of this research is "to construct a theoretical scale and type of built environment and lifestyle for a community whose $E F$ is equal to or below the fair earth share EF". This scenarios chapter uses the results from chapter 5 , as well as the outcomes from the community workshops. The aim of creating scenarios is to show how various NZ urban forms and lifestyles affect the footprints of individuals and communities, and what NZ might look like within a fair earth share future.

In 2007 the total biocapacity available on Planet Earth was 10.85 billion gha (Ewing, Moore, et al., 2010). This figure can be converted into NZha using the yield factors and equivalence factors calculated for NZ in the GFN's (2011) New Zealand National Accounts (table 3.1), giving a 2007 world biocapacity of 8.45 billion NZha. Dividing this by 7 billion people (Crossette, 2011; DESAPD, 2009; Population Division of the Department of Economic and Social Affairs of the United Nations Secretariat, 2010; United Nations Population Fund, 2012), the fair earth share is $1.21 \mathrm{NZha/person.}$

\subsection{Theoretical Fair Earth Share Footprints}

A simple way to show how NZ might live within its fair earth share (Vale \& Vale, 2009a, 2009b, 2010) uses the research results to calculate how far NZ is above the fair earth share and then suggest ways to reduce the total EF by this amount.

Chapter 4 showed the average NZ footprint in 2007 was 2.49 NZha. To be within a fair earth share this must be reduced by at least $51 \%$. Table 6.1 shows the total NZ average EF (by category) and the required reductions if all categories were reduced by $51 \%$. The average community sample footprint of 2.79 NZha would need to reduce by $58 \%$ to be within the fair earth share is also shown. The results are shown diagrammatically in figure 6.1.

Individual or community footprints differ in various ways depending on both urban form and lifestyle choices (see Chapter 5). The theoretical EF reduction shown in table 6.1 may not be practical without real or perceived hardships. However some actions, such as reducing the food $E F$, have a much bigger effect on reducing the overall EF than others, meaning more expensive or difficult reductions may not be required to reach the goal. 
Table 6.1: NZ average EF and community sample average EFs, and reductions required to achieve a theoretical fair earth share EF

\begin{tabular}{|c|c|c|c|c|c|c|c|c|}
\hline EFs & $\begin{array}{l}\text { Food } \\
\text { and } \\
\text { drink }\end{array}$ & Travel & $\begin{array}{l}\text { Consumer } \\
\text { goods }\end{array}$ & Holidays & Housing & $\begin{array}{l}\text { Household } \\
\text { energy }\end{array}$ & Citizenship & $\begin{array}{l}\text { NZ } \\
\text { EF }\end{array}$ \\
\hline & NZha & NZha & NZha & NZha & NZha & NZha & NZha & NZha \\
\hline NZ Average & 1.41 & 0.19 & 0.57 & 0.12 & 0.06 & 0.05 & 0.09 & 2.49 \\
\hline $\begin{array}{l}\text { Proportion } \\
\text { of N NZ } \\
\text { average EF }\end{array}$ & $57 \%$ & $8 \%$ & $23 \%$ & $5 \%$ & $3 \%$ & $2 \%$ & $4 \%$ & \\
\hline $\begin{array}{l}\text { Fair earth } \\
\text { share EF }\end{array}$ & 0.68 & 0.09 & 0.27 & 0.06 & 0.03 & 0.02 & 0.05 & 1.21 \\
\hline $\begin{array}{l}\text { Community } \\
\text { sample } \\
\text { average }\end{array}$ & 1.05 & 0.26 & 0.86 & 0.28 & 0.08 & 0.16 & 0.09 & 2.79 \\
\hline $\begin{array}{l}\text { Proportion } \\
\text { of } \\
\text { community } \\
\text { average EF }\end{array}$ & $38 \%$ & $10 \%$ & $31 \%$ & $10 \%$ & $3 \%$ & $6 \%$ & $3 \%$ & \\
\hline $\begin{array}{l}\text { Fair earth } \\
\text { share EF }\end{array}$ & 0.46 & 0.11 & 0.37 & 0.12 & 0.03 & 0.07 & 0.04 & 1.21 \\
\hline
\end{tabular}

Table 6.2 provides examples of how actions could reduce the NZ average EF. The actions were selected based on suggestions in the community workshops and are not specific to a particular community. For example, increasing the quantity of renewable electricity to NZ homes is a large and expensive action and would only reduce the overall average EF by $1 \%$, while changes in eating habits, such as consuming 50\% home-grown food and reducing meat consumption could reduce the footprint by $28 \%$. These results suggest that some of the biggest reductions in footprint come from lifestyle change rather than large-scale government intervention.

Some of the actions in table 6.2 could modify other behaviours and have flow-on effects for other aspects of an individual or community's EF. For example, if all New Zealanders adopt the habit of 'meat free Mondays' this may increase their consumption of other foods, or even takeaways. This may decrease their household energy EF but increase their travel EF. Such flow-on effects are not considered in table 6.2, but were discussed at community workshops and are considered again in sections 6.2 and 6.3. 


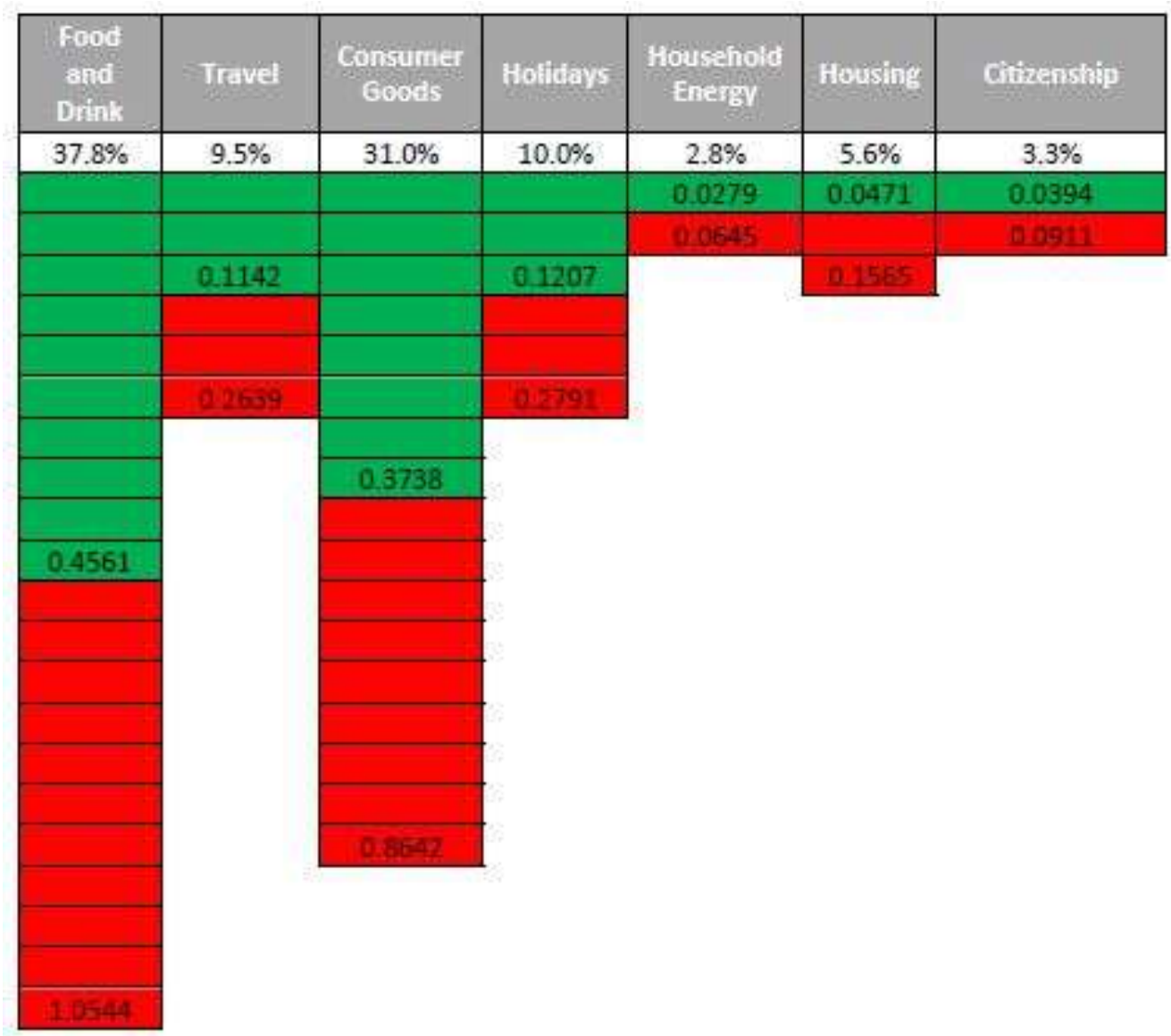

Figure 6.1: fair earth share EF (in green) in relation to current average community sample $\mathrm{EF}$ (in green + red), assuming a similar percentage reduction in each category.

Table 6.2: Examples of actions for reducing the average NZ EF

\begin{tabular}{|c|c|c|c|c|c|}
\hline \multirow[t]{2}{*}{ EF scenarios } & Category & $\begin{array}{l}\text { Category } \\
\text { sample } \\
\text { average }\end{array}$ & $\begin{array}{l}\text { New } \\
\text { category } \\
\text { EF }\end{array}$ & $\begin{array}{l}\text { New } \\
\text { total EF }\end{array}$ & $\begin{array}{l}\text { Reduction of } \\
\text { total EF }\end{array}$ \\
\hline & & NZha & NZha & NZha & $\%$ \\
\hline Meat free Mondays & $\begin{array}{l}\text { Food and } \\
\text { drink }\end{array}$ & 1.05 & 1.02 & 2.76 & $2 \%$ \\
\hline Zero fish consumption & $\begin{array}{c}\text { Food and } \\
\text { drink }\end{array}$ & 1.05 & 0.68 & 2.42 & $13 \%$ \\
\hline $\begin{array}{l}\text { Zero consumption of meat, fish } \\
\text { and seafood }\end{array}$ & $\begin{array}{c}\text { Food and } \\
\text { drink }\end{array}$ & 1.05 & 0.35 & 2.09 & $25 \%$ \\
\hline $\begin{array}{l}\text { Growing } 50 \% \text { of food in own } \\
\text { garden, some meat }\end{array}$ & $\begin{array}{c}\text { Food and } \\
\text { drink }\end{array}$ & 1.05 & 0.27 & 2.01 & $28 \%$ \\
\hline Small cars with 3 or more people & Travel & 0.26 & 0.13 & 2.66 & $5 \%$ \\
\hline $\begin{array}{l}\text { Zero high-resource pets, i.e. } \\
\text { medium and large dogs and large } \\
\text { pets }\end{array}$ & $\begin{array}{l}\text { Consumer } \\
\text { goods }\end{array}$ & 0.86 & 0.30 & 2.64 & $5 \%$ \\
\hline Zero flights for holidays & Holidays & 0.28 & 0.04 & 2.55 & $9 \%$ \\
\hline $\begin{array}{l}100 \% \text { renewable household } \\
\text { electricity generation }\end{array}$ & $\begin{array}{c}\text { Household } \\
\text { energy }\end{array}$ & 0.16 & 0.12 & 2.75 & $1 \%$ \\
\hline $\begin{array}{l}\text { Increase dwelling occupancy to } 4 \\
\text { people/dwelling }\end{array}$ & Housing & 0.08 & 0.05 & 2.76 & $1 \%$ \\
\hline
\end{tabular}




\subsection{Applying community outcomes}

At the community workshops, actions for reducing EF were suggested, and the amount of EF reduction for each action was calculated and discussed. These reduced footprint results and points from the ensuing discussions are presented here.

The workshops provided information on what people felt were the major threats and opportunities for their community in relation to land and biocapacity. A summary of the results from the community surveys was presented at each of the workshops to show the largest components of each community's EF and where action is most needed to reduce their EF.

Kapiti was the exception: it did not have a workshop because the community had already undertaken a number of community-based initiatives assisted by Kapiti Coast District Council. Therefore, there are no results for the funnel exercise described in section 6.2.1. However, actions have been carried out by the Kapiti residents in order to reduce their footprint, and these are included in section 6.2.2.

\subsubsection{Hitting the Wall of the Funnel}

The causes of 'unsustainability' are shown using the funnel metaphor in figure 1.2. The funnel metaphor describes the two trends: an increasing demand for, and a decreasing availability of, land and resources. The metaphor was used in the community workshops to initiate conversations about these trends and the consequent pressure on land, both globally and locally. Many of the causes discussed were the same for all communities, such as increasing global population and decreasing health of natural systems, but some were unique to particular communities.

The following is a summary of the most common pressures discussed by the community members at the workshops.

\section{Waiheke}

\section{Increasing}

a. Pressure from the Auckland Council to change land use 
b. Land wanted for new industries, e.g. viticulture

c. Land to be set aside for carbon sequestration

d. Land prices and people wanting to move to Waiheke

\section{Decreasing}

a. Land availability as population increases

b. Health of soil due to use of fertilisers and pesticides

\section{Waitakere}

1. Increasing
a. People's desire to move toward low footprint lifestyles
b. House prices as there is less urban land available to develop
c. Auckland's population

\section{Decreasing}
a. Central government political will to drive sustainability
b. Air and water quality

\section{Cromwell}

\section{Increasing}

a. Desirability of land for value crops such as vineyards

b. Food, as people eat more and want different foods

c. Expectations for more stuff which also requires more land to deal with waste

\section{Decreasing}
a. Productive land as it is covered in bigger homes
b. Biodiversity and native forests

\section{Tarras}

\section{Increasing}

a. Productivity of land as there is more available water

b. Area needed for landfills to deal with increased packaging and waste

\section{Decreasing}
a. Population as more people move to urban areas
b. Health of soils due to loss of topsoil (erosion) 


\subsubsection{Proposed community actions and EF reductions}

As a final exercise based on the community EF results, participants at the workshops were asked to work in groups and think about ideas for reducing their community EF. A summary of the key actions from each community is provided below, with the estimated reduction in the community's EF. The EF calculations and reductions are specific to each community, so are presented in separate community summary tables.

\section{Waiheke}

Waiheke's community EF was one of the lowest. Transport was the only EF category that was higher than for most other communities, largely due their dependence on travel by ferry to and from Auckland City. The Waiheke workshop attendees discussed a number of ways for reducing ferry use. Local travel around the island was a very small part of the overall transport $\mathrm{EF}$, and suggestions for further reduction of this are not included in table 6.3.

Table 6.3: Actions suggested by Waiheke residents (EF 2.51NZha) and potential EF reductions

\begin{tabular}{|c|c|c|c|c|c|}
\hline \multirow[t]{2}{*}{ Waiheke's actions } & Category & $\begin{array}{l}\text { Waiheke's } \\
\text { category } \\
\text { average }\end{array}$ & $\begin{array}{l}\text { New } \\
\text { category } \\
\text { EF }\end{array}$ & $\begin{array}{l}\text { New } \\
\text { total } \\
\text { EF }\end{array}$ & $\begin{array}{l}\text { Reduction } \\
\text { in total EF }\end{array}$ \\
\hline & & NZha & NZha & NZha & $\%$ \\
\hline $\begin{array}{l}100 \% \text { organic, } 100 \% \text { food } \\
\text { grown on the island; } 50 \% \\
\text { commercial, } 50 \% \text { in back } \\
\text { yards }\end{array}$ & $\begin{array}{l}\text { Food and } \\
\text { drink }\end{array}$ & 1.05 & 0.64 & 2.08 & $17 \%$ \\
\hline $\begin{array}{l}100 \% \text { renewable energy } \\
\text { for ferry }\end{array}$ & Transport & 0.32 & 0.15 & 2.13 & $7 \%$ \\
\hline $\begin{array}{l}\text { Double the average } \\
\text { number of people per } \\
\text { trip }\end{array}$ & Transport & 0.32 & 0.22 & 2.38 & $4 \%$ \\
\hline
\end{tabular}

Points raised by the community included:

1. Community and local council need to talk to Fullers Ferry about reducing the footprint of the ferries by increasing the number of passengers per trip and looking into alternative means for powering the boats. 
2. Reduce the number of people needing to travel to Auckland City each day by creating a Waiheke "Island Hub". This would provide a place to work away from home that was still social. Employers would need to support these initiatives.

3. More community food-growing activities and use of public land to grow food on Waiheke Island.

4. Increase the use of bicycles for moving around the Island.

The EF reductions from these suggestions are shown in table 6.3. Moving to $100 \%$ organic food grown on Waiheke Island could provide a total EF reduction of $17 \%$. The majority of the additional transport EF of Waiheke food from ferry travel has not been taken into account in these calculations. Although ferry transport is a considerable proportion of the Waiheke transport EF, and change to ferry technology or commuting behaviour could reduce this, a reduction in the transport $\mathrm{EF}$ does not significantly reduce the total community EF.

\section{Waitakere}

The largest component of the Waitakere EF was food and drink, which was also much higher than the total sample average. Waitakere's actions mainly focused on how its urban area could provide more local food on public land. Community suggestions included the following, with EF reductions shown in table 6.4:

1. Pockets of public areas available for growing food with up-skilling of the locals in food production to achieve $50 \%$ of food produced locally.

2. Increase car-pooling with 'hitching' posts set up around the community.

Table 6.4: Actions suggested by Waitakere residents (EF 2.62NZha) and potential EF reductions

\begin{tabular}{|c|c|c|c|c|c|}
\hline Waitakere actions & Category & $\begin{array}{l}\text { Waitakere } \\
\text { category } \\
\text { average }\end{array}$ & $\begin{array}{l}\text { New } \\
\text { category } \\
\text { EF }\end{array}$ & $\begin{array}{l}\text { New } \\
\text { total } \\
\text { EF }\end{array}$ & $\begin{array}{l}\text { Reduction of } \\
\text { total EF }\end{array}$ \\
\hline & & NZha & NZha & NZha & $\%$ \\
\hline $\begin{array}{l}50 \% \text { of food } \\
\text { produced locally on } \\
\text { public land }\end{array}$ & $\begin{array}{c}\text { Food and } \\
\text { drink }\end{array}$ & 1.12 & 0.71 & 2.20 & $16 \%$ \\
\hline $\begin{array}{l}\text { No one travels } \\
\text { alone by car }\end{array}$ & Transport & 0.18 & 0.12 & 2.55 & $2 \%$ \\
\hline
\end{tabular}


As shown in table 6.4, Waitakere could reduce their food EF by increasing the production of fresh locally-produced food on public land.

\section{Cromwell}

Cromwell's EF was the second lowest of the five communities. All categories were low relative to other communities. As a result most workshop outcomes were focused on food, particularly the need to localise its production. This would also have benefits by increasing local employment, and decreasing food transport, processing and packaging. Cromwell already has a business supplying wild meat for human consumption, and workshop attendees were keen to support this. Community suggestions were as follows, with EF reductions shown in table 6.5:

1. Create a food co-op to support more local food community assets, local farmers, consumption of pest species such as rabbit and possum, with easing of food regulations to make selling easier.

2. Help people buy locally by creating a local food map with information about seasonal food.

3. Create incentives for people to use alternative or no transport, e.g. working from home

4. Support the sharing, reuse and recycling of goods.

Table 6.5: Actions suggested by Cromwell residents (EF 2.59NZha) and potential EF reductions

\begin{tabular}{|c|c|c|c|c|c|}
\hline Cromwell actions & Category & $\begin{array}{l}\text { Category } \\
\text { average }\end{array}$ & $\begin{array}{l}\text { New } \\
\text { category } \\
\text { EF }\end{array}$ & $\begin{array}{l}\text { New } \\
\text { total } \\
\text { EF }\end{array}$ & $\begin{array}{l}\text { Reduction of } \\
\text { total EF }\end{array}$ \\
\hline & & NZha & NZha & NZha & $\%$ \\
\hline $\begin{array}{l}50 \% \text { of commercially- } \\
\text { grown food is locally- } \\
\text { grown }\end{array}$ & $\begin{array}{c}\text { Food and } \\
\text { drink }\end{array}$ & 0.99 & 0.89 & 2.48 & $4 \%$ \\
\hline $\begin{array}{l}50 \% \text { of all food is wild or } \\
\text { grown in back yards }\end{array}$ & $\begin{array}{c}\text { Food and } \\
\text { drink }\end{array}$ & 0.99 & 0.41 & 2.00 & $22 \%$ \\
\hline $\begin{array}{l}\text { All short trips are on } \\
\text { foot or bike }\end{array}$ & Transport & 0.20 & 0.10 & 2.48 & $4 \%$ \\
\hline $\begin{array}{l}\text { All consumer goods are } \\
\text { second hand }\end{array}$ & $\begin{array}{l}\text { Consumer } \\
\text { goods }\end{array}$ & 0.80 & 0.61 & 2.39 & $8 \%$ \\
\hline
\end{tabular}


As with the other communities, table 6.5 shows the biggest reductions in EF come from actions related to food and drink. Localising food and consuming more wild meat could reduce the Cromwell EF by $22 \%$. A complete shift to reusing consumer goods could reduce footprint by $8 \%$, although these second-hand goods will still need to be bought by someone, somewhere.

\section{Tarras}

Tarras had the largest EF of the community samples, which ought to make their EF reductions easier. However the turnout for the community workshop was low and only two potential actions emerged from the discussions. Although reducing the holiday footprint was not discussed in the workshop, an example of its potential reduction is provided in table 6.6. Community suggestions were:

1. Increase car-pooling options using an online booking system.

2. Coordinate services so they can be used collectively, e.g. when tradespeople visit Tarras, coordinate multiple appointments in the community.

Table 6.6: Actions suggested by Tarras residents (EF 3.44NZha) and potential EF reductions

\begin{tabular}{|c|c|c|c|c|c|}
\hline Tarras actions & Category & $\begin{array}{c}\text { Category } \\
\text { average }\end{array}$ & $\begin{array}{l}\text { New } \\
\text { category } \\
\text { EF }\end{array}$ & $\begin{array}{l}\text { New } \\
\text { total } \\
\text { EF }\end{array}$ & $\begin{array}{c}\text { Reduction of } \\
\text { total EF }\end{array}$ \\
\hline & & NZha & NZha & NZha & $\%$ \\
\hline $\begin{array}{l}\text { Increase car-pooling so } \\
100 \% \text { of trips are made } \\
\text { with at least two people }\end{array}$ & Transport & 0.38 & 0.17 & 3.24 & $6 \%$ \\
\hline All pet food is wild game ${ }^{1}$ & $\begin{array}{l}\text { Consumer } \\
\text { goods }\end{array}$ & 1.19 & 0.56 & 2.82 & $18 \%$ \\
\hline $\begin{array}{l}\text { Fly half the distance for } \\
\text { holidays }^{1}\end{array}$ & Holidays & 0.81 & 0.48 & 3.35 & $3 \%$ \\
\hline
\end{tabular}

1. These actions were not suggested by the residents

The pet footprint, which did not include working dogs, made up $24 \%$ of Tarras' total EF, therefore feeding their meat-eating pets on wild pet food makes a significant reduction (18\%). This would have the flow-on effect of decreasing the pest population which consumes valuable grass that would be better used to support stock. The Tarras transport footprint was also high, most of which was the need to travel long distances to reach a service centre. 
Options for reducing this footprint are difficult but an effective suggestion was to increase the amount of car-pooling.

\section{Kapiti Coast}

Kapiti had the second highest community EF in the sample, and the highest EF for food and drink. This was because fewer people grow their own food and they consume more processed food than the other communities. Kapiti also had a high pet EF, second only to Tarras. Though Kapiti had no community workshop, some suggested actions they could take are presented in table 6.7.

Table 6.7: Suggested EF actions that could be carried out by Kapiti residents (EF 2.77NZha)

\begin{tabular}{|lccccc|}
\hline \multicolumn{1}{c}{ Kapiti actions } & Category & $\begin{array}{c}\text { Category } \\
\text { average }\end{array}$ & $\begin{array}{c}\text { New } \\
\text { category } \\
\text { EF }\end{array}$ & $\begin{array}{c}\text { New } \\
\text { total EF }\end{array}$ & $\begin{array}{c}\text { Reduction of } \\
\text { total EF }\end{array}$ \\
\cline { 2 - 6 } NZha & NZha & NZha & $\%$ \\
\hline $\begin{array}{l}80 \% \text { community- } \\
\text { grown food, including } \\
\text { meat }\end{array}$ & $\begin{array}{c}\text { Food and } \\
\text { drink }\end{array}$ & 1.13 & 0.41 & 2.06 & $26 \%$ \\
\hline $\begin{array}{l}80 \% \text { local jobs, less } \\
\text { need to commute }\end{array}$ & Transport & 0.28 & 0.10 & 2.60 & $6 \%$ \\
\hline $\begin{array}{l}\text { Everyone catches } \\
\text { public transport }\end{array}$ & Transport & 0.28 & 0.11 & 2.61 & $6 \%$ \\
\hline
\end{tabular}

More backyard grown food and consuming less processed food reduced the Kapiti EF by $26 \%$. The Kapiti sample also travelled long distances; the travel EF could be reduced by more people taking public transport or having more local work opportunities.

\section{Summary}

The community footprint workshops provided insight into what the various communities perceived as the most important drivers of change for their community and the actions they thought necessary to reduce their EF. The resulting EF calculations provided much of the background thinking for the following EF scenarios. 


\subsection{Footprint scenarios}

Good scenarios help reveal how key drivers, such as governance systems and resource availability, might interact and affect the future weight and momentum of change. They sit between quantitative analysis (that models trends) and speculative approaches of telling stories about the imagined future (UNEP \& IPCC, 2001).

EF scenarios have been used in a number of EF projects as a way of communicating the impact that particular actions may or may not have on the footprint of the community. John Barrett (2001) was one of the first to use EF scenarios at a local level to communicate the impact of certain actions on reducing a community's EF. The Cardiff Footprint Project (A. Collins et al., 2005) was perhaps the most effective use of EF scenarios, showing the degree to which change could occur to the city's footprint and a strategy for reaching these goals. EF scenarios have been used for BedZED (Desai \& Riddlestone, 2002) explaining how the community could further reduce their EF towards 'One Planet Living'. These EF scenario examples are largely quantitative and show the impact of certain actions on the total EF.

There have also been recent explanations about international drivers of change and their global effects, such as futureagenda - The World in 2020 (Jones \& Dewing, 2011), and Exploring Sustainable Development by the World Business Council for Sustainable Development (Davis et al., 2011). In NZ there have been 4 Future Scenarios for New Zealand by the Landcare Research Scenarios Working Group (Frame, Brignall-Theyer, Taylor, \& Delaney, 2007), Strong Sustainability for New Zealand: Principles and Scenarios by Sustainable Aotearoa New Zealand (2009), and the Manukau City Council (2009) 'Towards 2060' Project.

However few EF scenarios have provided much detail on the sequence of events or pathways that could lead to reduced footprints and improved community resilience with respect to key drivers of global and local change. The outcomes from the community footprint workshops have been used here to create a story of what NZ may look like in 2040, looking back to the present day. The stories explore which decisions provided a resilient foundation for the community in the face of resource scarcity and which did not. 
The following four assumptions are based on those used for scenario development by the UK's Department of Trade and industry (2003, p. 4):

1. The future is unlike the past, and is significantly shaped by human choice and action.

2. The future cannot be foreseen, but exploring the future can inform present decisions.

3. There are many possible futures; scenarios therefore map within a 'possibility space'.

4. Scenario development involves both rational analysis and creative thinking.

A useful typology of scenarios (Börjeson, Höjer, Dreborg, Ekvall, \& Finnveden, 2006) presents contrasts between the predictive (asking what will happen, short term), the explorative (asking what can happen, what is possible, longer term) and the normative (how a vision or target can be reached). The four scenarios developed here are explorative.

\subsubsection{Using scenarios to provoke and inspire creative change}

The earlier sections of this chapter outlined the thoughts of the communities on the imminent threats to productive land, both locally and internationally, and the actions that would be effective in lowering the EF of the community. These discussions and other information about drivers of change have been used to create stories of what it might be like to live in 2040, looking back to 2013. The four community stories are based on a single global/NZ scenario (section 6.3.2). The community stories use the timeline in section 6.3 .2 but provide more detail about the resource constraints and opportunities available to each, depending on the urban form and lifestyles of the community members. The stories also provide some detail regarding how various actions might be used to reduce or increase the EF of the community. Some of these calculations are then used in the final fair earth share scenario (section 6.4).

\subsubsection{The Communities' Stories}

Each of the four stories reflects the main aims recommended by the communities as a way of reducing their EF. It is understood that different communities will have different options open to them for reducing their EF. The scenarios assume that money has become much less important, and consuming resources is based on a community's ability to provide for itself. While the scene, as set below, in which to build the community scenarios paints a pessimistic picture, it is a feasible one given current resource use trends. Despite this, the stories 
generated by each community show how they can adapt to a world where resource use must shrink to match more locally-generated availability. As such, even for those who think the scenarios are far-fetched, they are useful tools to generate thinking about a future which will be different from the resource-rich last century enjoyed by developed countries, and will encourage the emergence of innovative solutions.

\section{Setting the Scene}

2015 - The 2008 'Global Financial Crisis' is a distant memory. The production of goods, given global population increases, has long surpassed pre-2008 levels, with many people consuming more than ever. While employment worldwide is high, the gap between the 'haves' and 'have nots' of the world continues to increase. The Green movement has made some headway by increasing people's awareness of resource scarcity and the need to lower their EF, but it is a hard message to spread in the face of the influence of the global marketing giants. Some technological solutions have made a slow but reliable EF reduction but other technologies have increased it, leaving the overall EF the same. Fracking and oil-sands extraction technologies, which were recently scaled-up, have extended the life of hydrocarbon-based fuels and products, with a strong negative impact on global $\mathrm{CO}_{2}$ levels.

2020 - 'Tipping Point 2020' caused global chaos, sparked by a multitude of negative environmental and political trends which finally combined in conflict. This war destroyed global trade systems and halted international communication and movement. NZ is far from the central conflict regions but is still caught up in the trouble. Virtually all trading in and out of NZ stops and as international markets collapse, so does NZ's export industry. Imported hydrocarbons no longer reach NZ's shores as more dominant nations secure them first. The international community puts pressure on NZ to open up immigration to millions of climate refugees from across the Pacific. Entire new communities are built, particularly in NZ's South Island, in an effort to preserve the best northern growing land for primary production. Cut off from import markets, NZ's major cities are desperate to create local food systems to support their population and, initially, there is widespread hunger. Under the growing tension, fractures between socio-economic groups appear, caused by the global situation and 50,000 New Zealanders being sent to war. 
2025 - New global and local leadership models start to emerge. While conventional thinking continues to prolong conflict and is ineffective in bringing people together, emerging leadership slowly breaks down competitive models and reforms broken alliances. Globally, despair and poverty are rife but there is still some hope.

It does not take long for New Zealanders to regroup. Even with an increasing population, NZ has one of the highest rates of bioproductivity per person, an advantage which requires careful management to maximise the opportunities it brings in these difficult times. As the old government system collapses, a new locally-driven system forms. The social and organisational learnings from previous major events, such as the 2010 and 2011 Christchurch Earthquakes, allow New Zealanders to operate in efficient community working-parties. Whole communities are re-trained in previously-lost skills to deal with the decline in liquid fuels and limited transport options. Individuals with skills and knowledge on non-mechanised ways of producing goods and services become the new educational elite.

2030 - Many of the events set in motion during the '2020 Tipping Point' cease, although its effects are enormous and the world has been irreversibly altered. Through war and poverty 1 billion people died, and the global population has stabilised at 2012 levels of 7 billion. Conflict has devastated the transport and energy infrastructures of entire countries, although, as in previous wars, it has helped to fast-track technological development. Where infrastructure was available, renewable energy production became the new oil. New fossilfuel-free technology is finally fully supported. The focus has shifted from centralised to distributed electricity generation. Corporations, including the banks, have been ousted by communities across the world demanding they be in charge of their own economies.

NZ also experienced a massive shift. Much less of NZ's biocapacity is now going into exports, in order to feed the additional five million climate refugees who arrived between 2020 and 2030. New Zealanders had to pull together to recreate entire systems for building communities and producing goods and services, without the help of cheap oil. Many of the new technologies are highly effective although finding materials to build the infrastructure is expensive and difficult. Many of the smaller communities are returning to a simpler life where technologies play less of a role. 
2040 - By this time people are embracing the 'global revolution' and shifting to a new way of living. Life revolves around people-community and whanau (extended family). Wealth is measured in wellbeing and the ability to fulfil fundamental human needs rather than in monetary units. People are connected to their local communities, bound by the ability to feed and clothe themselves.

$\mathrm{NZ}$ is a very different country from 2015 with a very different view of the value of land. Land is taonga (a treasured thing), the foundation of the natural system, which in turn provides New Zealanders with the resources to fulfil their fundamental human needs. The international community is still important as a source of some consumer goods and information sharing, however the emphasis since the 2020 Tipping Point is different. By 2040 there are an additional 9 million climate refugees and a total population of 14 million, but NZ still has one of the highest biocapacity/person rates of 1.2NZha. This is more than most other countries. These continue to degrade their natural systems, thus affecting global environmental outcomes, especially climate change. However the outlook for NZ is good. Kiwis, old and new, work together for a locally sustainable and resilient future based on equity, trust and kaitiakitanga (guardianship and conservation).

\section{Waiheke's Isolation}

In 2040, the type of person living on Waiheke Island is not much changed from the present. Waiheke continues to be a desirable place to live, with those living there island-dwellers at heart. Waiheke continues to be a community of well-educated and highly motivated individuals who are capable of being self-sufficient. Waiheke has had to take measures to protect its isolated oasis. Its resource base has been protected from increasing pressures that are crippling less resource-rich societies throughout NZ and around the world. As climate refugees started flooding into NZ in 2020, many Aucklanders previously living in wealthy neighbourhoods found their own refuge on Waiheke. In 2021 island population growth was halted to protect its limited biodiversity and other natural resources.

Waiheke became independent, reversing the previous Auckland Council amalgamation. New laws were initiated preventing any immigration to the island, with visitors controlled. Sea level rise increased some pressures on the island, with many coastal properties in jeopardy of 
being inundated by water or eroding away. Sea level was expected to rise several metres as the Arctic completely disappears. The value of low lying coastal properties decreased considerably, and inner island property values rose to become the most expensive in the country. But no one sells for more house-building as the land is far more valuable for growing food and construction materials. The locals have agreed to keep native vegetation and builtup land at 2010 levels, with both requiring $25 \%$ of the island's land area. Of Waiheke's remaining 4,660ha, approximately $50 \%$ is in 'high producing exotic grassland' and has become the 'new gold'.

Waiheke's climate is good for food and timber production although extreme weather events have meant the construction of infrastructure to protect its fertile land. The increasing extremes of weather events, coupled with Waiheke's exposure and salination of the soil, means growing crops on Waiheke is becoming increasingly difficult. There is, however, access to the sea and although many kaimoana (seafood) stocks have collapsed, some locallymanaged and farmed stocks are available to locals. In 2015 Waiheke residents realised the increasing threat from the declining availability of food, and a group of individuals initiated a community-based food co-op. The Local Community Board supported this and Waiheke became the first Auckland community to deregulate the use of public land for the purpose of food production. From this came an exponential increase in community-supported gardens. By 2020, locals had reduced their food EF from an already low 1.05ha/person in 2012 to $0.2 \mathrm{ha} /$ person by 2030 , through increasing their consumption of crop food and decreasing their need for grazing land. The rate of meat consumption decreased from $30 \%$ of the diet in 2011 to only $5 \%$ by 2030 , mainly chicken, eggs and fish. Food no longer travels by fossil fuels but by electric bike. The residents require $500 \mathrm{~m}^{2} / \mathrm{yr}$ for wood and building materials. Waiheke's 2030 population of 11,671 people can achieve food and wood self-sufficiency using only $30 \%$ of the island's land area.

In 2015 a private investor leased 2,000ha of Waiheke's coastal land for the production of flax and hemp. By 2030 these crops have become the lifeblood of the local economy. A new technology combining these two crops has taken over the NZ market for high-yield durable materials for construction, clothing, medicinal purposes, and food. The island climate creates the perfect environment for these valuable exports. 
One of the major global breakthroughs in renewable technology prior to the 2020 Tipping Point was made in Auckland. The need for a low-resource form of transport was satisfied by simple technologies which were available in 2012. By 2018 the Hauraki Gulf ferries were using renewable energy (solar and wind), backed up by a hydrocarbon fuel made by LanzaTech's processes for using waste carbon monoxide and carbon dioxide (LanzaTech, 2012). Solar-wind combination ferries were produced by an Australian Company, "Solar Sailor" (SolarSailor, 2012), back in 2012, but adding LanzaTech's technology produced a versatile multi-fuel combination. The technologies were phased in as ferries needed refurbishing or replacing, to reduce capital monetary and resource costs. This reduced the operating costs and carbon land of the ferries by over $90 \%$. In 2020 , as imported oil became scarce, these ferries became the main mode for transporting goods around the country.

Waiheke's flax and hemp trade relies on electric bikes which can be plugged in at local recharging stations across the island. A new locally-designed micro-tidal power generator came online in 2028 , and Waiheke achieved $100 \%$ renewable electricity generation.

In 2040, Waiheke is still one of the most desirable places to live in the country. Due to a number of skilled community members, Waiheke has developed new technologies, new exports, and local food systems that have helped to it to be highly resilient to ongoing resource scarcity. Waiheke is in a unique position because, having closed its doors to an increasing population, it has enough biocapacity to support its island inhabitants and has additional biocapacity to export goods and services. As a result, Waiheke residents have reduced their footprint to $1.5 \mathrm{ha} /$ year, less than in 2011 , but not as low as other communities who are aiming to live within their fair earth share.

\section{Waitakere, NZ's Urban Farm}

Waitakere is NZ's showcase example of an integrated urban farm. By 2040 Waitakere's suburbs have been transformed into highly intensified communal living surrounded by lush areas of productive food and fibre growing areas. Much of the low-lying areas of Waitakere were flooded by rising sea-levels, causing a major rethink of its urban form. The Waitakere area now houses a blend of cultures and people. Tensions previously caused by top-down control-oriented governance systems were rectified using a new 'groundswell' of community 
decision-making processes. Self-sufficiency initiatives were put into action prior to the '2020 Tipping Point'; much earlier than many other communities throughout the country. This future-thinking decision-making was behind Waitakere's success.

In the build-up to the '2020 Tipping Point', the densely-populated suburbs of Whau and the Waitakere Ranges started an urban farm revolution. The development of a common vision of a 'resilient Waitakere that celebrates together', reminiscent of earlier shared values around an Eco-City, not only enabled people to work together but encouraged supportive political will within their governance circles. In 2015, 93\% of the Whau district was built-up, with the remainder being small pockets of native vegetation and sports fields. A forward-thinking Local Board Plan acknowledged the need for local food growing and "enabling strong community gardens as a way of providing food and passing on valuable gardening skills" (Whau Local Board, 2011, p. 22). Although only small-scale, this initiative provided the necessary genesis of food growing skill development in the community. The Waitakere Ranges Local Board also supported a shift to local food production (Waitakere Local Board, 2011). Years of debate and specific legislation had preserved the lower slopes of the Waitakere ranges for conservation purposes. Special legislation passed in 2018 allowed much of these to be turned over to food production, with a caveat that 'the integrity of the native flora and fauna must be retained'. Opportunity arose from the inundation of Waitakere's low-lying areas through sea-level rise, creating new shallow saltwater wetlands. The region developed expertise in propagating and growing saline-tolerant crop varieties and ecological fish farming. By combining resources, skills, and growing land, the Waitakere population of 200,000 in 2020 were able to reduce their food footprint to 40\% of its 2012 level. By 2040, with a population of 1 million, Waitakere's total footprint was only $40 \%$ of that in 2012 , because of a low individual footprint of $1.05 \mathrm{ha} /$ person.

Support for 'green' initiatives stayed somewhat static from 2010 to 2020, but as the prices of food, resources and personal transport climbed, so did recognition of the need for a stronger local economy. In the middle of the '2020 Tipping Point' chaos, community organisations such as EcoMatters Trust and the Sustainable Living Centre became the heart of 'groundswell' community decision-making. As NZ's government and much of its centralised infrastructure collapsed, support for these volunteer community-led organisations strengthened. They led 
the welcoming and organisation of millions of refugees who poured into the Auckland region from 2020. Organisational methods pioneered during the 2010 and 2011 Christchurch Earthquakes (Johnson, 2012), were used to mobilise tens of thousands of people in teams to set up make-shift communities. These set about providing themselves with food and a new urban form. Communal living was the only way people could survive; the collective 'celebration of life' was the glue.

By 2030 , these self-sufficient communities had become permanent. Characterised by a unique built form using locally-sourced clay and bamboo fibre, Waitakere's urban form was intensified to provide maximum growing land. While the living quarters looked modern, goods previously perceived as 'necessary comforts' such as televisions and computers were no longer personal items but community resources. As a result, the consumer goods footprint was almost zero. Consumer household goods were also acquired from Auckland's historical landfills, a technique described as 'resource rebirthing'.

In 2013, because of the poor public transport infrastructure, the Council assisted in developing and supporting carpooling facilities and systems. This occurred through a number of initiatives led by the Council, including a system for providing pool cars for three or more people, car-pooling lanes, preferential parking places, and eventually fuel rebates for private cars dedicated to car-pooling. These actions decreased Waitakere's travel footprint by $30 \%$ to 0.57 NZha. These actions also saved Auckland Council billions of dollars in roading costs, money then invested in public transport infrastructure.

In 2014, with a change in NZ's central government, the Auckland Council gained its support to expand Auckland's railway. This massive project was about two thirds complete by the '2020 Tipping Point'. The electric railway was Auckland's artery to the rest of the country, which in 2014 had also seen investment in rail transport. Auckland's upgraded railways provided a means for transporting goods and a limited number of people. Distribution points along the railway were eventually serviced by electrified vehicles, though initially these vehicles were scarce and personal mobility limited to NZ-made bamboo bikes (Calfee Design, 2012). 
By 2040 , Waitakere achieved an $80 \%$ reduction in the community's EF. A major part is the reduction in food EF, with the commercial growing land almost zero, and no food transport or packaging. Food processing is still required but this is carried out communally. The other major difference to Waitakere's EF is that all technologies and transport are now powered by $100 \%$ renewable energy, which has a much lower EF at only $15 \%$ of non-renewable energies.

\section{Everyone's moving to Cromwell}

By 2040, Cromwell is no longer isolated, as it is surrounded by multiple new communities in the Otago region that were built for the rapidly-increasing NZ population. Cromwell's population quadrupled between 2012 and 2040 as people congregated there in search of jobs, land and water. The area of the town also increased fourfold to cover 10,000 ha. The lifestyle of those living in Cromwell changed, as families on higher incomes moved in from the cities. These people tended to be more concerned with the consumption of goods than with making do with what they had. In 2015, due to the persistence and management of a team of locals, a local food co-operative, Crom-Co, was created to focus on the development of a food forest (Cambeis, 2012) throughout Cromwell's urban area. Climate change had caused an increase in rainfall with consequently higher primary productivity. Cromwell's transport EF remained small as the community grew and local businesses flourished.

In 2015 Cromwell became the central hub for the new Otago Council, an amalgamation resulting from the desire to centralise infrastructure planning. Further population increases occurred as climate refugees were redirected to many of NZ's small towns, drastically changing the make-up of the population. In 2012 skilled tradespeople made up a large portion of the working population, but this changed as people lacking practical trades arrived. As a result the community's 'number-8 wire' mentality decreased and the overall EF of the Cromwell community increased. By the time of the '2020 Tipping Point', the people of Cromwell and the Otago region needed to be retrained. Otago Polytechnic became a hub for the few remaining craftspeople, who had to re-educate people in valuable non-mechanised trades.

The Clutha River became the lifeblood of the region and plans were made for new communities along it. Cromwell residents were called on to start building multiple 
communities only a few kilometres away. There were a number of limitations to this development, an important one being the lack of locally-sourced wood. In 2020 other conventional building materials almost disappeared, for example, mining for gravel and lime was almost impossible due to the lack of fossil fuels for transport. New homes decreased to $63 \mathrm{~m}^{2}$, only a third the size of the average new home in 2012. Even with the dramatic reduction in house size, the region would need to have planted 1,500ha of forest each year from 1975 to 1985 if it were to keep up with the timber needed for the 100 new homes per week between 2015 and 2025. Because this local wood production was not planned, the rate of house production declined by 2025 . Unfortunately people continued to arrive in the region. Alternative building materials, particularly mud brick and clay, are used where they can be locally sourced. The average number of people per household increases but many live in make-shift homes built out of anything they can find. The region's tips are dug-up and become a source of valuable materials for reuse.

As the community increased in size so did the sprawl. Much of the land previously put aside for conservation went into residential plots. House sections remained large but most were not valued as food-growing areas until 2020 when food prices rose steeply. Food went from being $18 \%$ of overall household expenditure (Statistics New Zealand, $2007 \mathrm{c}$ ) to over $70 \%$. Fresh healthy food was in short supply. Although a number of local food systems had been created, their success was limited as Cromwell's new wealthy population did not provide support and local producers struggled to gain broad local support. In the light of research carried out in 2012, Crom-Co (Cromwell's local co-op) started to create food forests throughout Cromwell's greenways, but closed their doors in 2018 due to a lack of interest. The '2020 Tipping Point' required Crom-Co to regroup and re-energise. In 2021 Otago Council mandated all green areas within Cromwell's urban boundary were to be dedicated to food forests. By 2030 Cromwell's population of 11,500 was $100 \%$ fed by the community's 150 ha of food forests (just over $2 \%$ of the land within the community). Mature food forests produce 50t/ha of food (Cambeis, 2012), which fed 100 people/year/NZha on a low EF diet.

Weather patterns continued to become more extreme and only the hardiest plant varieties could withstand the summer temperatures under industrial food production methods. However, the food forest's successional levels of vegetation provided protection from the 
extreme climate, meaning a greater variety of plants could be grown within the forest than outside. Despite this, the variety of foods consumed by local Cromwell residents is more limited than the diet before 2020, particularly in the winter. As a result their food footprint is only $0.2 \mathrm{NZha/person}$.

As a central hub for the Otago region, Cromwell has some of the most successful transport systems in the country. In 2025 the Otago Rail trail was re-commissioned as a railway. It was completed in 2035, reconnecting Central and Coastal Otago. The railway was powered by electricity generated by solar and water technologies. The Clutha River has again become a major corridor for transporting goods. The many dams along the river are a limiting factor and multiple boats are needed as they cannot move between the sections.

Life in Cromwell in 2040 is mostly healthy and happy. People appreciate their access to the land which provides them with food and some of the materials needed for construction. Wood remains an extremely valuable resource and the local plantations (planted between 2020 and 2025) will not be ready for another 20 years. Alternative housing materials are becoming more readily accessible. Heavy machinery for harvesting wood from forests is still scarce as new renewable energy technology is very expensive. However, new housing materials are being sustainably harvested from the community's food forests. Cromwell residents are again inter-dependant on each other. People work on a time-banking system held 'in trust' by Crom-Co; paid work is a distant memory. Cromwell is still one of the fastest growing communities in the country.

\section{Tarras' milk but not so much honey}

Leading up to the '2020 Tipping Point', technology had transformed rural lifestyles. Farmers were no longer stewards of the land but technicians and engineers. However, post-2020, without easy access to petro-chemicals for fertilisers and pesticides and fossil fuels for machinery, the farming of healthy soil once again became a priority. Fortunately for Tarras the community has retained many of the required skills passed down through generations of families who had farmed the same land. By 2030, land in Tarras was in high demand due to the ever-increasing price of primary products. In 2040 there are farmers who understand the ecology of the land, biological systems and how agriculture can work alongside nature. 
However, the amount of available land per Tarras community member declined dramatically during the 'production boom' of 2010 onwards. The majority of primary products went overseas to those who could pay the highest price, leaving New Zealanders struggling to support their own needs.

"You can take a person out of Tarras, but you can never take Tarras out of a person". People who grow up in tight-knit rural communities will always 'belong' to that community. In 2040 little has changed in this respect; through the good and bad times the Tarras community remained supportive and rallied together to make decisions that would give the best outcome for their community. The local school, store, rugby club, golf course and café remain the centre of community life. Seasons are celebrated as a community and harvests are gathered with all helping.

The Tarras Irrigation Scheme was a celebrated feat of engineering, opening for business on 1 December 2013. The irrigation scheme, along with liberal amounts of fertiliser, created a landscape of lush green grass, doubling the grazing area and increasing the fertility of the land three-fold. The conversion from dry sheep farms to dairy was slow at first but increased steadily. In 2016 a new dairy factory was built on Ardgour Road; NZ was producing close to 6 million tonnes of milk per year, twice that of 2007. Farms were taking on more debt to provide the dairying facilities required. The community was also paying off the irrigation system, which was putting huge financial stress on many farms. The Tarras community had very quickly reached full water allocation. In the height of summer the Clutha River was fully allocated and running very low. Tarras was in peak production.

The value of Tarras land skyrocketed, and by late 2017 it was no longer viable to pass on the entire farm to the next generation. Taxes and dairy conversion costs were putting farms out of business. The only way to pay was to sell-off large portions of the farm to overseas investors. Farms were then divided up amongst the rest of the family. The Chinese conglomerate 'NZMilk' bought all available land and by 2020 owned $30 \%$ of the irrigated land and water rights in Tarras.

Life was good for a while and the NZ dairy industry flourished, producing $5 \%$ of the world's milk solids. Then in 2020 all changed. NZ's export markets collapsed, but dairy was hit the 
hardest. Asia had been $90 \%$ of NZ's dairy market but they no longer had the money to spend on expensive imports. The irrigation scheme collapsed and fertiliser was no longer available. Almost overnight, Tarras turned brown and the destruction caused by a decade of high fertiliser use and irrigation was obvious. Tarras was less productive than before the irrigation scheme. Initially farmers struggled to work the land to provide enough food for their own families, and slowly old farming methods were reintroduced.

In 2023 the local community started a Soils Rehabilitation Society, quickly becoming NZ's champions in land rehabilitation using permaculture design and new composting methods. Hectare by hectare the land in Tarras revived. The value of wool had increased as the price of synthetic materials also increased, and recycled fabrics made up a large portion of the world's fabrics. As the climate continued to change, rainfall increased in Tarras. Crops were diversified and the value of Tarras land again grew quickly. By 2030 Tarras was a production powerhouse. Tarras land was as valuable an asset for sheep, wool and wood farming as it had been pre-2015.

Throughout this time, moving people and resources in and out of Tarras was always a problem. Fonterra's milk transport costs were an important component of their bottom-line and they invested heavily in freight transport research and development. In 2018 Fonterra revolutionised milk freight using electrified trucks. The operation of farm machinery grew more costly as electric engine conversions were extremely costly. Farms relied on imported fuels until the '2020 Tipping Point'. Electric cars were introduced into the NZ market in 2015 but remained too expensive for the majority of people. In 2020 Tarras became a very remote part of the country with almost no transport in and out. When the dairy industry collapsed the Fonterra shareholders, the farmers, demanded that trucks be used for transporting goods to and from remote NZ communities. Construction materials and firewood become scarce. In 2015 the Otago Council had banned the planting of all tree species which became feral. This stopped local commercial forestry. Numbers of wilding pines and willows had reduced but there were enough for the firewood, cooking and heating needs of the Tarras community. Construction timber was much harder to come by. Many of the old wooden homesteads consequently fell into disrepair. 
International winter holidays became a distant memory. Family holiday destinations are now Twizel, Wanaka or the West Coast of the South Island. These trips are often by motorised bike and the slow journey has become an integral part of the holiday. In 2020 the definition of pets changed. Families no longer keep animals that are not useful either for food production, such as chickens, or farm work, such as bullocks and horses. Land is precious and land use is carefully monitored.

The Tarras Township is a thriving social hub for the community and the centre of the local economy. The local economy is based on exchange or bartering. The families who were able to remain hold on to many of the local farming values, which have continued within the community. This has also meant that Tarras is an inward-looking community, often unaware of the large-scale social changes happening elsewhere in NZ. The population has increased in the region but at a slower rate than the rest of the country, due to the remoteness and harshness of the area.

\subsection{Fair Earth Share Living}

This research has suggested that, for NZ to move towards sustainability, one of the goals should be to reach a fair earth share EF of 1.21NZha/person. The actions suggested for achieving this stem from the community footprint examples above and some of the pressing drivers of change explained in section 6.3.2. These actions impact on both urban form and lifestyles. A number of actions will be suggested for each EF category but only one or two chosen for the final fair earth share scenario. The aim of the chosen actions is to reduce the footprint category by at least $51 \%$ (as discussed in section 6.1 ) and selection will be based on their effectiveness for footprint reduction, the ease with which they can occur, and whether they avoid costly infrastructure changes.

The analysis assumes the global population remains at 7 billion but the NZ population increases to 14 million. Instead of existing cities being expanded, new 'independent urban centres' are developed. Results in chapter 5 showed that these smaller communities were the most efficient for transport and had maximum access to land for producing food and building materials. 


\section{Food: Urban Farms}

New Zealanders eat a fair earth share diet based on zero waste and the required level of calorie input. The amount of food consumed per person has decreased by $40 \%$ to $500 \mathrm{~kg} /$ year rather than the current average of $833 \mathrm{~kg} /$ year. Plant-based foods make up $85 \%$ of the total diet, rather than $69 \%$ as in 2007 . The major difference is a shift from conventionally-farmed animal-based products to plant-based foods produced on multi-use land. People consume much less red meat, with chicken, eggs and dairy products forming the main animal-based proteins. Limited sheep farming is still carried out in the high country where there are few alternative uses for the land. Meat from wild deer, pigs, possums and rabbits is obtained in NZ's conservation areas, although numbers of deer and pigs are dwindling, due to high demand. Overall, red meat is less than $2 \%$ of a New Zealander's diet by weight.

Food is almost completely local, apart from some regional importing and exporting of NZgrown grains. Every region has its specialty grain, with surpluses transported around the country by train. The train EF is less than $10 \%$ of that of diesel trains operating in 2007.

Eating seafood is rare due to the drastic decline in fish stocks and highly regulated fishing. Fish makes up less than $1 \%$ of NZ's diet. Proposed changes to NZ's food and drink EF are presented in table 6.8 .

Table 6.8: Proposed food and drink EF reductions

\begin{tabular}{|c|c|}
\hline Actions & $\begin{array}{l}\text { Category reduction per } \\
\text { person }\end{array}$ \\
\hline & $\%$ \\
\hline Consume less food, less meat and fish & $60 \%$ \\
\hline No fertilisers, renewable energy used & $2 \%$ \\
\hline Renewable energy only, half as much processed food & $2 \%$ \\
\hline $\begin{array}{l}\text { No personal transport for food, freight by train, some } \\
\text { imported food }\end{array}$ & $2 \%$ \\
\hline One quarter the 'shopping' premises required & $1 \%$ \\
\hline Half the amount of packaging, all recycled & $1 \%$ \\
\hline
\end{tabular}

The NZ food and drink average EF in 2007 was $1.42 \mathrm{NZha/person.} \mathrm{The} \mathrm{actions} \mathrm{in} \mathrm{table} 6.8$ show the reduction that NZ could make in its EF by renewing its food system. If all actions were implemented, the food EF would be $68 \%$ lower than the 2007 average. However, in order to 
achieve a fair earth share reduction of $51 \%$, it is more than enough to simply consume less food (particularly meat and fish), as this results in a $60 \%$ reduction in the food and drink EF to $0.56 \mathrm{NZha}$ /person. This action is included in the final fair earth share scenario (table 6.14).

\section{Transport: Use less, and use renewable energies}

The NZ fair earth share travel EF is a result of change in the urban form. Communities are condensed living areas clustered around the service and business district. They are walkingand cycling-friendly. There could be a bus service, but all vehicles maximise the number of passengers per trip. Jobs and education are local so there is less need to commute long distances. For long distance travel a nationwide rail system is used.

The most effective way to reduce the transport EF is not to travel. The second most effective way is to have more people per vehicle, whether a bus, train, ferry or car. The operation and embodied energy of a medium-sized NZ car is $3.95 \mathrm{MJ} / \mathrm{pkm}$. One person in a car is responsible for the total footprint. If there are two people, the EF is $1.98 \mathrm{MJ} / \mathrm{pkm}$, and with four people $0.99 \mathrm{MJ} / \mathrm{pkm}$. In 2007 each New Zealander travelled an average of 7,453km in a car by themselves, with an EF of $0.20 \mathrm{NZha}$, which was $84 \%$ of the total average transport EF. If a person travelled the same distance with four people in the car their footprint would reduce to $0.05 \mathrm{NZha} / \mathrm{yr}$. If people live in more intensified urban areas it could be assumed they would only travel by vehicle one quarter the distance they did in 2007, reducing their EF to 0.01NZha/yr. These options are presented in table 6.9.

Table 6.9: Proposed travel EF reductions

\begin{tabular}{|lc|}
\hline \multicolumn{1}{|c|}{ Actions } & $\begin{array}{c}\text { Category reduction per } \\
\text { person }\end{array}$ \\
\cline { 2 - 2 } & \multicolumn{1}{|c|}{$\begin{array}{c}\text { Few } \\
\text { pewer kilometres travelled by cars and vans and increased } \\
\text { passenger numbers }\end{array}$} \\
\hline $100 \%$ renewable electricity used for public transport & $45 \%$ \\
\hline $\begin{array}{l}\text { One quarter the use of off-road vehicles, and pleasure craft } \\
\text { used only for transport }\end{array}$ & $27 \%$ \\
\hline
\end{tabular}

Previous research by Wackernagel and Rees (1996) found the EF of renewable electricity was an average of $1,000 \mathrm{GJ} / \mathrm{ha}$, which is $15 \%$ the $\mathrm{EF}$ of non-renewable energy sources. If all NZ 
transport operated using renewable energy, the average total transport EF would be $0.03 \mathrm{NZha} /$ person.

The NZ travel EF in 2007 was 0.19NZha/person. If New Zealanders reduced their personal vehicle travel and increased the occupancy rate, this could be reduced by $45 \%$ to a total travel EF of 0.10 ha/person.

\section{Consumer Goods: Need less, closed loop manufacturing, and reuse}

Scarce resource availability has increased the need to share and live collectively. Consumer goods are much less available so people buy less and there are fewer shops. Some items are still imported in efficient cargo ships and transported overland by train. There is significantly less packaging. The manufacturing sector runs on $100 \%$ renewable energy. All products are reused or recycled, reducing the raw materials use, such as wood for paper and cotton for clothing.

The only people who have pets are those able to hunt for pet food. Pets always have a purpose and are no longer a 'consumer item'. The number of dogs and cats in NZ has dramatically declined as have the number of pest species. Possum, rabbit, stoat and wild cat meat and fur have become sought-after commodities. As a result NZ's native wildlife is reviving and the Kiwi has been saved from extinction. Horses are a valuable commodity for transport but very few people live close to enough land to keep them year-round without additional food. These options are shown in table 6.10.

Table 6.10: Proposed consumer goods EF reductions

\begin{tabular}{|lc|}
\hline \multicolumn{1}{|c|}{ Actions } & $\begin{array}{c}\text { Category reduction } \\
\text { per person }\end{array}$ \\
\cline { 2 - 2 } & $\%$ \\
\hline Embodied manufacturing energy is 100\% renewable & $22 \%$ \\
\hline $\begin{array}{l}\text { Recycled materials results in a 60\% reduction in the need for virgin } \\
\text { materials and growing land, i.e. wood and cotton }\end{array}$ & $16 \%$ \\
\hline $\begin{array}{l}\text { Freight transport by train and half the amount of packaging, less } \\
\text { retail so half the shops and no waste }\end{array}$ & $16 \%$ \\
\hline $\begin{array}{l}\text { Half the number of pets, consuming only wild meat. Same number } \\
\text { of large pets but only grazing land }\end{array}$ & $29 \%$ \\
\hline
\end{tabular}


The NZ consumer goods average EF in 2007 was $0.57 \mathrm{NZha/person.} \mathrm{Two} \mathrm{actions} \mathrm{have} \mathrm{been}$ included in the fair earth share scenario in table 6.14. The first increases the recycled material in products, reducing the growing land required to produce new products. In the second, there is half the number of pets and they consume wild meat. Together these reduce the consumer goods EF by $45 \%$.

\section{Holidays: Frequency or distance}

There are two options for reducing the holiday EF. First is to reduce the frequency of holidays and second to reduce the distance travelled, particularly if the holiday includes flying.

If there were no international holidays the air travel component of the average NZ holiday EF would reduce to zero with an overall reduction in the holiday EF of $50 \%$. Alternatively, reducing the number of international holidays to $20 \%$ of their 2007 value reduces the holiday footprint by $40 \%$. If NZ provides $100 \%$ renewable electricity for accommodation and activities, this would reduce the holiday EF by $9 \%$. These ideas are shown in table 6.11 .

Table 6.11: Proposed holiday EF reductions

\begin{tabular}{|lc|}
\hline \multicolumn{1}{|c|}{ Actions } & $\begin{array}{c}\text { Category reduction per } \\
\text { person }\end{array}$ \\
\cline { 2 - 2 } & $\%$ \\
\hline No international air travel for holidays & $50 \%$ \\
\hline International air travel every five years & $40 \%$ \\
\hline $\begin{array}{l}\text { Accommodation and activities powered by 100\% renewable } \\
\text { energy }\end{array}$ & $9 \%$ \\
\hline
\end{tabular}

The average NZ holiday EF in 2007 was $0.12 \mathrm{NZha} /$ person. Cutting the number of international holidays by $80 \%$ of the 2007 value gives an international flight footprint of 0.01 NZha and a total holiday EF of 0.07 NZha, a $40 \%$ reduction. If air travel becomes more fuel efficient, then the EF would be further reduced. Fewer flights would halve the airport EF.

\section{Households and energy: Small is best}

The trend for bigger housing reverses. This is a result of people needing to live communally to share resources. The large houses still in use have more people living in them. Denser communities that include work, schools, and services help to lower the community EF. Food 
production in more compact urban communities is viable, particularly on crop land; the limiting factor is the lifestyle choices made by urban residents. If food was scarce and people needed to grow food, there would be space to do so.

Total electricity use for the country has not increased since 2007 due to electricity consumption per person being $50 \%$ of that in 2012 , because of increased efficiencies and fewer consumer goods. This reduces the combined categories of housing and household energy by $39 \%$ to $0.07 \mathrm{NZha/person.} \mathrm{Instead} \mathrm{of} \mathrm{being} \mathrm{only} 66.7 \%$ renewable, electricity is now $100 \%$ renewably generated. New micro-dams were built to supply local communities, and solar and tidal technologies were introduced, reducing the housing and household energy EF by a further $36 \%$. These ideas are presented in table 6.12 .

In comparison, if the number of people per residential section doubled and the size of the house, impermeable surface and garden halved, the average housing EF would reduce from $282 \mathrm{~m}^{2} /$ person to $71 \mathrm{~m}^{2} /$ person, reducing the housing and household energy EF by $19 \%$.

Table 6.12: Proposed housing and household energy EF reductions

\begin{tabular}{|lc|}
\hline \multicolumn{1}{|c|}{ Actions } & $\begin{array}{c}\text { Reduction for both categories per } \\
\text { person }\end{array}$ \\
\cline { 2 - 2 } & $\%$ \\
\hline $100 \%$ renewable household electricity & $36 \%$ \\
\hline Half the household energy consumption per person & $39 \%$ \\
\hline $\begin{array}{l}\text { Double the number of people per house and half the } \\
\text { house size }\end{array}$ & $19 \%$ \\
\hline
\end{tabular}

The NZ housing and household energy average EF in 2007 was $0.11 \mathrm{NZha/person.} \mathrm{The} \mathrm{fair}$ earth share scenario in table 6.14 includes two of the actions in table 6.12: halving household electricity use and doubling the number of people per household. The new EF is $0.05 \mathrm{NZha} /$ person, a reduction of $55 \%$ of the $2007 \mathrm{EF}$.

\section{Shared citizenship footprint}

As a result of reduced use of private vehicles there is a major decrease in the embodied energy of roading maintenance. Some of this energy has been diverted into public transport infrastructure, particularly the nationwide railway. The infrastructure EF reduces as there are fewer cars on the road and only $20 \%$ of the international flights, reducing the airport EF. 
The NZ citizenship average EF in 2007 was $0.09 N Z h a / p e r s o n$. The scenarios show some reduction could be made by converting to $100 \%$ renewable energy, but more significant reductions can be made by reducing consumption, such as halving electricity use in buildings, and reducing paper use and travel. Lower EF from the reduction in roading and airports, and from reduced resource use, give an overall reduction of $36 \%$ (table 6.14).

Table 6.13: Proposed citizenship EF reductions

\begin{tabular}{|lc|}
\hline \multicolumn{1}{|c|}{ Actions } & $\begin{array}{c}\text { Category } \\
\text { reduction }\end{array}$ \\
\cline { 2 - 3 } & $\%$ \\
\hline Half the amount of roading maintenance and airport EF & $34 \%$ \\
\hline All government buildings 100\% renewable electricity & $22 \%$ \\
\hline $\begin{array}{l}\text { All government buildings halve their electricity, paper and card use, } \\
\text { and travel }\end{array}$ & $47 \%$ \\
\hline All services run using 100\% renewable electricity & $28 \%$ \\
\hline All services buildings halve their electricity and paper and card use & $36 \%$ \\
\hline
\end{tabular}

\subsection{Summary}

By reducing each component of the average NZ EF, it is possible to show how New Zealanders could live within their fair earth share EF (table 6.14).

When compared to the $2007 \mathrm{NZ}$ average EF of 2.49NZha, the fair earth share of $1.2 \mathrm{NZha}$ is a $52 \%$ reduction. The fair earth share EF is based on a population of 14 million as proposed in the 'setting the scene' scenario (section 6.3).

The lists of actions for how to piece together a fair earth share EF depends on the number of people living in NZ. They are the actions that are easiest to carry out. In some categories, such as citizenship, it seems difficult to achieve the target fair share shown in figure 6.1 , which means that other categories may have to make larger reductions. 
Table 6.14: New individual and total NZ 'fair earth footprints' for 14 million citizens

\begin{tabular}{|c|c|c|c|}
\hline Fair Earth Share action & $\begin{array}{l}\text { Category } \\
\text { reduction }\end{array}$ & $\begin{array}{l}\text { fair earth } \\
\text { share } \\
\text { EF/person }\end{array}$ & $\begin{array}{l}\text { fair earth } \\
\text { share EF for } \\
\text { NZ }\end{array}$ \\
\hline & $\%$ & NZha & NZha \\
\hline Consume less food, less meat and fish & $60 \%$ & 0.56 & $7,858,200$ \\
\hline $\begin{array}{l}\text { Fewer kilometres travelled by cars and vans } \\
\text { and increased passenger numbers }\end{array}$ & $45 \%$ & 0.10 & $1,458,800$ \\
\hline $\begin{array}{l}\text { Increase recycled materials and half the } \\
\text { number of pets }\end{array}$ & $45 \%$ & 0.35 & $4,862,200$ \\
\hline International holidays by air every five years & $40 \%$ & 0.073 & $1,015,000$ \\
\hline $\begin{array}{l}\text { Double the number of people per house or } \\
\text { halve the house size and halve the } \\
\text { household energy consumption per person }\end{array}$ & $55 \%$ & 0.05 & 699,648 \\
\hline $\begin{array}{l}\text { Halve the amount of roading maintenance } \\
\text { and airport EF, government and services } \\
\text { halve their electricity and paper and card } \\
\text { use and government halves its travel EF }\end{array}$ & $36 \%$ & 0.06 & 854,107 \\
\hline Total & & 1.20 & $16,747,955$ \\
\hline Fair Earth Share & & 1.21 & $16,879,839$ \\
\hline
\end{tabular}




\section{Chapter 7: Discussion and conclusions}

This research uses primary EF data to better understand collective resource use by New Zealand individuals and communities. The aim of the research was to find a fair earth share EF that is achievable, with accompanying scenarios relating to urban form and lifestyle that offer a range of options for reaching this goal. Future research opportunities include using local social and economic indicators to inform communities about the benefits of EF reduction.

The research question asks what types of urban form and lifestyle scenarios provide a basis for New Zealanders to live within their fair earth share of the Earth's biological capacity. Chapter 5.4 describes one of the project participants whose current EF is already within their fair earth share, and chapter 6 discusses a range of possible actions that could enable other individuals and communities to live within a fair earth share EF. These sections provide a range of answers to the research question.

\subsection{Ecological Footprint}

The EF tool communicates the available biocapacity on which society can rely to supply goods and services and assimilate waste, and also measures the demands on that biocapacity. Together this mass-balance exercise is unique.

Ecological Footprinting provides a clear and concise way to communicate complex information to a broad audience. Throughout the research, the EF tool was highlighted as being unique for its ability to provide a single quantitative measure of the resources consumed and the waste produced by a given population. This simplification was found to be useful to a range of stakeholders: regional and city councils, community groups and individuals. The footprint calculations were used at multiple stages of the project in order to create plans for moving communities toward lower footprint futures. The EF calculations provided a clear vision in the form of a fair earth share footprint to use as a comparable baseline, and also provided a way of measuring the effectiveness of proposed actions to meet the vision. 
Internationally, awareness and collaboration to develop widely-accepted resource accounting tools has increased since 2008 with the creation of The Economics of Ecosystems and Biodiversity (TEEB) initiative (TEEB, 2013). TEEB takes resource accounting further than many of the previous tools by demonstrating the economic significance of biodiversity loss and ecosystem degradation in terms of negative effects on human well-being (TEEB, 2012, p.3). These tools are useful to show the benefits of retaining environmental health in order to ensure that the environment can supply the services required by society. On the other hand there are few tools that provide data showing an individual's or group's total demands on nature. There is limited understanding of what the particular resources are used for and whether the resources are being used in an efficient way to improve well-being. The EF complements tools such as TEEB. Together, they provide better understanding about why society puts such high demands on nature. This improved awareness can inform better decision-making.

Many individuals interviewed during the survey were genuinely interested in the outcome of their EF calculations. There were numerous requests for this information, which was also backed up by the eagerness of the community workshop attendees. The workshops provided a broad background of the total supply and demand of land on planet earth, and the fair earth share for each person. This was enough to provide a context. The workshop attendees appreciated the detailed information provided by their EF calculations, and the in-depth understanding of the workshop facilitator.

The project highlighted a number of the EF's weaknesses. As mentioned in chapter 3 the EF tool does not provide a complete assessment at whether a project or action will move society towards a sustainable future. Concern was raised at the Auckland Council workshop that the EF does not have a standardised method to immediately measure the effects of toxic chemicals or land changes that reduce biodiversity. Both of these effects do show up over time, but are only visible in retrospect as the total available biocapacity decreases.

As with many measurement tools the EF explains only part of the sustainability picture. Used on its own, the EF does not judge whether the size and shape of an individual's or community's EF is being used in a way that fulfils economic, social and environmental wellbeing. This point was picked up in a newspaper article after the research was criticised for 
being too simplistic. The EF results must be articulated in the light of economic and social measures and in the context of the community in question.

This is particularly true for local government partners who highlighted the benefits of using ecological accounting to inform their decision-making and communication with the broader public. Unfortunately the feedback from local government partners identified multiple barriers to having these alternative measures embedded and communicated through integrated accounting methods. A valuable next step for this research would be to work closely alongside local government partners in order to test how the EF tool could be used in strategic documents. A step-by-step guide for Council showing how to integrate these tools would be invaluable in achieving real change.

The EF provides a snapshot of the land required to support society's resource consumption. In summary, the EF is an effective communication tool. It provides a unique perspective on resource use in the form of a single, quantitative assessment. However it must be used in the context of a clear understanding of what it is measuring and what it is trying to achieve. When used to complement other environmental and social accountancy tools the EF is useful to individuals, community groups and local councils to measure what and how they use resources and inform decisions to support their EF reduction.

\subsection{Fair Earth Share summary}

The research question was, 'what types of urban form and lifestyle scenarios provide a basis for New Zealanders to live within their fair earth share of the Earth's biological capacity?' This question can be answered with a summary of the chapter 6 results.

The research suggests that the most effective fair-earth-share urban form is probably an 'independent urban centre'. These centres are separated by agricultural land that provides space for the production of essential resources such as food and wood. A small urban centre contains sufficient infrastructure, resources and labour to enable consumer goods to be produced locally. Waste can be reduced through intricately-connected community-wide manufacturing systems. Residents benefit from the densification of housing by reduced travel 
distances to service centres, work, and educational opportunities. Dwellings are designed to house more people in a condensed space.

Fair-earth-share lifestyles are communally centred, and acting ethically is integral to the community way of life. Growing food together is the centre of community life, and other community-focused activities stem from these relationships. People require very little money, as possessions are of much less importance, and there is little need to buy food. As a result people spend less time in employment, increasing the amount of time spent with friends and family and contributing to community needs. Resource-use efficiency is normal behaviour, and communal living increases trust and connectivity in communities which increases overall well-being. There are still high-EF luxuries but they are consumed in moderation and are offset by a reduced EF elsewhere.

\subsection{Research highlights}

The research achieved the objectives set out at the beginning of the project. The footprint results highlighted the most common, and also the more unique, characteristics of the NZ EF.

Research objectives 1 to 4 were fully achieved. Objective 5 is discussed further in section 7.4 (method limitations).

Major methodology steps in the research were as follows:

1. Chapter 4 discussed gathering data and calculating the average NZ EF. It highlighted aspects of urban form and lifestyle that make up the largest proportions of individual and community EF.

2. Chapter 5 described the method used for gathering and analysing data from five NZ communities regarding personal and household resource use.

3. Community discussions were used to guide the creation of a variety of scenarios in chapter 6 . These describe how people with different NZ lifestyles, residing in various urban forms, could live within their fair earth share EF.

4. Chapter 6 also showed the creation of a theoretical ideal type and scale of both the built environment and behaviour for a community with an EF that is equal to, or below, their fair earth share EF. 
5. The top-down-bottom-up component-based methodology used during the project was flexible enough to use for the purpose of the research and was realistic in terms of resources and time. It could be replicated in further research; however, it was time- and data-intensive.

\subsection{Method limitations}

There are a number of improvements that could be made to the EF methodology for calculating the NZ average EF. The most significant would be to include the calculation of degraded land as suggested by Lenzen and Murray (2001). The modified EF method would account for reduction in the health of land when it is being caused by an activity, rather than accounting for it later as a reduction in biocapacity (after the degradation has already occurred). This would ensure that both the demand and supply of land were being measured in real time.

In order to clarify the footprint calculations and increase accuracy, gathering and monitoring of NZ EF resource data need to be increased, with wider access to data. National food and drink and consumer goods EF data were particularly difficult to locate using a componentbased EF method, due to the lack of resource life-cycle accounting, and data were even more difficult to find at the local level.

Including survey questions asking how individuals spend their time and money would have provided additional insight into the relationship between time, money and resource needs and wants.

Improvements to the EF survey could be made by amalgamating questions to shorten it, and by clarifying some questions so they are easier to understand and can be completed independently by the respondent. The EF calculator also needs to be updated, as new data have become available since its initial design.

Increasing the number of individual respondents and types of urban form would provide a broader representation of New Zealanders. It is acknowledged that the community sample is likely to be skewed due to the voluntary nature of the survey. 


\subsection{Research reflections}

The New Zealand Footprint Project proved to be a worthwhile piece of research both personally and professionally. The opportunity to combine project management and research roles allowed for the development of understanding in scientific investigation, communication of scientific results to a range of audiences, and in planning and implementing large research projects. Three questions were used to help to reflect on the experience. The results highlighted that the research exceeded personal expectations.

The Framework for Strategic Sustainable Development's Prioritising Questions (Holmberg et al., 1999; Robèrt et al., 2002) were used to measure the degree of success achieved by the project. The three questions are:

1. Did the project move me towards my vision of success?

2. Is the project a flexible platform for future change?

3. Were the outcomes of the project seen as a good return on investment?

The following section will use the three prioritising questions to reflect and assess the outcomes and impacts of the project both from a professional and personal perspective.

\section{Did the project move me towards my vision of success?}

How scientific research can help to inform sustainable governance and decision-making has been the focus of much of my research for the past decade. My vision is that ecological and social data is mainstreamed in local, regional and national governments to the same extent as economic data. The tools required to achieve this will be able to quantify the ecological and social strengths and weaknesses of decisions and would complement economic performance indicators. An area of particular interest is to redesign the food distribution system to support localisation. This requires reconnecting local producers with local consumers, and defining and removing the current barriers created through local and national policy. 
The NZ Footprint Project and PhD research provided a great opportunity to further explore my vision and create networks with other institutions and individuals who are also working to achieve similar aims. Previous studies in law, ecology, planning and the Framework for Strategic Sustainable Development provided a broad base on which to take the additional step of using a well-known resource accounting tool and testing it with decision-makers and the broader public. The insight and experience of communicating scientific information with such a broad range of stakeholders was invaluable.

Researching and discussing NZ's food system became central to the outcome of the footprint research. The large portion of the NZ EF required for food and drink was surprising and gathered media and public attention. Consumer demands on the food and beverage industry for more accountability continue to grow, as highlighted during the recent botulism scare in Fonterra products (Fonterra, 2013). Such concerns have increased the public's interest in New Zealand's food system. The food footprint shows the complexity and inefficiency of the food system, particularly in relation to the embodied energy in processing, transport and packaging. These inefficiencies could be drastically reduced through the use of more localised systems. The scenarios in chapter 6 showed that changes to the food system could revolutionise NZ's EF.

The footprint research has progressed my professional development toward my goal to provide frameworks for decision-makers to make more informed decisions based on natural and social science. The next step is to gain further understanding of how decisions are made in the reality of government organisations; to achieve this I need to be elected into Council.

\section{Is the project a flexible platform for future change?}

The footprint research was broad-reaching and dynamic due to its multi-disciplinary nature. Although the research was specialist in the sense that it required detailed understanding of the EF tool, it required a foundational knowledge of both the natural and social sciences. As a result the research provided considerable insight into different research methods, its value to government organisations, and how this science could be presented to a range of audiences. 
The current research design was constructed from an understanding of a range of disciplines and a desire to gain broad insight rather than focusing deeply on any one area. The use of a mixed-methods approach also resulted in much breadth and depth of qualitative and quantitative data. There is a considerable amount of data that can then be analysed and recalibrated in different ways depending on the particular part of the footprint the audience is interested in. As a result the data will be useful for a long time into the future, providing content for numerous publications and ongoing research opportunities.

The results of the research have the potential to be shared amongst multiple disciplines. The challenge is to ensure that the information reaches a range of audiences in a way that is meaningful to each. However, a limitation of this research is that a succession plan was not built into its design, yet further development of the background EF data is required to transfer the data into a more widely usable form. Because of the lack of knowledge-sharing between scientists and policy people in different areas and disciplines these developments completely rely on the researcher's motivation to progress the work. This is potentially a major weakness of the research and could prove to be a barrier to ensuring that the research is distributed to those stakeholders who will find it valuable. The aim for the future is to revisit the data and reorganise it alongside a fellow researcher who will continue on with the research.

The data are incredibly flexible and could continue to be used in many ways. However, there was short-sightedness during the development of the project: the ongoing sustainability of the project should not come down to an individual but a team of people.

\section{Was the project a good return on investment?}

The research provided an amazing opportunity so that I continue to work with Otago Polytechnic and undertake full-time study concurrently. The project and PhD research were completed within the 3-year timeframe. Upon reflection the research was carried out efficiently both in relation to the time, funding and emotional dedication required.

The opportunity to both manage the New Zealand Footprint Project and carry out my PhD research within the project was significant. This 'professional' qualification with a direct benefit to both Otago Polytechnic as an employer, and to myself in gaining real-world 
experience as a student, is a model that could continue to be replicated with wide-reaching benefits.

The EF research provided an opportunity to increase my skill-set in research, critiquing and developing accounting methodologies, statistical analysis, Excel datasheets, developing quantitative research tools such as questionnaires, and general problem-solving when faced with huge amounts of data.

The emotional investment in a project of this size is difficult to fully appreciate initially. Particularly in the field of sustainability, and being required to front up at numerous public appearances, it is crucial to believe that the research will make a difference and that the future is a positive one. There is an inherent need to interact with people who are passionate about working together to redesign the world for a happier and healthier future. Personally it is imperative to be able to look them in the eye and say "I do not know what the future will bring but I know that every project and action that works towards this vision is one step closer. The future is a positive one."

The current research project made a valuable contribution to clarifying the high EF activities New Zealand and possible ways to reduce them. This has provided more direction to New Zealand on where EF reduction efforts should be concentrated in the future. The ongoing challenge is to ensure that the information is disseminated widely, and in an easily usable form, so that groups and individuals use it to strengthen their own strategic plans and actions for moving towards a more sustainable future. The research also provided considerable opportunities to those involved in the research, as its multi-disciplinary stance enabled engagement with a wide range of stakeholders. The EF research provides a flexible platform from which to launch further research; however, it is important to ensure the detailed EF data are in an easily usable form. Upon reflection, the time, money and emotional investment required by the project was thought to provide a good return.

\subsection{Further research}

EF data continues to be used by organisations globally as a way of communicating the impacts of resource consumption and for measuring the effectiveness of resource reduction initiatives 
(BioRegional \& WWF, 2008; Desai \& Riddlestone, 2002; Global Footprint Network, 2010; Stockholm Environment Institute, 2011; Wiedmann, Barrett, \& Lenzen, 2007; WWF, 2010). The EF can also be used alongside other indicators (such as the Happy Planet Index (New Economics Foundation, 2012)) to show the relationship between social and economic wellbeing. Well-being indicators relating specifically to resource consumption and liveability in NZ would be valuable, particularly at the individual and community level. Suitable indicators could provide an improved understanding of the relationship between resource use and wellbeing. 'Social return on investment' (New Economics Foundation, 2004; The SROI Network International, 2012) paired with EF calculations could provide new insights using monetary terms for the social impacts of increasing and decreasing community footprints. A possible future research question is: "what barriers need to be removed in order to maximise people's ability to increase their well-being in the face of reduced resource availability?"

The research presented in this thesis provides a set of data that could be used for footprinting individuals, organisations and communities. A range of footprint calculators could be created, making these calculations easy and engaging to a range of audiences. Organisations such as Hampden Community Energy (McTavish, 2013), Enviroschools (The Enviroschools Foundation, 2012), Sustainable Living (Sustainable Living Education Trust, 2012), Auckland Council (Auckland Council, 2012) and Otago Polytechnic (Otago Polytechnic, 2012) have already shown interest in using these calculators to monitor the effectiveness of their courses and projects. A further step would be the development of organisation and community calculators designed to provide footprint scenarios, similar to the community calculators offered by the Stockholm Environment Institute (Dawkins, Roelich, \& Owen, 2010; Paul et al., 2010; Stockholm Enviroment Institute, 2008; Wiedmann et al., 2004), but specific to NZ. The calculators could also be used by local councils to improve resource efficiency in relation to community planning and policy making (Lawton et al., 2012). All of these calculators could serve as tools to assist in NZ's transition to a less resource-intensive way of life in a future where the resources that New Zealanders currently take for granted are no longer so freely available. 


\subsection{Conclusions}

The research found the make-up of the NZ EF to be quite different from that of most other countries, due to the high level of renewable electricity and high land productivity. The inclusion of EF categories such as pets and holidays, which are not common in EF projects, also alters the NZ EF distribution. The use of NZha rather than gha also means that many of the findings are not directly comparable to international EF projects.

The food and drink EF is $54 \%$ of the average NZ EF, and the most effective way of reducing this is to use private or public garden land for food-growing. The second most effective action is to reduce consumption of high EF foods such as beef and fish. Community food footprints vary depending on the amount of animal-based products consumed, particularly fish, and the degree of dependence on shop-bought food.

It was surprising to find that pet EF is a significant portion of the total NZ EF. The community survey showed that some households kept multiple high-EF pets which increased one household's consumer goods EF to six times the fair earth share. A fair earth share pet EF would allow each person 0.08NZha, which is enough land to keep two low-resource pets (birds or guinea pigs) or to share a medium-resource pet (cat or small dog) with 4-5 other people.

Flying anywhere for a holiday increases an individual's total EF. The EF of flying from NZ to Europe or Africa is 1.11 NZha, which is almost as much as the total of an individual's fair earth share (1.21NZha). However, there were examples of individuals with small EFs who did use air travel but offset it by reducing their EF elsewhere, such as not eating meat or keeping pets.

The community EF results affirmed some assumed community stereotypes related to resource use. These included lower housing footprints in denser urbanised communities; and higher travel and pet footprints, and lower food footprints, in rural communities. However, the results revealed that many individuals living in main urban centres and satellite urban communities also have high travel footprints from single-occupancy car use. Residents of urban areas who used public transport (except ferries) reduced their travel EF. 
Those with the lowest income had, on average, lower footprints, and this correlation increased when the pet EF was removed. However, household income showed less correlation with EF than that suggested in other case studies. It is unclear whether these results were due to a limitation in the survey or whether, as discussed in chapter 1.2, a higher income can be used to reduce an individual's EF if the individual's lifestyle decisions are focused in this direction. These findings highlight that income level, on its own, is not a consistently effective indicator of individual or community EF. 
Appendices 


\section{Appendix 1: NZ Footprint Survey}

Welcome and thank you for supporting our research by filling in this questionnaire. Please remember that unless stated, the questions should be considered on average for the ENTIRE HOUSEHOLD.

Please note: The following questionnaire is only concerned with your personal lifestyle, not those aspects that you consider as WORK. Those items/travel supplied by work, paid by work and predominantly for the purpose of your job should not be included in your answers.

1. i. Are you:

Male Female

ii. What is your age:
a. Under 25
b. 25 to 34
c. 34 to 44
d. 45 to 54
e. 55 to 64
f. $65+$

\section{iii. What ethnic group do you identify} with?
a. European / Pakeha
b. Maori
c. Pacific Island
d. Asian

iv. What is your highest educational qualification?
a. A tertiary degree or professional diploma
b. A trade certificate or diploma
c. No tertiary qualifications (only school or no qualifications)

\section{FOOD}

2. How often do you eat animal-based products?

i. Beef / lamb
a. never
b. infrequently (once every few weeks)
c. occasionally (one-three times a week)
d. often (nearly every day)
e. all the time (most days most meals)

iii. Fish
b. infrequently (once every few weeks)
a. never
c. occasionally (one-three times a week)
d. often (nearly every day)
e. all the time (most days most meals)

ii. Pork
a. never;
b. infrequently (once every few weeks)
c. occasionally (one-three times a week)
d. often (nearly every day)
e. all the time (most days most meals)

iv. Poultry (chicken, duck, turkey)
a. never
b. infrequently (once every few weeks)
c. occasionally (one-three times a week)
d. often (nearly every day)
e. all the time (most days most meals 
v. Milk \&dairy
a. never
b. infrequently (once every few weeks)
c. occasionally (one-three times a week)
d. often (nearly every day)
e. all the time (every day most meals)

vi. Eggs
a. never
b. infrequently (once every few weeks)
c. occasionally (one-three times a week)
d. often (nearly every day)
e. all the time (every day most meals)

\section{How often do you eat fruits, vegetables and grains?}

\section{i. Vegetables}
a. never
b. infrequently (about once a week)
c. occasionally (one-three times a week)
d. often (nearly every day)
e. all the time (every day most meals)

iii. Bread
a. never
b. infrequently (once every few weeks)
c. occasionally (one-three times a week)
d. often (more than 3 times a week)
e. all the time (every day)

\section{v. Wheat pasta}
a. never
b. infrequently (once every few weeks)
c. occasionally (one-three times a week)
d. often (more than 3 times a week)
e. all the time (every day)

\section{ii. Fruit and nuts -}
a. never
b. infrequently (about once a week)
c. occasionally (one-three times a week)
d. often (nearly every day)
e. all the time (every day most meals)

iv. Rice
a. never
b. infrequently (once every few weeks)
c. occasionally (one-three times a week)
d. often (more than 3 times a week)
e. all the time (every day)

\section{vi. Pulses (such as beans and legumes)}
a. never
b. infrequently (once every few weeks)
c. occasionally (one-three times a week)
d. often (more than 3 times a week)
e. all the time (every day)

4. How much of the food that you eat is organically produced (without the use of chemicals)?
a. don't know;
b. none that I know of (I don't purposefully buy organic)
c. some (I occasionally buy organic milk and sometimes I buy from the organic market)
d. most (I always aim to buy organic at the shop and do not use chemicals on my garden)
e. all (I only eat food that I know has been organically grown) 
5. Fresh, not packaged and local food

i. How much of your diet is based on fresh, unpackaged foods?

a. don't know

b. none of it (the business of life means I have to eat quick)

c. about a quarter of it (I very rarely supplement my baked beans with a home cooked meal)

d. about half and half (sometimes I cook local food, sometimes I order pizza)

e. most of it (I'm a farmers market fiend but I really like potato chips)

f. all of it (I only eat fresh, unprocessed, unpackaged food)

ii. How much of the food that you eat is locally grown or produced within the region that you live?

a. don't know (I never pay any attention to where it is grown)

b. very little (most of the food I eat is not grown locally)

c. about a quarter (I sometimes stop at roadside stalls to buy fruit)

d. about a half (I try to get to the local markets every week to buy fruit and veges)

e. about three-quarters (we buy from the market what we cannot grow ourselves but I don't know where our meat/seafood comes from)

f. all of it (all of the food I eat is grown/produced locally)

iii. How much of the food that you eat has NOT been bought but either caught or gathered yourself, produced on your own land, or exchanged or bartered with others?

a. none (I don't know anyone who grows their own food and I don't gather my own)

b. very occasionally (my parents live on an orchard an send me a box of apples every month)

c. occasionally ("recreational hunter" - I love collecting wild fruit and we often go fishing and/or hunting)

d. often ("the farmer" - we never buy meat and have a thriving vegetable garden in the summer)

e. always ("Off the Radar" - I am fully self-sufficient and only buy the bare essentials like sugar and flour)

6. i. Do you have a home garden?

a. Yes

b. No. Why not? (go to question 7)

iii. How much fruit and veges do you grow and consume?

a. Not much - some herbs

b. A bit - some salad greens from a summer garden $\left(1 \mathrm{~m}^{2}\right)$

c. Some - we eat something from the garden each day during summer $\left(1-3 \mathrm{~m}^{2}\right)$

d. A lot - we eat mostly from the garden in summer and some in winter $\left(3-10 \mathrm{~m}^{2}\right)$

e. Most - we eat mostly from the garden in summer and have additional food that we store for winter $\left(10-20 \mathrm{~m}^{2}\right)$

f. All - almost all our fruit and veges are from our garden (larger than $20 \mathrm{~m}^{2}$ ) ii. Do you grow edible plants and fruits in your garden?

a. Yes

b. No. Why not? (go to question 7)

iv. Why do you have a garden? (you may tick more than one)

a. Saves money

b. Is therapeutic to get outside

c. Enjoy eating my own food

d. Convenience, fewer trips to supermarket

e. Health, I know how it is grown

f. Environmental - less impact on the environment

g. Always have, it is what we do 
7. Eating out and take-aways.

i. How often do you grab a meal from a cafe or fast-food restaurant? (do not include coffee)

a. never (I love to cook at home, and it saves me money)

b. occasionally (once every few weeks on special occasions)

c. every week (fish and chip Friday is my favourite)

d. 2-3 times a week (I need my coffee fix and I never remember to make my lunch)

e. every meal (I am too busy to buy food and cook at home)

ii. How often do you go to a restaurant to have a sit-down meal?

a. never (I love to cook at home, my food is always better)

b. occasionally (once every few weeks on special occasions)

c. every week (we go out for dinner or brunch every weekend)

d. 2-3 times a week (I have a very busy social calendar which means I eat out a lot)

e. every meal (I live at restaurants)

iii. Do you eat the same kinds of food when you eat out, as you do at home?

a. No (I like to treat myself when I go out for dinner so I can have a steak or the seafood platter that I don't eat at home)

b. most of the time (sometimes I splurge on a fancy meal)

c. yes (when I eat out I would eat a similar size and type of meal that I would eat at home)

\section{iv. What is your primary alcoholic drink of choice?}
a. Wine/Cider
b. Beer
c. Spirits
d. Other
e. None

\section{Your Household}
8. i. How many people live in your household?
a. 1
b. 2
c. 3
d. 4
e. 5
f. 6
g. $7+$

iii. What best describes your spending and saving habits?
a. I spend all my income and then some
b. live within my means
c. I am a frugal spender and save for the future
v. What best describes your drinking frequency?
a. Never - I don't drink or very rarely drink
b. 1-4 glasses of wine/spirit or 1-6 stubbies a week
c. 1-2 bottles of wine a week, 5-10 glasses of spirit/mixer, 7-15 beer stubbies
d. More

\section{ii. In what range is your household income?}
a. No comment
b. $\$ 40,000$ or less
c. $\$ 40,001-\$ 60,000$
d. $\$ 60,001-\$ 80,000$
e. $\$ 80,001-\$ 100,000$
f. $\$ 100,001-\$ 120,000$
g. $\$ 120,000-\$ 140,000$
h. $\$ 140,001+$

9. Your Property

i. How would you best describe where you live?
a. Rural
b. rural-residential
c. suburban
d. urban
e. inner city 
ii. Which best describes your property?
a. High country station
b. A working farm
c. Lifestyle block (0.4-30 hectares)
d. Free standing house on large section $\left(1,000-4,000 \mathrm{~m}^{2}\right)$
e. Free standing house on small section (less than $1,000 \mathrm{~m}^{2}$ )
f. Single storey apartment with no section
g. Apartment in a multi-storey building

iv. In addition to your house, how much of your land is covered with a solid (impermeable) surface? E.g. driveway, garage, pool etc.
a. None
b. $1-10 \mathrm{~m}^{2}$
c. $11-20 \mathrm{~m}^{2}$
d. $21-30 \mathrm{~m}^{2}$
e. $31-40 \mathrm{~m}^{2}$
f. $40 \mathrm{~m}^{2}+$

iii. What is the size of your house (not including the garage)?
a. $50 \mathrm{~m}^{2}$ or less
b. $51-100 \mathrm{~m}^{2}$
c. $101-150 \mathrm{~m}^{2}$
d. $151-200 \mathrm{~m}^{2}$
e. $201-250 \mathrm{~m}^{2}$
f. $251-300 \mathrm{~m}^{2}$
g. $301-350 \mathrm{~m}^{2}$
h. $351 \mathrm{~m}^{2+}$

v. Do you own your own home?
a. Yes
b. No, we rent privately
c. No, it is state housing

vi. What would you say comes closest to the materials your house is constructed of? (you may choose more than one)
a. Timber frame
b. steel frame
c. clay brick
d. Mud brick / rammed earth/ straw bale
e. I don't know or other

10. Energy for your whole HOUSEHOLD (please average your bills for the year, or winter average plus summer average divided by 2)

i. On average what do you typically spend PER MONTH on electricity for your home?
a. I don't use mains electricity
b. I don't know
c. $\$ 0-50$
d. $\$ 56-100$
e. $\$ 101-150$
f. $\$ 151-200$
g. $\$ 201-250$
h. $\$ 251+$

ii. What do you typically spend PER MONTH on natural gas/LPG/diesel (please circle) for your home?
a. I don't use gas
b. I don't know
c. Under $\$ 25$
d. $\$ 26-\$ 35$
e. $\$ 36-\$ 45$
f. $\$ 46-\$ 55$
g. $\$ 56-\$ 65$
h. $\$ 66-\$ 75$
i. $\$ 76+$

iii. What do you typically spend PER MONTH iv. How much wood do you use EACH on coal for your home?
a. I don't use coal
b. I don't know
a. I don't use wood
c. Under $\$ 100$
b. I don't know
d. $\$ 100-\$ 150$
c. $0-2 \mathrm{~m}^{3}$
d. $3-5 \mathrm{~m}^{3}$

YEAR? (average it over the whole year) 

e. $\$ 151-\$ 200$
f. $\$ 200+$

\section{Water}

i. Do you rely on mains water?
a. Yes
b. No (Go to Q12)
e. $6-10 \mathrm{~m}^{3}$
f. $11-15 \mathrm{~m}^{3}$
g. $15 \mathrm{~m}^{3}+$

\section{ii. How much water do you use?}

a. Not much (we conserve or don't need much)

b. Average

c. A lot (use it to top-up the pool, water a large area of garden, have many appliances that require water)

12. Compared with the typical New Zealander, how much waste do you think you generate?

i. Electronics: How often do you buy new home entertainment, personal computer equipment and electronic gadgets including tools?
a. Rarely (I do not have many electronic gadgets, except perhaps a mobile phone)
b. infrequently (I generally only replace broken TVs, computers, etc)
c. occasionally (I replace out of date models and occasionally buy a new gadget
d. often (I own many of the newest gadgets on the market)

ii. Clothing: What would you say comes closest to the typical amount of NEW clothing, footwear and/or sporting goods that you purchase EACH MONTH?
a. Not much (new socks and underwear every few months, majority of my clothes are second hand)
b. a little (I buy high quality that lasts a long time so maybe a t-shirt and underwear)
c. some (new pants and a new shirt most months)
d. a lot (I'm up to date with all the latest fashion trends)

iii. Furnishings: What would you say comes closest to the typical amount of new household furnishings you purchase EACH YEAR?
a. None (everything I own is second hand / hand-me-down)
b. very little (maybe some new bedding, pots and pans and some artwork)
c. some (a new lamp or table just to spruce things up)
d. a fair bit (a couch, new bedroom set, I change it up from time to time)
e. a lot (I completely refurbish my living room with new furniture - it's an annual ritual)

iv. Appliances: How often do you buy new household appliances such as toasters, dishwashers and toastie-pie makers?
a. rarely (I don't purchase major appliances for my home, but may buy small items like a blender)
b. infrequently (We have most of the 'typical' household appliances, but only replace them when they break)
c. occasionally (I replace out-or-date appliances with new models regularly)
d. often (we have every TV commercial gadget there is and I replace most of my appliances with the latest and greatest models)

v. Reading material: How often do you buy new books, magazines, and newspapers?
a. Very rarely (I buy a newspaper, magazine or new book a few times a year)
b. infrequently (I subscribe to a magazine I receive once every two months)
c. occasionally (I buy the weekend paper and buy the 'Women's Day' every week) 

d. often (I receive the newspaper daily)
e. very often (I buy the newspapers daily and buy books or magazines multiple times a week)

vi. Waste: How many standard sized rubbish bags does your household throw out EACH WEEK?
a. Less than one (or 1-3 shopping bags)
b. one or two (or 4-8 shopping bags)
c. more than two (or more than 9 shopping bags)

vii. Recycling: How much do you recycle?
a. Everything (all electronics, paper, card, plastic 1-7, glass, aluminium/tin and food scraps)
b. most (I recycle all plastic and have a home compost bin)
c. some (I recycle my milk bottles and cardboard)
d. I don't recycle anything (either because you don't want to or because recycling collection is not provided in your community)

viii. When you buy clothing or paper products, how often do you select items labelled as recycled, natural, organic, or made of alternative fibres such as hemp or bamboo?
a. Almost never (I would only buy them if they are exactly what I was looking for and didn't cost any more)
b. sometimes when I can (I search them out but sometimes the price tag gets in the way)
c. almost always (these are the only products/clothes I buy)

ix. When you are in the supermarket/shop/market do you consider the amount of waste associated with the products you are buying?
a. Never (I do not consider waste)
b. a little (I sometimes try to limit the number of plastic bags I need)
c. often (I try to buy products in bulk and buy refills to limit waste)
d. all the time (I do not buy products that are associated with a lot of waste)

\section{Travel by personal vehicle}

i. How often do you bicycle or walk to get around? (you choose to leave your car at home so travel somewhere)
a. Almost never
b. seldom
c. occasionally (I walk to work most days but love a Sunday drive)
d. almost always (except when it's raining for example)

iii. What best describes the primary car that you travel in?
a. Compact car (2 door)
b. Hybrid car
c. a small-mid size car ( 2 or 4 door hatch)
d. a large car (4 door sedan)
e. a van, ute or minivan
f. SUV or performance car

\author{
ii. How far do you travel by car EACH \\ WEEK (as a driver or passenger)? \\ a. $0 \mathrm{~km}$ or I never ride in the car \\ b. $1-100 \mathrm{~km}$ \\ c. $100-180 \mathrm{~km}$ \\ d. $180-270 \mathrm{~km}$ \\ e. $270-410 \mathrm{~km}$ \\ f. $410 \mathrm{~km}+$
}

iv. Type of fuel?
a. Petrol
b. Diesel
c. LPG
d. Biofuel 
ii. In your primary car, how much driving do you do in urban areas (where you have to brake and accelerate often)?

a. $100 \%$ (I only drive in urban areas or sit in traffic)

b. $80 \%$ mostly in town but do go for a Sunday drive in the country

c. $50 \%$ (I spend half my time on urban roads stopping and starting and half on the motorway or open road highways)

d. $10 \%$ (I almost never drive in the city) iii. How often do you drive your car with someone else in it, rather than alone?
a. Almost never
b. occasionally
c. often
d. very often
e. almost always

\section{Motorbikes}

i. Do you own a motorbike?

a. Yes

b. More than one

c. No (go to Q16)

ii. What is the size of your motorbike engine?
a. I don't know
b. 1-50cc
c. 51-250cc
d. 251-649cc
e. $+650 \mathrm{cc}$

iii. How far do you travel by motorbike EACH WEEK (as a driver or passenger)?
a. $1-15 \mathrm{~km}$
b. $16-50 \mathrm{~km}$
c. $51-100 \mathrm{~km}$
d. $101-150 \mathrm{~km}$ $151 \mathrm{~km}+$

15. Do you use an additional recreational vehicle?
a. Sail boat? Yes / no
b. Motorised boat? Yes / no
c. Jet Ski? Yes / no
d. Light aircraft/helicopter? Yes / no

16. Toys: Do you own 2 or more of the following or similar items?
a. Yes
b. No

\begin{tabular}{|l|l|l|l|}
\hline Mountain bike & Skis / snow board & Wind surfer & Para glider \\
Road bike & Kayak & Surf board & Rock climbing gear \\
\hline
\end{tabular}

\section{Public Transport}

i. Do you regularly travel on public transport (bus, train, ferry)?
a. Yes
b. No (go to Q19) 


\section{ii. How far do you travel by bus EACH WEEK?}
a. $0 \mathrm{~km}$
b. $1-10 \mathrm{~km}$
c. $10-25 \mathrm{~km}$
d. $25-100 \mathrm{~km}$
e. $100 \mathrm{~km}+$

iii. How far do you travel by rail EACH WEEK?
a. $0 \mathrm{~km}$
b. $1-10 \mathrm{~km}$
c. $10-25 \mathrm{~km}$
d. $25-100 \mathrm{~km}$
e. $100 \mathrm{~km}+$

\section{iv. How far do you travel by ferry EACH WEEK?}

( $22 \mathrm{~km}$ one way btw Waiheke \& Akd))

(4.7km one way btw Devonport \& Akd)
a. I don't catch ferry's
b. $1-19 \mathrm{~km}$ (rtn 2x Dvpt)
c. $19-88 \mathrm{~km}(\mathrm{rtn} 5 \mathrm{x}$ Dvpt $\& 2 \mathrm{x}$ Whk)
d. $89-176 \mathrm{~km}$ (rtn $3-4 \mathrm{x}$ Whk)
e. $177-264 \mathrm{~km}(\mathrm{rtn} 4-6 \mathrm{x}$ Whk)
f. $265 \mathrm{~km}+$ per wk

18. Flying: How far do you fly EACH YEAR? (if you only fly once every 2 years, please average your flying over those two years and remember to calculate return flights - see below)

\section{i. Nationally:}

a. $0 \mathrm{~km}$ (I never fly nationally)

b. $1-800 \mathrm{~km}$

c. $801-1,600 \mathrm{~km}$

d. $1,601-3,000 \mathrm{~km}$

e. $3,001-6,000 \mathrm{~km}$

f. $6,001-12,000 \mathrm{~km}$

g. $12,001-30,000 \mathrm{~km}$

h. $30,001 \mathrm{~km}+$

\section{ii. Internationally:}

a. $0 \mathrm{~km}$ (I never fly internationally)

b. $1-9,000 \mathrm{~km}$ ( $2 x$ Sydney rtn)

c. $9,001-15,000 \mathrm{~km}$

d. 15,001-24,000km (Los Angeles or Vancouver rtn)

e. 24,001-40,000km (Africa or Europe rtn)

f. 40,001-80,000km (2x Europe rtn)

g. $80,001 \mathrm{~km}+$

Flight distance estimates (one way): www.mapcrow.info/

- Auckland to Christchurch $760 \mathrm{~km}$

- Auckland to Wellington $640 \mathrm{~km}$

- Auckland to Rotorua $230 \mathrm{~km}$

- Wellington to Nelson200km

- Wellington to Christchurch $440 \mathrm{~km}$

- Wellington to Dunedin $800 \mathrm{~km}$

- Auckland to Invercargill $1,600 \mathrm{~km}$

- Auckland to Queenstown $1,550 \mathrm{~km}$
- Auckland to Fiji 2,100km

- Auckland to Sydney $2,200 \mathrm{~km}$

- Auckland to Perth 5,300km

- Christchurch to Sydney 2,100km

- Auckland to Singapore $8,400 \mathrm{~km}$

- Auckland to Los Angeles 10,500km

- Auckland to London, Amsterdam, Paris $18,300 \mathrm{~km}$

- Auckland to Dubai $14,200 \mathrm{~km}$

- Auckland to Vancouver $11,400 \mathrm{~km}$ 
19. Holidays: A holiday is staying anywhere other than the family home.

i. How often do you go on holiday each year? (you can choose more than one)

a. Never (go to question 21)

b. One or two weekends away

c. We save up for a long summer/winter holiday

d. We like to go away often, once a month

e. Multiple weekends away during the year ii. How far do you travel to go on holiday? (you can choose more than one)

a. We travel by car, less than $100 \mathrm{~km}$

b. We travel by car between $100-400 \mathrm{~km}$

c. We travel by car more than $400 \mathrm{~km}$

d. We travel by plane nationally

e. We travel by plane internationally (Australia)

f. We travel by plane internationally (Europe)

g. Other

iv. What are your reasons for going on holiday? (you can choose more than one)

a. Spending time with family and friends

b. Seeing new places, experiencing new things

c. Relaxing - doing as little as possible

d. Gathering /hunting food

e. Sports event

f. Changes every year

g. Staying at hotels/backpackers \& eating out

h. Other

\section{PETS}

Do you have any pets? (this does not include animals you eat or that do work around the farm) YES, please answer this section; NO, please go to question 22.

i. Very low resource pet (goldfish, rabbit with all food and bedding produced onsite). How many animals? 1, 2, 3, 4, 5+

ii. Low resource pet (birds, hens, hamsters, guinea pigs etc). How many animals? 1, 2, 3, $4,5+$

iii. Medium resource pet (cats and small dogs - Chihuahua, Jack Russell etc). How many animals? $1,2,3,4,5+$

iv. High resource pet (medium and large dogs). How many animals? 1, 2, 3, 4, 5+

v. Do you own a horse, sheep or cattle as a pet? Yes / no.

21. What are the major barriers to having a less resource intensive lifestyle? (you can choose as many options as you like)

a. Not interested (I don't think about reducing the amount of resources I use)

b. Responsibility (I feel I do my bit, the government needs to make it easier)

c. Defiant (I think about it a lot but I wonder "what difference will my actions make") 
d. Lack of support (I am a lone voice in a big household, I do what I can to influence my personal consumption)

e. Cost (the cost of going green is a major barrier)

f. Change of habit (I have a hectic lifestyle and I sometimes need to go with convenience)

g. Community and housing (where I live is not conducive to using fewer resources because...)

\section{Your Tribe}

\section{i. Please read through the list below and indicate the statements that seem most} typical of you. You may tick more than one box.

a. Acting ethically is so much more important than financial gain

b. Getting rich is one of my life goals

c. I usually go off things I've liked when they become popular

d. I am more at home in my own culture than in the general Kiwi culture

e. I am part of a tight knit ethnic community

f. I can make things for a fraction of the cost of buying them

g. I don't care about "getting ahead", I just need to be free

h. I identify with my working class roots

i. I identify with the down to earth people you find in country areas

j. I seem to need to do things my own way, whatever the cost

k. I strive to get the best house and car I can afford

l. I would die if I had to live in the provinces - the inner city is my heartland

m. If I did wrong it wouldn't just affect me, it would bring shame on my whole family

n. It's important to take responsibility for the social and environmental effects of your lifestyle choices

o. It's more useful to do practical things with your hands than it is to be a brain box

p. I've grown up as part of a wealthy privileged class

q. Most people haven't heard the new music I'm into

r. My appearance is always pretty under-stated

s. My family has a tradition of using our wealth to help people of lower classes

t. My private school education has connected me with important social networks

u. My sense of taste and style is obscure

v. Old money has class, new money is crass

w. People who shout about how good they are are heading for a fall

x. Possessions are pretty unimportant in the scheme of things

y. Buying new stuff is one of the great joys of life

z. The church is the centre of our community's social life

aa. The older I get, the less I fit into the mainstream

bb. The things I own show what I've achieved so far

cc. There's no point chopping and changing all the time, you should make a plan and stick to it

dd. There's nothing better than a knotty intellectual issue to discuss

ee. We must change the way we live our individual lives, so we can change the world

ff. You don't want to aim too high in life, just keep it simple

\section{ii. Now look back over the statements in the previous question you stated as being indicative of you and find the ONE statement you agree with most or that most resonates with you.}

a. Acting ethically is so much more important than financial gain

b. I am more at home in my own culture than in the general Kiwi culture 
c. I can make things for a fraction of the cost of buying them

d. I identify with the down to earth people you find in country areas

e. If I did wrong it wouldn't just affect me, it would bring shame on my whole family

f. It's important to take responsibility for the social and environmental effects of your lifestyle choices

g. My appearance is always pretty under-stated

h. My family has a tradition of using our wealth to help people of lower classes

i. Possessions are pretty unimportant in the scheme of things

j. The older I get, the less I fit into the mainstream

k. There's nothing better than a knotty intellectual issue to discuss

l. We must change the way we live our individual lives, so we can change the world 


\title{
Appendix 2: Participant Information and Consent Forms
}

\author{
Participant Information Sheet: A study of resource use in households and regarding individual \\ lifestyle choices.
}

Researcher: Ella Lawton: School of Architecture and Design, Victoria University of Wellington.

The New Zealand Footprint project will gather data to develop a better understanding of the resources consumed by communities in relation to urban form, and by individuals in relation to their lifestyle choices. The project will be led by researchers from the School of Architecture at Victoria University of Wellington. I am a PhD student within this faculty and will be undertaking the data collection and analysis as part of a research project leading to a thesis. The University requires that ethics approval be obtained for research involving individuals and communities.

I am inviting the members of four communities, either as individuals or as part of community groups, to participate in this study. Participants have two options depending on the level of engagement they wish to have. On completion of either option participants will be invited to take part in a community workshop.

Option 1 is a detailed analysis of an individual's resource consumption requiring the completion of an interview to clarify the process and complete a questionnaire. A 'Log Book' will also be completed.

Option 2 has a lesser level of engagement with only the household questionnaire being completed.

The household diary under option 1 should be completed each day for 14 days by filling in a preprinted booklet. The data required is a record of all those resources that participants have acquired or bought, i.e. food, clothing, furniture, fuel for car, public transport etc. during the 14 day period. After 14 days, surveys will be collected by the researcher. At this time participants will be asked for another short interview to ensure that the diary has been filled out correctly and participants have had an opportunity to ask any outstanding questions.

It is very important for participants to fill out their diaries daily rather than waiting until the end of the two week period. It is envisaged that the questionnaire will take between 5 and 15 minutes to complete each day depending on how much they buy or receive. Forms will be either picked up by the research team or returned in the stamped addressed envelope provided.

Responses collected will form the basis of my research project and will be put into a written report on a confidential basis. It will not be possible for you to be identified personally. Only grouped community responses will be presented in this report. All material collected will be kept confidential. No other person besides the Footprint team will see the diaries or questionnaires. The thesis will be submitted for marking to the School of Architecture and deposited in the University Library. It is intended that one or more articles will be submitted for publication in scholarly journals. Diaries and questionnaires will be destroyed two years after the end of the project.

All participants who have taken part in either option 1 or 2 above will have the opportunity to take part in a community workshop if they wish. These workshops will be designed specifically for each specific community and framed as an opportunity to discuss current and future global and local resource constraints. They are an opportunity to share initial collated results from the interviews, questionnaires and diaries. Please see the workshop sheet for further detail. 
Should any participants feel the need to withdraw from the project, they may do so without question at any time within one month of submission of the questionnaire or interview.

If you have any questions or would like to receive further information about the project, please contact Ella Lawton at lawtonella@myvuw.ac.nz or my supervisor, Professor Robert Vale, at the School of Architecture and Design at Victoria University, P.O. Box 600, Wellington, phone 044636275. 


\section{VICTORIA UNIVERSITY OF WELLINGTON}

\section{CONSENT TO PARTICIPATION IN RESEARCH}

\section{Footprinting New Zealand Urban Forms and Lifestyles}

I have been given and have understood an explanation of this research project. I have had an opportunity to ask questions and have them answered to my satisfaction. I understand that I may withdraw myself (or any information I have provided) from this project without question at any time within one month of submission of the questionnaire or interview without having to give reason. I understand that if I withdraw from the project, any data I have provided will be destroyed.

I understand that any information I provide will be kept confidential to the researcher and the Footprint team. I understand that the information I have been provided will be used only for this research project. The published results will not use my name, and no opinions will be attributed to me in any way that will identify me, unless additional consent has been granted in writing. I understand that the tape recording of interviews will be electronically wiped at the end of the project (December 2012) unless I indicate that I would like them returned to me.

I would like to take part in (please tick one):

$\Delta$ Option 1: The interview, questionnaire and household log book.

$\Delta$ Option 2: The interview and questionnaire only.

(Please circle one) Upon completion of option 1 or option 2 I would / would not like an invitation to my local community workshop.

I would like to continue to be informed about the research the outcomes of the Footprint Project.

[Please provide email]

OR [postage address for a hard copy]

Name of participant/guardian (please print clearly):

$[\mathrm{Or}$,

under my guardianship, may take part in this research]

Signed:

Date: 


\section{Appendix 3: Breakdown of crop and grazing land tables for food consumed in NZ in 2007.}

In the table values are given for food from the most common countries of import to NZ.

Table 1: EF for fruit consumed in NZ in 2007

\begin{tabular}{|c|c|c|c|c|}
\hline Fruit & $\begin{array}{l}\text { NZ consumption } \\
(2007)^{1}\end{array}$ & $\begin{array}{l}\text { Average per } \\
\text { capita }\end{array}$ & Yield $^{2}$ & $\begin{array}{l}\text { Individual } \\
\text { EF }\end{array}$ \\
\hline & tonnes & $\mathrm{kg} / \mathrm{cap}$ & $\mathrm{kg} / \mathrm{ha}$ & NZha \\
\hline Apples & 23,009 & 5.44 & 38,391 & 0.0001 \\
\hline Bananas & 74,685 & 17.66 & $17,135^{3}$ & 0.0010 \\
\hline Citrus, other & 8,634 & 2.04 & 10,128 & 0.0002 \\
\hline Coconuts & 8,913 & 2.11 & $7,222^{3}$ & 0.0003 \\
\hline Dates & 1,729 & 0.41 & $5,121^{3}$ & 0.0001 \\
\hline Fruits, other & 144,123 & 34.09 & 11,367 & 0.0030 \\
\hline Grapefruit & 3,159 & 0.75 & 24,390 & 0.0000 \\
\hline Grapes & $78,746^{4}$ & 20.73 & 6,415 & 0.0032 \\
\hline Lemons and limes & 4,765 & 1.13 & 15,361 & 0.0001 \\
\hline Oranges and mandarins & 96,190 & 22.75 & 11,525 & 0.0020 \\
\hline Pineapples & 18,075 & 4.27 & $37,357^{3}$ & 0.0001 \\
\hline Total & 462,029 & 109.27 & N/A & 0.0098 \\
\hline
\end{tabular}

1. (FAO, 2007. Food Supply - Crops Primary Equivalent - Food supply quantity (tonnes))

2. (FAO, 2007. Production - Crops - Yields)

3. Banana and pineapple yields from the Philippines, coconut yields from Tonga and date yields from Iran (FAO, 2007. Trade - TradeSTAT - Detail trade flows)

4. Fruit were calculated separately, the final amount was 470,942t. Fruit excluding wine total (FAO, 2007. Production - Crops - Yields) was 462,029t. The difference of 8,913t is assumed to be the grapes used for the majority of winemaking. 
Table 2: EF for vegetables consumed in NZ in 2007

\begin{tabular}{|lcccc|}
\hline \multirow{2}{*}{$\begin{array}{l}\text { Vegetables } \\
\text { Olives }\end{array}$} & $\begin{array}{c}\text { NZ consumption } \\
(2007)^{1}\end{array}$ & $\begin{array}{c}\text { Average per } \\
\text { capita }\end{array}$ & Yield $^{2}$ & $\begin{array}{c}\text { Individual } \\
\text { EF }\end{array}$ \\
\cline { 2 - 5 } & tonnes & $\mathrm{kg} / \mathrm{cap}$ & $\mathrm{kg} / \mathrm{ha}$ & NZha \\
\hline Cassava & 1,588 & 0.38 & 2,486 & 0.0002 \\
\hline Potatoes & 4,825 & 1.14 & $12,333^{3}$ & 0.0001 \\
\hline Sweet potatoes & $\mathbf{2 6 8 , 0 1 5}$ & 63.37 & 42,985 & 0.0015 \\
\hline Vegetables, other & 16,742 & 3.96 & 12,026 & 0.0003 \\
\hline Tomatoes & 437,049 & 103.36 & 25,696 & 0.0040 \\
\hline Totals & 114,910 & 27.18 & 129,870 & 0.0002 \\
\hline
\end{tabular}

1. (FAO, 2007. Food Supply - Crops Primary Equivalent - Food supply quantity (tonnes))

2. (FAO, 2007. Production - Crops - Yields)

3. Cassava yields for Samoa and olive yields for Spain (FAO, 2007. Trade - TradeSTAT - Detail trade flows)

Table 3: EF for grains consumed in NZ in 2007

\begin{tabular}{|lcccc|}
\hline \multirow{2}{*}{ Grains } & $\begin{array}{c}\text { NZ consumption } \\
(2007)^{1}\end{array}$ & $\begin{array}{c}\text { Average per } \\
\text { capita }\end{array}$ & Yield ${ }^{2}$ & $\begin{array}{c}\text { Individual } \\
\text { EF }\end{array}$ \\
\cline { 2 - 5 } & tonnes & $\mathrm{kg} /$ cap & $\mathrm{kg} / \mathrm{ha}$ & NZha \\
\hline Barley & 603 & 0.14 & 6,908 & 0.0000 \\
\hline Cereals, Other & 16,676 & 3.94 & 6,047 & 0.0007 \\
\hline Maize & 6,802 & 1.61 & 10,900 & 0.0001 \\
\hline Oats & 7,378 & 1.75 & 4,769 & 0.0004 \\
\hline Rice (Milled Equivalent) & 38,604 & 9.13 & $5,721^{3}$ & 0.0016 \\
\hline Rice (Paddy Equivalent) & 57,877 & 13.69 & $5,721^{3}$ & 0.0024 \\
\hline Rye & 500 & 0.12 & 571 & 0.0002 \\
\hline Wheat ${ }^{4}$ & 255,844 & 60.50 & 1,079 & 0.0561 \\
\hline Totals & $\mathbf{3 8 4 , 2 8 4}$ & $\mathbf{9 0 . 8 8}$ & $\mathbf{N} / \mathbf{A}$ & $\mathbf{0 . 0 6 1 5}$ \\
\hline
\end{tabular}

1. (FAO, 2007. Food Supply - Crops Primary Equivalent - Food supply quantity (tonnes))

2. (FAO, 2007. Production - Crops - Yields)

3. Rice yields (milled and paddy equivalent) for both Australia and Thailand, and rye and wheat yields for Australia (FAO, 2007. Trade - TradeSTAT - Detail trade flows.)

4. Cereals were calculated separately, the final amount was 442,161 tonnes. 'Cereals excluding beer total' (FAO, 2007. Production - Crops - Yields) was 384,283.75 tonnes. The difference of $57,877.25$ is assumed to be the wheat used for the beer making. Wheat used for beer making has been subtracted and added to the beverages table 4.7 
Table 4: EF for beverages consumed in NZ in 2007

\begin{tabular}{|lcccc|}
\hline \multirow{2}{*}{$\begin{array}{l}\text { Beverages } \\
\text { Beer }\end{array}$} & $\begin{array}{c}\text { NZ consumption } \\
(2007)\end{array}$ & $\begin{array}{c}\text { Average per } \\
\text { capita }\end{array}$ & Yield & $\begin{array}{c}\text { Individual } \\
\text { EF }\end{array}$ \\
\cline { 2 - 5 } & Tonnes $^{1}$ & $\mathrm{~kg} / \mathrm{cap}$ & $\mathrm{kg} / \mathrm{ha}^{2}$ & NZha \\
\hline - wheat for beer & 321,474 & 76.03 & $\mathrm{~N} / \mathrm{A}$ & $\mathrm{N} / \mathrm{A}$ \\
\hline Other alcoholic beverages & $57,877^{4}$ & $13.69^{4}$ & 1,079 & 0.0127 \\
\hline Wine & 14,748 & 3.49 & $\mathrm{~N} / \mathrm{A}$ & $\mathrm{N} / \mathrm{A}$ \\
\hline - grapes for wine & 35,169 & 8.32 & 8,200 & 0.0010 \\
\hline Coffee & $8,913^{4}$ & $2.11^{4}$ & 6,415 & 0.0003 \\
\hline Tea & 17,941 & 4.24 & $2,559^{3}$ & 0.0017 \\
\hline Total & 2,045 & 0.48 & 1,359 & 0.0004 \\
\hline
\end{tabular}

1. (FAO, 2007. Food Supply - Crops Primary Equivalent - Food supply quantity (tonnes))

2. (FAO, 2007. Production - Crops - Yields)

3. Green coffee yields for Vietnam and tea yield for Indonesia (FAO, 2007. Trade - TradeSTAT - Detail trade flows.)

4. Not included in the total consumption weight as they are consumed in the form of the associated beverage.

Table 5: EF for 'other foods' consumed in NZ in 2007

\begin{tabular}{|c|c|c|c|c|}
\hline Other foods & NZ consumption (2007) & $\begin{array}{c}\text { Average per } \\
\text { capita }\end{array}$ & Yield & $\begin{array}{c}\text { Individual } \\
\text { EF }\end{array}$ \\
\hline & tonnes $^{1}$ & $\mathrm{~kg} / \mathrm{cap}$ & $\mathrm{kg} / \mathrm{ha} \mathrm{a}^{2}$ & NZha \\
\hline Spices & 2,541 & 0.60 & 1,784 & 0.0003 \\
\hline Other stimulants & 921 & 0.22 & 420 & 0.0005 \\
\hline Sugar and sweeteners & 235,163 & 55.62 & 89,072 & 0.0006 \\
\hline Treenuts & 17,542 & 4.15 & 2,689 & 0.0015 \\
\hline $\begin{array}{l}\text { Vegetable oils and } \\
\text { oilcrops }\end{array}$ & 68,257 & 16.14 & 41,933 & 0.0004 \\
\hline Pulses, other & 12,547 & 2.97 & 2,017 & 0.0015 \\
\hline Honey & 4,821 & 1.14 & $?$ & $?$ \\
\hline Total & 341,792 & 80.83 & N/A & 0.0049 \\
\hline
\end{tabular}

1. (FAO, 2007. Food Supply - Crops Primary Equivalent - Food supply quantity (tonnes))

2. (FAO, 2007. Production - Crops - Yields)

3. Average yield from Australia and the USA (FAO, 2007. Trade - TradeSTAT - Detail trade flows.) 
Table 6: EF for meat and meat products consumed in NZ in 2007

\begin{tabular}{|lcccc|}
\hline \multirow{2}{*}{$\begin{array}{c}\text { Meat and meat } \\
\text { products }\end{array}$} & $\begin{array}{c}\text { NZ consumption } \\
(2007)^{1}\end{array}$ & $\begin{array}{c}\text { Average per } \\
\text { capita }\end{array}$ & Yield ${ }^{2}$ & $\begin{array}{c}\text { Individual } \\
\text { tonnes }\end{array}$ \\
\cline { 2 - 5 } & 134,742 & $\mathrm{~kg} / \mathrm{cap}$ & $\mathrm{kg} / \mathrm{ha}$ & NZha \\
\hline Bovine meat & 15,828 & 3.74 & 928.97 & 0.0969 \\
\hline Meat, other & 97,634 & 23.09 & 231.50 & 0.0997 \\
\hline $\begin{array}{l}\text { Mutton and goat } \\
\text { meat }\end{array}$ & 96,071 & 22.72 & $1,268.18$ & 0.0179 \\
\hline Pig meat & 58,443 & 13.82 & 589.85 & 0.0234 \\
\hline Animal fats & $\mathbf{4 2 4 , 6 2 9}$ & $\mathbf{1 0 0 . 4 3}$ & $\mathbf{N} / \mathbf{A}$ & $\mathbf{0 . 2 4 2 0}$ \\
\hline Total & & & & \\
\hline
\end{tabular}

1. (FAO, 2007. Food Supply - Livestock and Fish Primary Equivalent - Food supply quantity (tonnes))

Table 7: EF for poultry and eggs consumed in NZ in 2007

\begin{tabular}{|lcccc|}
\hline \multirow{2}{*}{$\begin{array}{c}\text { Poultry and } \\
\text { eggs }\end{array}$} & $\begin{array}{c}\text { NZ consumption } \\
(\mathbf{2 0 0 7})^{1}\end{array}$ & $\begin{array}{c}\text { Average per } \\
\text { capita }\end{array}$ & Yield ${ }^{2}$ & $\begin{array}{c}\text { Individual } \\
\text { EF }\end{array}$ \\
\cline { 2 - 5 } & tonnes & $\mathrm{kg} / \mathrm{cap}$ & $\mathrm{kg} / \mathrm{ha}$ & NZha \\
\hline Poultry meat & 145,499 & 34.41 & $1,406.28$ & 0.0247 \\
\hline Eggs & 39,169 & 9.26 & $1,599.19$ & 0.0058 \\
\hline Total & $\mathbf{1 8 4 , 6 6 8}$ & $\mathbf{4 3 . 6 7}$ & $\mathbf{N} / \mathbf{A}$ & $\mathbf{0 . 0 3 0 3}$ \\
\hline
\end{tabular}

1. (FAO, 2007. Food Supply - Livestock and Fish Primary Equivalent - Food supply quantity (tonnes))

Table 8: EF for dairy products consumed in NZ in 2007

\begin{tabular}{|lcccc|}
\hline \multirow{2}{*}{$\begin{array}{c}\text { Dairy products } \\
\end{array}$} & $\begin{array}{c}\text { New Zealand } \\
\text { consumption } \\
(2007)\end{array}$ & $\begin{array}{c}\text { Average per } \\
\text { capita }\end{array}$ & Yield & $\begin{array}{c}\text { Individual } \\
\text { EF }\end{array}$ \\
\cline { 2 - 5 } & tonnes $^{1}$ & $\mathrm{~kg} / \mathrm{cap}$ & $\mathrm{kg} / \mathrm{ha}^{2}$ & ha \\
\hline Butter, ghee & 39,123 & 9.25 & 468.13 & 0.0198 \\
\hline Cheese & $\mathbf{2 0 , 6 1 5}$ & 4.88 & $1,365.26$ & 0.0036 \\
\hline Cream & $\mathbf{7 2 9}$ & 0.17 & $1,593.65$ & 0.0001 \\
\hline $\begin{array}{l}\text { Milk - excluding } \\
\text { butter }\end{array}$ & 435,175 & 102.92 & $9,960.30$ & 0.0103 \\
\hline Total & $\mathbf{4 9 5 , 6 4 2}$ & $\mathbf{1 1 7 . 2 2}$ & $\mathbf{N} / \mathbf{A}$ & $\mathbf{0 . 0 3 3 8}$ \\
\hline
\end{tabular}

1. (FAO, 2007. Food Supply - Livestock and Fish Equivalent Primary - Food supply quantity (tonnes)) 


\section{Appendix 4: Summary of Tribe Questions}

\begin{tabular}{|c|c|c|c|c|c|c|}
\hline & Tarras & Cromwell & Kapiti & Waitakere & Waiheke & $\begin{array}{l}\text { Total } \\
\text { average }\end{array}$ \\
\hline Acting ethically is so much more important than financial gain & $68 \%$ & $62 \%$ & $57 \%$ & $59 \%$ & $69 \%$ & $62 \%$ \\
\hline Getting rich is one of my life goals & $4 \%$ & $10 \%$ & $9 \%$ & $9 \%$ & $10 \%$ & $9 \%$ \\
\hline I usually go off things I've liked when they become popular & $0 \%$ & $7 \%$ & $7 \%$ & $6 \%$ & $3 \%$ & $5 \%$ \\
\hline $\begin{array}{l}\text { I am more at home in my own culture than in the general kiwi } \\
\text { culture }\end{array}$ & $24 \%$ & $14 \%$ & $9 \%$ & $22 \%$ & $28 \%$ & $18 \%$ \\
\hline I am part of a tight knit ethnic community & $4 \%$ & $2 \%$ & $2 \%$ & $13 \%$ & $7 \%$ & $5 \%$ \\
\hline I can make things for a fraction of the cost of buying them & $40 \%$ & $29 \%$ & $22 \%$ & $31 \%$ & $38 \%$ & $30 \%$ \\
\hline I don't care about "getting ahead", I just need to be free & $24 \%$ & $19 \%$ & $17 \%$ & $25 \%$ & $38 \%$ & $23 \%$ \\
\hline I identify with my working class roots & $28 \%$ & $26 \%$ & $28 \%$ & $34 \%$ & $10 \%$ & $26 \%$ \\
\hline $\begin{array}{l}\text { I identify with the down to earth people you find in country } \\
\text { areas }\end{array}$ & $92 \%$ & $62 \%$ & $35 \%$ & $56 \%$ & $38 \%$ & $53 \%$ \\
\hline I seem to need to do things my own way, whatever the cost & $12 \%$ & $26 \%$ & $7 \%$ & $19 \%$ & $14 \%$ & $15 \%$ \\
\hline I strive to get the best house and car I can afford & $4 \%$ & $7 \%$ & $4 \%$ & $9 \%$ & $7 \%$ & $6 \%$ \\
\hline $\begin{array}{l}\text { I would die if I had to live in the provinces - the inner city is my } \\
\text { heartland }\end{array}$ & $0 \%$ & $0 \%$ & $2 \%$ & $0 \%$ & $3 \%$ & $1 \%$ \\
\hline $\begin{array}{l}\text { I did wrong it wouldn't just affect me, it would bring shame to } \\
\text { the whole family }\end{array}$ & $60 \%$ & $33 \%$ & $30 \%$ & $50 \%$ & $10 \%$ & $35 \%$ \\
\hline $\begin{array}{l}\text { It's important to take responsibility for the social and } \\
\text { environmental effects of your lifestyle choices }\end{array}$ & $84 \%$ & $79 \%$ & $70 \%$ & $72 \%$ & $72 \%$ & $75 \%$ \\
\hline $\begin{array}{l}\text { It's more useful to do practical things with your hands than it is } \\
\text { to be a brain box }\end{array}$ & $48 \%$ & $31 \%$ & $20 \%$ & $31 \%$ & $28 \%$ & $30 \%$ \\
\hline I've grown up as part of a wealthy privileged class & $12 \%$ & $0 \%$ & $4 \%$ & $6 \%$ & $24 \%$ & $8 \%$ \\
\hline Most people haven't heard the new music l'm into & $4 \%$ & $0 \%$ & $4 \%$ & $3 \%$ & $7 \%$ & $3 \%$ \\
\hline My appearance is pretty under-stated & $32 \%$ & $38 \%$ & $35 \%$ & $22 \%$ & $24 \%$ & $31 \%$ \\
\hline
\end{tabular}




\begin{tabular}{|c|c|c|c|c|c|c|}
\hline $\begin{array}{l}\text { My family has a tradition of using our wealth to help people of } \\
\text { lower class }\end{array}$ & $20 \%$ & $7 \%$ & $6 \%$ & $9 \%$ & $14 \%$ & $10 \%$ \\
\hline $\begin{array}{l}\text { My private school education has connected me with important } \\
\text { social networks }\end{array}$ & $8 \%$ & $2 \%$ & $0 \%$ & $0 \%$ & $7 \%$ & $3 \%$ \\
\hline My sense of taste and style is obscure & $8 \%$ & $7 \%$ & $7 \%$ & $6 \%$ & $14 \%$ & $8 \%$ \\
\hline Old money is class, new money is crass & $4 \%$ & $7 \%$ & $2 \%$ & $3 \%$ & $10 \%$ & $5 \%$ \\
\hline $\begin{array}{l}\text { People who shout about how good they are are heading for a } \\
\text { fall }\end{array}$ & $36 \%$ & $48 \%$ & $31 \%$ & $25 \%$ & $17 \%$ & $29 \%$ \\
\hline Possessions are pretty unimportant in the scheme of things & $48 \%$ & $55 \%$ & $59 \%$ & $63 \%$ & $62 \%$ & $58 \%$ \\
\hline Buying stuff is one of the great joys of life & $24 \%$ & $17 \%$ & $11 \%$ & $9 \%$ & $0 \%$ & $12 \%$ \\
\hline The church is the centre of our community social life & $8 \%$ & $2 \%$ & $2 \%$ & $16 \%$ & $3 \%$ & $5 \%$ \\
\hline The older I get, the less I fit into mainstream & $28 \%$ & $12 \%$ & $22 \%$ & $28 \%$ & $41 \%$ & $25 \%$ \\
\hline The things I own show what l've achieved so far & $12 \%$ & $17 \%$ & $15 \%$ & $39 \%$ & $3 \%$ & $12 \%$ \\
\hline $\begin{array}{l}\text { There's no point chopping and changing all the time, you } \\
\text { should make a plan and stick to it }\end{array}$ & $44 \%$ & $40 \%$ & $15 \%$ & $39 \%$ & $3 \%$ & $29 \%$ \\
\hline There's nothing better than a knotty intellectual issue to discuss & $28 \%$ & $21 \%$ & $17 \%$ & $16 \%$ & $17 \%$ & $19 \%$ \\
\hline $\begin{array}{l}\text { We must change the way we live our lives, so we can change } \\
\text { the world }\end{array}$ & $48 \%$ & $50 \%$ & $41 \%$ & $59 \%$ & $69 \%$ & $52 \%$ \\
\hline You don't want to aim too high in life, just keep it simple & $44 \%$ & $26 \%$ & $15 \%$ & $14 \%$ & $21 \%$ & $27 \%$ \\
\hline
\end{tabular}




\section{Appendix 5: Low Footprint Lifestyles from each community}

\section{Table 1: Low 'Satellite Urban Centre' Footprint}

Waitakere: 1.38 hectares per year. 45-54 years of age with 4 people in the house. New Zealand Pakeha with a trade certificate or diploma.

\section{Food}

- Occasionally eats beef, chicken and eggs, infrequently eats pork and never eats fish. Often consumes milk. Has vegetables and bread all the time but fruit and pulses only occasionally. Often eats rice and pasta.

- Some of the food is organic, but only about a quarter is fresh, about half is local and often consumes food that is not bought. Grow some of their own food.

- Eat out very rarely, takeaways once every few weeks and eating out at a restaurant almost never. Drinks a little each week.

\section{Travel}

- Never walks and drives 1-100pkm per week, 50\% of time on urban roads and often with someone else.

- Never takes public transport. 


\section{Consumer Goods}

- Infrequently buys electronics and appliances and buys a little new clothing. Buy some new furnishings, just to spruce things up. Very rarely buys reading material.

- Produces a lot of rubbish, more than 2 rubbish bags per week. They recycle most stuff but don't really consider waste when purchasing products.

- Have one pet that is a medium resource pet such as a cat or small dog.

\section{Holidays}

- Does not fly anywhere.

- Weekend holidays less than $100 \mathrm{pkm}$ away to visit friends and relatives, spend time with family and relax.

\section{Household}

- Income less than $\$ 40,000$ per year

- House between $151-200 \mathrm{~m}^{2}$ with more than $40 \mathrm{~m}^{2}$ additional impervious surface

- Spends on average between \$151-200 per month on electricity, but has no other forms of heating

- Consumes an average amount of water

\section{Values}

- Barrier to lower footprint lifestyle is responsibility.

- Act ethically, strive for the best house and car, if did wrong it would bring shame to the whole family, take responsibility for the environmental and social effects of your lifestyle and church important part of life. Acting ethically is most important.

- Papatoetoe and Otara tribal associations with a Balclutha and North Shore. 
Table 2: Low 'Remote Rural Area’ Footprint

Tarras: 1.46 hectares per year. Over 65 years of age with 2 people in the house. New Zealand Pakeha with a trade certificate or diploma.

Food

- Infrequently eats pork, fish, poultry, eggs and pulses. Often eats beef, dairy, vegetables, fruit and bread. Consumes rice and pasta occasionally.

- Most of the food they eat is organic. Almost all of it is fresh and unpackaged. About three quarters of it is local and food is very rarely bought from a store. They grow most of what they eat on their own property in summer with enough to store for winter.

- Eat at takeaways and restaurants very occasionally and drink a little each week.

Travel

- Never walk to get around. They do however catch the bus occasionally long distance.

- Drive 1-100km per week on the open road and almost always drives with someone else.

\section{Consumer Goods}

- Infrequently buy electronics and furnishings. They never buy new clothing or appliances. Occasionally buy reading material.

- Produces very little rubbish per week, less than one rubbish bag. Recycles most things and only rarely considers waste when purchasing products. They do not buy low footprint or 'eco' products

- They have seven small low resource pets such as birds, hens, guinea pigs. 


\section{Holidays}

- They do not fly and they never go on holiday.

\section{Household}

- Household income is $\$ 40,001-\$ 60,000$ per year.

- House between $101-150 \mathrm{~m}^{2}$ with more than $21-30 \mathrm{~m}^{2}$ of additional impervious surface

- Spends on average between $\$ 151-200$ per month on electricity but do not use gas or coal. They uses more than $12-15 \mathrm{~m}^{3}$ of wood per year.

\section{Values}

- There are very few barriers to lowering their footprint and none of them were in the list given.

- 'Act ethically', 'I am more at home in my own culture than in the general kiwi culture', 'I can make things for a fraction of the cost of buying them', 'I don't care about "getting ahead", I just need to be free', 'I identify with my working class roots', 'identify with the down to earth people found in country areas', 'if did wrong it would bring shame to the whole family', 'take responsibility for the environmental and social effects of your lifestyle', 'it is more useful to do practical things with your hands than to be a brain box', 'my appearance is under-stated', 'the things I own show what I've achieved so far', 'there's no point chopping and changing all the time, you should make a plan and stick to it' and 'you don't want to aim too high in life, just keep it simple'. But most importantly 'acting ethically is so much more important than financial gain'.

- Papatoetoe and Balclutha tribes. With very little of anything else. Definitely not Cuba Street. 


\section{Table 3: Low 'Independent Main Centre’ Footprint}

\section{Cromwell: 1.53 hectares per year. 45-54 years of age with 4 people in the house. New Zealand Pakeha with a tertiary qualification.}

\section{Food}

- Eats beef and lamb often, never pork, fish and poultry infrequently. Dairy all the time but eggs and pulses only occasionally. Have vegetables, fruit and bread all the time. Wheat often and rice infrequently.

- Some of the food is organic, and most of the food is fresh and unprocessed. About half of it is local, and a lot of the food they consume has not been bought. Most of the food they eat is from the garden and there is enough to save for winter.

- Eat takeaways and eat-out at restaurants on special occasions. They do not drink.

Travel

- Seldom walks to get around and never takes public transport.

- Drives 1-100pkm per week mostly in town and almost always with someone else.

\section{Consumer Goods}

- Infrequently buys electronics, clothing, furnishings and appliances. Often buys reading material.

- Produces less than one bag of rubbish per week, recycles everything and almost always considers waste when purchasing products. They don't have any pets.

\section{Holidays}

- Flies between 801-1,600pkm nationally per year and 1-9,000pkm internationally per year.

- Weekend holidays and long holidays each year. Travel 100-400pkm by car for some holidays and some flying. They go camping and visit friends and relatives. 


\section{Household}

- Household income is $\$ 120,000-140,000$ per year.

- House between $251-300 \mathrm{~m}^{2}$ with $31-40 \mathrm{~m}^{2}$ of additional impervious surface

- Spends on average between $\$ 201-250$ per month on electricity, uses under $\$ 100$ of coal per month and $8-11 m^{3}$ of wood per year.

\section{Values}

- Barrier to lower footprint lifestyle is responsibility and cost.

- 'I usually go off things I've liked when they become popular', 'I can make things for a fraction of buying them', 'identify with the down to earth people found in country areas', 'I seem to need to do things my own way, whatever the cost', 'take responsibility for the environmental and social effects of your lifestyle', 'my appearance is under-stated', 'old money is class, new money is crass', 'possessions are unimportant', 'the older I get the less I fit into mainstream' and 'we must change the way we live our individual lives, so we can change the world'. But most importantly 'I can make things for a fraction of buying them'.

- Very much Raglan and some Balclutha and Grey Lynn. 


\section{Table 4: Low ‘Main Urban Form’ Footprint}

\section{Kapiti: 1.59 hectares per year. 55-64 years of age with 2 people in the house. New Zealand Pakeha with no qualifications.}

\section{Food}

- Eats beef, lamb and poultry occasionally, pork and fish infrequently, dairy all the time and eggs often. Have vegetables all the time, and fruit and bread often. Pasta and rice infrequently.

- It was not noted the amount of food that is organic, but about half is unprocessed and unpackaged and about half is local. A reasonable amount of the food they consume has not been bought, particularly that they grow most of the food themselves.

- Eat takeaways and eat-out at restaurants occasionally and have a few drinks during the week.

\section{Travel}

- Almost always walk to get anywhere.

- Drives $1-100$ pkm per week $50 \%$ in town but primarily alone.

- Never takes public transport.

\section{Consumer Goods}

- Occasionally buys electronics, clothing and appliances and very few furnishings or reading material.

- Produces less than one bag of rubbish per week, recycles everything. Almost never buys 'eco' products but does consider waste when purchasing produces.

- They don't have any pets. 


\section{Holidays}

- They state that they never go on holiday, but they fly between $801-1,600 \mathrm{pkm}$ nationally per year and 9,000-15,000pkm internationally per year.

- Weekend holidays only for visiting friends and family.

\section{Household}

- Household income is less than $\$ 40,000$ per year.

- House between $151-200 \mathrm{~m}^{2}$ with more than $40 \mathrm{~m}^{2}$ of additional impervious surface.

- Spends on average between $\$ 101-\$ 150$ per month on electricity, under $\$ 25$ per month on gas and $4-7 \mathrm{~m}^{3}$ of wood per year. Use an average amount of water.

\section{Values}

- 'It is more useful to do practical things with your hands than to be a brain box'.

- Identified with Papatoetoe tribe, though it is difficult to gain insight into their lifestyle when they only suggest one statement. 


\section{References}

Aall, C., \& Norland, I. T. (2005). The Use of the Ecological Footprint in Local Politics and Administration: Results and Implications from Norway. Local Environment, 10(No. 2), 159172.

Abramovitz, J. N., \& Mattoon, A. T. (1999). Paper Cuts: Recovering the Paper Landscape. Worldwatch Paper \#149. Washington: WorldWatch.

Adalberth, K. (1997). Energy use during the life cycle of single-unit dwellings: Examples. Building and Environment, 32(4), 321-329.

Aeronautical Information Publication New Zealand. (2012). Charts. Retrieved 23 February 2012, from Civil Aviation Authority of New Zealand http://www.aip.net.nz/NavWalk.aspx?section=CHARTS

Alcorn, A. (2003). Embodied Energy and $\mathrm{CO}_{2}$ Coefficients for NZ Building Materials. Centre for Building Performance Research. Wellington, New Zealand: Victoria University of Wellington.

Andrew, R., \& Forgie, V. (2009). An Analysis of New Zealand's Ecological Footprint as Estimated by the Global Footprint Network (pp. 15). (unpublished). Palmerston North: New Zealand Centre for Ecological Economics.

Andrew, R., Forgie, V., Nielsen, P., Hodgson, C., Reid, T., \& McDonald, G. (2005). Ecological Footprint Plus: Calculating the total environmental impacts of New Zealand's food and fibre industries. New Zealand Centre for Ecological Economics. Palmerston North. Retrieved from http://nzcee.massey.ac.nz/research projects/ecologicalfootprints.html

Andrew, R., \& Patterson, M. G. (Producer). (2008). Household ecological footprint calculator for TV3 programme 'Wa\$̦ted'.

Angus \& Associates, The Knowledge Warehouse, \& Tourism Resource Consultants. (2010). Domestic Tourism Market Segmentation - Stage 2. Prepared for the Ministry of Tourism. Wellington: Ministry of Tourism.

Animal Welfare Advisory Committee. (1993). Code of Recommendations and Minimum Standards for the Welfare of Horses. Code of Animal Welfare No. 7. Wellington: Ministry of Agriculture and Forestry. 
Aporo, N., Chiron, M., Kagan, Z., McCool, C., O’Leary, N., Perano, D., \& Walton, S. (2007). An Ecological Footprint Analysis of the School of Business, University of Otago. Otago Management Graduate Review, 5 (2007), 1-16.

ARP Consultants. (2011). Economic impacts of Rotorua regional airport. Rotorua, NZ: Rotorua District Council.

ARPASS. (2008). Off Road Motorised Recreation in the Auckland Region - Issues and Potential Responses Paper. Auckland: Auckland Regional Physical Activity \& Sports Strategy.

Ashby, M., Coulter, P., Ball, N., \& Bream, C. (2012). The CES EduPack Eco Audit Tool -A White Paper. (Vol. Version 2.1). Cambridge, UK: Granta Design Ltd.

Assadourian, E. (2010). Transforming Cultures from Consumerism to Sustainability State of the World (pp. 20). Washington, DC: The Worldwatch Institute.

AsureQuality. (2012). AgriBase - Equine Property Registration. Retrieved 02 March, 2012, from AsureQuality http://www.asurequality.com/capturing-information-technology-acrossthe-supply-chain/agribase-database-for-nz-rural-properties.cfm

Auckland Airport. (2010). Facts \& Figures. Top 10 airports 2009/2010. Manukau: Auckland Airport.

Auckland Council. (2010). Auckland Council waste assessment overview. (Produced under the auspices of the ATA). Auckland: Auckland Council.

Auckland Council. (2012). Auckland Council. Home. Retrieved 13 January, 2013, from http://www.aucklandcouncil.govt.nz

Auckland Transport. (2010). Long Distance Rail Numbers Up. Retrieved 12 April, 2011, from http://www.aucklandtrains.co.nz/2010/10/02/long-distance-rail-numbers-up/

Baldwin, C., Becken, S., \& Allen, W. (2008). Hey! What's your Footprint? Land Environment and People Research Report (Vol. No. 5). Lincoln: Land, People and Environment, Lincoln University.

Bannister, P., Guan, L., Isaacs, N., \& Page, I. (1998). Testing commercial building energy standards. IPENZ Transactions, 25(1), 22-31.

Barlow, N. D. (1987). Pastures, pests and productivity: simple grazing models with two herbivours. New Zealand Journal of Ecology, 10, 43-55.

Barrett, J. (2001). Component Ecological Footprint: developing sustainable scenarios. Impact Assessment and Project Appraisal, 19(2), 107-118. 
Barrett, J., Birch, R., Baiocchi, G., Minx, J., \& Wiedmann, T. (2006). Environmental impacts of UK Consumption - Exploring links to Wealth, inequality and Lifestyle. Paper presented at the Factor 10 Engineering for Sustainable Cities, IABSE Henderson Colloquium, Cambridge. http://www.istructe.org/IABSE/Files/Henderson06/Paper 01.pdf

Barrett, J., Birch, R., Cherrett, N., \& Wiemann, T. (2005). Reducing Wales' Ecological Footprint. A resource accounting tool for sustainable consumption. York: Stolckhom Environment Institute and WWF Cymru.

Barrett, J., \& Simmons, C. (2003). An Ecological Footprint of the UK: Providing a Tool to Measure the Sustainability of Local Authorities. Stockhom: Stockholm Environment Institute.

Barrett, J., Vallack, H., Jones, A., \& Haq, G. (2002). The Eco Footprint of York: York lifestyles and their environmental impact. York: Stockholm Environment Institute.

Barry, M. (2008, 15-21 November). Natural Born Gardeners. Listener, 215.

Bascand, G. (2012). Planning for the future: Structural change in New Zealand's population, labour force, and productivity. Paper presented at Affording Our Future Conference. Wellington: Statistics New Zealand.

Becken, S. (2009). The Carbon Footprint of Domestic Tourism. Technical Report. Wellington, New Zealand: The Hikurangi Foundation \& LEAP.

Becken, S., Frampton, C., \& Simmons, D. (2001). Energy consumption patterns in the accommodation sector-the New Zealand case. Ecological Economics, 39 (2001), 371386.

Becken, S., \& Gnoth, J. (2004). Tourist consumption systems among overseas visitors: reporting on American, German, and Australian visitors to New Zealand. Tourism Management, 25(3), 375-385.

Becken, S., \& Patterson, M. (2006). Measuring National Carbon Dioxide Emissions from Tourism as a Key Step Towards Achieving Sustainable Tourism. [Article]. Journal of Sustainable Tourism, 14(4), 323-338.

Becken, S., \& Simmons, D. G. (2002). Understanding energy consumption patterns of tourist attractions and activities in New Zealand. Tourism Management, 23(4), 343-354.

Becker, J. (2012). Becoming Minimalist. Retrieved 29 May, 2012, from http://www.becomingminimalist.com/2012/05/08/becoming-minimalist-start-here/

Beef NZ. (2008). New Zealand's Agricultural Economy. Statistics. Retrieved 29 July, 2011, from http://www.beef.org.nz/statistics/sld001.asp 
Bell, A. (2006). Pasture Assessment and livestock production. Prime Facts - Profitable \& Sustainable Primary Industries. Retrieved from http://www.dpi.nsw.gov.au/agriculture/livestock/nutrition/feeds/pasture-assessmentlivestock-production/pasture-assessment-and-livestock-production.pdf

Beloe, S., Elkington, J., Fennell, S., Greenfield, O., Narberhaus, M., \& Salazar, C. (2007). One Planet Business - Creating Value Within Planetary Limits (First ed., pp. 60). Surry: WWF \& SustainAbility.

Berg, P. (2009). Radiata pine - Multi-purpose plantations. Settled landscapes - Trees and Gardens. Retrieved 14 September, 2011, from http://www.teara.govt.nz/en/radiata-pine/5

Best Foot Forward Ltd. (2002). City Limit: A resource flow and ecological footprint analysis of Greater London. London: IWM (EB) Chartered Institution of Wastes Management Environmental Body.

Beynon, M. J., \& Munday, M. (2008). Considering the effects of imprecision and uncertainty in ecological footprint estimation: An approach in a fuzzy environment. Ecological Economics, 2008(67), 373-383.

Bicknell, K. B., Ball, R. J., Cullen, R., \& Bigsby, H. R. (1998). New methodology for the ecological footprint with an application to the New Zealand economy. Ecological Economics, 27, 149160.

Biddle, J. (Producer). (2011, January). Average age of a NZ car now exceeds 13 years. Monitoring Blog. Retrieved from http://www.aa.co.nz/motoring/aa-torque/motoring-blog/faultssafety-reliability/average-age-of-a-nz-car-now-exceeds-13-years/

Biello, D. (2009). Is birth control the answer to environmental ills? Retrieved 10 October, 2012, from http://www.scientificamerican.com/blog/post.cfm?id=is-birth-control-the-answerto-envi-2009-09-23

Bin Inn. (2010). Bin Inn. About Us. Retrieved 27 September, 2011, from http://www.bininn.co.nz/

Biofuel.org.uk (Producer). (2010). Biofuel from waste. Biofuels - the fuel of the future. Retrieved from http://biofuel.org.uk/biofuel-from-waste.html

BioRegional, \& WWF. (2008). One Planet Living. Retrieved 26 August, 2010, from http://www.oneplanetliving.org/index.html

Bluebridge. (2009a). About Us. Bluebridge Cook Strait Shipping. Retrieved 29 August, 2011, from http://www.bluebridge.co.nz/aboutus/

Bluebridge. (2009b). Timetable. Retrieved 29 August, 2011, from http://www.bluebridge.co.nz/timetable/index.aspx 
Bluebridge. (2011). Our Ships. Our Services. Retrieved 17 November, 2011, from http://www.bluebridge.co.nz/our-services/our-ships/

Bluebridge representative (2011). [Bluebirdge passenger numbers.].

Boisvert, A., Leung, P., Mackrael, K., Park, C., \& Purcell, M. (2009). Planning Guide for Sustainability - A Starter Guide (New Zealand). In L. Roberts \& S. Henry (Eds.). Christchurch.

Börjeson, L., Höjer, M., Dreborg, K.-H., Ekvall, T., \& Finnveden, G. (2006). Scenario types and techniques: Towards a user's guide. Futures (London), 38(7), 723-739.

Bowden, J. (2010). Banger for you buck. New Zealand Listener. February.

Brown, K. W., \& Kasser, T. (2005). Are psychological and ecological well-being compatible? The role of values, mindfulness, and lifestyle. Social Indicators Research, 74, 349-368.

Brown, L. (2009). Personalising Consumption? The legitimacy of an individual carbon quota scheme in the UK. (Programme in Environmental Studies and Sustainability Science, Master of Science), University of Lund, Sweden, Online.

Brown, L., \& Plume, H. (2004). New Zealand's Greenhouse Gas Inventory 1990-2002. Wellington: Ministry for the Environment \& New Zealand Climate Change Office.

Brown, L. R. (2012). Full Planet, Empty Plates - The New Geopolitics of Food Security. New York: W.W. Norton \& Company.

Brundtland Commission. (1987). Our Common Future Report of the World Commission on Environment and Development. Online: United Nations Development and International Co-operation: Environment.

Calcott, A., \& Bull, J. (2007). Ecological footprint of British city residents. Surry: WWF-UK.

Caldwell, J., \& Brown, C. (2007). 8 Tribes - The Hidden Classes of New Zealand. (First ed.). Wellington: Wicked Little Books.

Caldwell, J., \& Brown, C. (2010). Find Your Tribe. 8 Tribes. Retrieved 9 December, 2012, from http://www.8tribes.co.nz/find.php

Calfee Design. (2012). Bamboo. Calfee Design. Retrieved 7 December, 2012, from http://www.calfeedesign.com/products/bamboo/

Cambeis, A. (2012). Hawea Flat Food Forest. Sustainable Practice - Inspiring Capability for Real Change. Retrieved 10 January, 2013, from http://www.sustainable-practice.org/node/56 
Canadian Centre for Policy Alternatives. (2008, June 24). Richest $10 \%$ create bigger ecological footprint. Projects \& Initiatives: Climate Justice Project, Growing Gap. Retrieved 10 August, 2011, from http://www.policyalternatives.ca/newsroom/news-releases/richest10-create-bigger-ecological-footprint

Caplan, B. (2012). Externalities. Retrieved 10 October, 2012, from http://www.econlib.org/library/Enc/Externalities.html

carbon footprint. (2011). UK tree planting. Carbon Offsetting. Retrieved 02 December 2011, from http://www.carbonfootprint.com/plantingtrees.html

Carbon Neutral. (2008). Comprehensive Calculator (GHG-EnergyCALC) Background Information. Retrieved from http://www.goeco.com.au/images/products/1221010917comp calc backg. info proposal format.pdf

CarboNZero. (2011). Mitigate your greenhouse gas emissions. CarboNZero. Retrieved 06 December, 2011, from http://www.carbonzero.co.nz/options/mitigate.asp

Catton, J. W. R. (1980). Overshoot: The Ecological Basis of Revolutionary Change. Urbana: University of Illinois Press.

Chambers, N., Child, R., Jenkin, N., Lewis, K., Vergoulas, G., \& Whiteley, M. (2005). Ecological Footprint Analysis and Sustainability Assessment. In N. Jenkin \& C. Stentiford (Eds.), Stepping Forward: A resource flow and ecological footprint analysis of the South West of England. Oxford: Best Foot Forward Ltd.

Chambers, N., Griffiths, P., Lewis, K., \& Jenkin, N. (2004). Scotland's Footprint: A Resource Flow and Ecological Footprint Analysis of Scotland. Oxford: Best Foot Forward.

Chambers, N., Simmons, C., \& Wackernagel, M. (2000). Sharing Nature's Interest: Ecological Footprints as an indicator of sustainability. London: Earthscan.

Chen, B., \& Chen, G. Q. (2006). Ecological footprint accounting based on emergy-A case study of the Chinese society. Ecological Modelling, 198, 101-114.

Clark, A. E., Frijters, P., \& Shields, M. A. (2008). Relative Income, Happiness and Utility: An Explanation for the Easterlin Paradox and Other Puzzles. Journal of Economic Literature, 46(1), 95-144.

Cobb, C., \& Douglas, P. (1928). A Theory of Production. The American Economic Review, 18(1), 139-165.

Cockerham, W. C. (2005). Health Lifestyle Theory and the Convergence of Agency and Structure. Journal of Health and Social Behaviour, 46 (March), 51-67. 
Cointreau, S. (2008). Landfill ER Revenues versus Landfill Costs. Washington: FEU/URB - World Bank.

Collins, A., Cowell, R., \& Flynn, A. (2007). Leaving a mark? The institutionalisation of Ecological Footprinting. School of City and Regional Planning, Cardiff University. Cardiff.

Collins, A., Cowell, R., \& Flynn, A. (2009). Evaluation and environmental governance: the institutionalisation of ecological footprinting. Environment and Planning A, 41, 1707 1725.

Collins, A., \& Fairchild, R. (2007). Sustainable Food Consumption at a Sub-national Level: An Ecological Footprint, Nutritional and Economic Analysis. Journal of Environmental Policy \& Planning, 9(1), 5-30.

Collins, A., \& Flynn, A. (2005). Cardiff's Ecological Footprint. Cardiff: Cardiff Council, BRASS Research Centre, Cardiff University, WWF Cymru.

Collins, A., \& Flynn, A. (2008). Engaging with the Ecological Footprint as a Decision-Making Tool: Process and Responses. Local Environment, 12(3), 295-312.

Collins, A., Flynn, A., \& Netherwood, A. (2005). Reducing Cardiff's Ecological Footprint: A resource accounting tool for sustainable consumption (pp. 183). Cardiff: WWF Cymru.

Collins, A., Flynn, A., Wiedmann, T., \& Barrett, J. (2006). The Environmental Impacts of Consumption at a Subnational Level - The Ecological Footprint of Cardiff. Journal of Indutrial Ecology, 10(3), 9-24.

Collins, S. (2012, 17 July). Knowledge bank for bright ideas., The New Zealand Hearld. Retrieved from http://www.nzherald.co.nz/nz/news/article.cfm?c id=1\&objectid=10731837

Community Matters. (2012). Visible Community - your quality standard. Becoming Sustainable. Retrieved 20 November, 2012, from http://www.communitymatters.org.uk/content/392/Becoming-sustainable

Cornforth, A. (2009). Behaviour Change: Insights for Environmental Policy Making from Social Psychology and Behavioural Economics. Policy Quarterly 5(4), 21.

Corvalan, C., Hales, S., \& McMichael, A. (2005). Ecosystems and Human Wellbeing - Health Synthesis. In J. Sarukhán \& A. Whyte (Eds.), Millennium Ecosystem Assessment. Geneva: World Health Organisation.

Cotton Incorporated. (2011). Monthly Economic Letter: U.S. and Global Market Fundamentals. Retrieved 20 February, 2012, from Cotton Incorporated, http://www.cottoninc.com/MarketInformation/MonthlyEconomicLetter/\#5 
COVEC. (2007). Recycling: Cost Benefit Analysis. Final Report Prepared for Ministry for the Environment. Wellington: Ministry for the Environment.

Crompton, T., \& Kasser, T. (2009). Meeting Environmental Challenges: The Role of Human Identity. Surrey: WWF-UK.

Crossette, B. (2011). UNFPA State of World Population 2011. In R. Kollodge (Ed.), People and possibilities in a world of 7 billion. New York: Information and External Relations Division of UNFPA, the United Nations Population Fund.

CSIRO. (1998). Canberra's Ecological Footprint. Resource Futures Program. Canberra, Australia: Commonwealth Scientific and Industrial Research Organisation.

Dairy NZ. (2011). New Zealand Dairy Statistics 2010-11. Hamilton: Statistics LIC.

Dalton, C. (n.d.). Cats and the countryside. Pests. Retrieved 02 March, 2012, from http://www.lifestyleblock.co.nz/pests/article/877-cats-and-the-countryside.html

Davis, G., Flowers, B. S., Golüke, U., Heinzen, B., Khong, C., Länge, K., . . W Wouters, A. (2011). Exploring Sustainable Development. Global Scenarios 2000 - 2050. Online: World Business Council for Sustainable Development.

Dawkins, E., Roelich, K., \& Owen, A. (2010). A Consumption Approach for Emissions Accounting the REAP Tool and REAP Data for 2006. Project Report. York: Stockholm Environment Institute.

DBH, Compliance Document for New Zealand Building Code, Clause B2 - Durability. (2011).

DEFRA. (2008). A framework for pro-environmental behaviours. London: Department of Environment, Food and Rural Affairs.

Department of Conservation. (2012). Nga Whenua Rahui Fund. Funding. Retrieved 18 October, 2012, from http://www.doc.govt.nz/getting-involved/volunteer-join-or-start-aproject/start-or-fund-a-project/funding/nga-whenua-rahui/nga-whenua-rahui-fund/

Department of Conservation. (n.d.). Threats to kiwi. Saving our kiwi. Retrieved 02 March, 2012, from http://www.doc.govt.nz/publications/conservation/native-animals/birds/savingour-kiwi/threats-to-kiwi/

Department of Labour. (2010). Employment and skills snapshot - govenrment administration and defence. Skillsinsight Tool (SIT). Retrieved 19 February, 2012, from http://www.dol.govt.nz/services/LMI/tools/skillsinsight/snapshots/government/index.a $\underline{\mathrm{sp}}$ 
Department of Trade and Industry. (2003). Foresight Futures 2020: Revised scenarios and guidance. London, UK: DTI.

Desai, P. (2009). One Planet Living: A Real Guide to Sustainable Living. Australia: John Wiley \& Sons

Desai, P., \& Riddlestone, S. (2002). BioRegional Solutions. For Living on One Planet. Cornwall, UK: Green Books.

DESAPD. (2009). World Population Prospects: The 2008 Revision, highlights. New York: United Nations Department of Economic and Social Affairs Population Division.

DIAL. (2008). Annual Report for the Year ended 30 June 2007. In G. W. Crombie (Ed.). Dunedin: Dunedin International Airport Limited.

Diamond, J. (2005). Collapse: How Societies Choose to Fail or Succeed. New York City: Viking Press.

Dimitri, C., \& Oberholtzer, L. (2009). Marketing U.S. Organic Foods: Recent Trends From Farms to Consumers. A Report from the Economic Research Service. Pennsylvania, USA: United States Department of Agriculture.

Doerr, J. (Writer). (2007). Salvation and profit in greentech. United Sates: TED Talks.

Dostine, V. (2011a). The Equestrian Economy. Projects. Retrieved 02 March, 2012, from http://www.nzhorseriders.info/projects/projects/theequestrianeconomy

Dostine, V. (2011b). Equestrian Statistics. Equine Statistical Data. Retrieved 02 March, 2012, from http://www.nzhorseriders.info/publications-and-resources/research-and-statistics

Dudding, A. (2010, 22 August). The supersized homes puzzle, Sunday Star Times. Retrieved from www.sstlive.co.nz

e-Stat. (2008). Portal Site of Official Statistics of Japan. Retrieved 01 July, 2012, from Official Statistics of Japan http://www.estat.go.jp/SG1/estat/ListE.do?bid $=000001025163 \&$ cycode $=0$

EECA. (2007). Energy End-Use Database. Retrieved 15 September, from Energy Efficiency and Conservation Authority (EECA) http://www.eeca.govt.nz/research-centre/energy-enduse-database

EECA. (2011). Buying a Vehicle. How to be Energy Efficient - Travelling and Vehicles. Retrieved 14 November, 2011, from http://www.energywise.govt.nz/how-to-be-energyefficient/travelling-and-vehicles/buying-a-vehicle 
Emigrate New Zealand. (2011). Housing. Emigration New Zealand: Relocation Guide. Retrieved 20 September, 2011, from http://www.migrationnews.com/new zealand/country profile

Engineering Toolbox. (2011). Units of biomass energy - converting values. Biomass Energy. Retrieved 29 July, 2011, from http://www.engineeringtoolbox.com/bio-mass-energyd 1183.html

Erisman, J. W., Sutton, M. A., Galloway, J., Klimont, Z., \& Winiwarter, W. (2008). How a century of ammonia synthesis changed the world. Nature Geoscience, 1(10), 636-639.

Europa. (2012). Getting there. Travelling in Europe 2012-13. Retrieved 19 July, 2012, from http://europa.eu/travel/gettingthere/index en.htm

Evergreen Forests Limited. (1996). Radiata Pine - Investment Overview. Auckland.

Ewing, B., Moore, D., Goldfinger, S., Oursler, A., Reed, A., \& Wackernagel, M. (2010). Ecological Footprint Atlas 2010. Oakland: Global Footprint Network.

Ewing, B., Reed, A., Galli, A., Kitzes, J., \& Wackernagel, M. (2010). Calculation Methodology for the National Footprint Accounts, 2010 Edition. (Vol. 1.1). Oakland: Global Footprint Network.

Ewing, B., Reed, A., Rizk, S. M., Galli, A., Wackernagel, M., \& Kitzes, J. (2008). Calculation Methodology for the National Footprint Accounts (2008 ed., Vol. Version 1.1, pp. 19). Oakland, CA: Global Footprint Network.

FAO. (2007). FAOSTAT. Retrieved 3 March, 2011, from http://faostat.fao.org/default.aspx

FAOSTAT. (2007). TradeSTAT. Trade. Retrieved 1 February, 2012, from http://faostat.fao.org/site/406/default.aspx

Far North Environment Centre. (2011). Sustainable Living Activation. Sustainable Living Retrieved 13 January, 2012, from http://www.ecocentre.co.nz/

Farner, B. (2012). Serving Sizes. Thrifty Living - News you can Use. Retrieved 24 October, 2012, 2012, from http://urbanext.illinois.edu/thriftyliving/tl-serving sizes.html

Ferguson, A. (2001). Comments on Eco-Footprinting. Ecological Economics, 37(1), 1-2.

Fiala, N. (2008). Measuring sustainability: Why the ecological footprint is bad economics and bad environmental science. Ecological Economics, 2008(67), 519-529.

Field, C. (2011). The Ecological Footprint of Wellingtonians in the 1950s. (Master of Building Science), Victoria University of Wellington, Wellington. 
Fisher, P., \& Bender, A. (1975). The Value of Food. Oxford: Oxford University Press.

Fitt, H., \& McLaren, S. ( 2010). An introduction to sustainable consumption. In B. Frame, R. Gordon \& C. Mortimer (Eds.), Hatched: The Capacity for Sustainable Development. Lincoln: Landcare Research.

FoodStuffs. (2005). Four Square. Retrieved 27 September, 2011, from http://www.foursquare.co.nz/

Fonterra. (2013) Fonterra's Precautionary Recall. Retrieved 18 August, 2013 http://productrecall.fonterra.com/

Forsyth Barr. (2011). Construction. Forsyth Barr Stadium. Retrieved 1 September, 2011, from http://www.forsythbarrstadium.co.nz/stadium/construction

Frame, B., Brignall-Theyer, M., Taylor, R., \& Delaney, K. (2007). 4 Future Scenarios for New Zealand: Work in Progress, Edition 2. (2 ed.). Lincoln: The Landcare Research Scenarios Working Group.

Freeling, N. (2012). August 22 is Earth Overshoot Day. Retrieved 1 September, 2011, from http://www.footprintnetwork.org/en/index.php/GFN/page/earth overshoot day/

Fricker, A. (1998). The Ecological Footprint of New Zealand as a step towards sustainability. Futures, 30(6), 559-567.

Gaballa, S., \& Abraham, A. B. (2007). Food Miles in Australia: A preliminary study of Melbourne, Victoria. East Brunswick, Victoria: CERES Community Environment Park.

Gatersleben, B., Meadows, J., Abrahamse, W., \& Jackson, T. (2008). Materialistic and environmental values of young people. Unpublished manuscript. University of Surrey. United Kingdom.

Ghosh, S., \& Vale, R. (2009). Typologies and Basic Descriptors of New Zealand Residential Urban Forms. Journal of Urban Design, 14(4), 507 - 536.

Ghosh, S., Vale, R., \& Vale, B. (2007). Metrics of Local Environmental Sustainability: A Case Study in Auckland, New Zealand. Local Environment 12(4), 355 - 378.

Giddens, A. (1991). Modernity and Self-Identity: Self and Society in the Late Modern Age. Cambridge: Polity Press.

Global Footprint Network. (2009). Ecological Footprint Standards 2009. In J. Kitzes (Ed.). Oakland, CA: Global Footprint Network. 
Global Footprint Network. (2010). Footprint Calculator (Calculator). Retrieved 9 July, 2011, from Global Footprint Network http://www.footprintnetwork.org/en/index.php/GFN/page/calculators/

Global Footprint Network. (2011). National Accounts - New Zealand 2007.

Global Footprint Network. (2012). Glossary. Footprint Science. Retrieved 7 November, 2012, from http://www.footprintnetwork.org/en/index.php/GFN/page/glossary/

Glubiak, O. (2009). Cowboys new stadium a reminder of how to waste energy. EE Life. Retrieved 18 February, 2012, from http://www.eetimes.com/electronics-blogs/green-supplylineblog/4030352/Cowboys-new-stadium-a-reminder-of-how-to-waste-energy

Goff, H. D. (2009). World-wide Milk Consumption and Production. Dairy Science and Technology. Retrieved 27 November, 2012, from http://www.uoguelph.ca/foodscience/dairyscience-and-technology/introduction-dairy-science-and-technology-milk-historyconsumption-pr-1

GoodPlanet.info. (2012). Biocapacity. Indicators. Retrieved 10 October, 2012, from http://www.goodplanet.info/eng/Zones/Etat-du-monde/Indicateur/Biocapacite

Google. (2012). Google Maps. Get Directions. Retrieved 1 February, 2012, from http://maps.google.co.nz/

Green Building Council of Australia. (2012). Green Star - Communities. Communities Home. Retrieved 20 November, 2012, from http://www.gbca.org.au/green-star/green-starcommunities/

Green Globe. (2012). Home Page. Green Globe Certification. Retrieved 20 November, 2012, from http://greenglobe.com/

Hall, G. M. J., \& Hollinger, D. Y. (1997). Do the indigenous forests affect the net $\mathrm{CO}_{2}$, emission policy of New Zealand? New Zealand Forestry, 14(4), 24-31.

Hamilton City Council. (2008). Taking On Climate Change: Hamilton's Local Action Plan. Communities for Climate Protection. Hamilton: Hamilton City Council.

Hamilton Int'l Airport. (no date). Facts and Figures. Retrieved 7 July, 2011, from http://www.hamiltonairport.co.nz/page/hamair 21.php

Hammond, G., \& Jones, C. (2011). Embodied Energy. Inventory of Carbon \& Energy (ICE)' V2.0. Retrieved 17 July, 2012, from http://www.greenspec.co.uk/embodied-energy.php 
Hammond, K. M., Wyllie, A., \& Casswell, S. (1999). The extent and nature of televised food advertising to New Zealand children and adolescents. Australian and New Zealand Journal of Public Health, 23(1), 49-55.

Hardin, G. (1968). The Tragedy of the Commons. Science \#13, 162(3859), 1243-1248.

HIA. (2007). Hamilton International Airport Annual Report 2007. In M. G. Taris (Ed.). Hamilton: Hamilton International Airport.

Hollinger, D. Y., Maclaren, J. P., Beets, P. N., \& Turland, J. (1993). Carbon Sequestration by New Zealand Plantation Forests. New Zealand Journal of Forestry Science, 23(2), 194-208.

Holmberg, J. (1998). Backcasting: A Natural Step in Operationalising Sustainable Development. GMI, 23(Autumn).

Holmberg, J., Lundqvist, U., Robèrt, K.-H., \& Wackernagel, M. (1999). The Ecological Footprint from a Systems Perspective of Sustainability. International Journal of Sustainable Development and World Ecology, 6(1), 17-33.

Holmberg, J., \& Robèrt, K.-H. (2000). Backcasting from non-overlapping sustainability principles - a framework for strategic planning. International Journal of Sustainable Development and World Ecology, 7(291-308).

Huang, N. (2010). A modified Ecological Footprint method for assessing sustainable transport in the Auckland Region. Doctor of Philosophy in Architecture and Planning. PhD. The University of Auckland. Auckland.

Hunter, C., Carmichael, K., \& Pangbourne, K. (2006). Household Ecological Footprinting Using a New Diary-Based Data-Gathering Approach. Local Environment, 11(3), 307-327.

I Bike Toronto. (2010). Embodied energy of our vehicles. Retrieved 14 July, 2011, from http://www.ibiketo.ca/blog/2009/07/13/embodied-energy-our-vehicles

IBIS World. (2011). Freight Rail Transport in China: Market Report. Freight Rail Transport in China Market Research Report. Santa Monica: IBIS World.

ICAC. (2010). ICAC Cotton World Statistics Bulletin. Washington: International Cotton Advisory Committee.

ICLEI. (2012). About ICLEI. ICLEI - Local Governments for Sustainabiltiy. Retrieved 22 February, 2012, from http://www.iclei.org/index.php?id=about

Immigration NZ. (2010). Housing. Life in New Zealand. Retrieved 21 September, 2011, from http://www.newzealandnow.govt.nz/housing 100.html 
IMO Library Services. (2006). International Shipping and World Trade: Facts and figures. London: International Marine Organisation.

Interislander. (2011). Our Ships \& Services. Kaitaki - Facts and Figures. Retrieved 21 July, 2011, from http://www.interislander.co.nz/Our-Ships-And-Services/Kaitaki/Facts-AndFigures.aspx

IPCC. (2000). Special Report: Land use, land-use change and forestry. Nairobi: UNEP \& WMO.

Isaacs, N., Camilleri, M., Burrough, L., Pollard, A., Saville-Smith, K., Fraser, R., . . Jowett, J. (2010). Energy Use in New Zealand Households - Final Report on the Household Energy End-use Project (HEEP). Judgeford, New Zealand: BRANZ Ltd.

Johnson, M., Fryer, K., \& Raggett, N. (2008). Household Sustainability Survey. Wellington: Research New Zealand.

Johnson, R. B., \& Onwuegbuzie, A. J. (2004). Mixed Methods Research: A Research Paradigm Whose Time Has Come. Educational Researcher, 33 (No. 7), 14-26.

Johnson, S. (2012). The Student Volunteer Army. Blog. Retrieved 7 December, 2012, from http://www.samjohnson.co.nz/about-the-student-volunteer-army/

Jolley, C. (2012). Manipulated Public Opinion Trumps Real Science - Again, Food Safety News. Retrieved from http://www.foodsafetynews.com/2012/01/cleverly-manipulated-publicopinion-trumps-real-science-again/

Jon C. (2011). Next Big Commuter Challenge. Auckland, Transport \& Urban Design - Issues and Trends. Retrieved 25 June, 2012, from http://www.aktnz.co.nz/2011/06/16/fat-peoplenow-a-problem-on-buses/

Jones, T., \& Dewing, C. (2011). futureagenda - The World in 2020. Oxford, UK: Infinite Ideas limited.

Kapiti Coast District Council. (2011). How the competition works. Greenest Streets. Retrieved 13 September, 2011, from http://www.kapiticoast.govt.nz/Our-District/greeneststreet/How-the-competition-works/

Kasser, T. (2005). Frugality, generosity, and materialism in children and adolescents. In K. A. Moore \& L. H. Lippman (Eds.), What do Children Need to Flourish?: Conceptualizing and Measuring Indicators of Positive Development (pp. 357-373). New York: Springer Science.

Kenworthy, J. R. (2008). Energy use and CO2 production in the urban passenger transport systems of 84 international cities: findings and policy implications. In P. Droege (Ed.), Urban Energy Transition - From fossil fuels to renewable power. Oxford: Elservier. 
Kirschbaum, M., Mason, N., Watt, M., Tait, A., Ausseil, A., Palmer, D., \& Carswell, F. (2011). Productivity surfaces for Pinus radiata and a range of indigenous forest species under current climatic conditions. MAF Technical Paper No. 2011/45 (pp. 129). Wellington: Landcare Research.

Kitzes, J., Peller, A., Goldfinger, S., \& Wackernagel, M. (2007). Current Methods for Calculating National Ecological Footprint Accounts. Science for Environment \& Sustainable Society, 4(1).

Kitzes, J., Wackernagel, M., Loh, J., Peller, A., Goldfinger, S., Cheng, D., \& Tea, K. (2008). Shrink and share: humanity's present and future Ecological Footprint. Philosophical Transactions of the Royal Society B, 363(467-475).

Kiwirail. (2009). Statement of Corporate Intent 2009-12. Wellington: KiwiRail.

Klinsky, S., Sieber, R., \& Mered, T. (2009). Creating local ecological footprints in a North American context. Local Environment, 14(6), 495-513.

Koordinates. (2010). NZ Railway Tracks. Land Information New Zealand. Retrieved 1 August, 2012, from http://koordinates.com/layer/34-nz-railway-tracks/

Kooten, G. C. V., \& Bulte, E. H. (2000). The ecological footprint: useful science or politics? Ecological Economics 2000(32), 385-389.

Koveshnikova, K. (2010, Tuesday November 02, 2010). Waitakere City Council bags award on first day of supercity., The National Business Review. Retrieved from http://www.nbr.co.nz/article/waitakere-city-council-bags-award-first-day-supercity$\underline{132497}$

Kreider, T. (2012). The 'Busy' Trap. The New York Times.

Krongkaew, M. (2003). The Philosophy of Sufficiency Economy. Kyoto Review of Souteast Asia. Retrieved 14 September, 2009, from http://kyotoreview.cseas.kyotou.ac.jp/issue/issue3/article 292.html

Kunstler, J. H. (2005). The Long Emergency: Surviving the Converging Catastrophes of the Twentyfirst Century. New York City: Grove/Atlantic.

Land Transport Safety Authority. (2004). RSS 22 - Road markings Traffic standards and guidelines 2003/2004 survey. Wellington: Land Transport Safety Authority.

LanzaTech. (2012). Home. LanzaTech. capturing carbon. fuelling growth. Retrieved 7 December, 2012, from http://www.lanzatech.com/ 
Larsen, C. S. (1995). Biological Changes in Human Populations with Agriculture. Annual Review of Anthropology., 24(October), 185-213.

Laurance, W. F., Cook, J., \& Verweij, P. (2012). Living Planet Report 2012. In M. Grooten (Ed.), (9th ed.). Oakland: WWF International, Global Footprint Network, European Space Agency \& Institute of Zoology.

Lawlor, E., Kersley, H., \& Steed, S. (2009). A Bit Rich: Calculating the real value to society of different professions. Valuing What Matters. London: New Economics Foundation.

Lawson, B. (1995). Embodied Energy of Building Materials in. Environment Design Guide, Pro 2, Royal Australian Insitute of Architects, NSW, pp. 1-6.

Lawton, E. (in press). Footprint and Income. In R. Vale \& B. Vale (Eds.), Living within a fair share footprint. London: Thames and Hudson.

Lawton, E., Huser, B., Lawton, M., O’Connell, M., Roos, J., \& Vale, R. (2012). Complementary dual approach to planning and policy development using the Ecological Footprint. Paper presented at the Asia-Pacific Science Policy Studies Research Conference, Wellington, New Zealand.

Lawton, E., Vale, R., \& Vale, B. (2010). Ecological Footprint of New Zealand Lifestyles. Paper presented at the Footprint Forum 2010: Meeting the Winners of the 21st Century, Colle di Val d'Elsa, Italy.

Lawyer, D. S. (2010). Train vs Airplane Energy Efficiency. Retrieved 24 June, 2012, from http://www.lafn.org/ dave/trans/energy/rail vs airEE.html

Lee, P., Willis, P., Hollins, O., \& WRAP. (2010). Waste arisings in the supply of food and drink to households in the UK - Final Report. Oxon: WRAP (Waste \& Resources Action Programme).

Lenzen, M., Borgström Hansson, C., \& Bond, S. (2007). On the bioproductivity and landdisturbance metrics of the Ecological Footprint. Ecological Economics, 61(6-10).

Lenzen, M., \& Murray, S. A. (2001). A modified ecological footprint method and its application to Australia. Ecological Economics, 37(2001), 229-255.

Lenzen, M., \& Murray, S. A. (2003). The Ecological Footprint - Issues and Trends. (Vol. 01-03). Online: The University of Sydney Integrated Sustainability Analysis.

Leontief, W. (1936). Quantitative input and output relations in the economic system of the United States. The Review of Economic Statistics, XVIII(3), 105-125. 
Librova, H. (2008). The Environmentally Friendly Lifestyle: Simple or Complicated? Sociologický časopis/Czech Sociological Review, 44 (6), 1111-1128.

Loh, J., Green, R. E., Ricketts, T., Lamoreux, J., Jenkins, M., Kapos, V., \& Randers, J. (2004). The Living Planet Index: using species population time series to track trends in biodiversity. Phil. Trans. R. Soc. B(360), 289-295.

Lukaszyk, J. (n.d.). Estimating Canberra's Ecological Footprint - The Built Environment. University of Canberra Research Project. University of Canberra. Canberra.

M\&W NZ. (2008). Wool 2008 Snapshot. In Meat and Wool New Zealand (Ed.), Internet. Wellington: Meat and Wool NZ.

M.J. Bradley \& Associates. (2007). Comparison of Energy Use \& CO2 Emissions From Different Transportation Modes. Washington, DC: American Bus Association.

Maclean, H., \& Lave, L. (1998). A Life-Cycle Model of an Automobile. Environmental Science and Technology, 32(13), 322A-330A.

Mander, S. (2011, 29 June, 2011). [Per capita waste estimates for the Central Otago region].

Manukau City Council. (2009). Towards 2060 - Think of the Possibilities. Retrieved 24 February, 2010, from http://www.towards2060.org.nz/

Maritime New Zealand. (2007). Boating Safety Strategy. 2007 Review of the New Zealand Pleasure Boat Safety Strategy. Wellington: Maritime New Zealand for the National Pleasure Boat Safety Forum.

Maritime Rules: Part 25 - Nautical Charts and Publications (2008).

Market Economics. (2006). Waikato Region Ecological Footprint 2004. Technical Report (pp. 45): Environment Waikato.

Maslow, A. H. (1943). A theiry of human motivation. Psychological Review, 50(4), 370-396.

Max-Neef, M. A. (1991). Human Scale Development - Conception, Application and Further Reflections. New York \& London: The Apex Press.

McCracken, H. (2008). Wellington Railway Station. The Register. Retrieved 27 August, 2011, from http://www.historic.org.nz/TheRegister/RegisterSearch/RegisterResults.aspx?RID=1452 \&m=advanced

McDonald, G. (2011, 14 September). [Email communication with Ella Lawton "The New Zealand Footprint Project"]. 
McDonald, G., Forgie, V., \& MacGregor, C. (2006). Treading lightly: Ecofootprints of New Zealand's aging population. Ecological Economics 56 424- 439.

McDonald, G., \& Patterson, M. (2001). Ecological Footprint of the Waikato Region. Auckland: McDermott Fairgray Group Ltd.

McDonald, G., \& Patterson, M. (2003). Ecological Footprints of New Zealand and its Regions 1997/98. Wellington, New Zealand: Ministry for the Environment.

McDonald, G., \& Patterson, M. (2004). Ecological Footprints and interdependencies of New Zealand regions. Ecological Economics, 50(1-2), 49-67.

McNeely, J. A. (1999). Mobilizing broader support for Asia's biodiversity: how civil society can contribute to protected area management. Manila, Philippines: Asian Development Bank.

McTavish, D. (2013). Hampden Community Energy. Hamraki Rag. Retrieved 13 January, 2013, from http://hamrakirag.blogspot.co.nz/

Meinhold, B. (2012). Apogee Stadium: US' First LEED Platinum Stadium Uses Wind Turbines to Power its Games. Green Design Will Save the World. Retrieved 19 February, 2012, from http://inhabitat.com

Kirschbaum , M., Trotter, C., Wakelin, S., Baisden, T., Curtin, D., Dymond, J.,. . . Ward, M. (2009). Carbon Stocks and Changes in New Zealand's Soils and Forests, and Implications of Post2012 Accounting Options for Land-Based Emissions Offsets and Mitigation Opportunities. Wellington: Ministry of Agriculture and Forestry, New Zealand Government. Retrieved from http://www.landcareresearch.co.nz/publications/researchpubs/LULUCF Report Apr 09 .pdf

Millennium Ecosystem Assessment. (2005). Current State and Trends Assessment, Volume 1. In R. Hassan, R. Scholes \& N. Ash (Eds.), Ecosystems and Human Well-Being. Washington: Millennium Ecosystem Assessment.

Milne, B. (2006). Researves Strategy 2006. For Hastings District Council. Hastings, New Zealand: Prophet Infrastructure Asset Management.

Ministry for the Environment. (1997). National Waste Data Report. National Environmental Indicators Programme. Wellington: Ministry for the Environment.

Ministry for the Environment. (2005). Gentle Footprints: Boots ' $n$ ' All. Wellington: newzealand.govt.nz. Retrieved from http://www.mfe.govt.nz/publications/ser/gentlefootprints-may06/5-kiwi-cars.pdf 
Ministry for the Environment. (2007a). New Zealand's Greenhouse Gas Inventory 1990-2005. Wellington: Ministry for the Environment.

Ministry for the Environment. (2007b). Report of the Ministry for the Environment for the year ended 30 June 2007. Wellington: New Zealand Government.

Ministry for the Environment. (2007c). Targets in the New Zealand Waste Strategy - 2006 Review of Progress. (pp. 84). Wellington, New Zealand: Ministry for the Environment.

Ministry for the Environment. (2008a). Chapter 2: Our Environment and People. Environment New Zealand 2007. Wellington: Ministry for the Environment. Retrieved from http://www.mfe.govt.nz/publications/ser/enz07-dec07/chapter-9.pdf

Ministry for the Environment. (2008b). Chapter 6: WasteEnvironment New Zealand 2007. Wellington, New Zealand: Ministry for the Environment. Retrieved from http://www.mfe.govt.nz/publications/ser/enz07-dec07/chapter-6.pdf

Ministry for the Environment. (2008c). Chapter 9: Land. Environment New Zealand 2007. Wellington, New Zealand: Ministry for the Environment. Retrieved from http://www.mfe.govt.nz/publications/ser/enz07-dec07/chapter-9.pdf

Ministry for the Environment. (2009a). Calculation and Payment of the Waste Disposal Levy Guidance for waste disposal facility operators. Wellington, New Zealand: Ministry for the Environment.

Ministry for the Environment. (2009b). Land cover class areas. Retrieved 22 August, 2011, from Ministry for the Environment http://www.mfe.govt.nz/issues/land/land-cover-dbase/

Ministry for the Environment. (2009c). Solid Waste Composition. Environmental Report Card. Wellington: Ministry for the Environment.

Ministry for the Environment. (2010a). Legally protected conservation land in New Zealand. Online: newzealand.govt.nz. Retrieved from http://www.mfe.govt.nz/environmentalreporting/report-cards/biodiversity/2010/

Ministry for the Environment. (2010b). Total distance travelled (total vehicle kilometers travelled). Environmental Reporting - Transport - VKT. Retrieved 22 June, 2012, from http://www.mfe.govt.nz/environmental-reporting/transport/vehicle-km-travelled/totalvkt/

Ministry for the Environment. (2011). Waste Disposal Levy Webpage. Retrieved 7 July, 2011, from http://www.mfe.govt.nz/issues/waste/progress-and-outcomes/waste-disposallevy.html 
Ministry for Tourism. (2008). New Zealand Aviation Overview: Flights, passengers and related statistics. Wellington, New Zealand: Ministry of Tourism.

Ministry of Agriculture and Forestry. (2012). Dairy. Agriculture. Retrieved 21 February, 2012, from http://www.maf.govt.nz/agriculture/pastoral/dairy

Ministry of Economic Development. (2010a). New Zealand Energy Data File. In Energy Information and Modelling Group (Ed.), 2009 Calender Year Edition (pp. 172). Wellington: Ministry for Economic Development.

Ministry of Economic Development. (2010b). New Zealand Energy Greenhouse Gas Emissions. In 2009 Calendar Year (Ed.). Wellington: Ministry of Economic Development.

Ministry of Primary Industries. (2012). New Zealand's Quota Management System (QMS). Quota Management System. Retrieved 18 October, 2012, from http://fs.fish.govt.nz/Page.aspx?pk=81

Ministry of Transport. (2007). Annual seat hours offered by air. Retrieved from: http://www.transport.govt.nz/ourwork/TMIF/TV037/

Ministry of Transport. (2008). New Zealand Household Travel Survey. (Vol. 2). Wellington, New Zealand: Ministry of Transport.

Ministry of Transport. (2009a). Cycling for Transport: Ongoing New Zealand Household Travel Survey 2006 - 2009. Household Travel Survey (Vol. 2.0). Wellington: Ministry of Transport.

Ministry of Transport. (2009b). How New Zealanders Travel - Trends in New Zealand household travel 1989 - 2008. (pp. 48). Wellington, New Zealand: Ministry of Transport.

Ministry of Transport. (2009c). New Zealand Transport Statistics. Transport Monitoring Indicator Framework. Wellington, New Zealand: Ministry of Transport.

Ministry of Transport. (2009d). Road VKT billions of $\mathrm{km}$ by vehicle type. Retrieved from: http://www.transport.govt.nz/ourwork/TMIF/TV002/

Ministry of Transport. (2010). Distance travelled by walking and cycling by residents of main and secondary urban areas. Transport volume : Walking and cycling. Retrieved 8 July, 2011, from http://www.transport.govt.nz/ourwork/TMIF/TV018/

Mithraratne, N., Vale, B., \& Vale, R. (2007). Sustainable living: the role of whole life costs and values.: Butterworth-Heinemann.

Molloy, L. (2009). Protected areas.Te Ara - the Encyclopedia of New Zealand. Wellington: newzealand.govt.nz. Retrieved from http://www.TeAra.govt.nz/en/protected-areas/1 
Monette, A., Colman, R., \& Wilson, J. (2001). Small Province, Big Feet: Nova Scotia's Ecological Footprint. Executive Summary. Glen Haven, NS: GPI Atlantic.

Monfreda, C., Wackernagel, M., \& Deumling, D. (2004). Establishing national natural capital accounts based on detailed ecological footprint and biological capacity accounts. Land Use Policy, 21(3), 231-246.

Mont, O., \& Power, K. (2010). The Role of Formal and Informal Forces in Shaping Consumption and Implications for a Sustainable Society. Part I. Sustainability, 2, 2232-2252.

Moran, D. D., Wackernagel, M., Kitzes, J. A., Goldfinger, S. H., \& Boutaud, A. (2007). Measuring sustainable development - Nation by Nation. Ecological Economics, 64(3), 470-474.

Morgan, T. K. K. B. (2004). A Tangata Whenua Perspective on Sustainability using the Mauri Model. Towards decision making balance with regard to our social, economic, environmental and cultural well-being. Paper presented at the International Conference on Sustainability Engineering and Science, 7 - 9 July 2004, Auckland, New Zealand.

Morrison, A. (1999). 'Space for Maori in tertiary institutions: Exploring two sites at the University of Auckland'. (Masters.), University of Auckland, Auckland. Retrieved from http://www.kaupapamaori.com/assets//MorrisonA/space for maori chpt4.pdf

Morrison Low. (2010). Tasman-Nelson Join Waste Assessment Report. Auckland: Tasman District \& Nelson City Council.

Mortimer, C., \& Abrahamse, W. (2010). We are what we buy - aren't we? The influence of identity on behaviour and consumption. In B. Frame, R. Gordon \& C. Mortimer (Eds.), Hatched: The Capacity for Sustainable Development. Lincoln: Landcare Research.

Mumma, T. (1995). Reducing the embodied energy of buildings. Home Energy Magazine Online, January/February.

Murray, J., \& Lenzen, M. (2010). Introduction to Input-Output Analysis. In J. Murray \& R. Wood (Eds.), The Sustainability Practitioner's Guide to Input-Output Analysis. Illinois: Common Ground Publishing LLC.

Nautical Know How. (2009). Chapter 3 - The Boat. Boating basics Online. Retrieved 25 June 2012, from http://www.boatingbasicsonline.com/content/general/3 7.php

Navran, F. J. (2010). Defining Values, Morals, and Ethics. Navran Associates., 14. Retrieved from http://www.navran.com/article-values-morals-ethics.html

Neuman, W. L. (1997). Social Research Methods - Qualitative and Quantitative Approaches (3rd ed.). Needham Heights: Allyn and Bacon. 
New Economics Foundation. (2004). Measuring social impact: the foundation of social return on investment (SROI). London: London Business School, New Economics Foundation, Small Business Service.

New Economics Foundation. (2012). Happy Planet Index. About. Retrieved 13 January, 2013, from http://www.happyplanetindex.org/about/

New York Yankees. (2010). Renewable Energy. Yankee Stadium Green Initiatives. Retrieved 19 February, 2012, from

http://newyork.yankees.mlb.com/nyy/ballpark/information/index.jsp?content=green i $\underline{\text { nitiatives }}$

New Zealand Dog Safety. (2011). How many dogs are there in New Zealand? FAQs. Retrieved 02 March, 2012, from http://www.dogsafety.govt.nz/dogsafety.nsf/wpg URL/FAQsIndex!OpenDocument

New Zealand Forest Industries Council. (2010). Position on FSC Prinicple 10. Developed for the FSC plantation review (pp. 9). New Zealand: NZ Forest Owners Association, NZ Forest Industries Council \& NZ Farm Forestry Association.

New Zealand Government. (2008). The New Zealand Transport Strategy 2008. www.sustainability.govt.nz. Wellington: NZ Government.

New Zealand Petfood Manufacturers Association. (2011). Home. Retrieved 17 July, 2012, from http://www.petfoodnz.co.nz/

New Zealand Trade \& Enterprise. (2012). Food and Beverage. Growth Industries. Retrieved 21 February, 2012, from http://www.nzte.govt.nz/access-international-networks/exploreopportunities-in-growth-industries/growth-industries/pages/food-andbeverage.aspx\#categories

New Zealand Transport Authority. (2009). New Zealand motor vehicle registration statistics 2009. Wellington, New Zealand: NZ Transport Agency.

New Zealand Transport Authority. (2011). Frequently Asked Questions. Retrieved 7 July, 2011, from http://www.nzta.govt.nz/network/operating/faqs.html

NPD Group. (2009). A Look into the Future of Eating. National Eating Trends. New York, USA: The NDP Group.

NZCEE. (2007). Eco-calculator (Calculator). Retrieved 9 July, 2011, from New Zealand Centre for Ecological Economics \& TV3 Wa\$ted. http://www.wastedtv.co.nz/index.cfm?\&action=calculator

On Track. (2009). Annual Report 2008. Wellington: New Zealand Railways Corporation. 
One Planet Economy Network. (2010). EuREAPa. Retrieved 9 July, 2011, from EuREAPa http://www.oneplaneteconomynetwork.org/index.html

Oswald, J. (2011). Evaluation of the Energy Use of Packaging in the Food Industry. (MPhil in Engineering for Sustainable Development), University of Cambridge, Cambridge. Retrieved from http://www-esdmphil.eng.cam.ac.uk/dissertations/2010-11/Oswald

Otago Polytechnic. (2012). Otago Polytechnic. Home. Retrieved 13 January, 2013, from http://www.otagopolytechnic.ac.nz/

Outhwaite, A. (2009). Backcasting. Tools. Retrieved 17 October, 2012, from http://wearearising.org/2009/01/13/backcasting/

Oxford University Press. (Ed.) (2010) Oxford English Dictionary - online. Oxford: Oxford University Press.

Page, I. (2008). Building materials in new houses. BUILD, 2008.

Page, I. (2009). Timber in new buildings. BUILD, April/May.

Paper Round. (2010). How much wood is required to make a tonne of paper? FAQs. Retrieved 25 July, 2011, from http://www.paperround.com.au/faq.html

Parliamentary Commissioner for the Environment. (2004). Growing for Good: Intensive farming, sustainability and New Zealand's environment. Wellington: Parliamentary Commissioner for the Environment.

Parnell, W., Blakey, C., Gray, B., Fleming, L., \& Walker, H. (2010). 2008/09 New Zealand Adult Nutrition Survey. Retrieved from http://nutrition.otago.ac.nz/linzunit

Paterson, J. (2005). What is a "lifestyle block" and is it a form of "rural gentrification"? Paper presented at the Focus on Rural Research, Hamilton. www.waikato.ac.nz/wfass/subjects/geography/research/.../trtwebpage1.doc

Paul, A. (2006). Beyond a Calculator: Exploring the Feasibility of an Ecological Footprint Tool for Communities. Heslington, York: Stockholm Environment Institute.

Paul, A., Wiedmann, T., Barrett, J., Minx, J., Scott, K., Dawkins, E., . . . Gray, I. (2010). The Resources and Energy Analysis Programme (REAP). In J. Murray \& R. Wood (Eds.), The Sustainability Practitioner's Guide to Input-Output Analysis. Illinois: Common Ground Publishing LLC.

PBSAG. (1999). Pleasure Boat Safety Advisory Group - Final Report. Wellington: Maritime Safety Authority of New Zealand. 
PCNZ. (2009). Five years on: recycling up by 26\%. Towards Sustainable Packaging. Retrieved 25 July, 2011, from http://www.packaging.org.nz/packaging info/packaging consum.php

Pearce, D. G., Reid, L., \& Schott, C. (2009). Travel Arrangements and the Distribution Behaviour of New Zealand Outbound Travelers. Journal of Travel \& Tourism Marketing, 26(1), 80-97.

Pimentel, D., \& Wilson, A. (2004). World Population, Agriculture, and Malnutrition. Population and its discontents, 1.

Plant and Food Research. (2008). Fresh Facts. In Plant and Food Research (Ed.). Auckland: Plant and Food Research.

Plumptre, T., \& Graham, J. (1999). Governance and Good Governance: International and Aboriginal Perspectives. Publications. Ontario, Canada: Institute On Governance.

PNIA. (2007). Palmeston North Airport Limited Annual Report 2007. Annual Report for the Year Ended 30 June 2007: Palmeston north International Airport.

Population Division of the Department of Economic and Social Affairs of the United Nations Secretariat. (2010). World Urbanization Prospects: The 2007 Revision Population Database from United Nations Population Division http://esa.un.org/unup/

Power, K., \& Mont, O. (2010). The Role of Formal and Informal Forces in Shaping Consumption and Implications for a Sustainable Society. Part II. Sustainability, 2, 2573-2592.

PTUA. (2009). Myth: Public transport doesn't really save money. Common Urban Myths about Transport. Retrieved 15 July, 2011, from http://www.ptua.org.au/myths/energy.shtml

QACL. (2007). 2007 Annual Report. In P. Gulliver (Ed.). Queenstown: Queenstown Airport Corporation Limited.

Queensland Government. (2005). Solid Waste Overview - R1, Eco-efficiency resources for the food processing industry. Eco-Efficiency for Queensland Manufacturers. Retrieved 16 September, 2011, from

http://www.ecoefficiency.com.au/Portals/56/factsheets/foodprocess/waste/ecofoodw aste fsr1.pdf

QV New Zealand. (2011). Average house size by area. Knowledge Centre. Retrieved 1 July, 2011, from http://www.qv.co.nz/propertyinformation/KnowledgeCentre/Averagehousesizebyarea1 2042011.htm

RANZ. (2008). Food Service Facts. Restaurant / Foodservice Industry Annual Sales Statistics and Analysis. Auckland: Restaurant Association of New Zealand. 
Ravensdown. (2011). Ravensdown fertiliser products. Products. Retrieved 22 September, 2011, from

http://www.ravensdown.co.nz/nz/products/pages/fertiliser/default.aspx?k=IsDocumen t\%3A1\&start1=1

Ravetz, J. (2007a). One Planet Wales Pathways towards a sustainable future. (Centre for Urban \& Regional Ecology School of Environment \& Development, Trans.). Oxford: Manchester University.

Ravetz, J. (2007b). One Planet Wales Report summary. Transforming Wales for a prosperous future within our fair share of the Earth's resources. Cardiff: WWF-Cymru.

Real Journeys. (2011a). Stewart Island Experience. About Us. Retrieved 21 July, 2011, from http://www.stewartislandexperience.co.nz/newzealand/aboutus/

Real Journeys. (2011b). Stewart Island Ferry Services. Ferry Services between Bluff \& Stewart Island. Retrieved 21 July, 2011, from http://www.stewartislandexperience.co.nz/newzealand/ferryservices/

Reddy, B. V. V., \& Jagadish, K. S. (2002). Embodied energy of common and alternative building materials and technologies/. Energy and Buildings, 35(2), 129-137.

Redefining Progress. (2006). Ecological Footprint Calculator. Centre for Sustainable Economy. Retrieved 10 December, 2009, from http://www.myfootprint.org/en/

Rees, W. (1992). Ecological footprints and appropriated carrying capacity: what urban economics leaves out. Environment and Urbanization, 4(2), 121-130.

Rees, W., \& Wackernagel, M. (1996). Urban Ecological Footprints: Why Cities cannot be Sustainable and why they are the key to Sustainability. Environmental Impact Assessment Review, 16, 223-248.

REN21. (2011). Renewables 2011 Global Status Report. Retrieved 19 July, 2012, from http://www.ren21.net/Portals/97/documents/GSR/GSR2011 Master18.pdf

Richard Paling Consulting. (2008). National Freight Demands Study. Wellington, New Zealand: Commissioned by Ministry of Transport, NZ Transport Agency and Ministry of Economic Development.

Richardson, J. (2012). Envision Resilient Wellington: Ecological Footprinting for Resilient Regional Design and Sustainability Education. Victoria University of Wellington. Wellington.

Richins, M. L., \& Dawson, S. (1992). A consumer values orientation for materialism and its measurement: Scale development and validation. Journal of Consumer Research, 19, 303316. 
RITA. (2007). The Nation's Freight. Freight in America. Washington: Research and Innovative Technology Administration (RITA), U.S. Department of Transportation.

Robèrt, K.-H. (2009). Real change through backcasting from sustainability principles: presentation of an international research programme built on a unifying Framework for Strategic Sustainable Development (FSSD). Progress in Industrial Ecology - An International Journal, 6(3), 207-215.

Robèrt, K.-H., Schmidt-Bleek, B., Larderel, J. A. d., Basile, G., Jansen, J. L., Kuehr, R., . . . Wackernagel, M. (2002). Strategic sustainable development - selection, design and synergies of applied tools. Journal of Cleaner Production 10(3), 197-214.

Robin, V., \& Dominguez, J. (1992). Your Money or Your Life. New York: Viking Penguin.

RPBC. (2003). Radiata Pine Wood Density. In Radiata Pine Breeding Company Ltd. (Ed.), Internet. Rotorua, New Zealand.

Russell, D., Parnell, W., \& Wilson, N. (1999). NZ Food: NZ People. Key results of the 1997 National Nutrition Survey. Dunedin: LINZ Activity \& Health Research Unit, University of Otago for the Ministry of Health.

Ryan, B. (2004). Ecological footprint analysis: An Irish rural study. Irish Geography, 37(2), 223 235.

Ryan, R. (2011). [Off-road vehicle types and sizes].

Sanne, C. (2002). Willing consumers-or locked-in? Policies for a sustainable consumption. Ecological Economics, 42(2002), 273-287.

SANZ. (2009). Strong Sustainability for New Zealand: Principles and Scenarios. One, 52. Retrieved from http://www.nz.phase2.org/strong-sustainability-for-new-zealand

Sarmiento, J. L., \& Gruber, N. (2002). Sinks for Anthropogenic Carbon. Physics Today, August 2002, 30-36.

Saunders, C., Barber, A., \& Taylor, G. (2006). Food Miles - Comparative Energy/Emissions Performance of New Zealand's Agriculture Industry. (Agribusiness and Economics Research Unit, Trans.) Research Report No. 285. Christchurch, New Zealand: Lincoln University.

Saville-Smith, K., Babylon, M., Bishop, R., Camilleri, M., Donn, M., Jowett, J., . . Roberti, H. (2010). Building Energy End-Use Study (BEES) Year 3. In N. Isaacs (Ed.), BRANZ Study Report SR 236. Porirua City: BRANZ Ltd. 
Scientific American (Producer). (2009). Is Algae the Biofuel of the Future? Greenwire: Energy and Sustainability. Retrieved from http://www.scientificamerican.com/article.cfm?id=algaebiofuel-of-future

Simmons, C., \& Chambers, N. (1998). Footprinting UK households: How big is your ecological garden? Local Environment, 3(3), $355-362$.

Simmons, C., Lewis, K., \& Barrett, J. (2000). Two feet - two approaches: a component-based model of ecological footprinting. Ecological Economics 32, 375-380.

SKF. (2010). Increasing the energy efficiency of new commercial aircraft. Göteborg, Sweden: SKF.

Smith, M. (2003). Track Gauge \& Loading Gauge. Goods \& Not So Goods - An overview of railway freight operations for modellers.

Smith, S. (2012). [Information regarding Environment House (MfE Administration)].

Sodeman, B. (2008). Customer lock-in. Retrieved 1 January, 2013, from http://billso.com/2008/02/22/customer-lock-in/

SolarSailor. (2012). Home. Retrieved 7 December, 2012, from http://solarsailor.com/

Soulé, M. E., \& Sanjayan, M. A. (1998). Conservation Targets: Do They Help? Science, 279(5359), 2060-2061.

Spaargaren, G., \& Vliet, B. V. (2000). Lifestyles, consumption and the environment: The ecological modernization of domestic consumption. Environmental Politics, 9(1), 50-76.

Spearing, E. (2012). An EF template for Major New Zealand Events. Otago Polytechnic. Wanaka.

State Services Commission. (2009). Establishment Numbers for Public Service Departments and Selected Crown Entities as at 30 June 2009 and 31 December 2008. Publicatins and Resources. Wellington: State Services Commission.

State Services Commission. (2011). A guide to New Zealand's Central government agencies. In newzealand.govt.nz (Ed.), online. Wellington: New Zealand Government.

Statisitcs New Zealand. (n.d.). Livestock Unit (LSU). Glossary Term. Retrieved 02 March, 2012, from http://www2.stats.govt.nz/domino/external/omni/OMNI.NSF/23f076d733ded7e74c256 570001d92b4/d6bb954075272ab0cc2569030012ad2c?OpenDocument

Statistics Bureau. (2010). Population Census of Japan. Tokyo: Government of Japan Retrieved from http://www.e-stat.go.jp/SG1/estat/ListE.do?bid=000001029548\&cycode=0. 
Statistics New Zealand. (1957). Population Census 1956: Vol IX Dwellings \& Households. Wellington: Statistics New Zealand.

Statistics New Zealand. (2002). Hectares of Land Certified as Organic by Farm Type. Retrieved from: http://www.stats.govt.nz/browse for stats/industry sectors/agriculturehorticulture-forestry/2002-agricultural-census-tables.aspx

Statistics New Zealand. (2003). Fertiliser Applied by Farm Type (ANZSIC) during the year ended 30 June 2002. Retrieved 14 February, from Statistics New Zealand http://www2.stats.govt.nz/domino/external/web/prod serv.nsf/929f646420956813cc2 56b16006b9ec1/876ff09528f44b37cc256dcd0080b49b?OpenDocument

Statistics New Zealand. (2004). New Zealand: Urban/Rural Profile. Wellington: Statistics New Zealand.

Statistics New Zealand. (2006a). Fertiliser Use and the Environment. Wellington: Statistics new Zealand.

Statistics New Zealand. (2006b). Heating fuels - QuickStats About Housing. 2006 Census Data Retrieved 23 March, 2010, from http://www.stats.govt.nz/Census/2006CensusHomePage/QuickStats/quickstats-abouta-subject/housing/heating-fuels.aspx

Statistics New Zealand. (2006c). Quick Stats About a Place. Retrieved 18 December 2012, from Statistics New Zealand http://www.stats.govt.nz/Census/2006CensusHomePage/QuickStats/AboutAPlace.aspx

Statistics New Zealand. (2006d). Types of Dwellings - QuickStats About Housing. 2006 Census Data. Retrieved 01 July, 2011, from http://www.stats.govt.nz/Census/2006CensusHomePage/QuickStats/quickstats-abouta-subject/housing/types-of-dwelling.aspx

Statistics New Zealand. (2007a). Building Consents Issued August 2007. Hot Off the Press. Wellington: Statistics New Zealand.

Statistics New Zealand. (2007b). Exports and Imports tables. Retrieved 21 February, 2012, from New Zealand Govnerment http://www.stats.govt.nz/tools and_services/tools/tablebuilder/exports-and-importstables.aspx

Statistics New Zealand. (2007c). Household Economic Survey: Year ended 30 June 2007. Retrieved from: http://www.stats.govt.nz/browse for stats/people and communities/Households/Ho useholdEconomicSurvey HOTPYeJun07.aspx 
Statistics New Zealand. (2007d). Tourism Satellite Account. Wellington: newzealand.govt.nz Retrieved from http://www.stats.govt.nz/browse for stats/industry sectors/Tourism/tourismsatellite-account-2007.aspx

Statistics New Zealand. (2008a). Energy and the Economy: 1997-2006. Wellington: Environmental Accounts, Statistics New Zealand.

Statistics New Zealand. (2008b). Global New Zealand - International Trade, Investment and Travel profile: June 2008. Import and Exports. Wellington: Statistics New Zealand.

Statistics New Zealand. (2008c). Topic 8: Waste -Measuring New Zealand's Progress Using a Sustainable Development Approach: 2008. Wellington: Statistics New Zealand. Retrieved from

http://www.stats.govt.nz/browse for stats/environment/sustainable development/su stainable-development/waste.aspx.

Statistics New Zealand. (2008d). Wool Export Data from July 2007 to June 2008. Retrieved from: http://www.beeflambnz.com/main.cfm

Statistics New Zealand. (2009a). National Accounts: Year ended march 2009. Retrieved from: http://www.stats.govt.nz/browse for stats/economic indicators/NationalAccounts/inf o-releases.aspx

Statistics New Zealand. (2009b). National family and household projections. Projections Overview. Retrieved 22 December 2011, from http://www.stats.govt.nz/browse for stats/population/estimates and projections/pro jections-overview/nat-family-hhold-proj.aspx

Statistics New Zealand. (2010a). International overseas travel and region T3.

Statistics New Zealand. (2010b). International travel from New Zealand regions: 2009. (International Travel and Migration, Trans.) (pp. 10). Wellington: Statistics New Zealand.

Statistics New Zealand. (2010c). Volume of Wool Production.

Statistics New Zealand. (2011a). Building Consents Issued - March 2011. Retrieved from: http://www.stats.govt.nz/browse for stats/industry sectors/Construction/BuildingCon sentslssued HOTPMar11.aspx

Statistics New Zealand. (2011b). Global New Zealand - International trade, investment, and travel profile. Year ended December 2010. Wellington: Statistics New Zealand \& Ministry of Foreign Affairs and Trade. 
Statistics New Zealand. (2011c). New Zealand Income Survey: June 2011 quarter. Income and Work. Wellington: New Zealand Government.

Statistics New Zealand. (2011d). Selected NZGSS measures by level of education. Retrieved from: http://www.stats.govt.nz/browse for stats/people and communities/Households/nzg ss HOTP2010/Definitions.aspx

Statistics New Zealand. (2011e). Time Use Survey: 2009/10. Retrieved 25 January, 2012, from newzealand.govt.nz http://www.stats.govt.nz/browse for stats/people and communities/time use.aspx

Statistics New Zealand. (2011f). Total estimated resident population 1991-2010. Retrieved from: http://www.stats.govt.nz/browse for stats/population/estimates and projections/nat ional-pop-estimates.aspx

Stockholm Enviroment Institute. (2008). REAP - Environment Accounting for People and Places, from http://www.resource-accounting.org.uk/

Stockholm Environment Institute. (2011). Footprint Calculator (Calculator). Retrieved 9 July, 2011, from WWF http://footprint.wwf.org.uk/.

Stodolsky, F., Vyas, A., Cuenca, R., \& Gaines, L. (1995, 16-19 October). Life-Cycle Energy Savings Potential from Aluminum-Intensive Vehicles. Paper presented at the Total Life Cycle Conference \& Exposition, Vienna, Austria.

Strudwick, S. (2012). Murray Darling Basin. Discover Murray River ${ }^{T M}$ - Official Murray River Travel Website. Retrieved 23 July, 2012, from http://www.murrayriver.com.au/about-themurray/murray-darling-basin/

Sullivan, C., \& O'Fallon, C. (2003). Vehicle occupancy in New Zealand's three largest urban areas. Paper presented at the Australasian Transport Research Forum Wellington. http://www.pinnacleresearch.co.nz/survey/occupancy.html

Sullivan, C., \& O'Fallon, C. (2010). Kilometres travelled and vehicle occupancy in urban areas: improving evaluation and monitoring. Research Report. Wellington: New Zealand Trasnport Authority.

Suncorp Stadium. (2010). The Stadium. Suncorp Stadium - Queensland's Premier Sports \& Outdoor Concert Venue. Retrieved 1 September, 2011, from http://www.suncorpstadium.com.au/The Stadium.aspx

Sustainability Report. (2002). Human Pressure on Earth's Carrying Capacity Increases. The Sustainability Report. Retrieved 18 August, 2010, from http://www.sustreport.org/news/footprint2002.htm 
Sustainable Living Education Trust. (2012). Sustainable Living. Home. Retrieved 13 January, 2013, from http://www.sustainableliving.org.nz

Swarbrick, N. (2009). Pets - Pets and other animals. Introduction Plants and Animals. Retrieved 02 March, 2012, from http://www.teara.govt.nz/en/pets/1

Swartz, K. L. (2011). Airlines of Europe. Airline of the World. Retrieved 19 July, 2012, from http://www.kls2.com/airlines/europe.html

Tay, L., \& Diener, E. (2011). Needs and Subjective Well-Being Around the World. Journal of Personality and Social Psychology., 101(2), 354-365.

Taylor, R., \& Allen, W. (2010). Seeking pro-sustainability household behaviour change: What works? In B. Frame, R. Gordon \& C. Mortimer (Eds.), Hatched: The Capacity for Sustainable Development. Lincoln: Landcare Research.

Taylor, R., \& Smith, I. (1997). Chapter 3: Production and Consumption Patterns. In A. Saunders, D. Swain \& B. Wall (Eds.), The State of New Zealand's Environment. Wellington: The Ministry for the Environment.

TEEB. (2013). TEEB - The Economics of Ecosystems and Biodiversity. Home. Retrieved 18 August, 2013, from http://www.teebweb.org/

TEEB. (2012). The Economics of Ecosystems and Biodiversity, TEEB for local and regional policy makers. Malta: Progress Press.

The Economist Online. (2012). Kings of the Carnivores. The Economist.

The Enviroschools Foundation. (2012). Enviroschools. Retrieved 13 January, 2013, from http://www.enviroschools.org.nz/

The New Zealand Road Safety Trust. (2006). New Zealand Travel Survey. Wellington, NZ: Land Transport Safety Authority.

The Outlook From Someday. (2008). 2.0 A Maori Perspective on Sustainability. 5. Retrieved from http://snipurl.com/vaqtz

The SROI Network International. (2012). The SROI Network. Home. Retrieved 13 January, 2013, from http://www.thesroinetwork.org/

The Treasury. (2011). Information on State-owned Enterprises and Crown Entities. Retrieved 1 August, 2012, from http://www.treasury.govt.nz/government/financialstatements/yearend/jun11/92.htm

Tilford, D. (Producer). (2000). Why Consumption Matters. Sustainable Consumption. Retrieved from http://www.sierraclub.org/sustainable consumption/tilford.asp 
TIME. (2011). TIME Special Report: The World at 7 Billion. TIME magazine, 26 October.

Transit New Zealand. (1999). Pedestrian plaforms - Manuels and Resources. Retrieved 7 July, 2011, from http://www.nzta.govt.nz/resources/road-safety-survey/rss11/appendix3.html

Transit New Zealand. (2002). The State Highway Geometric Design Manual Wellington: New Zealand Government. Retrieved from http://www.nzta.govt.nz/resources/statehighway-geometric-design-manual/docs/shgdm-part-6.pdf

Trueman, C. (2012). Rationing and World War One. History Learning Site. Retrieved 12 October, 2012, from http://www.historylearningsite.co.uk/rationing and world war one.htm

UNEP, \& IPCC. (2001). 1.2. What are Scenarios? Emissions Scenarios: A Special Report of IPCC Working Group III. Cambridge University Press: United Nations Environment Programme (Intergovernmental Panel on Climate Change).

United Nations Framework Convention on Climate Change. (1990).

UNFPA. (2007). Unleashing the Potential of Urban Growth. State of world population 2007. New York: United Nations Population Fund.

United Nations. (2011). UNcomtrade. United Nations Commodity Trade Statistics Database. Retrieved 01 March, 2012, from http://comtrade.un.org/

United Nations Department of Economic and Social Affairs Population Division. (2010). Frequently Asked Questions. World Population Prospects, the 2010 Revision. Retrieved 4 November, 2012, from http://esa.un.org/wpp/other-information/faq.htm

United Nations Environment Programme. (1992). Agenda 21 - 10.1 Integrated Approach to the Planning and Management of Land Resources: United Nations. Retrieved from http://www.unep.org/Documents.Multilingual/Default.asp?DocumentID=52\&ArticlelD= $\underline{58}$.

United Nations Population Fund. (2012). World Population Day 2012: Universal Access to Reproductive Health Services. Retrieved 10 October, 2012, from http://www.unfpa.org/public/world-population-day/

United States Central Intelligence Agency. (2008). The 2008 CIA World Factbook. Retrieved 1 August, 2012, from http://www.hotfreebooks.com/book/The-2008-ClA-World-FactbookUnited-States-Central-Intelligence-Agency--82.html

United States Environmental Protection Agency (Producer). (2004, 10 July, 2012). Let's go green shopping. Online. Retrieved from http://www.epa.gov/osw/education/pdfs/shopping.pdf 
UNWTO. (2012). Methodological Notes to the Tourism Statistics Database. Madrid, Spain: United Nations World Tourism Organisation.

Utter, J., Scragg, R., Schaaf, D., Fitzgerald, E., \& Wilson, N. (2007). Correlates of body mass index among a nationally representative sample of New Zealand children. International Journal of Pediatric Obesity, 2(2), 104-113.

Vale, R., \& Vale, B. (2009a). Footprinting urban form and behaviour in New Zealand. [Invited Paper]. Architectural Science Review, 52(4), 7.

Vale, R., \& Vale, B. (2009b). Time to Eat the Dog? The Real Guide to Sustainable Living. London: Thames and Hudson.

Vale, R., \& Vale, B. (2010). Your (Carbon?) Ration Book. Paper presented the Sustainable Building 2010 (SB10), Wellington. http://www.sb10presentations.co.nz/

Vale, R., \& Vale, B. (2013). Living within a Fair Share Ecological Footprint. Oxon, England: Routledge.

Venetoulis, J., \& Talberth, J. (2006). Refining the Ecological Footprint (pp. 47). Oakland, CA: Redefining Progress.

Victoria Transport Policy Institute. (2011). Energy Conservation and Emission Reduction Strategies. Canberra, Australia.

Wackernagel, M. (2001). Using Ecological Footprint Analysis for Problem Formulation, Policy Development, and Communication. Advancing Sustainable Resource Management. Oakland: Redefining Progress.

Wackernagel, M., Kitzes, J., Moran, D., Goldfinger, S., \& Thomas, M. (2006). The Ecological Footprint of cities and regions: comparing resource availability with resource demand. Environment and Urbanization, 18(1), 103-112.

Wackernagel, M., Monfreda, C., Moran, D., Wermer, P., Goldfinger, S., Deumling, D., \& Murray, M. (2005). National footprint and biocapacity accounts 2005: the underlying calculation method. Oakland, California: Global Footprint Network.

Wackernagel, M., Onisto, L., Bello, P., Callejas Linares, A., Susana López Falfán, I., Méndez García, J., ... Guadalupe Suárez Guerrero, M. (1999). National natural capital accounting with the ecological footprint concept. Ecological Economics, 29(3), 375-390.

Wackernagel, M., \& Rees, W. (1996). Our Ecological Footprint: Reducing Human Impact on the Earth. Gabriola Island, BC: New Society Publishes. 
Wackernagel, M., Schulz, N. B., Deumling, D., Linares, A. C., Jenkins, M., Kapos, V., ... Randers, J. (2002). Tracking the ecological overshoot of the human economy. Proceedings of the National Academy of Aciences of the United States of America., 99(no.14), 9266-9271.

Wackernagel, M., \& Yount, J. D. (2000). Footprints for Sustainability: the Next Steps. Environment, Development and Sustainability, 2, 21-42.

Wada, Y. (1994). Biophysical productivity Data for Ecological Footprint Analysis. Vancouver: Report to the UBC Task Force on Healthy and Sustainable Communities.

Waikato Stadium. (2011). Facts and Figures. Wakato Stadium. Retrieved 1 September 2011, from http://www.waikatostadium.co.nz/page/pageid/2145834899/Facts and Figures

Waitakere City Council. (2009). Annual Report 2008/09, including sustainability reporting. Waitakere: Waitakere City Council.

Waitakere Local Board. (2011). Waitakere Local Board Plan 2011. Auckland NZ: Auckland Council.

Walnum, H. J. (2011). Energy use and $\mathrm{CO}_{2}$ emission from cruise ships - A discussion of methodological issues. Sustainable Destination Norway 2025. Sogndal, Norway: Vestlandsforsking - Western Norway Research Institute.

Walsh, C., O'Regan, A. M. B., Moles, R., \& Curry, R. (2010). The application of the ecological footprint in two Irish urban areas: Limerick and Belfast. Irish Geography, 39(1), 1 - 21.

Walter, A. (2012). Human behaviour and adequacy of satisfiers in the light of sustainable development. FH Wiener Neustadt. Austria. Retrieved from http://mpra.ub.unimuenchen.de/38800/

Washington State University. (2000). What is ANOVA? A field guide to Experimental Design. Retrieved 8 September, 2012, from http://www.tfrec.wsu.edu/anova/basic.html

Waste Not Consulting. (2006). Waste Composition and Construction Waste Data. Prepared for the Ministry for the Environment.

Watson, D. (2003). Appendix B: Tranz Metro (Wellington) - attachement to report 03.295. Tranz Metro Wellington Issues (Vol. 03.295): Greater Wellington Regional Council.

Wellington City Council. (n.d.). Wellington City Council Greenhouse Gas Emissions Analysis and Forecast. Milestone One Report: Communities for Climate Protection ${ }^{T M}$ - New Zealand Programme. Wellington: Wellington City Council.

Whau Local Board. (2011). Whau Local Board Plan 2011 - Your voice for your community. Auckland NZ: Auckland Council. 
White, T. J. (2007). Sharing resources: The global distribution of the Ecological Footprint. Ecological Economics, 64, 402-410.

Wholesale Distributors Ltd. (2011). Becoming a Franchise. Supervalue - just what you need. Retrieved 9 September, 2011, from http://www.supervalue.co.nz/About-Us/Becominga-Franchisee-(1)

WIA. (2009). Airport Info. Retrieved 19 July, 2011, from http://www.wellingtonairport.co.nz/html/airportinfo/index.php

Wiedmann, T., \& Barrett, J. (2010). A Review of the Ecological Footprint Indicator - Perceptions and Methods. Sustainability, 2(6), 1645-1693.

Wiedmann, T., Barrett, J., Billing, M., \& Birch, R. (2004, 5-6 March). The REAP Tool - Creating Physical Accounts for the UK and Evaluating Policy Scenarios. Paper presented at the International Workshop on Driving Forces of and Barriers to Sustainable Consumption., School of the Environment, University of Leeds.

Wiedmann, T., Barrett, J., \& Lenzen, M. (2007, 8-10 May). Companies on the Scale: Comparing and Benchmarking the Footprints of Businesses. Paper presented at the Stepping up the Pace: New Developments in Ecological Footprint Methodology, Policy \& Practice, Cardiff.

Wiedmann, T., \& Lenzen, M. (2007). On the conversion between local and global hectares in Ecological Footprint analysis. Ecological Economics, 60, 673 - 677.

Wiedmann, T., Wood, R., Lenzen, M., Tovey, J., \& Moloney, S. (2007a). Modelling Ecological Footprints for sub-regional Levels: A Detailed Footprint of Consumption in Local Areas of Melbourne and Victoria. Paper presented at the International Ecological Footprint Conference - Stepping up the Pace: New Developments in Ecological Footprint Methodology, Policy \& Practice, Cardiff.

Wiedmann, T., Wood, R., Lenzen, M., Tovey, J., \& Moloney, S. (2007b). Modelling Ecological Footprints for sub-regional Levels: A Detailed Footprint of Consumption in Local Areas of Melbourne and Victoria. Paper presented at the International Ecological Footprint Conference, Cardiff.

Wikipedia. (2011a). List of Airports in New Zealand. Retrieved 8 July, 2011, from http://en.wikipedia.org/wiki/List_of airports in_New_Zealand

Wikipedia. (2011b). List of railways in New Zealand. Retrieved 7 July, 2011, from http://en.wikipedia.org/wiki/List of New Zealand railway lines

Wilkinson, R., \& Pickett, K. (2009). The Spirit Level: Why More Equal Societies Almost Always Do Better. New York: Bloomsbury Press. 
Wilson, J. (2001). The Alberta GPI Accounts: Ecological Footprint (Vol. 28, pp. 39). Drayton Valley, Alberta: Pembina Institute.

Wilson, J., \& Grant, J. L. (2009). Calculating ecological footprints at the municipal level: what is a reasonable approach for Canada? Local Environment, 14(10), 963-979.

Winkelmann, L., \& Winkelmann, R. (1998). Why are the unemployed so unhappy? Evidence from panel data. Economica, 65, 1-15.

Wood, R., \& Garnetta, S. (2009). An assessment of environmental sustainability in Northern Australia using the ecological footprint and with reference to Indigenous populations and remoteness. Ecological Economics (68), 1375 - 1384.

Wood, R., Lenzen, M., Dey, C., \& Lundie, S. (2006). A comparative study of some environmental impacts of conventional and organic farming in Australia. Agricultural Systems, 89(2006), 324-348.

WWF. (2010). Living Planet Report 2010 - Biodiversity, biocapacity and development. In D. Pollard (Ed.), (pp. 57). Switzerland: World Wide Fund for Nature.

Zorondo-Rodríguez, F., Demps, K., Ariza-Montobbio, P., Gómez-Baggethun, E., García, C., \& Reyes-García, V. (Producer). (2011, 25 June, 2012). An Operative Definition of Quality of Life: Human Needs and Satisfiers among People from Kodagu (Karnataka, India). NSFCultural Anthropology Program. [Research] Retrieved from http://icta.uab.cat/Etnoecologia/proyecto.php?ld proyecto $=69$ 